L Loughborough

University Library

University

Author/Filing Title .....T..ETLEE.. A.....

Class Mark . . .......... .. $\quad$.... !

Please note that fines are charged on ALL overdue items.

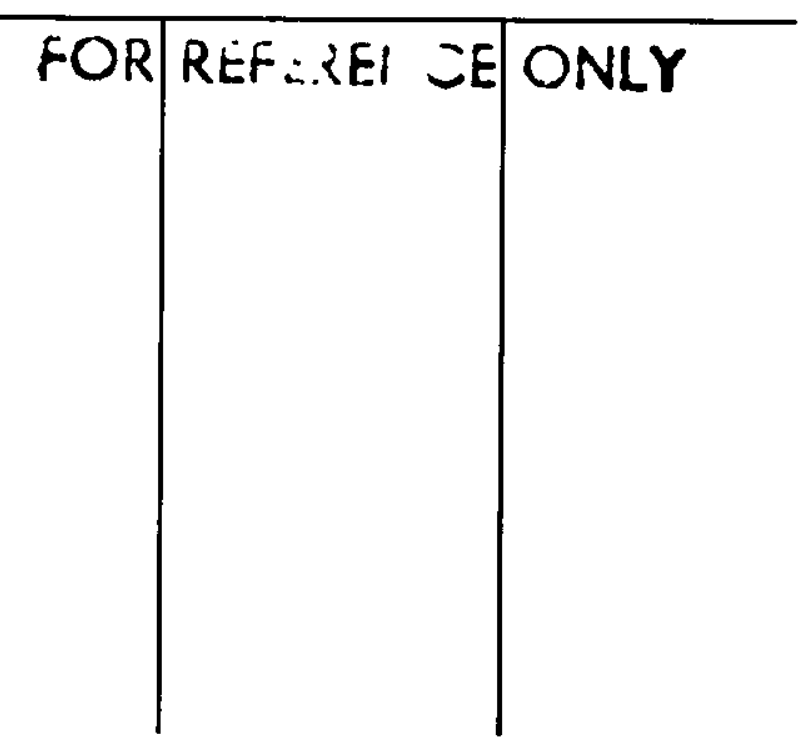

0403603498

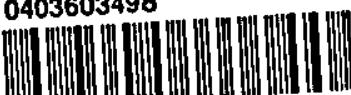





\section{Individual differences in food-cue reactivity}

by

Amanda Tetley

A Doctoral Thesis

Submitted in partial fulfilment of the requirements for the award of Doctor of Philosophy of Loughborough University.

September 2006

C by Amanda Tetley (2006) 


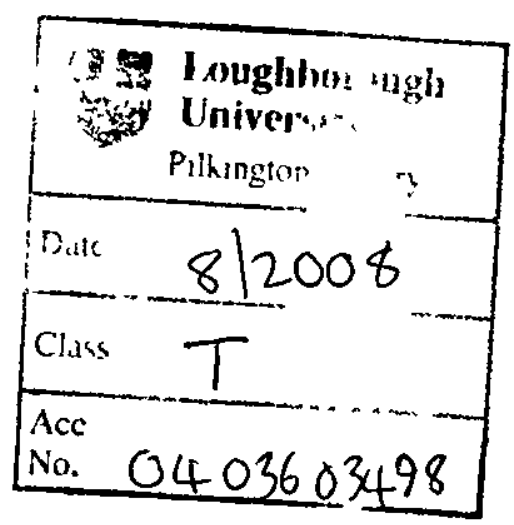




\begin{abstract}
Previous studies have suggested that brief exposure to the sight and smell of food can elicit a momentary increase in desire to eat that food and can stımulate food intake. This thesis sought to explore individual differences in this 'food-cue reactivity.' Specifically, it aimed to explore associatıons between reactivity to food cues and 1) dietary restraint (Experiments 1 to 6), 11) dietary disinhibition (Experiments 1 to 6), 111) everyday portion-size selection (Experiments 3 to 5), 1v) body weight (Experiments 5 and 6), v) sensitivity to reward (BAS trait) (Experıment 6), and vi) ımpulsıvity (Experıment 6) Using a typical cue reactıvity paradıgm, female students (Experiment $1 \mathrm{n}=56$, Experıment $2 \mathrm{n}=120$, Experıment $3 n=30$, Experıment $4 n=30$, Experıment $5, n=120$, Experıment $6 n=120$ ) from Loughborough University (aged between 18 and 30) were exposed to a food cue and then a senes of subjective (appetite ratıngs), and behavioural (intake and desired portion size), markers of appetite were assessed
\end{abstract}

Notably, two main findings emerged from this research. Firstly, there was little evidence to suggest that food-cue reactivity shared any association with dietary restraint status per se Rather, sensitivity to reward, impulsivity, and dietary disinhibition, were identıfied as potentıally important determinants of sensitivity to food cues. Secondly, some experiments (Experiments 3 and 5) suggested that foodcue reactivity might be elevated in individuals who are overweight, and who select larger everyday portion sizes Based on these findings, conclusions are drawn regarding the potential mechanısms which might govern food-cue reactivity, and the possible consequences of greater reactivity for everyday food consumption. In particular, it is concluded that food-cue reactivity might result from a universal sensitivity to stımuli which predict the occurrence of a reward, and from an inability to exercise sufficient self-control in the presence of tempting environmental cues In addition to this, it is also suggested that, over time, a greater susceptibility to the effects of food cues might contribute to, greater everyday food intake, and weight gain. To move forward within this research area, studies should continue to investigate the role of food-cue reactivity in overcating, and seek to further identify the mechanisms which promote greater reactivity to these cues 


\section{ACKNOWLEDGEMENTS}

Firstly, I would like to thank Dr Jeff Brunstrom and Dr Paula Griffiths for therr supervision, encouragement, and contınued support throughout this research Thanks must also go to Professor Mark Lansdale (Director of Research) for his advice and support, and to Professor Eef Hogervorst for acting as my Director of Research throughout the final stages of my $\mathrm{Ph} \mathrm{D}$

I would also like to thank those who participated in the experiments, the Department of Human Sciences for providing the financial support required to complete this research, and the staff in the department for therr technical support, and therr feedback on my research progress. Sincere thanks must also go to the participants at conferences I have attended for their invaluable advice on this research project, and to my peers in the Ingestıve Behaviour Laboratory and Human Growth and Development Cluster for therr contınued support and advice

Finally, sincere thanks must go to my family, Paul, Carol, and Adam, for all their support, and encouragement, throughout my education, and to Chris for his outstanding patıence, help, and encouragement during my Ph.D. 


\section{TABLE OF CONTENTS}

$\begin{array}{lr}\text { ABSTRACT ___ } & \text { ii } \\ \text { ACKNOWLEDGEMENTS } & \text { ii } \\ \text { TABLE OF CONTENTS } & \mathrm{x} \\ \text { LIST OF TABLES__ } & \mathrm{xvii}\end{array}$

INTRODUCTION

CHAPTER 1:EXTERNAL DETERMINANTS OF DIETARY CONTROL 3

1.1 Chapter Introduction 3

12 Set-point, and settling point, models of dietary control 3

1.3 The role of external sensory stımuli in dietary control 6

1.3.1 Flavour-flavour and flavour-nutrient learning 7

1.3.2 Conditioned meal initiation 11

1.4 Non-food specific theones of motivated behaviour 13

1.41 Instrumental/Operant conditioning 14

1.42 Drive reduction theories 15

1.4.3 Incentıve motıvation 15

1.4.4 Incentive salıence 16

1.4.5 Relevance of non-food specific learning theories for dietary control 18

1.5 Chapter summary 19

CHAPTER 2:CUE REACTIVITY 21

21 Chapter Introduction 21

PART I

2.2 Drug-cue reactivity 22

2.2.1 Drug-cue reactıvity summary 27

2.3 Food-cue reactivity 27

23.1 Food-cue reactıvity summary 30

PART II 31

24 Introduction 31 
25 Overview of the issues considered in this thesis 31

26 ISSUE 1 Food-cue reactıvity and everyday dietary behaviour 33

261 Precedents to dietary restraint The 'externality' hypothesis 33

2.62 External eatıng behaviour and dietary restraint 37

2.7 ISSUE $2 \cdot$ Food-cue reactivity, BMI, and everyday portion-size selection _ 43 28 ISSUE 3: Potentral role of personality characteristics in food-cue reactivity 45

2 8.1 Potential role of the BAS in food-cue reactivity 45

2.8.2 Food-cue reactivity and impulsivity 49

2.9 SECONDARY ISSUE $1 \cdot$ Cue specificity 51

2.10 SECONDARY ISSUE 2: Role of motivational state 54

211 Summary and thesis overview 58

\section{CHAPTER 3:FOOD-SPECIFIC REACTIVITY AND EVERYDAY DIETARY} BEHAVIOUR

31 Chapter Overview 59

PART I: Experiment 1 59

32 Introduction 59

33 Method 63

3.3.1 Overview 63

3.3.2 Design 63

333 Participants 63

3.3.4 Measures 64

3.3.5 Procedure 65

336 Data analysis 66

34 Results 68

3.41 Outlers 68

3 4.2 Partıcıpant characteristıcs and baseline measures 69

3.4.3 Descriptive statıstıcs for measures of cue reactivity 71

3 4.4 Dietary restraint, disinhıbitıon, and subjectıve appetıte 72

3 4.5 Dietary restraint, disinhibition, and pizza intake 77

3.46 Summary table of results 78

35 Discussion 79

PART II: Experiment 2 84

3.6 Introduction 84 
37 Method____________________ 86

37.1 Overview ___ 86

3.7 2 Participants ___

373 Design _________ 87

37.4 Measures ___ 87

3.7.5 Procedure ___ 88

376 Data analysis _____ 89

38 Results ___ 92

3.8.1 Participant characteristıcs and baseline measures ___ 92

382 Descriptıve statistics for measures of cue reactivity ___ 94

38.3 Food-cue reactivity and dietary behaviour _____ 95

384 Awareness Questionnare ___ 97

39 Discussion ___ _ _ 99

310 Re-test of TFEQ-disinhibition scores ___ 102

310.1 Method ___ 102

3.10.1.1 Procedure ________ 102

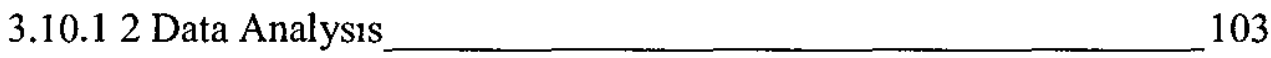

310.2 Results ___ 103

3.102 .1 Partıcipant characteristics ___ 103

31022 TFEQ-disinhibition scores___________ 104

3.103 Discussion_______________ 105

3.11 Chapter Summary ___ 105

\section{CHAPTER 4: IMPLICATIONS OF FOOD-CUE REACTIVITY FOR}

EVERYDAY PORTION-SIZE SELECTION ___ 107

4.1 Chapter overview _ـ_ 107

4.2 Introduction 107

4.3 Method _ 109

43.1 Overview _ـ 109

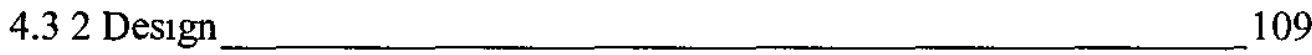

434 Participants ___ 110

4.35 Measures_____________ 110

436 Procedure ___ 112

4.3.7 Data analysis ____________ 113 
44 Results 114

441 Partıcipant characteristics 114

4.4 2 Baseline measures 114

44.3 Descriptıve statıstics for measures of cue reactıvity 115

444 Cue reactivity and everyday portion-size selection 116

445 Cue reactivity, dietary restraint, and TFEQ-disinhibition scores 118

4.4.7 Awareness questionnaire 120

4.4.6 Summary of results 121

4.5 Discussion 122

46 Chapter summary 126

\section{CHAPTER 5:FOOD-SPECIFIC REACTIVITY AND EVERYDAY} PORTION-SIZE SELECTION

5.1 Chapter overview 127

5.2 Introduction 127

5.3 Method 130

5.3.1 Overview 130

5.3.2 Design 131

5.3.3 Participants 131

5.3.4 Measures 131

535 Procedure 134

536 Data Analysis 135

54 Results 136

5.4.1 Partıcipant characteristics 136

542 Baselıne measures 137

5.4.3 Descriptive statıstıcs for measures of cue reactıvity 137

54.4 Effect of food models on subjectıve appetite 139

5.45 Cue reactivity and everyday portion size 139

5.4 6 Cue reactivity, dietary restraint, and disinhibition scores 139

5.4.7 Awareness Questionnarre 142

55 Discussion 143

5.6 Chapter summary 146 
CHAPTER 6:FOOD-CUE REACTIVITY AND BMI

6.1 Chapter overview 148

61 Introduction 148

63 Method 151

6.3.1 Overview and procedure 151

632 Participants 152

6.3.3 Measures 152

6.3.4 Data Analysis 153

64 Results 154

641 Partıcıpant characteristıcs 154

6.4.2 Baselıne measures 155

6.4.3 Descriptive statıstics for measures of cue reactıvity 155

6.44 Effects of food models on subjective appetite 157

6.4.5 Cue reactıvity and being overweight 158

64.6 Cue reactivity and everyday portion size 161

6.4.7 Does being overweight act as a proxy measure of everyday portion size? 163

648 Relationships between cue reactivity and dietary behaviour 164

6.4.9 Association between change in desired potion size and being overweight after controlling for disinhibition scores 166

6410 Awareness questionnaire 166

6.4.11 Summary table of main results 168

65 Discussion 170

6.6 Chapter Summary 177

\section{CHAPTER 7:INDIVIDUAL DIFFERENCES IN FOOD-SPECIFIC} REACTIVITY IN FOOD-DEPRIVED AND NON-DEPRIVED INDIVIDUALS 178

7.1 Chapter overview 178

7.2 Introduction 178

73 Method 181

7.3.1 Overview 181

7.3.2 Design 182

7.33 Participants 182 
7.3.4 Measures 183

735 Procedure 185

7 3.6 Data Analysıs 186

7.4 Results 189

741 Outliers 189

7.4.2 Partıcipant characternstics 190

74.3 Baselıne measures 191

7 4.4 Lunch manipulation 191

7.45 Descriptıve statıstıcs for measures of cue reactıvity 192

746 Effects of food models on subjective appetite 194

7.4.7 Associations between food-cue reactivity and sensitivity to reward 196

74.8 Associations between food-cue reactivity and impulsıvity 201

7481 Stop start task 201

7.4.8.2 EPQ-impulsivity scores 201

74.9 Associations between cue reactivity, everyday dietary behaviour, and body we1ght 209

74.10 Awareness Questionnaire 213

7.4.11 Summary table of main results 215

7.5 Discussion 216

76 Chapter summary 229

\section{CHAPTER 8:GENERAL DISCUSSION} 230

8.1 Chapter Introduction 230

8.2 Food-cue reactivity and dietary restraint 230

8.3 The role of dietary disinhibition, impulsivity, and sensitivity to reward, in food-cue reactivity 234

84 Potential consequences of greater food-cue reactivity for everyday food consumption and being overweight 241

85 Implications of this research for interventions designed to reduce obesity_245

86 Limitations and methodological considerations

8.7 Directions for future research 254

88 Final remarks and conclusions 256 
APPENDIX A 300

APPENDIX B 302

APPENDIX C 303

APPENDIX D 305

APPENDIX E 305

APPENDIX E 306 APPENDIX F 307 APPENDIX G 308 APPENDIX H 310 


\section{LIST OF TABLES}

Table 3.1 70

Between-subjective t-tests, means, and standard deviations, for participant characteristıcs (DEBQ-restraint scores TFEQ-disınhıbıtıon scores) and baselıne preexposure ratıngs in both conditions

Table 3.2

Between-subject t-tests, means, and standard deviations, for changes in subjective appetite and for pizza intake in the no-cue, and pizza-cue, condition after cue exposure.

Table 3.3

Adjusted' parameter estımates from linear regression models for interactions between condition (no cue/pizza cue) and dietary behaviour (dietary restraint and disinhibition) for changes in subjective appetite, and for pizza intake.

Table 3.4 78

Summary table of the observed interactions between dietary behaviour (dietary restraint and disinhibition) and condition (no-cue and pizza-cue) for each of the outcome measures in this experiment.

Table 3.5 92

Dummy vanable coding.

Table 3.6 93

One-way between-subject ANOVAs, means, and standard deviations, for baseline ratıngs (hunger, desire-to-eat pizza, desıre-to-eat chıps, craving for pizza, and craving for chips), and for particıpant characteristıcs (DEBQ-restraint scores TFEQdisinhibition scores). 
Table 3.7 95

One-way between-subject ANOVAs, means, and standard deviations, for changes in subjective appetite, and for $a d-l l b$ intake in the no-cue, pizza-cue, and chip-cue, condition

Table 3.8

Adjusted' parameter estımates from linear regression models for interactions between the pizza-cue, or chip-cue, condition (Reference; no-cue condition) and dietary behaviour (dietary restraint and disinhıbition) for changes in subjective appetite, and for pizza intake

Table 3.9 98

Summary of responses to the awareness questionnaire. All total are given in percentages.

Table 3.10 104

Means and standard deviations for partıcipant characteristics (TFEQ-disinhibition scores, DBEQ-restraint scores, and BMI)

Table 3.11 104

TFEQ-disinhibition scores obtained via email and in experiment 2, separately, for each condition (no-cue, pizza-cue, chip-cue).

Table 4.1 114

Mean and standard deviations for participant characteristics.

Table 4.2 116

Withın-subject t-tests, means, and standard deviations, for pre-exposure, and postexposure, measures of cue reactivity. 
Table 4.3

Adjusted $^{1}$ parameter estımates from linear regression models of associations between the three measures of dietary behaviour (TFEQ-disinhibition score, DEBQrestraint scores, and everyday portion size) and change in generalised measures of appetite (hunger and fullness), and change in appetite (craving and desire to eat) for pizza

Table 4.4

Summary of responses to the awareness questionnaire. All total are given in percentages

Table 4.5 122

Summary table to show the significant associations between the outcome vanables and the predictor variables.

Table 5.1 136

Means and standard deviatıons for partıcıpant characterıstics

Table 5.2 138

Within-subject t-tests, means, and standard deviations, for pre-exposure and postexposure subjective appetite and portion-size selections.

Table 5.3

Adjusted $^{\prime}$ parameter estimates from linear regression models of associations between the two measures of dietary behaviour (TFEQ-disinhibition score, and DEBQ-restraint scores) and the change in measures of cue reactivity (subjective appetite and desired portion size)

Table 5.4 143

Summary of responses to the awareness questionnaire. All total are given in percentages 
Table 6.1 154

Mean and standard deviatıons for partıcıpant characterıstıcs

Table 6.2 156

Within-subject t-tests, means, and standard deviations, for pre-exposure, and postexposure, subjective appetite and portion-size selections.

Table 6.3 157

Means and standard deviations for hunger, fullness, craving for chocolate, craving for chips, and craving for peanuts, before and after pre-exposure portion-size selections using the food models

Table 6.4 159

Adjusted $^{l}$ parameter estimates from linear regression models for associations between changes in the measures of food-cue reactivity and BMI, and everyday portion-size selection

Table 6.5 160

Predicted values from the linear regression model for overweight, and normal weight, individuals for pre-exposure portion-size selection, and the total amounts these individuals would be expected to consume'

Table 6.6 162

Predicted values from the linear regression model for pre-exposure pizza size, and the total amounts individuals would be expected to consume in Kcalories for small, medium, and large, portion sizes (calculated as the average value in each tertile of the data) ${ }^{1}$.

Table 6.7 165

Adjusted ${ }^{1}$ parameter estimates from linear regression models of associations between the two measures of dietary behaviour (TFEQ-disinhibition score and DEBQ-restraint scores) and changes in measures of cue reactivity. 
Table 6.8 168

Summary of responses to the awareness questionnare. All total are given in percentages.

Table 6.9 169

Summary table of the significant associations between the predictor variables and the outcome variables for this experiment.

Table 7.1 190

Mean and standard deviatıons for partıcipant characteristics

Table 7.2 192

Means and standard deviations for baseline hunger $(\mathrm{mm})$ and fullness $(\mathrm{mm})$ before, and after, lunch.

Table 7.3

Within-subject t-tests, means, and standard deviations, for changes in hunger ( $\mathrm{mm}$ ) and fullness (mm) and changes in appetite ratıngs (desire to eat and craving) (mm) and portion-size selection, for the cued (pizza,) and non-cued, foods (chips, and chocolate cake) before lunch.

Table 7.4 194

Withın-subject t-tests, means, and standard deviations, for changes in hunger ( $\mathrm{mm}$ ) and fullness ( $\mathrm{mm}$ ), and changes in appette ratıngs (desıre to eat, and craving) (mm) and portion-size selection, for the cued (pizza), and non-cued (chips, and chocolate cake), foods after lunch

Table 7.5 195

Withın-subject t-tests, means and standard deviatıons, for changes in hunger ( $\mathrm{mm}$ ) and fullness ( $\mathrm{mm}$ ), and changes in appetite ratıngs (desire to eat, and craving) (mm) for the cued (pizza), and non-cued (chips, and chocolate cake), foods after preexposure portion-size selections, while participants were hungry. 
Table 7.6 196

Withın-subject t-tests, means, and standard deviations, for changes in hunger (mm) and fullness ( $\mathrm{mm}$ ), and changes in appetite ratıngs (desire to eat, and craving) (mm) for the cued (pızza), and non-cued (chips, and chocolate cake), foods after preexposure portion-size selections in the absence of hunger.

Table 7.7 198

Adjusted parameter estımates ${ }^{1}$ from linear regression models for associations between sensitivity to reward scores and measures of cue reactivity before lunch

Table 7.8 199

Adjusted parameter estımates' from linear regression models of associations between sensitivity to reward scores and measures of cue reactivity after lunch

Table 7.9 200

Predicted pre-exposure pizza size and calculated post-exposure portion size after lunch for individuals with low (7.23), medium (11.28), and high (15.95), sensitivity to reward scores.

Table 7. 10 203

Adjusted parameter estımates' from linear regression models for associations between impulsivity scores and measures of cue reactivity before lunch.

Table 7.11 205

Predicted pre-exposure pizza size and calculated post-exposure portion size after lunch for individuals with low (2.82), medium (7 49), and high (12 65), impulsivity scores.

Table 7.12 207

Adjusted parameter estımates' from linear regression models for associations between impulsivity scores and measures of cue reactivity after lunch 
Table 7.13

Predicted pre-exposure pizza size and calculated post-exposure portion size for individuals with different combinations of TFEQ-disinhibition scores and impulsivity scores.

\section{Table 7.14}

Predicted hunger ratıngs $(\mathrm{mm})$ prior to the pre-exposure portion-size selection based on the parameter estimates from the regression model.

Table 7.15

Summary of responses to the awareness questionnaire All totals are given in percentages

Table 7. 16 216

Summary of the significant associatıons between the predictor variables and the main outcome variables. 


\section{LIST OF FIGURES}

Figure 3. 1

Predicted change in craving for pizza (A), chips (B), and cookies (C), (mm) for the no-cue (continuous lines), and pizza-cue, conditions (dashed lines) separately, across disinhibition scores estımated using the parameter estımates from linear regression models for change in craving for chips, pizza, and cookies in the two conditions (no cue and pizza cue)

Figure 3. 2 76

Predicted change in desire-to-eat pizza (A), chips (B), and cookies (C), (mm) for the no-cue (contınuous lines), and pizza-cue, conditions (dashed lines) separately, across disinhibition scores estımated using the parameter estimates from linear regression models for change desire-to-eat chips, pizza, and cookies, in the two conditions (no cue and pizza cue).

Figure 3. 3 77

Predicted pizza intake in the no-cue (continuous lines) and pizza-cue conditions (dashed lines) separately, across restraint scores estımated using the parameter estımates from linear regression models for pizza intake in the two conditions (no cue and pizza cue)

Figure 4. 1 118

Predicted portion size of pizza in Kcalories (kcal) after cue exposure for individuals who report consuming small (2.89), medium (3.73), and large (4.80), everyday portion sizes estımated using the everyday portion-size selection parameter estımate $(B=309601)$ from the linear regression models for predicted portion size of pizza after cue exposure. 
Figure 4. 2

Predicted pizza size in Kcalones (kcal) after cue exposure for individuals with low (3.8), medium (7.7), and high (11.3), disinhibition scores estımated using the parameter estimate $(B=649.69)$ from linear regression models for pizza portion size.

Figure 6. 1 160

Predicted change in pizza-size in Kcalories (kcal) for overweight and nonoverwerght indıviduals after cue exposure estimated using the parameter estimates from the linear regression model $(B=2343.13)$

Figure 6. 2 162

Predicted change in pizza size in Kcalones (kcal) for individuals with small (2 82), medium (3.71) and large (4.52) average everyday portion size (calculated as the average score in each tertile of the data) estımated using the parameter estımates from a linear regression model for change in pizza sıze $(B=1161.65)$

Figure 7. 1 200

Predicted changes in desıred pızza size (kcal) after lunch for individuals with low (7.23), medium (1128), and high (1595), sensitivity to reward scores from a regression model used to predict this measure $(B=441.61)$.

Figure 7. 2 204

Predicted changes in craving for pızza (mm) (A) and desıred pizza size (kcal) (B) before lunch for individuals with low (2.82), medium (7.49), and high (12 65), Impulsivity scores from a regression model used to predict these measures $(B=0.88$ ,$B=647.72$, respectively).

Figure 7. 3. 205

Predicted changes in desired pizza size (kcal) for individuals with low (3.93)/high (11.25) impulsivity and low (817)/high (1443) sensitivity to reward from a regression model used to predict change in desired pizza size before lunch. 
Figure 7. 4 208

Predicted changes in hunger ( $\mathrm{mm})(\mathrm{A})$, desire-to-eat pizza $(\mathrm{mm})(\mathrm{B})$, and craving for pizza (mm) (C) after lunch for individuals with small (2 82), medium (7 49), and high (12.65), impulsivity scores from three regression models used to predict these measures $(B=-0.633,1049,1.159$, respectively).

Figure 7. 5 210

Predicted changes in desired pizza size (kcal) after lunch for individuals with different combinations of TFEQ-disinhibition scores and impulsivity scores based on parameter estimates from regression models. 


\section{INTRODUCTION}

Levels of obesity are reaching epıdemic proportions worldwide In England in 2004, $236 \%$ of men and $256 \%$ of women were found to be obese (BMI > 30) In addition to this, $43.9 \%$ of men, and $347 \%$ were reported to be overweight (BMI $=25-2999$ ) (Health Survey For England, 2004). Similarly, in the US, between the years of 1999 and $2000,64.5 \%$ of the population were reported as overwerght, and $30.5 \%$ as obese (Flegal, Carroll, Ogden \& Johnson, 2002) This is partıcularly alarming since obesity is associated with increased mortality (Calle, Thun, Petrelli, Rodnguez, \& Heath, 1999, Hu, Tuomilehto, Silventoinen, Barebgo, Peltonen, \& Jousilılahtı, 2005; Jain, Miller, Rohan, Rehm, Bondy, Ashley et al, 2005), a higher risk of cardiovascular heart disease (Cunlso, Toyoshıma, Date, Yamamoto, Kıkuchı, Kondo, et al, 2005), Type II diabetes, sleep apnoea, hypertension, and cancer (WHO, 1998)

In light of these increases in levels of obesity there has been an increased interest in the factors that can motivate food consumption Traditionally, it was assumed that physiological factors solely controlled food intake (e g., Kennedy, 1953; Mayer, 1955). However, more recent evidence has suggested that external environmental cues associated with food ingestion also have the capacity to promote food consumption (e g, Weingarten, 1983, 1984). These external cues might include food cues, such as the sight and smell of food which are present immediately pror to food ingestion, contextual cues including particular locations where specific foods are regularly eaten, and particular times of the day when meals are typically consumed.

The research presented in this thesis is primanly interested in the effect of environmental food cues, such as the sight and smell of food, on motivation to eat. To date, studies explonng this 'food-cue reactivity' have suggested that bref exposure to food-related stımuli, such as the sight and smell of food, can elicit a momentary increase in desıre to eat and can stımulate food intake (e g., Fedoroff, Herman, \& Polivy, 1997; Nederkoorn, Smulders Havermans, \& Jansen, 2004) 
However, despite this basic research, very few studies have sought to explore individual differences in this reactivity to food cues An investigation of this kind might be important because it might enhance our understanding of both the causes and consequences of this dietary phenomenon. For this reason, this thesis considers individual differences in food-cue reactivity. Specifically, it explores associations between food-cue reactivity and everyday dietary behaviour, everyday portion-size selections, being overweight, and personality characteristics, such as impulsivity and sensitivity to reward These associations are explored in a series of six experimental studies

The subsequent chapters provide a detalled account of the background literature relevant to the research conducted here, and the detalls of each individual experment including the methodologies employed, and a systematic review of the findings In the next chapter, the importance of external food-cues in dietary control is considered Following this, the second chapter considers the evidence for foodcue reactivity to date (Part I) It then identrfies more clearly the questions addressed in this thesis, and discusses the literature relevant to these questions (Part II) Chapters 3-7 report the rationale, methodology employed, and the findings, for each of the six experiments The final chapter (Chapter 8) presents a discussion of the combined results from these empincal experiments, evaluates the limitations of the work presented, and considers proposals for future research. 


\section{CHAPTER 1}

\section{EXTERNAL DETERMINANTS OF DIETARY CONTROL}

\subsection{Chapter Introduction}

The primary aim of this chapter is to review the evidence pertaining to the role of external environmental stımuli in motivating food intake The review begins by describing models of food intake which adhere to a purely physiological account of dietary behaviour, and by considering the limitations of these. This is followed by the identification of a theory which also recognises the potentral contribution of non-physiological factors, such as environmental cues, in dietary control. After this, specific consideration is given to evidence suggestıng that external sensory stımuli (e.g , the favour of a food, or the sight and smell of a food) can control what, when, and how much, food is eaten. It is suggested that this occurs as these stımuli become associated with particular aspects of food ingestion (learned dietary responses). In the final part of this chapter, non-food specific theories of the learned mechanisms underlying externally-cued behaviour are discussed. These theories are reviewed here because they develop a broader understanding of the mechanisms which might govern responses to external food cues.

\subsection{Set-point, and settling point, models of dietary control}

Previously, it has been suggested that eatıng behaviour is controlled exclusively by physiological changes which signal the state of the body's energy resources (Kennedy, 1953, Mayer, 1955). Eatıng 1s assumed to occur when an energy deficit is perceived, and is terminated once energy resources are at their optımal level. According to this perspective, a set-point represents the ideal energy level of the 
body. Actual physiological state can then be compared contınuously with this setpoint. If this comparison signals that energy resources are below this set-point, an error signal (negatıve feedback) will be produced. This signal will then promote food ingestion. Food ingestion will then continue untıl the set-point is reached. At this point a meal will be terminated. In this way, the set-point acts to maintain homeostasis, which literally means it maintains a stable internal state (Cannon, 1932)

Regulation of the set-point has been suggested to occur in one of two ways Firstly, Mayer (1955) argued that energy status is signalled by glucose utilisation (glucostatic hypothesis) More specifically, he argued that energy depletion is signalled by glucoreceptor cells levels signalling zero. He suggested that once these levels are detected, eating behaviour is initiated Consistent with this hypothesis, Rezek and Kroeger (1976) showed that manıpulations which depress glucose utılisation (2-deoxyglucose, 2DG) often stimulate food ingestion. However, although Smith, Gibbs, Strohmayer, and Strokes (1972) confirmed that 2dexyglucose (2DG) stımulates eatıng behaviour, they also showed that ingestion occurs only when depletion falls to levels which are rarely observed in animals or humans. Thus, these findings can be taken to suggest that this mechanism is unlikely to regulate a set-point. A second hypothesis based upon the notion of a setpoint is the lipostatic hypothesis (Kennedy, 1953). According to this hypothesis, a set-point exists for body fat levels. Thus, if body fat falls below the set-point, adjustments in eatıng will be made, such that body fat levels return to this set-point. In support of this model, research suggests that leptin could feasibly act as a negative feedback signal (Seeley \& Schwartz, 1997). This is because, firstly, there are leptin receptors in the brain, and, secondly, curculating levels of leptin are correlated with adıpose tissue in humans and animals. However, against the lipostatıc hypothesis, it has been suggested that the accumulation of fat does not in fact appear to generate any biological drive to undereat (Blundell \& Halford, 1994). Indeed, if it did, the dramatic increases in obesity recently observed are unlikely to have occurred. 
Interestingly, Levitsky (2002) provides a clear argument against a set-point model of eating behaviour regulation $\mathrm{He}$ quite nghtly assumes that if a homeostatic system of eating behaviour exists, then intake at one meal should be contıngent on the amount consumed at the previous meal, and also on the length of time since that meal However, as Levitsky (2002) reveals, evidence from expenmental work has not in fact supported this possibility Firstly, it has been found that the amount of food an anmal eats is not related to the pre-meal interval (Le Magnen \& Tallon, 1963; Le Magnen, 1966, both cited in Levitsky, 2002). Secondly, several studies have found that the energy consumed by eatıng snacks between meals is not compensated for at standard meal times during that day (Morgan \& Guegan, 1986, cited in Levitsky, 2002), and eliminating a meal does not encourage greater Kcalorie intake at other meals (Feldman \& Levitsky, unpublished, cited in Levitsy, 2002)

Given the evidence against a set-point model of food intake, Wirtshaftrer and Davis (1977) proposed a settling point theory of eating behaviour This theory suggests that werght tends to drift around a settling point. A settling point is a level at which the various factors that influence body weight achieve an equilbrium. These factors are likely to be hormonal factors, neural factors, and external environmental factors, such as food avallability and palatability. According to a settling point model, body weight remains stable as long as no long-term changes in these factors occur. If there is a change in one of these factors, a new settling point will be reached as the other factors re-establish equilibrium Therefore, according to this model, recent increases in obesity are unlikely to be due to higher physiological set points, but are likely to have occurred because environmental changes in food avallability and palatablity have forced new settling points to be reached (Berridge, 2004)

The importance of a settling point theory is that it suggests that physiology does not determine a fixed body werght. Rather, it acknowledges that other factors might also influence food intake, and consequently body weight. Consistent with this perspective, empincal evidence suggests that factors other than physiological signals do play an important role in dietary control. Amongst others, these nonphysiological cues might include the taste of the food, learned responses to external cues, and social factors For example, the number of people present at a meal can 
influence the amount that is eaten (De Castro \& Brewer, 1992), as can the avallable portion size of the food (e g Dilibertı, Bordı, Conklın, Roe, \& Rolls, 2004; Rolls, Morris, \& Roe, 2002, Rolls, Roe, Meenings \& Wall, 2004;), the palatability of a food (Decke, 1971, Rodın, 1975a; Yeomans, 1996), and the presence of attractive food cues (e g, Fedoroff et al, 2004). Since the research presented in this thesis specifically aims to explore the effect of external food cues on motivation to eat, the remainder of this review will focus on evidence which suggests that sensory external stımuli ( $1 \mathrm{e}$., the flavour of a food and visual and olfactory cues) can gain the capacity to control food intake as they become associated with food ingestion (1.e, through learned associations).

\subsection{The role of external sensory stimuli in dietary control}

Learned associations between external sensory stımuli (1.e., the flavour of a food or visual and olfactory cues) and food ingestion have been found to be powerful determinants of dietary behaviour. The ability of stimuli to evoke behaviours, or responses, which they do not naturally elicit, was onginally discovered by Ivan Pavlov in 1927 Following from this discovery, Pavlov (1927) formulated a theoretical account of this learned behaviour. He suggested that as a neutral stımulus becomes associated with a stımulus which elicits an unconditional reflexıve response (unconditioned stimuli), this neutral stımulus eventually acquires the capacity to elicit this reflexive response This response is therefore called a conditioned response (CR) and the previously neutral stimulus which elicits it is called the conditioned stimulus (CS) This form of learning is now typically referred to as Pavlovian, or Classical, conditioning

Learned associations between the sensory characteristics of food and its ingestion occur in a similar way to that proposed by Pavlov (1927). Specifically, an external sensory stımulus (e g., flavour of a food, visual or olfactory food cue) (CS) becomes associated with the an already liked, or disliked, flavour (flavour-flavour learning), a feeling of satiety (learned satiety), or a feeling of reward (conditioned meal initiation) (UCS). Thus, on subsequent occasions these stimuli elicit a representation of the UCS which it has become associated with. Such associations have been 
implicated in the establishment of flavour preferences (flavour-nutrient learning, flavour-flavour learning), meal termination (learned satiety), and meal initiation (conditioned meal initration). Although this thesis aims to specifically explore conditioned meal intiation, it is important to consider the fundamental role that dietary learning might have, not only to meal initiation, but also for other aspects of dietary control. For this reason, the subsequent sections begin by considerng the role of dietary learning in the establishment of flavour preferences, and meal termination This is then followed by a review of the literature pertinent to conditioned meal initiation.

\subsubsection{Flavour-flavour and flavour-nutrient learning}

One form of dietary learning known to facilitate flavour preferences is referred to as 'flavour-flavour learning.' This is the result of a novel flavour (CS) being parred with an already liked, or disliked, flavour (UCS), such that the valence of the novel flavour shifts in the direction of the UCS In this way, a novel flavour parred with an already liked flavour will become liked, while a flavour parred with a disliked flavour will become disliked Several studies have suggested that painng a novel flavour with an already liked flavour can evoke a preference for this previously neutral flavour in humans (Brunstrom, Downes \& Higgs, 2001, Zellner, Rozin, Aron, \& Kulısh, 1983,) For example, Zellner, et al (1983) found that preference for a novel flavour (CS) was enhanced after being repeatedly parred with the sweet taste of sugar (UCS). Likewise, a number of studies have provided evidence to suggest that parring a novel flavour with a disliked flavour can bring about learned dislıkes. Baeyens et al (1988, 1990, 1996), for example, reported that liking for novel flavours decreases after being repeatedly paired with Tween 20 , a rather distınctıve dislıked flavour.

Furthermore, flavour preferences might also be enhanced or inhıbited by a different form of learning. Indeed, associations formed between a food's flavour and its postingestive consequences can factlitate or inhibit food preferences (flavournutrient learning) in humans and animals For example, when a novel flavour (CS), is paired with reinforcing postingestive effects (UCS), this flavour will become 
liked Similarly, when a novel flavour is parred with aversive postıngestıve effects, such as nausea, or gastrontestinal illness, this flavour will become disliked and will be avolded on subsequent occasıons (Logue, Ophir, \& Strauss, 2002). Consistent with this, several studies have reported that pairng a novel flavour with a nutritive substance which is rewarding metabolically can enhance preference for this flavour in animals In the first study to report this nutrient-based flavour learning in anımals, Holman (1968) trained rats to drink a flavoured solution paired with an intragastric infusion of liquid diet (CS + ), and another solution paired with intragastric infusions of water (CS-), in alternate sessions. When subsequently offered the two flavours in a two-bottle choice test, rats displayed a significant preference for the flavour previously pared with the liquid diet Using a varation of this basic experimental paradigm, a large number of subsequent studies have also reported flavour preferences conditioned by intragastric infusions of complete diets or individual macronutrients (for e.g., glucose, polycose, casein, corn o1l, ethanol) in deprived and non-deprived anımals, traned in short (10-30 min) or long term (2023hr) sessions (Booth, Stoloff, \& Nicholls, 1974, Elizalde \& Sclafani, 1990; Holman, 1968; Perez, Ackoff, \& Sclafant, 1996, Perez, Fanızza, \& Sclafanı, 1999, Sclafanı \& Nıssenbaum, 1988; Warwıck \& Weingarten, 1996).

Albeit relativity less sparse, in humans, similar conditioned flavour preferences have also been reported For example, several studies have suggested that repeatedly parnng a novel flavour with the ingestion of energy in the form of proten, fat, or carbohydrate, can enhance liking for that flavour in both adults and children (Baker, Booth, Duggan, \& Gibson, 1987, Booth, Mather, \& Fuller, 1982; Gibson, Wainwnght, \& Booth, 1995, Johnson, McPhee, \& Birch, 1991, Kern, McPhee, Fisher, Johnson, \& Birch, 1993). For example, Gibson, et al (1995) conditioned participants to associate a novel-flavoured blancmange dessert with the postingestıve rewarding consequences of proten over four conditioning thals. Surprisingly, even after the first of these trials, the authors found that liking for the dessert had increased significantly. In a similar study, Johnson, et al (1991) parred novel flavoured yoghurts with a high or a low fat content over etght conditioning trials On test days, the authors found that the chlldren's preference for the highdensity parred flavour was enhanced. Since the flavour was presented in the absence of fat on this test day, it is clear that the change in preference was for the flavour 
1tself, not for the fat substance it had been parred with. Other substances known to offer a postıngestıve reward have also been found to facilitate flavour preferences in humans. For example, several studies have suggested that parring caffeine with novel flavours can reinforce changes in flavour preference when individuals are caffeine-deprived (Richardson, Rogers, \& Elliman, 1996, Yeomans, Durlach, \& Tinley, 2005, Yeomans, Jackson, Lee, Steer, Tinley, Durlach, \& Rogers, 2000b; Yeomans, Spetch, \& Rogers, 1998; Yeomans, Jackson, Lee, Nesic, \& Durlach, 2000a). Specifically, Yeomans, et al (1998) demonstrated that liking for a novelflavoured drink increases significantly after it has been paired repeatedly with caffeine over several conditıoning trials.

Similar associations formed between the flavour of a food and its postıngestive properties can also come to control meal termination. As suggested above, a homeostatic model of meal termination proposes that a meal is ended when some physiological detector informs the brain that enough energy has been absorbed, and no further food needs to be eaten. However, nearly half a century ago, Le Magnen (1955) recognised that the answer could not be this simple. The reason for this is that food is emptied far more gradually from the stomach into the upper small intestine, where absorption takes place, than the rate at which it is eaten. Therefore, by the time a person terminates a meal very little energy has been absorbed (Carbonnel, Lemann, Rambaud, Mundler, \& Jian, 1994) Given this, Le Magnen (1955) realised that ending a meal was in essence a prediction of later energy absorption based on what was being consumed. More recently, this idea has been formalised and is termed 'learned satiety' It refers to the fact that future anticipatory control of meal size occurs when the flavour of a food (CS) becomes associated with the foods postingestive consequences (UCS) (Booth, 1977; Stunkard, 1975,)

Expenmental support for learned satiety originally comes from studies using rats (Booth, 1972; Davis \& Campbell, 1973), and was also later reported in monkeys (Booth \& Grinker, 1993) In an initial experiment, Booth (1972) presented rats with two flavours paired with different energy densities over a senes of conditioning trials. In the test phase, the energy content was manipulated such that it was Identical for each of these flavours It was set at a value between the two contents 
presented in the conditioning trials Not surprisingly, in the test phases the rats increased the size of their feeding bout on the flavour previously parred with the dilute nutrient, and reduced the size of their feeding bout on the flavour previously paired with the more concentrated nutrient Since the rats cannot have been responding to real differences in the energy content in the test phase, their behaviour must result from the fact that the flavour paired with the more concentrated nutrient had come to predict greater feelings of satiety, therefore encouraging the rats to consume smaller amounts of this flavoured food. More recently, Gibson and Booth (2000) have also suggested that associations formed between the odour of a food and its postingestive after effects can come to control meal size in rats In this study, the authors found that in a two-bottle choice test, rats drank more of a fluid which had a novel odour, than one which had previously been associated with a concentrated starch (maltrodextrin) solution.

Following initial demonstrations of learned satiety in anımals, flavour-postıngestive associations were also found to determine meal termination in humans (Birch \& Deysher, 1985, Booth, et al , 1982;). For example, Booth et al (1982) showed that if a soup flavour is repeatedly paired with starch augmentation across a number of training trials, $a d-l l b$ intake following this soup is subsequently reduced, despite the fact that the flavour is presented in the absence of starch augmentation. Again, this is because the previously novel flavour has come to predict greater feelings of satiety generated by starch ingestion.

Taken together, the evidence presented in this section suggests that particular sensory charactenstics of a food, such as the taste of food, can gain the capacity to control flavour preferences and meal termination in animals and humans. This evidence is interesting because it highlights the importance of dietary learning for decisions made about what, and how much, to eat. However, most important to this thesis is how learned associations between external stımuli and eating might gain the capacity to control when individuals might initiate food intake. This learned phenomenon has received relatively less attention in the ingestive behaviour literature than other forms of dietary learnıng. Despite this, this issue ments consideration This is because it is important to understand why individuals consume food when they do, particularly in light of the recent increases in obesity 
(see Introduction) Therefore, the following section reviews the theories of conditioned meal initiation proposed to date.

\subsubsection{Conditioned meal initiation}

As suggested previously (see Section 1.3), Pavlov (1927) initially described how formerly neutral stımuli can come to elicit new responses after being associated with a stimulus which elicits this response (Pavlovian/ Classical conditioning). In forming his principles of Pavlovian (Classical) conditıoning, Pavlov (1927) was in fact the first to suggest that learned associations between external food cues (visual and olfactory) and food ingestion can come to control appetite While investigating neural mechanisms controlling glandular secretions during digestion in dogs, Pavlov (1927) found that the appearance of his laboratory assistant began to elicit salivary responses in these dogs. Pavlov assumed that the reason for this was that his laboratory assistant began to predict the food which the dogs would subsequently be given To explore this possibility further, Pavlov placed inexperienced dogs in a harness and occasionally gave them small amounts of food powder. Before placing the food powder in the dog's mouth, Pavlov sounded a bell, a buzzer, or some other auditory stimul (CS). After repeated pairings of the food powder and auditory stımuli the dog began to salıvate in the presence of the auditory stımulı alone (CR) Thus, the auditory stımulı had come to predict the presence of food.

Following this early work by Pavlov (1927), several authors have theorised about the extent to which external stimulı might gain the capacity to motıvate appetite and food intake (Weingarten, 1983, 1984, 1985; Woods 1991, Woods \& Ramsey, 2000; Woods \& Strubbe, 1994, Wardle, 1990) Identical to all these authors' theories is the idea that previously neutral environmental stımuli (CS) can stimulate food intake (CR), after these stımuli have been repeatedly paired with food consumption (UCS) Weingarten $(1983,1984,1985)$ called this appetitive motıvation elicited by an external cue 'incentive-induced hunger'. By contrast, Wardle (1990) suggested that environmental stımuli in fact elicit a biological state which is similar to 'real hunger.' She called this 'deprivation-induced hunger,' and emphasised the physiological changes that this might involve. Similar to Wardle's (1990) 
perspective, Woods and colleagues (Woods 1991, Woods \& Ramsey, 2000; Woods \& Strubbe, 1994) have referred to a cue-elicited motivation to eat as anticipatory hunger. They (Woods 1991; Woods \& Ramsey, 2000, Woods \& Strubbe, 1994) suggested that external stimuli (e.g., time of day) which signal food intake, are followed by physiological changes which prepare the body for food ingestion. These signals are then interpreted as feelings of hunger.

Experimental support for this learned meal initiation comes from several studies which have suggested that cues which have been parred with food ingestion over a number of conditioning trals can stımulate meal initiation, and can elicit instrumental responding for food, in both anımals (Calvin, Bicknell, Sperlıng, 1953; Edgar, Hall, \& P1erce, 1981; Flatt \& Balley, 1983, Lovibond, 1983; Lovibond, 1980; Zentall, Hogan, Compomizz1, \& Compomizz1, 1976; Werngarten, 1983, 1984), and humans (Birch, McPhee, Sulıvan, \& Johnson, 1989) Specifically, Weingarten $(1983,1984)$ found that stimulı conditioned to food ingestion can determine when rats will initiate a meal and the amount of food they will consume. In these studies, rats were typically fed a liquid diet in six irregularly spaced meals each day. During this training phase each meal was signalled by a buzzer and a light (the conditioned stımulı CS+) presented for four minutes before, and 60 seconds after the meal was made avalable. In the test phase the CS+ was presented while rats were non-food deprived. The rats responded 'rapidly and robustly' to the CS+ by takıng a meal whıch was approxımately $20 \%$ of their total dally Kcalone intake. In contrast, they did not respond to another stimulus (a steady tone CS-) which had been present exactly midway in each inter-meal interval For Weingarten (1983, 1984), these findings suggested that external cues associated with food ingestion gain the capacity to stımulate food ingestion even in the absence of nutritional need.

In a similar study using human participants, Birch et al. (1989) found that children were more motivated to eat in the presence of cues which had been previously parred with food consumption. In this study, the authors traned preschool children to associate the presence of a red rotating light, a particular piece of music, and a specific location (external stımuli) with the consumption of snack foods They did 
this by presentıng these external stımuli for 30 seconds before food presentation, and for four and a half minutes after this food had been made avallable. During the test trials, the conditioned stımulı was presented to the children while they were satiated In these trials all fifteen children ate immediately in the presence of the conditioned stımul and consumed meals that comprised $10 \%$ to $15 \%$ of the Recommended Dally Average (RDA) of Kcalones for children of this age. In contrast, when the children were presented with stımuli which had not been paired with the consumption of snack foods durng conditioning trials, only three out of 15 of the children began to eat the snack foods immediately, and on average they consumed smaller amounts of these foods

Thus, taken together, the findings reviewed here suggest that external stımuli can in fact be conditioned to motivate eatıng behaviour. A more detalled review of these conditioned responses is considered in Chapter 2. However, the remainder of this chapter considers food-cue reactivity in relation to non-food specific theories of motivated behaviour.

\subsection{Non-food specific theories of motivated behaviour}

The idea that external stımulı can motivate behaviour is not exclusive to dietary control. Rather, external stımul are assumed to control much of our motıvated behaviour. For example, it might control drug-takıng behaviour, sexual behaviour, attention-seekıng behaviour, behaviour motıvated towards social approval etc. For this reason, a number of theories have been proposed to explain how external stımuli generally gain the capacity to motivate behaviour The subsequent sections will provide an historical review of these theores, and identıfy how they might inform our understanding of conditioned meal initiation 


\subsubsection{Instrumental/Operant conditioning}

The first author to discuss motivated behaviour in response to external stımulı was Thorndike (1905, 1908, 1911). He described a form of learnıng known as 'operant,' or 'instrumental,' conditioning Essentially, this form of learning suggests that organısms engage in behaviours associated with particular stımulı (such as a string or lever) if these behaviours have previously resulted in desirable consequences such as food, a drug, attention, or social approval

Thorndike's ideas were based exclusively upon his observations from experimental work In this work, Thorndike typically placed hungry cats in so-called 'puzzle boxes' These boxes contained a dangling piece of string, which when pulled released the cage's latch, allowing the cats out of the box where they received a bowl of food. When first placed in the puzzle box, a cat would claw and bite at the confining bars and wire. Through random trial and error behaviour, the cat would eventually pull the string and open the cage to reach the food When placed in the box again, the cat would pull the string more quickly, unt1l after several trials, the cat would pull the string immediately when placed in the box The reason for this is that pulling the string had become reinforced by the reward of eatıng the food Thus, the previously neutral string had acquired motivational properties and consequently was able to elıcit the 'pulling' behaviour.

Following Thorndike's theorising, Skınner $(1938,1953)$ proposed a simılar model. Like Thorndike, he also suggested that some events which follow responses have the effect of increasing the likelihood that the response will be repeated. Again, Skınner $(1938,1953)$ was able to show that a previously neutral stımuli (a lever) could gain the capacity to motivate an instrumental response because it was associated with a reward, $1 \mathrm{e}$, a food pellet 


\subsubsection{Drive reduction theories}

Later theorsts (e.g, Guthree, 1934, 1952; Hull, 1935, 1943, Tolman, 1932) continued to suggest that environmental stimuli could gain the capacity to motivate behaviour. However, they also went on to suggest that previously neutral environmental stımuli elicit these behaviours because they become associated with a drive reduction. For example, they were suggesting, that if pressing a lever results in the administration of food, the lever will become associated with a reduction in hunger dnve Likewise, if it is associated with water it will become associated with a reduction in thirst drive Thus, on occasions where organisms are hungry, or thirsty, environmental stımuli which are associated with a reduction in these drives w1ll be approached and behaviour to reduce this drive will be initrated. By contrast, in circumstances where individuals are not hungry or thirsty, these stimuli will not be approached. For Tolman (1932), learning about these associations between environmental stimulı and a particular drive reduction results in environmental stımul gainıng the capacity to elicit an 'expectancy' of the forthcoming 'reward' or 'reduction in drive.' This expectancy arises from memories of previous occasions where a particular stımulus has preceded a reduction in a particular drive or motivation and it is this expectation which subsequently motivates behaviour.

\subsubsection{Incentive motivation}

Following from these drive reduction theones, a series of authors suggested that rather than sıgnalling drıve reductıon, neutral environmental stımulı in fact acquire incentive motivation (e.g., Bindra, 1974, Bolles, 1972;). Thus, the stimuli come to signal a tasty reward, rather than a reduction in hunger drive For example, one incentıve motıvation theorist, Bolles (1972), suggested that this incentıve motivation is an expectation of a pleasurable reward. What is learned, according to Bolles (1972), therefore, is a contıngency between certain previously neutral environment stimulı (S) and a hedonic reward $\left(\mathrm{S}^{*}\right)$, such as a tasty food. The previously neutral stımuli therefore elicit an 'expectancy' of the preceding reward. 
This cognitive expectancy is similar to that proposed by Tolman (1932), and is generated by memories of previous expenences of this hedonic reward

Contrary to Bolles (1972), Bindra (1974), another incentive motivation theorist, suggested that rather than causing an expectation of a hedonic reward per se, environmental stimuli associated with a hedonic reward in fact elicit the same incentive motivational state normally caused by the reward itself. Thus, according to Bindra (1974), the previously neutral stımuli gains incentıve value. This contrasts Bolles (1972) theory which suggests that the stımul only gans an expectation of the reward, and does not acquire incentive motivation itself. In an illustration of Bindra's (1974) theory, he suggested that after repeatedly pairng a light with the presentation of food, the light will come to elicit a representation of the rewarding effects of the food, and thereby has gained incentive value. In this way, previously neutral environmental stımulı can come to elicit motivational arousal. According to Bindra (1974), this arousal consequently elicits goal-directed behaviour to obtain the reward associated with this incentive motivation.

\subsubsection{Incentive salience}

More recently, the notion of incentive salience (Berndge, 2004; Berndge \& Robinson, 1998) has been proposed to explain how environmental cues can come to motivate particular behaviours Importantly, this concept follows Bindra (1974) and Toates (1981) rules for incentive conditioning (Berridge, 2004). It suggests that once incentive salience has been attributed to an external stımulus, on subsequent occasions when this cue is encountered, the incentive associated with that cue will become highly salient. However, perhaps the greatest distinction between this theory and the incentive motivation theories described above is that it suggests that 'likıng' and 'wantıng' a reward are not synonymous, and that it is in fact wanting, not liking, which motıvates responding to incentive stımuli.

For Berndge and colleagues, 'lkıng' essentially refers to sensory pleasure It is triggered by the immediate receipt of a reward, such as a sweet taste It can also be triggered by a CS as this predicts a hedonic reward, but it is not capable of 
motivatıng behaviour towards this reward In contrast to this, 'wantıng,' or incentive value, reflects the motivational incentive value of the same reward, and is not a sensory pleasure. This wantıng system is therefore able to attribute incentive salience to previously neutral stımul. When this incentive salience is attributed to a reward representatıve, it makes that stımulus attractıve, and attention grabbing.

This 'incentive salience' model results from findings from neurological studies. These studies have suggested that brain dopamine is activated by the sensory pleasure of a reward. However, Berridge and his colleagues (Berridge, 2004; Berridge \& Robinson, 1998; ) have reviewed a body of evidence which suggests that manıpulations of mesolımbic/neostriatal dopamıne systems (through blockıng dopamine, or electrically stımulatıng dopamine) modify motıvation to eat (wanting), but fall to alter likıng measured by hedonic or aversive reaction patterns. On the basis of this evidence, they concluded that hedonic reaction (liking) and incentive motivation are two separable constructs and that only the latter of these is involved in responding to environmental stımulı.

The incentive salience hypothesis specifies that the attribution of incentive salience involves three distinct psychological processes. The first of these is 'hedonic activation' In this stage, novel stımulı trigger hedonic pleasure or likıng. Thus, an individual might eat a food which triggers a hedonic response. The second stage is 'associatıve learning.' In this phase, associatıve learnıng identıfies the correlation between the hedonic activation ( 1 e., liking for the food) and the predictive external event or conditioned stımulus that preceded it. Therefore, taken together, these first two stages are sufficient to associate the CS with a hedontc response. However, these processes alone do not suffice to make a CS attractive or to motivate behaviour towards it They simply make it possible for the CS to activate an affective state. The final stage involves attribution of incentıve salience. Incentive salience is required to transform the 'neutral' perception of a conditioned stımulation into an attractıve incentıve capable of elicitıng appetıtıve or instrumental behaviour towards it Only on this final stage does the stımulus event become 'wanted' as well as 'liked' This occurs as incentıve salience is attributed to the stimulı by activation of dopamıne-related systems guided by associative learnıng. Interestıngly, Berndge and Robinson (1998) also suggest that on each subsequent 
encounter with a 'wanted' and 'liked' stimulus, its capacity to support wanting is maintained or strengthened by associative 'reboosting' of the incentive salience assigned to the representation. Reboosting occurs when a wanted incentive is followed again by activation of hedonic liking. If reboosting occurs the reward will again be 'wanted' on later occasions.

\subsubsection{Relevance of non-food specific learning theories for dietary control}

The literature reviewed here relating to non-food specific theories of learned motivated behaviour suggests that previously neutral environmental stımuli can elicit conditioned responses etther though a process of drive reduction, whereby behaviour associated with a particular behaviour is known to reduce a specific drive, by eliciting expectancy or a representation of a hedonic reward, or by gaining incentive salience. Therefore, these theories provide alternative views of the process by which an external cue might gain the capacity to motivate eatıng behaviour.

A drive reduction theory of food-cue reactivity would suggest that an external stimulus associated with food ingestion signals a reduction in hunger. Thus, when individuals are hungry they are likely to approach these stimult to reduce their hunger drive. However, according to this theory, in the absence of hunger these stımulı are likely to be ignored. Yet, evidence relatıng to conditioned meal initiation reviewed in Section 1.3.2 suggested that external cues which have been associated with food intake elicit eatıng behaviour in both satiated, rats (Weingarten, 1983, 1984) and humans (Brrch et al, 1989). Therefore, it is unlikely that this theory provides an accurate account of the mechanısm underlyıng food-cue reactivity.

Contrary to the drive reduction theory, incentıve motivation theonsts (e.g, Bindra, 1974), suggest that a food cue gains incentive motıvation. This would therefore elicit a motivation to eat. Somewhat similar to this, Berndge and colleagues' (Berridge, 2004; Berridge \& Robınson, 1998;) Incentıve Salıence hypothesis suggests that a cue previously associated with food ingestion gains incentive salience by activation of dopamıne-related systems guided by associatıve learning This incentive salience then guides attention towards the cue and makes it attractive. 
Since the drive reduction theory was rejected here as an explanation of the process by which external cues motivate eatıng behaviour based on existing evidence in the literature, it seems appropnate to adhere to an incentive motivation account of conditioned meal initiation. Notably, to date, the literature pertaining to food-cue reactıvity provides little evidence to reject this potential explanation Therefore, one possibility is that an external cue which has become associated with food intake signals the avallability of an incentive. This would thereby be sufficient to motivate eatıng behaviour to gain this reward.

\subsection{Chapter summary}

The evidence reviewed in this chapter suggests that a set-point model of dietary control is not sufficient to account for the complexity of eating behaviour. Rather, it suggests that it more plausible that body weight settles at the point at which internal physiological factors and external environmental stımul achieve equilibnum. It has been suggested that external cues such as the sensory characteristics of a food can gain the capacity to influence dietary choices, meal termination, and meal initiation. This occurs as these characteristics become associated with particular aspects of food ingestion For example, it was suggested that an already liked, or disliked, flavour can facilitate food preferences, or food aversions (flavour-flavour learning). Likewise, associations formed between a novel flavoured food and it's reinforcing, or aversive, postıngestıve effects can determıne our preference for this novel flavour (flavour-postıngestıve learnıng), and meal termınatıon (learned satiety). Finally, and most importantly to this thesis, visual and olfactory food cues associated with food ingestion have been found to elicit a motivation to eat.

In this chapter, various theories of externally-cued motivated behaviour which are not specific to eatıng behaviour have also been reviewed. These theones suggest that previously neutral environmental stımuli can elicit conditioned responses either though a process of drive reduction, whereby behaviour associated with a particular cue is known to reduce a specific drive, by eliciting an expectancy or a representation of an hedonic reward, or by gaining incentive salience These theories were referred to in this chapter to enhance understanding of the process by 
which a conditioned cue comes to motivate eatıng behaviour. Since experimental evidence was not found to support the view that cues signal a reduction in hunger drive; one possibility is that conditioned cues signal the avallability of a food incentıve and thereby motivate eatıng behaviour. 


\section{CHAPTER 2}

\section{CUE REACTIVITY}

\subsection{Chapter Introduction}

In Chapter 1 evidence was reviewed which suggested that an external stımulus can gain the capacity to motivate food intake after it has been associated with food ingestion (conditioned meal initiation). The aim of this chapter is to provide a more detalled review of the evidence pertaining to these conditioned responses (cue reactivity), and to identıfy how these findings are related to the questions addressed in this thesis

This chapter is divided into two parts. Part I provides a detailed review of evidence suggestıng that external stimuli can motıvate appetıtıve responses. Most importantly, this includes a discussion of evidence suggestıng that cues associated with food intake can elicit a motivation to eat. However, prior to this, it considers the ability of external cues associated with drug use to stimulate drug-taking behaviour. This literature is particularly relevant to the research undertaken for this thesis because 'drug-cue reactivity' relies on simılar learned associations as foodcue reactivity. Following these reviews, Part II of this chapter presents the literature relevant to the specific questions addressed in this thesis. 


\section{PART I}

\subsection{Drug-cue reactivity}

When exploring dietary phenomenon it is important to consider other behaviours which rely on similar principles. Therefore, it is particularly relevant to this thesis that drug cues are also assumed to gain the capacity to initiate, and increase, drugtaking behaviour. Indeed, the effect of drug cues on drug use has been explored extensively in the drug literature. Typically, studies have suggested that exposure to drug-related cues can elicit a desire, or urge, for the cued drug, can stımulate greater use of this drug, and can increase physiological responsiveness, such as heart rate, and blood pressure in heavy users. This cue reactivity has been found to occur in the presence of stimuli associated with a range of drugs, including alcohol, tobacco, opiates, and cocaine

Studies exploring drug-cue reactivity typically expose participants to either, a drug cue, such as the sight of the drug itself or paraphernalia associated with the drug, (e g., a hypodermic needle), or to a neutral cue or 'no cue' (control condition), for a fixed amount of time After this, a range of subjective, behavioural, and physiological, measures are assessed These responses are then compared between the two conditions (no cue and drug-cue) and across heavy users of the drug, and light, or non-users

In the alcohol-cue reactivity literature, for example, participants are typically exposed to an alcoholic drink, which might be their favounte drink (e g., Cooney, Litt, Morse, Bauer, Gaupp, 1997) or their most commonly consumed beverage (e g , Staiger \& White, 1991), or they are exposed to a context which they associate with drinkıng, for example a bar (e g, Wigmore \& Hinson, 1991) Their responses to these cues are then compared to their reactivity to neutral cues (e g. a non-alcoholic dnnk, or laboratory settıng) and relatıve to the responses observed in social 
drinkers. Using this paradigm, several studies have suggested that alcoholics report greater craving for alcohol, or a greater urge to drınk alcohol (Cooney, Gillespie, Baker, \& Kaplan, 1987, Greenley, Swift, Prescott, \& Heather, 1993; Payne, Rappaport, Smith, Etsche1dt, Brown, \& Johnson, 1992; Pomerlau, Fertıg, Baker, \& Conney, 1983; Wiesbeck, Weijers, \& Gross, 2000), expenence increased heart rate (Breteler, Schippers, De Jong, \& van der Stark, 2000; Payne et al, 1991), have greater event-related potentials (ERP's) ${ }^{1}$ (Herrman, We1jers, Wiesbeck, Bonıng, Fallagatter, 2001) experience increased salıvation (Gullıver, \& Sirora, 1994; Pomerlau et al, 1983, Rubonis, Colby, Montı, Rohsenow,) and consume greater amounts of alcohol in relation to those exposed to a neutral cue (Wigmore \& Hinson, 1991). These findings occur across age groups, as even alcoholic adolescents (aged 14-19) are found to experience greater craving and salivation while holding and sniffing their favourte alcoholic drunk (Thomas, Drobes, \& Deas, 2005). They are also found irrespective of detoxification (Staiger \& White, 1991), or previous treatment (Pomerlau et al., 1983).

Similar to alcohol-cue reactıvity, reactıvity to smokıng cues has also been found to be elevated in smokers, relative to non-smokers, in the presence of smoking-related cues such as smokıng paraphernalı (e.g., Rikard-Figuero, \& Zerchner, 1985), contexts where smokıng previously occurred (e g., Thewissen, van der Hout, Havermans, \& Jansen, 2005), cigarettes (Herman, 1974), or virtual reality smoking cues (Bordnick, Graap, Copp, Brookes, \& Ferrer, 2005). Specifically, after exposure to such stimuli, smokers report a greater urge to smoke (Burton \& Tiffany, 1997; Drobes \& Tiffany, 1997; Field, \& Duka, 2005; Hutchınson, Niaura, \& Swıft, 1999; Thweissen et al, 2005), expenence increased salivation (Field \& Duka, 2005), greater skin conductance levels (Burton \& Tiffany, 1997), increased heart rate (Rikard-Figueroa, \& Zeichner, 1985), and are more likely to initıate smokıng (Herman, 1974) and to smoke more quickly (Droungas, Ehrman, Childress, \& O'Brien, 1995) Simılar physiological, behavioural, and subjectıve, responses have also been reported in cocaine and oprate users In particular, in the presence of drugrelated cues (e g., drug-related slides, videos, or objects) these drug users when

\footnotetext{
I An event-related potential is electrical activity produced by the brain in response to sensory stımuli or associated with the execution of a motor, cognitıve, or psychophysiological task
} 
compared to non-users, have shown significant increases in heart rate, skin conductance level, pupil dilation, and craving for drugs (Franken, de Haan, van der Meer, Haffmans, \& Hendnck, 1999, Hugdahl \& Ternes, 1981; Kranzler \& Baller, 1992; Sideroff \& Jarvik, 1980, Teasdale, 1973).

Similar to food-cue reactivity, this reactivity to drug-related cues is also assumed to result from associations formed between the cue and drug use. In fact, several theories of this learned behaviour have been proposed. These differ primarily in their conception of the representation elicited by the drug-related stımuli after learning has occurred. Some suggest it represents a drug-like response, while others have suggested that it represents a drug-opposite effect, or a drug withdrawal-like state.

In an early model of drug-cue reactivity proposed by Wikler and colleagues (W1kler, 1948; W1kler \& Pescor, 1967), it was suggested that environmental stımuli become associated with the withdrawal effects of the drug (conditioned withdrawal model) Accordingly, when subsequently encountered, these environmental stımulı elicit withdrawal-like effects, which act as a drive to obtain the drug In support of this model, studies have shown that drug-withdrawal can be conditioned in both humans and rats. For example, Wikler and Pescor (1967) found that rats made dependent on morphine and then transferred to a regimen in which a single high dose was given at the start of the day, lead to a dally cycle of withdrawal. In a similar study, O'Brien (1976) showed that opiate withdrawal symptoms can also be conditioned in humans.

In contrast to the conditioned withdrawal model, S1egel (1999) proposed a compensatory conditionng model In this model, Siegel (1999) suggested that environmental stımulı become associated with compensatory, or adaptıve, drug responses that serve to counteract the drugs effects. For Siegel, it is these drug compensatory responses which consequently stimulate drug use Consistent with this model, McCaul, Turkhan, and Stitzer (1989) reported drug-like physiological responses in alcoholics after exposure to a drink which on previous occasions contained alcohol. In this experiment, alcoholic partıcıpants were given a dose of alcohol for four days, before substituting a placebo drink on a fifth day. A control 
group experienced the placebo drink on each of the four days and also on the fifth test day. For the experimental group, in which the vehicle drink was intended to be CS (conditioned stımuli) for alcohol delivery, there was a fall in heart rate and skın conductance relative to controls following the placebo drink on the test day. Since these physiological responses are opposite to the assumed effect of alcohol, this was taken as evidence of drug-opposite conditioned effects.

While the conditioned withdrawal and compensatory conditioning models differ in their conceptualisation of the conditioned stimul, they both regard the conditioned response as a motivational drive to procure drugs in an attempt to correct a need state. However, an alternative possibility proposed by Stewart, de Wit, and E1kelboom (1984) is that environmental stimuli paired with drug use come to elicit drug-like conditioned responses. It is these conditioned responses which Stewart et al (1984) propose create a motivational state similar to that caused by the drug itself. This motivational state consequently acts as a 'priming' dose and stımulates drug use. This model has been referred to as the 'conditioned incentive model,' since it presumes that environmental stimuli become associated with the incentive, or reinforcing, value of the drug. (This theory is similar to more general scientific incentive learning theories reviewed in Chapter 1, Section 143 ). In support of this model, Schwartz and Cunningham (1990) reported drug-like responses in rats exposed to stımuli which previously signalled morphine infusion. In this study, rats were infused with morphine through an indwelling catheter, and temperature responses were monitored In the experimental group, the infusion was given 30 seconds after the onset of a light and white noise lasting 15 minutes. In the control group, the drug was given 75 minutes after the onset of light and noise. Thus, for the experimental group the conditioned stımul predicted the onset of the drug effects, whereas this contingency was absent for the control group. In the test session, the infusion was delayed in order to observe responding to the conditioned stımuli The authors found that the expectation of the morphine infusion produced an increase in body temperature similar to that observed when the morphine had previously been infused. According to Stewart et al. 's (1984) model these drug-like effects experienced by the rats provided an incentive to obtain the drug 
In light of these three differing models of drug-cue reactivity, several authors have attempted to evaluate the evidence in support of each model. However, findings from cue reactivity studies typically provide support for all three models For example, a number of studies have suggested that participants report withdrawallıke symptomology after drug-cue exposure (Powel, Gray, \& Bradley, 1993, Sta1ger \& White, 1991), and also experience physiological responses consistent with a withdrawal state (e g, increased skin conductance) (Glautier \& Drummond, 1994). Similarly, other studies report drug-opposite responses after exposure to drugrelated stımuli (MacFarlane \& White, 1989; Newlin, 1985, Staiger \& white, 1988). For example, Newlin (1985) found that exposure to alcohol cues causes a fall in heart rate and skin conductance level, responses which are opposite to those reported after alcohol consumption (Nauna, Rohsenow, Blinkoff, Mont1, Pedraza, \& Abrams, 1988) And finally, several studies have also reported increased drug-like responses after exposure to alcohol, including increased skin conductance, heart rate responses, and intoxication, (Newlin, 1985). However, in reviews of the literature, Stewart et al ,'s (1984) incentive model is typically found to recerve the most empircal support (Glautier \& Remington, 1995; Nauna et al, 1988,). In a recent meta-analysis of 41 cue reactıvity studies, Carter and Trffany (1999) found that the profile of significant conditioned responses across all drugs of abuse (1.e., smoking, alcohol, heron, cocaine) was characterised by increases in heart rate, increases in sweat-gland activity, and decreases in skin temperature. Given that these responses are the same as those that would be observed after ingestion of the drug itself, the authors viewed this finding as suggesting that the conditioned response elicited by exposure to a drug cue constitutes an incentive-motivational state This is interesting because it is similar to conclusions drawn in Chapter 1 regarding food-cue reactivity. In Chapter 1 it was suggested that the process by which food cues gain the capacity to stimulate food intake might be via a process of incentive salience. Therefore, this suggests that the underlying process by which drug and food cues gain the capacity to motivate behaviour could be similar. 


\subsubsection{Drug-cue reactivity summary}

Evidence reviewed in the previous section suggests that brief exposure to a cue associated with drug use can elicit physiological responses, induce urges and craving for the drug, and can encourage drug use by eliciting an incentivemotivational state. This evidence is relevant to this thesis because similar (but foodspecific) responses are reported after individuals have been exposed to food cues. These food-specific responses will be reviewed in detail in the following section.

\subsection{Food-cue reactivity}

Contrary to drug-cue reactivity, food-cue reactivity has been explored less extensively. This is surprising because exploning food-cue reactivity might in fact enhance our understanding of eatıng behaviour. More specifically, it might provide one explanation for why some individuals are more susceptible to weight gain and overeatıng than others. To date, studies which have begun to explore the possibility of food-cue reactivity have followed the drug-cue reactivity literature and have focused primarily on the effects of exposure to a food-cue, such as the sight and smell of food, or thought of food, on physiological, subjectıve, and behavioural, eating-related responses

Using this cue reactivity paradigm, a range of physiological responses have been found to increase after food-cue exposure. For example, Nederkoorn, Smulders, and Jansen (2000) found that exposing participants for 16-minutes to three plates of diverse kinds of their favourite food, and asking them to look at 1 , to smell 1 , to 1magine how it would taste (exposure period), and finally to taste the food (intensified exposure penod), stımulated increases in heart rate, heart rate variability (HRV), salivation, blood pressure, skin conductance, and gastric actıvity Likewise, Nederkoorn and Jansen (2002) reported similar increases in heart rate, gastric activity, and salivation in some of their participants (unrestrained eaters) after exposure to a variety of foods. Since Cephalic Phase Responses (CPRs) are elicited during exposure to a food cue to prepare the body for food ingestion, Nederkoorn et 
al (2000) suggest that these CPRs were elicited in response to the food cue to gear the body up for food ingestion.

Similar to both Nederkoorn et al 's (2000) and Nederkoorn and Jansen's (2002) findings, Nederkoorn, Smulders Havermans, and Jansen (2004) found that asking participants to intensively smell their favourite foods elicited increases not only in heart rate and skin conductance, but also stimulated decreases in finger pulse amplitude (FPA). According to the authors, this reduced FPA presumably results from the fact that after food-cue exposure blood flowing to the intestines increases in anticipation of digestion of the expected food.

Other studies have focused primanly on the effect of food-cue exposure on salıvation. For example, Brunstrom, Yates, and Witcomb (2004) and Tepper (1992) explored changes in salivation after brief exposure to the sight and smell of pizza, and found that exposure to this food cue was able to stımulate salıvary responses. Other authors have conducted similar studies (e g., Hodgson \& Greene, 1979; Lappalainen, Sjoden, Karhunen, Gladh, \& Lesinska, 1994) using chocolate. However, they have found that mere exposure to the sight of this food does not elicit salivation Rather, only priming with the taste of chocolate was found to elicit salivary responses in these studies. The reason for this might be that by not having the same olfactory qualities as pizza, chocolate is unable to readily stimulate the same salıvary responses that a food like pizza can stımulate. Consistent with this, a study conducted by Overduin, Jansen, and E1lkes (1997) explonng physiological responses to pictures of participant's favourte food did not report increases in heart rate, or skin conductance levels, suggesting that mere pictures of food might also have an inability to elicit a 'preparedness to eat.'

It is perhaps feasible to conclude that if food-cue reactivity can elicit a physiological preparedness to eat, it also elicits a subjective appetite to eat and stimulates food intake. However, since some food-cue reactıvity studies have found that physiological responses do not correlate well with subjective and behavioural measures (e.g, Nederkoorn, et al, 2000, Nederkoorn \& Smulders, 2002; Nederkoorn, et al , 2004), it is important that studies also explore the effects of cue exposure on subjective, and behavioural, measures separately. A number of studies 
have done this and have reported momentary increases in food craving, desire to eat, and also hunger, after food-cue exposure For example, Nederkoorn and Jansen (2002) found that craving increased to a greater extent after exposure to a food-cue, relatıve to craving expenenced after exposure to a bar of soap (neutral cue) Likewise, several other studies have found that exposure to the sight, smell, and taste of, participants favourite foods, or slides depicting these foods, can elicit general food craving (Alsene, L1, Chaverneff, \& de Wit, 2003, Nederkoorn, et al, 2000; Nederkoorn, et al, 2004; Overduin, et al, 1997; Sobık, Hutchinson, \& Craighead, 2005) Furthermore, other studies have suggested that exposure to pictures of food, food itself, the taste of food, and written food cues, can stımulate feelıngs of hunger (Oakes \& Slotterback, 2000), a desıre to eat (Lambert, Neal, Noyes, Parker, \& Worrell, 1992; Oakes \& Slotterback, 2000), and can reduce feelıngs of fullness (Oakes \& Slotterback, 2000).

In addition to reporting increases in subjective appetite after food-cue exposure, several studies have also suggested that food-cue exposure can stımulate intake of the cued food. In one such study, Fedoroff, et al (1997) exposed 91 food-deprived participants (two hours food-deprived) to either no cue, an olfactory food cue, a cognitive food cue, or a combination of the two types of food cues for ten minutes. In the olfactory cue condition, the smell of baking pizza wafted into the testing room, while in the cognitive cue condition, participants were instructed to think about przza and were asked to record these thoughts on paper. The results suggested that exposure to the smell and thought of pizza separately, stımulated subjective appetite and also encouraged greater pizza consumption, as did exposure to a combination of these cues

Notably, in the studies reported above, participants were tested while they were nether hungry nor satiated. However, in other studies the effects of food-cue exposure have been tested in satiated participants. One example of this is a study conducted by Cornell, Rodin, and Weingarten (1989). In this study, participants were offered a buffet lunch prior to cue exposure to ensure that they were non-food deprived. Rather than following a basic cue reactivity paradigm, and exposing participants to either no cue or a food cue, the authors cued all participants with the sight of one of two target foods (przza or 1ce-cream) Thus, when explonng 
evidence for cue reactivity in non-depnved participants, Cornell et al (1989) assumed that when satiated participants should eat nothing, and consequently compared consumption in this group to zero. Using this procedure, the authors found that intake was significantly greater than zero in their satiated group They therefore concluded that cue exposure was able to stimulate intake even in the absence of nutritional need. However, this conclusion was flawed because Cornell et al (1989) assumed that individuals would eat nothing when satiated, despite a lack of evidence for this proposal. Consequently, it is unclear whether increased intake in Cornell et al's study was in fact a result of cue exposure, or whether similar results would be observed even in the absence of this exposure. For this reason, it is important for studies to include a control condition Herman, Ostovich, and Polivy (1999) did this in their study exploning changes in subjective appetite (hunger) after exposure to a food-related cue in hungry, and satiated, participants. Seventy-five food-deprived and non food-deprived partıcıpants were exposed to a food video showing a restaurant review depictıng appetızing foods, such as pancakes, waffles, hamburgers, eggs, and p1e, an engaging non-food video (nocue/comedy), and a non-engaging neutral video (no-cue/weather). For both deprived and non-deprived participants, exposure to the food video significantly increased hunger ratıngs compared to the neutral video, suggestıng that even in the absence of nutritional need, exposure to a food cue can stimulate subjective appetite. In support of this finding, in a more recent study, Marcelıno, Adam, Couronne, Koster, and Siefferman (2001) reported greater increases in desire to eat after exposure to a pizza cue even when indıviduals reported low levels of hunger.

\subsubsection{Food-cue reactivity summary}

The evidence reviewed in this section suggests that exposure to the sight, smell, or thought of food can elicit a momentary increase in desire to eat, a physiological preparedness to eat, and can stımulate food intake Despite this basic research, very few studies have recently sought to develop understanding of this dietary phenomenon further Therefore, this thesis presents an attempt to do this In the following part of this chapter the specific questions which were addressed in this thesis are considered 


\section{PART II}

\subsection{Introduction}

The aim of the second part of this chapter is to present the rationale for considering the specific questions addressed in this thesis These questions emerged as the thesis progressed. Therefore, in the first section, an overview of the development of the thesis is provided The purpose of this is to introduce the questions of interest before providing the rationale for considering each of these in the remaining sections of the chapter.

\subsection{Overview of the issues considered in this thesis}

Broadly, this thesis considers individual differences in food-cue reactıvity. Following directly from previous research which will be discussed below, the initial experments were designed to determıne the extent to which differences in everyday dietary behaviour (dietary restraint and disinhibition) predict food-cue reactivity. After these initial expenments, a series of further studies were designed to explore the more complex 1ssues related to this dietary phenomenon One possibility considered was that food-cue reactivity has implications for everyday food consumption and BMI. Therefore, a series of experiments explored the potential links between reactivity to food cues and everyday portion-size selections, and being overweight. Another possibllity which emerged after conducting these studies was that food-cue reactivity might in fact be determined more generally by personality characteristics. Notably, these characteristics might potentially share associations with dietary disınhibition and being overwerght Therefore, in the final experiment, associatıons between food-cue reactivity and particular personality characteristics, (ımpulsıvity and sensitıvity to reward) were examıned. 
Prior to conducting the initial experiments, it became evident from the literature that whilst exploring food-cue reactıvity in restrained, and disınhıbited, eaters it might be important to consider the specificity of this reactivity. Specificity literally refers to the extent to which a food cue is only able to elicit an appetite for the cued food To illustrate this, if after food-cue exposure, appetite for the cued food increases, but appetite for other non-cued foods remains unchanged, then the effects of the food cue can be sald to be specific to that food. By contrast, if appetite for a cued food increases along with appetite for non-cued foods, then the effects of food-cue exposure would be considered to be more general in nature In the initial experiments, evidence for this cue specificity in restrained and disinhibited eaters was considered. Given that this issue appeared to be central to an investigation of food-cue reactivity, in the following experiments it was also considered for the other predictor variables being examined (e.g., everyday portion-size selections, BMI, and personality charactenstics).

Notably, in the initial experiments conducted for this thesis, a decision was made to assess associations between everyday dietary behaviour and food-cue reactivity in satiated individuals. This followed Weingarten's (1985) proposals that food cues should elicit a motivational state even in the absence of nutritional need. However, it became evident that this design was limited. This was because, it was impossible to conclude from the findings that the same differences in food-cue reactivity would be evident across the predictor variables (dietary restraint, disinhibition, BMI, impulsivity, and sensitivity to reward) if individuals were tested while they were relatively hungry. For this reason, in the final experiment, individual differences in food-cue reactivity were explored before lunch, while participants were 4-hour food deprived, and immediately after they had eaten to satiety.

To summarise, this thesis explored a series of issues. The first issue relates to associations between food-cue reactivity and everyday dietary behaviour (dietary restraint and dietary disinhibition). The second issue relates to the potential influence of food-cue reactivity in decisions regarding everyday-portion size selections, and for BMI Finally, the third issue relates to the potential role of particular personality characteristics (impulsivity and sensitivity to reward) in foodcue reactivity. In addition to explonng these three primary issues, the experiments 
presented in this thesis also considered two secondary issues The first of these relates to cue specificity. The second relates to the effect of an individual's motivational state (hungry or satıated) on observed differences in food-cue reactivity. The rationale for considering each of the three main issues and the two secondary issues is presented in the remaining sections of this chapter.

\subsection{ISSUE 1: Food-cue reactivity and everyday dietary behaviour}

The aim of this section is to provide the rationale for exploring the association between food-cue reactivity and measures of dietary restraint and dietary disinhibition. An histoncal account of the association between dietary restraint and food-cue reactivity is presented This begins with a review of literature which prompted speculations that dietary restraint might be an important precedent of externally-motivated eatıng behaviour. This particular literature dates back to the 1960's and 1970's, and 1dentıfies overweight individuals as highly responsive to external cues. Following this, the introduction of the concept of dietary restraint is described, and it's relation to external eating behaviour is considered. After reviewing direct evidence associating food-cue reactivity with dietary restraint, the final sub-sections; 1) highlight the limitations of the measure used to assess dietary restraint in these studies, and il) consider the possibility that food-cue reactivity is associated with dietary disınhibition.

\subsubsection{Precedents to dietary restraint: The 'externality' hypothesis}

Speculation that dictary restraint might share an association with food-cue reactivity resulted from early work relating to externally mottvated behaviour in overweight individuals. In the late 1960's and early 1970's Schachter $(1968,1971)$ proposed that differences in BMI were the key determınant of externally-driven eatıng behaviour. Specifically, Schachter $(1968,1971)$ suggested that overweight individuals eat primarily in response to immediate external cues associated with food, and 1gnore internal physiological stımulı signalling hunger and fullness. By contrast, he suggested that the eating behaviour of normal-weight individuals is 
governed primarily by internal physiological signals of energy depletion. These 1deas became embodied in Schachter's $(1968,1971)$ 'externality' hypothesis. Early support for this hypothesis came from a study by Stunkard and Koch (1964). These authors found that stomach contractions and reports of hunger only coincided in normal-weight individuals In obese individuals, there was little correspondence found between gastric mobility and reports of hunger. A similar finding was also reported by Schachter, Goldman, and Gordan (1968). These authors found that obese individuals consumed similar amounts irrespective of hunger levels. In this study, the authors manipulated hunger state (hungry or satiated) by either askıng participants to refrain from eating prior to the onset of the experiment, or by presenting them with a meal of roast beef sandwiches on arrival In a subsequent taste test, the authors found that obese individuals ate as much, if not slightly more, when they were satıated, compared to when they were food-deprived In contrast, normal-weight individuals who had recently consumed lunch, ate considerably less than normal-weight partıcipants who were food deprived. These findings were taken as evidence to suggest that obese individuals' eatıng patterns are characterised by a failure to consider internal physiological need

Following these initial findings in support of Schachter's $(1968,1971)$ hypothesis, a large number of studies were conducted which provided further support for his proposals. At least two studies did this by exploring the eatıng behaviour of overweight, and non-overwe1ght, individuals in their naturalıstıc settıngs. In one study reported by Schachter (1971), the food intake of overweight, and nonoverweight, college students on weekends and weekdays was observed The study found that overweight individuals consumed greater amounts on weekdays than weekends. Given that Schachter (1971) suggested that college students' weekday schedule (which is likely to involve on-campus catering) exposes them to a greater number of food cues, he concluded from his findings that overweight individuals are more responsive to external food cues than non-overweight individuals. In another study, Goldman, Jaffa, and Schachter (1968) explored the possibility that in circumstances where external cues are absent, overweight individuals will have an easier time fasting than non-overweight individuals. The authors did this by investıgatıng 24-hour fastıng on a Jewish festıval Consistent with their expectations, the authors found that the more time overweight individuals spent in 
the synagogue that day away from external food-related cues, the easier they found fasting to be However, although both these studies are consistent with Schachter's $(1968,1971)$ externality hypothesis, they were limited because they falled to isolate the effects of external cues on eating behaviour by not experimentally manipulatıng exposure to these cues.

Unlike the studies reported above, numerous studies have in fact experimentally manipulated exposure to a food cue. In doing this, these studies have reported that various external cues can increase food intake in overweight individuals. For example, the avallability of food has been found to be an important determinant of food intake in overweight individuals (Abramson \& Stinson, 1977). In a widely cited study, Nisbett (1968a) explored the extent to which the amount of food avarlable affected food consumption in overweight, relative to normal-weight, individuals. To do this, Nisbett (1968a) manipulated avallability by presenting participants with either one or three beef sandwiches. He then assessed intake in the two conditions by telling the participants that there were plenty more of these sandwiches in the refngerator and instructıng them to help themselves to as many as they wanted. The findings from this study suggested that overweight individuals who were confronted with three sandwiches ate $57 \%$ more than overweight Individuals confronted with one sandwich. By contrast, normal-weight individuals were completely unaffected by the experimental conditions, and consumed similar amounts in the one- and three-sandwich conditions. These findings were assumed to result from the fact that three sandwiches provided a more salient cue to the 'external' eater and thereby it was harder for these individuals to resist this food (Nisbett, 1968a).

Other external cues have also been found to be potentially important determinants of food intake in overweight individuals. In several studies, food intake in overweight individuals has been found to be influenced to a greater extent by the accessibility of food, i e., whether the food is avallable for immediate consumption. Specifically, overweight adults and children have been found to initiate intake more quickly, and consume greater amounts, of shelled, compared to unshelled, nuts (e g Costanzo \& Woody, 1979; McArthur \& Bustein, 1975; Schachter, 1971 Schachter \& Friedman, 1974; Singh \& Sikes, 1979). However, this finding is not replicated 
when wrapped and unwrapped chocolates are used (Schumaker \& Wagner,1977, Singh \& Sikes, 1979). Singh and Sikes (1979) suggested that this discrepancy might result from the fact that individuals are prepared to have to unwrap chocolates because chocolates are typically encountered in wrappers, but they are not prepared to have to unshell nuts

In addition to food avallability and food accessibility being cited as important determinants of food intake in overweight individuals, the taste of food, contextual cues such as the time of day, and the salience of a food cue have also been reported to have differential mpacts on the eatıng behaviour of overweight, and nonoverweight, individuals. For example, the palatability of food has a greater impact on food consumption for overweight individuals (Decke,1971, Nisbett 1968b; Price \& Grnker, 1973), as does changing the time on a clock to make it appear to be closer to an individual's meal tume (Schachter \& Gross, 1968). Finally, makıng a food cue appear more salient (Johnson, 1974; Ross, 1974) also stımulates greater intake in overweight individuals

In light of the amount of evidence taken as support for Schachter's $(1968 ; 1971)$ model, it is perhaps not surprisingly that his internal/external dichotomy became a widely held framework used to explain differences between normal-weight, and overweight, individuals in the 1960's and 1970's However, as early as 1981, Rodin suggested that there were many indications that the internal versus external view was too simple a description of differences between weight groups. In support of Rodin's (1981) view, several studies suggested that internal signals alone are also poor regulators of intake in normal-weight individuals as these individuals have also been found to be responsive to external cues (Rodin, 1975b; Schachter \& Rodin, 1974; Rodin \& Slochower, 1976; Wooley, 1972). In addition to this, after reviewing the avallable evidence, Leon and Roth (1977) suggested that the evidence for Schachter's $(1968,1971)$ hypothesis was equivocal at best. This is because a number of studies falled to show reliable overweight/normal weight differences consistently from partıcipant population to partıcipant population, or even from study to study (e g, Rodın, Moskowitz, \& Bray, 1976; Rodın, Slocower, \& Fleming; 1977). 
Even prior to this criticism of the externality hypothesis, a novel framework for the external/1nternal distınction was devised by Nisbett (1972). As part of this framework, Nisbett (1972) argued that each person has an individually determined homeostatically defined ideal weight or 'set-point.' This set-point was assumed to be a direct function of the number of fat cells in the body (adipocytes) Nisbett (1972) suggested that, as a result of genetic inheritance and/or overfeeding, obese individuals have higher than average set points because they are over endowed with fat cells. In Nisbett's (1972) view, these individuals can retain this set point, and become seriously overweight, or can strive for a lower body weight thereby suppressing their set points through dieting Nisbett (1972) suggested that it is this biological deprivation caused by dietary restriction, rather than degree of overweight per se, which consequently produces external responsiveness observed in some obese individuals In support of his hypothesis, he pointed out several parallels between obese people and starving organisms. He noted that both groups are more taste-responsive, more emotional, and less active than their normal weight counterparts. Although more recent evidence reviewed in Chapter 1 (Section 1.2) suggests that set points are no longer important determinants of food intake, Nisbett's (1972) speculations are important to consider here because of the implications they have for our understanding of dietary restraint and reactivity to food cues

\subsubsection{External eating behaviour and dietary restraint}

Nisbett's (1972) observations described in the preceding section were extended by Herman and Mack (1975). These authors suggested that 'dietary restraint' (a tendency to restrict ones dietary intake), rather than body weight per se, might be the critical factor in the 'obese' pattern of eating To explore this possibility, they sought to determine the extent to which more restrained eaters consume a greater amount when attractive food cues are prominent if chronic restraints are experımentally elımınated This was achieved using a 'preloading' paradigm In this paradıgm, partıcipants are typically asked to consume a milkshake preload without knowledge of the Kcalorie content of this food, and are then offered $a d-l l b$. access to ice-cream in a disguised taste test. It is the preloading phase of the experiment 
which is assumed to remove chronic restraints by exceeding the 'permissible' limits on consumption, and subscquently causing normally restrained eaters to abandon their attempt at restriction. The taste test phase subsequently allows expermenters to assess intake in the presence of attractive food cues after these restrants have been removed

In Herman and Mack's (1975) study, participants were asked to consume, one, or two, milkshakes or were offered no mulkshake at all (control condition). All participants were then presented with three bowls of ice-cream (chocolate, vanilla, and strawberry) in a disguised taste test In this taste test, partıcipants were told that they should taste as much of each of the ice-creams as they liked and to rate its taste They were also told that they could help themselves to any remaining 1 cecream after they had made these ratıngs In this expenment, the authors believed that this taste test phase would allow them to compare $a d-l b b$ intake in the presence of attractive food cues in restrained and unrestrained eaters defined according to their scores on the Restraint Scale devised by Herman and Polivy (1980) The eating behaviour of unrestraned participants in this experiment seemed to conform to the pattern formerly thought to characterise all normal weight individuals, namely 'internal' regulation. These individuals consumed smaller amounts after a larger preload (mlkshake), than after no preload. In contrast, restrained eaters, although of normal weight, behaved in a manner that Herman and Mack (1975) described as 'external.' This is because they consumed larger amounts of food in the presence of attractive food cues once chronic restrants were removed by ingestion of a preload

Following Herman and Mack's (1975) study, a series of studies replicated their findings (e g, Hibscher \& Herman, 1977; Ruderman \& Christensen, 1983; Ruderman \& Wilson, 1979,). However, rather than being interpreted as evidence for 'externality' in restrained eaters, these findings were interpreted as suggesting that restrained eaters 'overeat' after forced consumption of a presumably high energy food because they perceive their diet to be broken. In support of this new interpretation, several studies suggested that restrained eaters' perception of 'breakıng' their self-imposed Kcalone confines causes them to overeat. For example, when told that a preload is high in Kcalones, restrained eaters eat somewhat more in a subsequent taste test, than when told the same milkshake is 
low-Kcalone (Polivy, 1976, Spencer \& Fremouw, 1979; Woody, Costanzo, Leifer, $\&$ Conger, 1981). This new perspective on the eatıng behaviour of restrained eaters was formalised in Herman and Polivy's (1984) boundary model of dietary restraint. This model suggests that as well as lower hunger boundaries, and higher satiety boundaries, dieters have a third self-imposed 'diet' boundary, marking their maximum desired consumption Herman and Polivy (1984) suggest that once restrained eaters transgress this diet boundary, the individual can be left feeling that self-control is no longer worth pursing (the "what the hell" effect, Herman \& Polivy, 1984), and consequently eat unt1l they reach the satrety boundary (the 'disinhibition effect').

Despite the fact that preloading studies were no longer interpreted as providing evidence of external eatıng behaviour in restrained eaters, studies using a more conventional methodology to assess food-cue reactivity have found evidence for greater sensitivity to food cues in restrained eaters. Specifically, apart from a few reports (e.g, Nederkoorn \& Jansen, 2002, Overduin, et al, 1997), restrained eaters (again defined according to scores obtained on Herman \& Polıvy's (1980) Restraint Scale) have been found to experience greater physiological responses in the presence of a food cue, to experience a greater urge to eat, and also to consume greater amounts of food. For example, in an early study of this kind, Collins (1978) found that exposure to either pictures of food, or recipes for food, stımulated greater intake in restrained eaters. In contrast, he found little evidence to suggest that eating behaviour was stimulated to a greater extent in these individuals after exposure to a scenery cue A similar pattern of results was also shown by Rogers and Hill (1989) using olfactory, cognitive, and, visual, food cues In two separate experiments, the authors found that exposure to the sight and smell of food (some of which was the participants preferred food), and imagining food, stimulated greater $a d-l l b$ consumption of biscuits in restrained, relative to unrestrained, eaters In a similar study, using a range of different foods, including cake, smarties, nuts, spiced biscuits, shortbreads, and soft sweets, Jansen and van den Hout (1991) also found that restrained eaters ate significantly more than unrestrained eaters after being asked to hold the food directly under their noses and to concentrate on the smell. More recently, studies have also suggested that restrained eaters consume greater amounts of a cued food when only one food is presented (Fedoroff et al , 1997), and 
have also suggested that elevated cue reactivity experienced by restrained eaters is cue specific (Fedoroff et al, 2003)

In relation to physiological responses to food cues, Nederkoorn, et al. (2000) have found that restrained eaters experience greater systolic, and diastolic, blood pressure after being instructed to look at, smell, and imagine eatıng, three plates of diverse kınds of their preferred foods. Likewise, dietary restriction has also been associated with greater salivation and insulin secretion in response to palatable food cues (Herman, Polıvy, \& Chhabra, 1981; Herman, Polivy, Klajner, \& Esses, 1981, Klajner, Sahakıan, Lean, Robbıns \& James, 1981; LeGoff \& Spıgelman, 1987; Tepper, 1992, Brunstrom, et al , 2004) For example, Klajner, et al (1981) found that salivary responses to the sight and smell of pizza and chocolate-chip cookies were significantly greater in restrained, relative to unrestrained, eaters. In the presence of food, salivation increased by only $17 \%$ in unrestrained eaters, while in restrained eaters, the authors observed a $56 \%$ increase. Similar increases in salivation have also been reported when participants are exposed to low-salience stımuli, such as the smell of palatable food (Herman, et al, 1981; LeGoff \& Spıgelman, 1987), and when partıcıpants have recently consumed lunch (Brunstrom et al., 2004).

The reason for restrained eaters heightened reactivity to food cues has been attributed to their attempt to suppress food consumption in the presence of food cues. Indeed, it is assumed that it is this cognitive suppression which in turn elicits desires for food (Fedoroff et al , 1997). This conceptualisation of the behaviour of restrained eaters comes from Tiffany's (1990) model of drug urges In this model, Tiffany (1990) suggests that after a history of drug use, aspects of drug procurement and drug use, become controlled by automatic action schemata. These are similar to the automatic processes described by Shriffrin \& Schneider (1977). When an individual is exposed to an 'enabling stimuli' (e g, the sight of a cigarette packet or drug paraphernalıa), automatic action schemata are actıvated and this requires no cognitıve effort. However, to abstain from behaviours governed by these automatic action schemata, individuals must recruit non-automatic cognitive processes in an attempt to impede the automatic schemata. Tiffany proposes that it is recruitment of these non-automatic action plans which elicits urges and cravings for the restricted 
substance. Extrapolating this model to dietary behaviour, it suggests that in the presence of a food-related cuc, automatic action plans are actıvated and individuals eat. However, for restrained eaters who are attempting to abstain from eatıng, nonautomatic cognitive resources must be drawn upon to impede these automatic eating action plans which in turn will elicit craving for this food

Taken together, the studies reviewed here provide compelling empincal and theoretical support for the notion that food-cue reactivity is elevated in restrained eaters However, it is important to note that dietary restraint has been assessed in these empirical studies using Herman and Polivy's (1980) Restraint Scale. Although this scale has become the most widely used measure of dietary restraint, its construct valıdity has been questioned on several occasions. This is because it has been found to measure at least two separate constructs; concern for dieting and weight fluctuation/disınhibited eatıng (Blanchard \& Frost, 1983; Drewnowsk1, Riskey, \& Desor, 1982; Heatherton, Herman, Polıvy, Kıng \& McGree, 1988; Johnson, Lake, \& Mahan, 1983, Lowe, 1984; Laessle, Tuschl, Kotthaus, Prrke, 1989) This is problematic because dietary restraint is not a unitary concept and restrained eaters may/or may not engage in disinhibited eatıng and expenence weight fluctuation. Other questionnaires, such as the Dutch Eating Behaviour Questionnaire (DEBQ, van Strien, Frijiters, Bergers, \& Defares 1986) and Three Factor Eatıng Questıonnaire (TFEQ; Stunkard \& Mcssıck, 1985), recognise this and measure dietary restraint independently of dietary disinhibition.

Given that food-cue reactivity has only previously been associated with the Restraint Scale and this scale conflates dietary restraint with disinhibition, one possibility is that food-cue reactivity is not associated with dietary restraint independently of dietary disinhibition or weight fluctuation. Relevant to this, several recent studies have suggested that other instances of overeating (e g., after consumption of a preload, and after exposure to a stressor) which are associated with the Restraint Scale, are not associated with independent measures of dietary restraint (Dntschel, Cooper, \& Charnock, 1993; Steere \& Cooper, 1993; Jansen, Vandenburg, \& Bulten, 1992; Lowe \& Klerfield, 1988,). The reason for this is likely to be that, unlike the Restraint Scale (Herman \& Polivy, 1980), these independent measures do not select individuals based on their predisposition to 
'disınhıbit' (Haynes, Lee, \& Yeomans, 2003). Indeed, using questionnaires that offer separate measures of disinhibition and dietary restraint [e g., DEBQ (van Strnen, Friıters, Bergers, \& Defares 1986) and TFEQ (Stunkard \& Messick, 1985)], recent studies have suggested that only individuals with simultaneously high restraint, and disinhibition, scores overeat in the presence of external triggers (1 e, preloads, stressors, and palatable tastes) (Haynes et al, 2003; Ouwens, van Strien, \& van der Stark, 2003, van Strien, Cleven, \& Shippers, 2000, Westenhoefer, Broeckamnn, Munch, \& Pudel, 1994, Yeomans, Tovey, Tinley, \& Haynes, 2004) Given this, the need to explore associations between food-cue reactivity and independent measures of dietary restraint and dietary disinhibition is imminent. One possibility is that reactivity to food cues might be associated with dietary disinhibition, rather than a pure measure of dietary restraint.

In Experiments 1 and 2, separate measures of restraint and dietary disinhibition were employed to explore this possibility. The Dutch Eating Behaviour Questionnaire (DEBQ; van Strien, Frijıters, Bergers, \& Defares 1986) was chosen as an independent measure of dietary restraint. Unlike Herman and Polivy's Restraint Scale, this scale has been found to measure intention to restrict, and actual restriction of food intake (Leselle, et al, 1989). For example, Wardle and Beales (1987) found that restrained eaters identified using the restraint scale of the DEBQ report consuming $300 \mathrm{kcal}$ a day fewer than unrestrained eaters. Likewise, Leselle et al (1989) found that mean dally calonic intake estımated by means of a 7-day food diary was negatıvely correlated with this restraint scale. Finally, high scores on this scale have been associated with lower scores on various overeating scales (van Strien, 1997), and are relatively less associated with being overwetght than the Restraint Scale (Rıdgeway \& Jeffrey, 1998) Dietary disinhıbitıon was assessed in these experiments using the Three Factor Eatıng Questionnaire (TFEQ; Stunkard \& Messick, 1985) disinhibition scale The scale was constructed using items from two existıng questionnaires, the Restraint Scale, and the Latent Obesity Questionnaire (Pudel, Metzdorff, \& Oettıng, 1975), and from newly written items based on the authors clinical experience of eatıng behaviour. This scale measures behavioural and weight liability, and reflects a more general dimension of disinhibited eating 


\subsection{ISSUE 2: Food-cue reactivity, BMI, and everyday portion-size selection}

The possibility that dietary disinhibition might be associated with food-cue reactivity has direct implications for considering other variables which might be important to food-cue reactivity. Notably, dietary disinhibition has been associated with the consumption of larger everyday portion sizes (Brunstrom, Mitchell, \& Baguley, 2005), and higher BMI's (Bellısle, Clement, la Barzıc, Le Gall, GuyGrand, \& Basdevant, 2004, Lindroos, Lissner, Mathıssen, Karlsson, Sullivan, Bengtsson, \& Sjostrom, 1997). Therefore, it is perhaps possible that food-cue reactivity might also be associated with being overweight and greater everyday food consumption

Several studies have suggested that exposure to a food cue can increase the amount of food that is subsequently ingested (see Part I, section 2 3) Thus, If, as would be expected, those individuals who are highly reactive to food cues in the laboratory are also highly sensitive to these cues outside the laboratory, it follows that they are likely to overeat whenever such cues are encountered. Over time, in the absence of increased energy expenditure, this 'overeatıng' is likely to result in a positive energy balance. This in turn is likely to accumulate in welght gain. Given this, a possibility worthy of consideration is the extent to which individuals who show elevated sensitivity to food cues in the laboratory consume larger amounts of food within their everyday lives, and are more likely to be overweight.

In the preceding section (26) evidence was reviewed which suggested that obese individuals might have greater sensitivity to environmental cues associated with food intake. However, as explained above, this externally-driven behaviour was later attributed to dietary restraint Given that it has been hypothesised here that food-cue reactivity might not be a result of dietary restriction, this constitutes another important reason for reconsidering associations between being overweight and reactivity to external food cues. Recently, Jansen, Theunissen, Slechten, Nederkoorn, Boon, Mulkens et al (2003) have reported greater sensitıvity to food 
cues in overweight children. However, despite this, there have been no recent demonstrations of greater food-cue reactivity in overweight adults.

In light of the evidence reviewed here, later experiments presented in this thesis considered the potential role of food-cue reactivity in everyday food consumption, and explored the implications of being overweight for sensitivity to food cues Experiments 3, 4, and 5 explored the association between food-cue reactivity and everyday-portion size selections, while Experiment 5 considered the association with being overwerght. 


\subsection{ISSUE 3: Potential role of personality characteristics in food-cue reactivity}

If, food-cue reactivity is associated with being overwerght, it might be important to begin to understand what it is about an overweight individual that causes this greater reactivity. One possibility is that some aspect of therr personality renders them more susceptible to the stımulatory effects of food cues than non-overweight individuals Based on evidence to date, it can be speculated that particular personality characteristics which might share an association with food-cue reactivity are impulsivity and sensitivity to reward. Given that these characteristics are expressed to a greater extent in obese, relative to non-obese individuals (Franken \& Murıs, 2005; Nederkoorn, Braet, Van Eijs, Tanghe, \& Jansen, in press; Nederkoorn, Smulders, Havermans, Roefs, \& Jansen, 2006,), one possibility is that they are in fact influentral varıables in determining levels of food-cue reactıvity. In this section, evidence for an association between food-cue reactivity and these personality charactenstics will be considered. The first subsection assesses evidence for a role of sensitivity to reward in food-cue reactivity This begins with an historical review of the ongins of the sensitivity to reward tratt. The following subsection introduces the notion of impulsivity and provides evidence for its potential involvement in food-cue reactivity

\subsubsection{Potential role of the BAS in food-cue reactivity}

Temperament is an aspect of personality that may be determined genetically and therefore could be biologically based. A very popular model of temperament was formulated by Eysenck $(1957,1967)$. He proposed that there are two mann dimensions of temperament: neuroticism/stability and extraversion/introversion. Thus, individuals lie at a particular point on the extraversion/ntrovertion continuum and at a particular point on the neuroticism/stability continuum. For example, one individual might be extraverted and neurotic, while another individual might be extraverted yet stable. According to Eysenck $(1957,1967)$, extraverts and introverts differ in the sensitivity of their cortical arousal system Extraverts have low cortical 
arousal and are therefore in need of external stimulation. In contrast to this, introverts have higher cortıcal arousal and are therefore over-aroused. Eysenck's second dimension, neuroticism, is based on activation thresholds in the sympathetic nervous system or visceral brain. Neuroticism, or emotionality as he referred to 1 , is characterized by high levels of negative affect such as depression and anxiety. The direct opposite of neuroticism was regarded by Eysenck as 'stable.' Individuals with this temperament, according to Eysenck were emotionally stable people who have high activation thresholds and good emotional control.

As part of his proposals of temperament, Eysenck's described the behaviour of an introvert as 'over-socialised,' and the behaviour of an extrovert as 'undersocialised.' He suggested that the process of socialisation involves a cluster of feared conditioned reactions. In determining why introverts form stronger conditioned fear reactions he suggested that it is because they are better at conditioning (Eysenck, 1965, 1966). However, in a discussion on this aspect of Eysenck's theory, Gray (1970) hypothesised that it is in fact because they are more susceptible to fear. More specifically, Gray (1970) was suggestıng that introverts have a heightened sensitivity to punishment or to warnings of punishment Following from this, he suggested that in contrast, the behaviour of extraverts is determined by potentıal rewards and is influenced to a lesser extent by the proposition of punishment. Consistent with Gray's formulation, extraverts have been found to condition best under rewarding conditions in instrumental tasks (e.g., Gupta, 1996; Gupta \& Nagpal, 1978; Gupta \& Shukla, 1989; Nagpal \& Gupta, 1979), and in more general performance tasks such as computer games, and calculations with recoded numbers (e g., Boddy, Carver, \& Rowley, 1986) For Gray (1970), Eysenck's notion of neuroticism reflects the degree of sensitivity to punishment and reward. Thus, neurotics are likely to be more susceptible to both punishment and reward. In contrast, those who fall on the opposite end of this dimension, 1 e., stable, are likely to be less susceptible to either of these sensitivities.

Following from his early writing, Gray $(1976 ; 1981,1987 \mathrm{a}, 1987 \mathrm{~b})$ formalised his Ideas in what has become known as the Reinforcement Sensitıvity Theory (STR) Not surprisingly, he suggested that two motivational systems underlie behaviour and affect. He refers to these two systems as a Behavioural Inhibition System (BIS) 
and a Behavioural Approach System (BAS) These two systems reflect individual differences in the sensitivity of two neurological systems in their responses to relevant motivational cues. The BIS inhibits behaviour in the presence of cues signalling that aversive consequences will follow should a certain response be made. It is therefore assumed to reflect the personality dimension of anxiety. The BAS is thought to be a reward, or approach ${ }^{2}$, system that responds to positive incentives by activating behaviour and is assumed to reflect the personality dimension of sensitivity to reward. The BAS continuously monitors the environment for signals of reward. When a cue associated with reward is encountered, the BAS is presumably activated through activation of the dopamınergic system (Gray, 1987b), and motor output is then increased towards the reward, further activatıng the BAS and promotıng approach behaviour (Kane, Loxton, Staiger, \& Dawe, 2004)

Notably, a higher BAS-trait has been associated with traffic violations (Castella \& Perez, 2004), finding actıon and adventure films more interestıng (Aluja-Fabregat \& Torrubia, 1998), and having higher sexual excitatory and satısfaction levels (Aluja, 2004). Furthermore it has also been associated with alcohol use/abuse (e.g., Chnstensen, Henderson, Jacomb, Korten, Rodgers, 1999; Clonınger, Sigvardsson, \& Bohman,1988; Howard, Kivlahan \& Walker; 1997; Jorm, Loxton \& Dawe, 2001; O'Conner \& Colder, 2005), a tendency to smoke (Howard, et al, 1997), and more generally with substance abuse (Knyazeu, 2004; Knyazeu, Slobodskaya, Kharchenko, \& Wilson, 2004; Masse \& Tremblay, 1997;). The reason that a high BAS-related trait is associated with these behaviours is likely to reflect the fact that the BAS activates behaviours which are associated with the delivery of a reward, such as alcohol use. Thus, it might be hypothesised that a hypersensitivity to reward might be the common vulnerability for all these behaviours.

In addition to responding to primary rewards, such as alcohol, the BAS is also assumed to respond to previously neutral cues which have become associated with a reward. In a relatıvely recent study, Franken (2002) sought to determine the extent

\footnotetext{
${ }^{2}$ An approach system is one which motivates behaviour to obtain a reward associated with a partıcular stımulus
} 
to which greater BAS activity is associated with reactivity to cues associated with alcohol use. To do this, 58 participants were recruited from an inpatient alcoholism treatment program, and from the general population. BAS activation was determined by scores obtained on Carver and White's (1994) BAS scale which comprises of a drive, reward sensitıvity, and a fun seeking, subscale. Alcohol reactivity in turn was determined by exposing participants to 10 different photographs of alcoholic beverages presented on a computer screen four tımes, and then assessing appetitive motivation. Consistent with the author's expectations, those individuals who obtained higher scores on the BAS-Drive subscale reported stronger desires and intentions to drink Likewise, those who obtained higher scores on the BAS-reward sensitivity scale expenenced greater negative reinforcement craving, which reflects the expected relief from negatıve states through drinkıng alcohol. However, one limitation of this study was that it did not include a control condition (1.e., a no-cue condition). Therefore, it is unclear whether the relationships observed between the BAS subscales and desires and craving for alcohol were in fact a result of exposure to the alcohol cues.

However, in a previous study conducted by Kambouropoulos and Statger (2001) this problem was addressed by adopting two cues; a neutral cue (a glass of water) and an alcohol cue (a glass of beer). Participants ( 38 heavy and light drinkers) were exposed intially to the neutral cue and then to the alcohol cue for three minutes. Durnng this exposure phase they were asked to take a sip of each drink. The extent to which those individuals who showed greater reactivity to the alcohol cue also had a high BAS-related tratt was assessed by calculating the effect of the alcohol cue on appetitive motivation and then by determining the extent to which this was related to BAS activity as defined by Carver and White's (1994) BAS scales. As well as explonng this association between BAS sensitivity and cue reactivity, Kambouropoulos and Staiger (2001) also moved a step backwards by determining the extent to which the BAS is activated after exposure to an alcohol cue. To do this, the authors explored reactivity of the BAS after exposure to the neutral cue, and then after exposure to the alcohol cue. BAS was assessed in this instance using the CARROT task (Powell, Al-Adawi, Morgan, \& Greenwood, 1996) This measures the increase in speed on a card-sorting task in response to a small financial reward. Consistent with Gray's conceptualisation of the BAS, the authors found that 
performance on the CARROT task was significantly greater after exposure to the alcohol cue than after exposure to the neutral cue. This suggests that the BAS was actıvated in response to conditioned alcohol cues Since greater performance on the CARROT task after exposure to the alcohol cue was only observed in heavy drinkers, it also suggested that it is only these individuals who expenenced greater BAS activation in the presence of alcohol-related cues This is perhaps not surprising in light of the finding that it was also only these individuals who expenenced a greater urge to drink after exposure to the alcohol, relative to the neutral, cues Following from this, the authors also found that those individuals who typically have a high BAS-related trait were found to expenence a greater urge to drink in the presence of alcohol, relative to being in the presence of the neutral cue. In a subsequent study, Kambouropoulos and Statger (2004) replicated this latter findıng by also suggestıng that reactıvity to an alcohol cue (1.e, drunking alcohol) was significantly associated with a measure of BAS sensitivity.

Therefore, taken together, the studies conducted by Kambouropoulos and Staiger (2001, 2004) appear to provide evidence to support 1) the contention that the BAS is activated during exposure to an alcohol relative to a neutral cue, and 11) that heightened sensitivity of the BAS is associated with greater reactivity to alcohol cues. Thus, it follows from these findings that other forms of cue reactivity, such as food-cue reactivity, might also be experienced to a greater extent in individuals with a highly reactive BAS. Therefore, the final experiment (Experiment 6) presented in this thesis explored associations between food-cue reactivity and the BAS-related trait.

\subsubsection{Food-cue reactivity and impulsivity}

Previously in this review (see section 2.62 ), it has been hypothesised that food-cue reactivity might be associated with dietary disinhibition This dietary behaviour can be conceptualised as a susceptibility to eat in the presence of external triggers, such as particular social situations, emotional cues, and external food cues One possibility is that as well as being associated with this specific deficit in dietary control, food-cue reactivity might also be associated with a more general inability to 
inhibit responses to cues which offer a reward In other words, it might also be associated with an impulsive personality trait. Indeed, it is conceivable that in the presence of a palatable food cue, impulsive individuals might be unable to resist the temptation to eat offered by this cue. This issue is worthy of consideration because it might aid in the development of our understanding of the fundamental processes governing some aspects of overeating.

Importantly, impulsivity has been associated with various behaviours which are assumed to offer some form of temptation Specifically, it has been associated with a tendency to smoke (Doran, Sprng, McChargue, Pergadia, \& Richmond, 2004, Grano, Vırtane, Vahtera, Elovainıno, \& Kivımakı, 2004; Mitchell, 1999;), alcohol consumption (Grau \& Ortet, 1999; Grano et al., 2004, Waldeck \& Miller, 1997,), methamphetamine use (Simons, Olıver, Gaher, Ebel, \& Brummels, 2005), and binge eatıng (Claes, Vandereycken, \& Vertommen, 2002; Nasser, Gluck \& Geliebter, 2004). Given this, it might be concluded that impulsivity does reflect an inability to resist temptation Thus, given that exposure to a food cue offers a tempting invitation to eat, it is likely that impulsivity is also associated with greater intake after food-cue exposure. However, despite the feasibility of this possibility, to date, it has not been considered empincally.

One possibility which has been considered, however, is the extent to which foodcue exposure reduces the ability to inhibit impulses to act. Nederkoorn, E1js, and Jansen (2004) explored this possibility in individuals already presumed to be highly reactivity to food cues (1.e, restrained eaters defined according to the Herman \& Polivy's Restraint Scale). The authors used the stop/start signal task to measure inability to inhibit responses. This task involves two concurrent tasks, a 'go' task which is a choice reaction time task and a 'stop' signal which informs participants to inhibit their response to the 'go' task. The participants in this study were asked to complete this task in the absence of cue exposure and after two exposure phases. In these exposure phases, participants were presented with a variety of chocolates and crisps. Initially, they were asked to select their favourite chocolate and their favounte crisps. After this, they were requested to smell the food and to taste a small piece of it. However, despite their attempt, the authors reported little evidence to suggest that inhibitory control decreased after food-cue exposure in individuals 
who have previously been found to experience greater cue reactivity $(1 \mathrm{e}$, restrained eaters) This suggests that deficits in general inhibitory control do not increase as a result of food-cue exposure

However, despite the fact that food-cue exposure does not increase deficits in inhibitory control, it remains possible that individuals who are typically more impulsive are generally more reactive to the food cues than less impulsive individuals For this reason, the final experiment presented in this thesis (Experiment 6) also assesses associations between food-cue reactivity and measures of impulsivity.

\subsection{SECONDARY ISSUE 1: Cue specificity}

A potentially interesting question in relation to food-cue reactivity is the extent to which exposure to a food cue elicits an exclusive appetite for the cued food, rather than an indiscriminate appetite for food. This possibility was originally considered by Weingarten and his colleagues (Weingarten, 1985; Weingarten \& Elston, 1990) and has lead to suggestions that the motivation elicited by an environmental food cue is in fact specific to the food which has been cued. By this, these authors mean that priming participants with pizza, for example, would stımulate appetite for this food, but would not stımulate appetite for another food, such as cookıes.

This notion of specific cued responses is consistent in some respects with similar suggestions made in reference to other aspects of eatıng behaviour, such as meal termination. Indeed, it is now well-established that satiety experienced after eating is specific to the sensory characteristics of the eaten food. This phenomenon has been referred to as sensory-specific satiety (SSS) and broadly suggests that meal termination is the result of a decline in pleasantness of the sensory charactenstics of an eaten food (Guinard \& Brun, 1998; Rolls \& Rolls, 1997, Rolls, Rolls, \& Rowe, 1983; Rolls, Rowe, Rolls, Kingson, \& Megson, 1981). Put simply, SSS suggests that as we eat a food the pleasantness of the taste, smell, and texture, of that food, but not others, declines Consequently, we might terminate intake of one food, but 
are more than happy to initiate intake of a new food with different sensory properties Therefore, taken together, this notion of SSS and Weingarten's notion of specific learned appetites suggests that both meal initiation and meal termination might incorporate these food-specific components.

Whilst there is a large body of evidence for food-specific meal termination, evidence for cue-specific meal initiation is relatıvely scarce. In fact, evidence of cue-specific reactıvity has come largely from Weingarten's unpublished work (Weingarten 1984, Unpublished data reported in Weingarten, 1984). From this unpublished data Weingarten reported that when conditıoned stımulı (CS) for a food 1s presented, anımals wait for the expected food to be delivered, even if food is continuously available in another place in the cage. This suggests that the stimulus does not elicit a general appetite for food, but rather a specific appetite for the food that is expected after presentation of the CS. In a similar way, other studies which Weıngarten uses to justıfy his cue specificity suggest that anımals who have learned to bar press for food continue to perform the instrumental response even when food 1s made freely avallable in the test situation (Osbourne, 1977; Neurnge, 1969).

In humans, the extent to which food-cue exposure stımulates a specific motivation to eat the cued food has been explored by Cornell, Rodin, and Weingarten (1989). In this study, the authors exposed satiated participants to either ice-cream, pizza, or to the same environment in the absence of food-cue exposure (no-cue condition). Following this, all participants were given $a d-l i b$ access to both ice cream and pizza. The authors were then able to compare $a d-l i b$ intake of the cued food relative to $a d-l i b$. intake of the non-cued food. Doing this, they provided evidence to suggest that the effects of cue exposure are specific to the cued food.

Given this evidence for cue-specific reactivity, one possibility is that if there are individual differences in the extent to which a food-cue can motivate eating behaviour, these differences in motivation to eat will be specific to the cued food. Recently, Fedoroff, et al (2003) explored the extent to which cue-elicited motivation to eat in restrained eaters (defined according to their scores on the Restraint Scale) was specific to the cued food. In this study, 132 food-deprived (two 
hours food-deprived) restrained, and unrestrained, eaters were exposed to the smell of either pizza, cookies, or to no smell, for 10 minutes. During this time, they were asked to write their thoughts (corresponding to the olfactory cue) about pizza, or cookies, or to record their thoughts in general. After cue exposure, all participants rated their subjective appetıte for both pizza, and cookıes, and were offered $a d-l i b$ access to these foods. The authors then compared subjective appetite for cookies and pizza, and intake of these two foods, separately, across the three conditions (pizza-cue, cookie-cue, no-cue), and determined the extent to which it interacted with restraint status. In doing this, the authors found that restrained eaters consumed larger amounts of pizza and cookies after exposure to these foods than unrestrained eaters. Furthermore, motivation to eat both these foods was greater in restrained relative to unrestrained eaters only after exposure to the cue associated with that specific food. When that food had not been cued, restrained eaters in fact consumed smaller amounts than unrestrained eaters. Restrained eaters also craved cookıes to a greater extent that restrained eaters only after being primed with this food. However, craving for pizza in this study surpnsingly did not differ across restrained and unrestrained eaters after cue exposure

As stated previously, the measure of restraint used in food-cue reactivity studies, such as that described above by Fedoroff et al (2003), is also associated with weight fluctuation and disinhibited eating (see section 26.2 ). For this reason, in the experiments presented in this thesis, separate measures of restraint and disinhibition were used to differentiate between the roles of these two dietary behaviours in cue reactivity (see section 262 ). Since the preceding discussion suggests that the Restraint Scale (Herman \& Polivy, 1980) predicts a cue-specific response, it follows that an assessment of the associations between food-cue reactivity and separate measures of dietary restraint and disinhibition should also explore cue specificity. Thus, the aim of Experiments 1 and 2 was to assess food-cue reactivity across separate measures of restraint and disinhibition, and to determine the extent to which any greater reactivity observed in restrained, or disinhibited, eaters is specific to the cued food. Where possible in the remainıng expenments, cue specificity was also explored in relation to the other predictor variables considered (e.g, everyday portion-size selection, BMI, sensitıvity to reward, and impulsıvity) This was because cue specificity appears to be fundamental to our understanding of food-cue 
reactivity

\subsection{SECONDARY ISSUE 2: Role of motivational state}

After a series of experiments which explored individual differences in food-cue reactivity in satiated participants, in the final experiment presented in this thesis it was also useful to assess these individual differences in the absence of satiety. Notably, the notion that the levels of hunger and satiety might determine the extent to which a conditioned stımulus (e g., a food cue) is able to elicit a conditioned response (e $\mathrm{g}$, eatıng behaviour) has been considered in a number of general scientific theories of learned motivated behaviours

The drive reduction theories reviewed in Chapter 1 (section 1.4.2) suggest that conditioned stimuli motivate behaviour because they are associated with a reduction in a particular drive Thus, according to this perspective, food cues motivate eatıng behaviour because they are associated with a reduction in hunger drive. By implication, therefore, according to this theory, food cues will only stımulate eatıng behaviour in the presence of a motivational drive to eat.

Contrary to the drive reduction theory, motivational state has not been integral in other theornes of externally-cued behaviour. However, despite this, several authors have speculated as to how it might be involved. For example, Bindra (1974) who suggests that the CS gains incentive motıvation and thereby motivates behaviour (incentive motivation theory; section 1.4.3) has suggested that these stımuli would only elicit this motivational arousal when the 'organismic state was appropriate' 1 e., when internal physiological factors were conducive. Toates (1981) elaborated on Bindra's (1974) view by proposing that 'internal state' can encourage or restrain responding to stımulı which have gained incentive motivation, suggesting that a response to an incentive stımuli is determined by the interaction between internal motivational state and the incentive value assigned to the stimulus In a similar way, Davidson (1993) in his theorising relating to goal-directed behaviour and motivational state suggested that physılogical deprivation (such as food deprivation) acts as a modulator of the relationship between external environmental 
stımulı (e g., sight and smell of food) and unconditioned stımulı (e g, reward value of food). In this way, food deprivation can strengthen this relationship increasing the probability of the environmental cue eliciting a conditioned response In contrast, in the absence of food deprivation, environmental cues alone cannot elicit this conditioned response. According to Davidson (1993), this is because the modulator determines the extent to which the US (Unconditioned Strmulus) memory requires actıvation. Thus, in states of extreme food deprivation, the threshold required for US memory activation will be low, while in the absence of these states this threshold will be high. Simılar to Davidson's (1993) modulators are 'establishing operations (EO)'discussed by Tapper (2005). These have also been termed 'motıvatıng operations (MO)' and were onginally devised by Michael (1982, 1993, 2000). They refer essentially to stimulus condition, or to environmental stimuli which have become associated with this condition. Interestingly, EO's increase the reinforcing, or punishing, ability of events and encourage behaviours associated with this event. For example, food deprivation might act as an EO, thereby encouraging the reinforcing value of food, and stımulating food intake. Most relevant to the current discussion is the fact that these operations might also affect the extent to which environmental stımuli are able to motivate behaviour. For example, like Davidson's (1993) modulator, these operations might encourage or discourage responses to environmental stımuli which predict a reward associated with the particular EO.

Coons and White (1977) presented a mathematical model of the interaction between motivational state and the effect of external stimulı on behaviour. Similar to the theories described above, this model suggests that energy state determines the current value of conditioned incentıve stımuli However, this model also proposed that internal motivational states can determine the incentive value that is assigned to a particular stımulus during conditıoning. For example, in some motivational states (e.g, when food deprived) an incentıve (e g., food) will be rewarding and thereby stımuli which preceded the occurrence of this reward (e.g., food cues) will gain incentive motivation By contrast, in some motıvational states (e.g., when satiated) an incentive might not be rewarding and therefore stımuli which preceded its occurrence will not be granted incentive motivation. 
This notion that internal motivational dnve can determine the incentive value assigned to neutral stımulı durıng conditioning is supported by research and theorising by Dickinson and his colleagues (Dickınson \& Balleine, 1994, 2002). Consistent with Coons and White (1977), these authors suggest that previous experience of an outcome in a particular motivational state determines its incentive value, a process they call 'incentive learning.' Thus, according to these authors the motivation aroused by an incentıve stımulus is contıngent upon the extent to which 1t was perceived as rewarding when it was previously expenenced in the current motivational state. For example, the incentive value of an ice-cream offered to a child in exchange for doing a simple task, such as cleaning their room, or taking the dog for a walk, would be determined by the child's previous experience with icecream. If the ice-cream was previously found to be rewarding when consumed in the current motivational state, it will have a high incentive value and will therefore encourage the child to engage in the task In contrast, if it was not previously found to be rewarding in the current motivation state the child is unlikely to engage in the current task, as the reward provides little incentive motıvation

Evidence for incentıve learning came largely from Balleıne's (1992) study on rats. In this study, Balleine (1992) examined the effects of shifts in motivational state from training to test phases using unfamiliar foods, such as the standard high protein Noyes rewards pellets or a poly-saccharıne (maltrodextrin) solution, as the outcome. Initially, Balleine (1992) found that when food-deprived rats were trained to press the lever for these outcomes, and then shifted to a non-deprived state in the test phase, the rats would continue to press the lever for the food and starch solution This is because the outcome had been assigned a high incentive value in the training phase when it was encountered while food-deprived. Indeed, Balleıne (1992) found that the rats only reduced lever presses while non-deprived in a test phase if they had previously encountered the outcomes while non-food deprived. This is because during training they had been able to assign the outcome a low incentive value because they were non-food deprived.

Further support for the concept of incentive learning in Balleine's (1992) study was found when non-deprived rats were taught that one action (lever-pressing or chain pulling) produced one outcome (Noyes pellets or the starch solution), and that the 
alternative action produced the alternative outcome Prior to this training, all animals had received access to one of the outcomes when non-food deprived and the other when food-deprived. When the animals were given the choice between the two alternatives when hungry they showed reliable preference for the action associated during training with the outcome that had been pre-exposed while hungry

Balleine's (1992) study is not alone in yielding support for an incentive learning model of instrumental responding. For example, several other studies have shown that a reduction in the level of food deprivation has no detectable effect on test performance unless the animals recerve prior experience with the food pellets in the non-deprived state (Balleıne \& Dickınson, 1994; Corbıt \& Balleıne, 2003; Dickınson, Balleıne, Watt, Gonzalez, \& Boakes, 1995), Lıkewise, a number of studies have found that non-deprived animals contınue to bar press for food, or drink, when they have previously experienced this outcome when hungry (Capald, Davıdson, \& Myers, 1981; Lopez, Balleine, \& Dickinson, 1992, Revusky, 1967, 1968). Finally, some studies have found that devaluing a particular substance by painng it with an aversive stımulı, or allowing anımals to experience it after being satiated on this food, can reduce the action onginally assocrated with this outcome, but does not reduce actions associated with different food outcomes (Balleine \& Dickinson, 1998; Rescorla, 1990).

Taken together, the theories reviewed here provide support for the contention that motivational state might play an important role in externally-cued motivated behaviour. Thus, given that throughout this thesis associations between food-cue reactivity and the various predictor variables (e.g, dietary restraint, dietary disinhibition, everyday portion-sıze selection, and being overweight) were assessed while individuals were satıated, it was also important to consider these associations in the absence of satiety. Therefore, the final expenment explored these associations when individuals were relatively hunger (1 e., after four hours food deprivation) and after they had eaten to satiety. 


\subsection{Summary and thesis overview}

This thesis considers individual differences in food-cue reactıvity. Specifically, Experiments 1 and 2 explore relationships between food-cue reactivity and separate measures of dietary restraint and disinhibition (Issue 1). The following experments assess the extent to which food-cue reactivity is elevated in individuals who typically select larger everyday portion sizes (Experiments 3, 4, and 5), and those who are overwerght (Experiment 5) (Issue 2) The primary arm of the final experment is to explore evidence for an association between food-cue reactivity and particular personality variables (impulsivity and sensitivity to reward) (Issue 3) As a secondary 1ssue, this final experiment also considers individual differences in food-cue reactivity when participants are relatively hunger ( $1 \mathrm{e}$., after four hours food deprivation), and after they have eaten to satıety (Secondary issue 2).

In the initial experiments (Experiments 1 and 2) evidence for cue specificity in restrained and disınhibited eaters is also considered (Secondary issue 1) Following this, in the subsequent experiments, specificity is explored in relation to each of the characteristics previously considered (e g., everyday portion-size selection, being overwetght, impulsıvity, and sensitıvity to reward). 


\section{CHAPTER 3}

\section{FOOD-SPECIFIC REACTIVITY AND EVERYDAY DIETARY BEHAVIOUR}

\subsection{Chapter Overview}

This chapter presents the methods and findings from Expermment 1 (Part I) and Experiment 2 (Part II) The aim of both these expenments was to assess associations between food-cue reactivity and separate measures of dietary restraint and disinhibition. As part of this, each of the experiments explored the extent to which these separate measures of dietary behaviour were associated with an exclusive motivation to eat the cued food (cue specificity). In Experiment 1, cue specificity was assessed by comparing subjective appette (desire-to-eat, and craving) for the cued food (pizza) with subjective appetite for two non-cued foods (chips and cookies). In Experiment 2, a more sophisticated method was employed This involved comparing $a d-l l b$ intake of a cued food (chips or pizza), with $a d-l l b$ intake of a non-cued food (chips or pizza).

\section{PART I: EXPERIMENT 1}

\subsection{Introduction}

Previous studies have reported that the effects of food-cue exposure are especially pronounced in restrained eaters (e g., Fedoroff, et al, 1997; Fedoroff et al, 2003; Rogers \& H1ll, 1989). However, these studies have tended to use the Restraint Scale devised by Herman \& Poilvy (1980), and unlike other measures of restraint, this scale is also associated with weight fluctuation and disinhibited eatıng. Given this, 
one possibility is that food-cue reactivity might in fact be more closely associated with dietary disinhibition. To address this issue, Experiment 1 explored associations between food-cue reactivity and separate measures of dietary restraint (DEBQ-R) and disinhibition (TFEQ-D) ${ }^{3}$. It was hypothesised that those individuals with high disinhibition scores would expenence greater cue reactivity than those individuals with lower disinhibition scores. By contrast, it was expected that restrained eaters would not experience any greater cue reactivity than unrestrained eaters

As part of this experiment, it was desirable to determine the extent to which any greater cue reactivity observed across individuals with specific dietary behaviours were spectfic to the cued food Previously, Fedoroff et al (2003) have explored the specificity of food-cue reactivity in restrained eaters defined according to their scores on Herman and Polıvy's Restraint Scale. The authors found that restraned eaters experience a greater appetite for the cued food than unrestrained eaters. However, their appetite for a food which had not been cued did not differ significantly to that experienced by unrestramed eaters. Given this, in this experiment, it was expected that if individuals with higher disinhibition scores expenence a greater motivation to eat after food-cue exposure than individuals with lower disinhibition scores, this differential motivation to eat will be exclusive to the cued food. Put simply, the change in appetite brought about by exposure to a food cue might be greater for the cued food in individuals with high, relative to low, disinhibition scores, but is unlikely to differ for the non-cued foods. Contrary to this, it was expected that restrained eaters appetite for the cued, and non-cued, foods would not differ after cue exposure to that expenenced by restrained eaters.

In Fedoroff et al 's study (2003), specificity was explored by exposing participants to either cookies, przza, or to the same environment in the absence of either of these foods, and then by assessing their motivation to eat both pizza and cookies. Fedoroff et al (2003) suggested that if food-cue reactivity reflects a food-specific

\footnotetext{
${ }^{3}$ The DEBQ-R was used in this experiment rather than the TFEQ-R because it was consistent with the measures used by the research group withm the Ingestive Behaviour laboratory at Loughborough University Therefore, using this scale ensured that the results were comparable across the research group Notably, initial analyses suggested that the results did not differ when the TFEQ-R was used as a measure of dietary restraint in this experiment
} 
response, then motivation-to-eat a particular food will be greater only after cueing with that specific food. It will thereby be unaffected by pre-exposure to a different food. To explore this possibility, the authors compared subjective appetite and intake of the two test foods (pizza and cookıes) after being cued with this food, after being cued with the other test food, and in the absence of prior cue exposure The authors expected that motivation to eat the test food would be greater than in the absence of cue exposure after cueng with that particular food, but not after cueing with another food Thus, for Fedoroff et al. (2003) using the no-cue condition as a reference group, appetite for cookies would only be elevated after exposure to this food After exposure to pizza, appetite for cookies would be similar to that observed in the absence of cue exposure, $1 \mathrm{e}$, in the no-cue condition. In a similar way, appetite for pizza would only be elevated with respect to the no-cue condition after cueing with this food Using this methodology, the authors were able to consider the effect of cue exposure on appetite for the cued food and for other non-cued foods across scores on the Restraint Scale.

In the present experiment a methodology akın to that used by Fedoroff et al (2003) was adopted to explore specificity across restraint and disinhibition scores However, there were several differences. Firstly, in this expenment, specificity was only assessed for subjective appette ratıngs. This was because only a measure of ad-lib intake of the cued food (pızza) was obtained in this experıment. The reason for this was that this experiment constituted a first attempt to explore food-cue reactivity across separate measures of restraint and disinhibition. Therefore, a simpler methodology was adopted.

Secondly, to further reduce the complexity of Fedoroff et al 's (2003) study for this prelıminary experiment, only one cued food was used. Thus, participants were either exposed to a pizza cue, or were exposed to the same environment in the absence of pizza. Following this, their subjective appetite (desire to eat and craving) for this food and for the non-cued foods was compared separately in the pizza-cue, relative to the no-cue, condition It was expected that if the effects of food-cue exposure were specific to the cued food for some individuals, then only appetite for 
pizza should be greater in the pizza-cue, relative to the no-cue, condition for these individuals Appetite for the non-cued foods should not differ after cueing with pizza relative to in the absence of cue exposure. Although this methodology was desirable because it provided a relatively simple method to assess food-cue reactivity in this initial experiment, it must be noted that it did limit the extent to which true cue specificity could be demonstrated. In particular, it was impossible to determine the extent to which food-cue exposure had an exclusive effect on intake of that food for a particular group of individuals

The final differences in the methodology used here were, firstly, that participants were tested while they were non-food deprived, $1 \mathrm{e}$, immediately after consuming a fixed lunch. As suggested in Chapter 2 (Part II) the decision to test participants in this state followed Weingarten's (1985) suggestions that exposure to a food-cue can motivate eatıng behaviour even in the absence of nutritional need Secondly, in response to one of the concerns associated with the methodology used by Fedoroff et al. (2003), in Experiment 1 the non-cued foods comprised one sweet (cookies), and one savoury (chips), food In Fedoroff et al's (2003) study, only one non-cued food was used and this comprised very different sensory characteristics to the cued food (p1zza and cookies). One possibility, therefore, is that the cue-specific effects observed in restrained eaters in their experiment were exaggerated by the fact that the non-cued food would not normally be consumed together with the cued food within the same course of a meal. Therefore, in this experiment the non-cued foods comprised one food (chips) which is more likely to be served within the same course of a meal as the cued food (pizza), and one food (cookies) which is less likely to be served in the same course of a meal as this food. 


\subsection{Method}

\subsubsection{Overview}

Experıment 1 used a typical cue reactivity paradigm Initially, partıcipants were asked to consume a sandwich lunch to ensure they were non-food deprived Partıcipants were then exposed to the sight, and smell, of pizza (pizza-cue condition), or to the same environment in the absence of pizza (no-cue condition). Both before and after this exposure phase, participants rated their appetite for the cued food (pizza) and the two non-cued foods (chips and cookies), and rated their hunger and fullness. After cue exposure they were also offered $a d-l b b$ access to pizza Following Fedoroff et al (2003), this phase was disguised as a taste test, and participants were asked to taste and rate the pizza presented in the exposure phase. They were invited to eat as much of the pizza as they liked in order to complete these ratıngs, and were told to eat as much of the pizza as they liked after the ratıngs were complete

\subsubsection{Design}

A between-subjects design was applied. Participants were randomly assigned to etther a pizza cue, or a no-cue, condition. Measures of cue reactivity (appetite ratings and $a d-l l b$ intake) were compared between the two conditions and across DEBQ-restraint scores and TFEQ-disinhtbition scores.

\subsubsection{Participants}

Participants were recruted from the population of female undergraduate students at Loughborough University and were aged between 18 and 30 (UK). Twenty-eight participants were recruited into the no-cue condition, and 27 were recruited into the 
pızza-cue condition. All participants were recruited via email and were financially reimbursed (5 sterling pounds) BMI was not measured

\subsubsection{Measures}

\section{Cue reactivity}

Cue reactivity was assessed using ratings of subjective appetite and a measure of $a d-l l b$ intake. Appetite ratıngs included measures of general appetite (hunger and fullness) and craving for, and desire-to-eat, the cued (pizza), and non-cued, foods (chips and cookies) (see Appendix A for examples of these). These were measured using 100-mm visual analogue rating scales. These were headed with "How hungry/full are you right now", "How strong is your desire-to-eat pızza/chips/cookies right now?", and "How much do you crave pızza/chıps/cookıes right now?" Respectively, these were anchored with the phrases "not at all hungry/full" and "very hungry/full", "not at all" and "extremely strong" and "not at all" and "very much."

The $a d-l l b$ intake measure was obtained via a disguised taste test. Participants were all presented with a plate of pizza and were asked to rate the pleasantness of its taste and smell, their desire-to-eat pizza, and also how salty and spicy they regarded the food to be Participants were told that they had 10 minutes to complete these ratıngs and that they could eat as much of the pizza as they wished in order to do this. They were also told that if they completed the ratings before the allocated time, then they could help themselves to more pizza as there was plenty more in the laboratory. The pizza was presented in eight equal-sized slices (3625 kcal per slice) heaped on a plate. Intake was assessed by recording the weight of the pizza before and after consumption.

\section{Dietary restraint and disinhibited eating}

Dietary restraint and disinhibition were assessed using the restraint section of the Dutch Eatıng Behaviour Questionnarre (DEBQ, van Strien et al, 1986) (see Appendix B for this questionnaire) and the disinhibition section of the Three Factor Eatıng Questionnaire (TFEQ, Stunkard \& Messick, 1985) (see Appendix C for this 
questionnaire). The DEBQ-restraint scale was chosen because this scale has been found to measure intention to restrict, and actual restriction of food intake (Lasselle, et al, 1989). Furthermore, this scale has been shown to have good internal consistency and factorial valıdıty (van Strien et al , 1986; Wardle, 1987). The scale contains 10 items (see Appendix B). Each item has five possible options, 'never,' 'seldom,' 'sometımes,' 'often,' and 'very often.' These responses obtain scores ranging from 1 to 5 . Some items also have a 'not relevant option,' which is not scored and therefore receives zero. The total score for the scale is calculated by summing the responses and dividing by the number of items that received a score of one or above A high score on this scale indicates a high level of dietary restraint

The TFEQ-disinhibition scale was used as a separate measure of dietary disinhibition. This scale has been shown to have good reliability and has been valıdated again measures of binge eating (see Stunkard \& Messick, 1985) The scale contains 16 items (See Appendix C). Items 1-13 require a true/false response. True responses receive a score of one and false items score zero apart from items 8,10 , and 12. These items score zero for true, and one for false. The remaining three items on the questionnaire (14-16) each have four possible options; 'never,' 'rarely,' 'often,' and 'always.' The first two of these recerve a score of zero and the remaining two receive scores of one. The scores are then summed across the 16 items. A higher score reflects a higher level of disinhtbition and a lower score reflects a lower level of disınhibition.

\subsubsection{Procedure}

Partıcipants were tested between $11 \mathrm{am}$ and $3 \mathrm{pm}$. All were instructed to refran from eatıng for at least 3 hours pror to the onset of the experiment. Before arriving at the laboratory, the experment was described as a 'taste perception study.' The participants were told that they would be asked to offer an opinion on different foods and that they would be required to consume some food. The identity of this food was not revealed. 
Upon arrival, participants were asked to sign a consent form and to rate their 'hunger,' and 'fullness.' Following this, they were instructed to consume a sandwich lunch, which was prepared using 2 slices of medium cut white bread and $375 \mathrm{~g}$ of mild cheddar cheese $(43388 \mathrm{kcal}$ ) The lunch was fixed to ensure that all individuals consumed the same amount However, using this approach, it was important to ensure that the fixed lunch did not exceed the amount individuals would be prepared to consume. For this reason, it was set at two slices of bread.

After lunch, a set of pre-exposure appetite ratıngs were taken (see Section 334 for details of these measures). Following this, the participants entered a three-minute exposure period. Those in the pizza-cue condition were exposed to the sight and smell of cooked pizza (supplied by Farmfoods Freezer Centres, Blaırlinn, Cumbernauld, $290 \mathrm{kcal} / 100 \mathrm{~g}$ ). The pizza was placed directly in front of the participants on the table, and the participants were instructed to sit and wait until the experimenter returned Participants in the no-cue condition were left in the same environment with no pizza present, and were also told to sit and wait until the experimenter returned. Following this exposure phase (no-cue/pizza-cue), the partıcıpants provided a second set of appetite ratıngs, and entered the $a d-l l b$ intake phase

In the final stage of the experiment, the participants completed the disinhibition scale of the Three Factor Eating Questıonnaire (TFEQ; Stunkard \& Messıck, 1985) and the restraint scale of the Dutch eating Behaviour Questronnarre (DEBQ-R; van Strien et al., 1986).

\subsubsection{Data analysis}

Measures of food-cue reactivity obtained in this experiment included eight measures of subjective appetite and a measure of $a d-l l b$. pizza intake. The measures of subjective appetite included ratings of, general appetite (hunger and fullness), appetite (desire to eat and craving) for the cued food (pizza), and appetite (desire to eat and craving) for two non-cued foods (chips and cookies). These ratings were taken both before and after the exposure phase. For this reason, change scores were derived from the difference between the measure of appetite taken before and after 
this phase Inttally in the analysis, the descriptive statistics (means and SD's) were produced for all measures of cue reactivity (change in subjective appetite and $a d-$ lib intake) in both the pizza-cue, and the no-cue, condition To compare the outcome measures ( $a d-l l b$ pizza intake, change in hunger, change in fullness, change in desire-to-eat pizza, chips, and cookies, and change in craving for these three foods) in both these conditions between-subject t-tests were used.

This experiment hypothesised that food-cue reactivity might be more closely associated with dietary disinhibition rather than restraint status. To address this hypothesis, the analysis sought to determine the extent to which the outcome measures (pızza intake and changes in appette ratıngs) were modulated by restrant, or disinhtbition, scores To do this, interactions between condition (no cue/pizza cue) and these dietary variables were explored for each of the outcome measures. Typically, when explorng such interactions, researchers split scores on the restraint and disınhbition scales at therr median value in the sample and consequently create categoncal vanables which can subsequently be analysed using Analysis of Variance (ANOVA). In Experment 1 (as in the following experiments), this approach was avoided for several reasons. Firstly, it reduces power and may produce spurious effects (see MacCallum, Zhang, Preacher, \& Rucker, 2002). Secondly, for scales such as the DEBQ-restraint scale and TFEQ-disınhıbition scale, it is unclear why some individuals who only have marginally different scores should be allocated to opposite groups on the basis that their scores happen to be modestly higher or lower than the median value in the sample. For these reasons, in the analyses conducted for the experiments presented in this thesis, regression analyses were used because, unlike ANOVA, this form of analysis allows associations between contınuous variables to be assessed. Thus, disinhibition and restraint scores were incorporated into the analysis as continuous predictors. Since condition was a categoncal variable, a dummy varable was created for this category This dummy variable distıngurshed between the no-cue and pizza-cue condition. Separate analyses were initially conducted to explore 1) the interactions between condition and dietary restraint, and 11) the interactions between condition and dietary disinhibition. However, since it was desirable to determine the extent to which any interactions between disinhibition scores and condition occurred irrespective of 
dietary restraint, in a further analysis, dietary restraint scores were entered as a covariate to allow this variable to be controlled for statistically

In all the regression analyses pre-exposure appetite ratıngs were controlled for statıstıcally. This was because, the point at which an individual starts on a scale will ultimately affect the change in this measure that these individuals can report. All analyses for the experiments presented in this thesis were conducted using SPSS Version 11 and the significance level tested was set at $\mathrm{p}<0.05$. The data was assessed usually parametric analyses because it was contınuous data, approximated to a normal distribution, and the vanance within the data was homogeneous. Twotalled tests were used for the analyses for each experiment. This was to ensure that each analysis was powered to detect an effect in either direction (1.e., a positive and negative effect). Thus, even tests of directional hypotheses were powered to detect an association even if the hypothesis was incorrect and the association was in the opposite direction to that predicted.

\subsection{Results}

\subsubsection{Outliers}

For two participants their recorded change in desire-to-eat pizza $(75 \mathrm{~mm}$ and $78 \mathrm{~mm})$ was more than three standard deviations away from the mean desire-to-eat pizza, and almost doubled the next lowest value. These data points were also more than three standard deviations from the predicted value in the regression model for change in desire-to eat pizza and thereby violated one of the assumptions of regression analysis. These individuals also ate less than average amounts of pizza in the $a d-l l b$ intake phase suggesting that it is unlikely that they experienced such great changes in desire-to eat after cue exposure. For these reasons, they were 
removed from the data set ${ }^{4}$ The final sample comprised 53 partıcipants; 28 in the no-cue condition, and 25 in the pizza-cue condition.

\subsubsection{Participant characteristics and baseline measures}

Initially, it was desirable to ensure that participants did not differ in their subjective appetite in the two conditions prior to cue exposure, and that measures of dietary behaviour were similar in both conditions. For this reason, a series of betweensubject t-tests were used to compare levels of subjective appetite (hunger, fullness, desire-to eat, and craving) before cue exposure across the two conditions, and to compare participants' scores on the dietary measures These analyses suggested that the two groups did not differ significantly in either their DEBQ-restraint scores or their TFEQ-disinhibition scores (Table 3.1). Likewise, they revealed no significant differences in hunger, or fullness, or in subjectıve appetite for pızza, or the non-cued foods (Table 3.1)

\footnotetext{
${ }^{4}$ Analysing the data with these outhers included did not change the extent to which specific results were statisttcally sıgnificant
} 
Table 31 Between-subjective t-tests, means, and standard deviations, for partictpant characteristics (DEBQ-restraint scores TFEQ-disinhibition scores) and baseline preexposure ratings in both conditions

\begin{tabular}{|c|c|c|c|c|c|c|}
\hline & \multicolumn{2}{|c|}{$\begin{array}{l}\text { No-cue } \\
(n=27)\end{array}$} & \multicolumn{2}{|c|}{$\begin{array}{l}\text { Przza-cue } \\
(\mathrm{n}=25)\end{array}$} & \multicolumn{2}{|c|}{$\begin{array}{c}\text { T-test } \\
\text { significance }\end{array}$} \\
\hline & Mean & SD & Mean & SD & $t$ & $p$ value \\
\hline \multicolumn{7}{|l|}{ Pre-exposture ratings } \\
\hline Hunger & 3879 & 2330 & 3778 & 2394 & 012 & 0904 \\
\hline Fullness & 4661 & 2401 & 4512 & 2006 & 0243 & 0809 \\
\hline Desıre-to-eat pızza & 3875 & 3075 & 4352 & 3050 & -057 & 0574 \\
\hline Desire-to-eat chips & 3193 & 2728 & 3720 & 27.99 & -0.70 & 0491 \\
\hline Desire-to-eat cookıes & 4211 & 2745 & 4588 & 2992 & -050 & 0634 \\
\hline Craving for pizza & 2729 & 3061 & 3664 & 31.58 & -109 & 0279 \\
\hline Craving for chips & 2454 & 2586 & 2860 & 2773 & -055 & 0583 \\
\hline Craving for cookıes & 3343 & 3063 & 3448 & 3071 & -013 & 0.901 \\
\hline \multicolumn{7}{|c|}{ Measures of dietary behaviour } \\
\hline DBEQ-restraint & 282 & 093 & 264 & 102 & 103 & 0308 \\
\hline TFEQ-disinhibition & 754 & 381 & 641 & 308 & 0.68 & 0497 \\
\hline
\end{tabular}




\subsubsection{Descriptive statistics for measures of cue reactivity}

As suggested here it was initally desirable to explore the descriptive statistics for the measures of cue reactivity in the two conditions Therefore, the means and standard deviations for changes in subjectıve appetite and for $a d-l i b$ pizza intake are summarised in Table 3.2. The results of between-subject $t$-tests used to compare these measures in the two conditions are also presented alongside these descriptive statistics.

It is evident that changes in desire-to-eat pizza and changes in craving for this food were significantly greater in the pizza-cue, relative to the no-cue, condition (Table 3 2) This suggests that exposure to the pizza cue had a significantly greater effect on subjective appetite for this food (Table 3.2) By contrast, there was little evidence to indicate that change in subjective appetite (desire to eat and craving) for chips, or for cookıes, was greater after cueing with pızza, relatıve to in absence of cue exposure (Table 32 ) Somewhat surprisingly, there was also little evidence to suggest that pızza-cue exposure stımulated greater intake of this food (Table 3.2). 
Table 32 Between-subject t-tests, means, and standard deviations, for changes in subjective appetite and for pizza intake in the no-cue, and pizza-cue, condition after cue exposure

\begin{tabular}{|c|c|c|c|c|c|c|}
\hline & \multicolumn{2}{|c|}{$\begin{array}{l}\text { No-cue } \\
(\mathrm{n}=27)\end{array}$} & \multicolumn{2}{|c|}{$\begin{array}{c}\text { Pizza-cue } \\
(n=25)\end{array}$} & \multicolumn{2}{|c|}{ T-test significance } \\
\hline & Mean & SD & Mean & $\mathrm{SD}$ & $t$ & pvalue \\
\hline \multicolumn{7}{|l|}{ Changes } \\
\hline Hunger & 696 & 16306 & 1172 & 1381 & 114 & 0260 \\
\hline Fullness & -621 & 1681 & -768 & 1749 & -031 & 0757 \\
\hline Desire-to-eat pizza & 500 & 1328 & 1352 & 1525 & 218 & $0034^{*}$ \\
\hline Desire-to-eat chips & 393 & 1349 & -068 & 1232 & -129 & 0202 \\
\hline Desire-to-eat cookies & -118 & 1232 & -200 & 1771 & -020 & 0844 \\
\hline Craving for pizza & -1117 & 1598 & 809 & 2160 & 371 & $0001^{*}$ \\
\hline Cravıng for chıps & 721 & 1581 & 556 & 1378 & -0404 & 0688 \\
\hline Cravıng for cookıes & 586 & 1713 & 036 & 12.59 & -132 & 0193 \\
\hline Pizza intake & 17035 & 8048 & 14603 & 7506 & -1133 & 0262 \\
\hline
\end{tabular}

* denotes $p<005$

\subsubsection{Dietary restraint, disinhibition, and subjective appetite}

To test the hypothesis of this experiment, the extent to whrch changes in appetite ratings after exposure to the pizza were modulated by TFEQ-disinhibition scores rather than successful dietary restraint, interactions between condition (pizza cue/no cue) and dietary behaviour (disinhibition or restraint scores) were explored using linear regression models For change in hunger, change in fullness, and for change in subjectıve appetıte (desıre-to-eat and craving) for the test foods (pızza, chips, or cookies), the interactions between dietary-restraint scores and condition were not statistıcally s1gnificant (Table 33.) This suggests that restrained eaters did not experience significantly greater changes in subjective appetite after cue exposure than unrestrained eaters. By contrast, disinhibition scores interacted significantly with condition for change in craving for pizza (Table 3.3). As Panel A in Figure 3.1 suggests, individuals with higher disinhibition scores, compared to those with lower scores, experienced a greater change in craving for pizza in the pizza-cue, relative to the no-cue, condition. After controlling statistically for restraint status, this 
interaction remained statıstically significant $(B=452, S E=148, p=0.004)$ This suggests that irrespective of restraint scores, individuals with high disinhibition scores experienced a greater change in craving for pizza in the cued, relative to the non-cued, condition. Despite the fact that Figure 32 Panel A provides some evidence to suggest that individuals with higher disinhibition scores also experienced a greater change in desire-to-eat pizza than individuals with lower disinhibition scores after pizza-cue exposure, this interaction effect was not statistıcally sıgnificant (Table 3.3)

With respect to changes in subjective appetite (desire to eat and craving) for the non-cued foods (chips and cookies), interactions between disinhibition scores and condition failed to reach statistical significance (Table 3.3) This suggests that individuals with high disinhibition scores did not expenence any greater change in subjective appetite for these foods than individuals with lower disinhibition scores after pizza-cue exposure (see Figure 31 and 3.2 Panels, B and C) All other interactions between disinhibition scores and condition failed to reach statistical significance (Table 3 3). 
Table 33 Adjusted $^{1}$ parameter estimates from linear regression models for interactions between condition (no ctie/pizza cue) and dietary behaviour (dietary restraint and disinhibition) for changes in subjective appettte, and for pizza intake

\begin{tabular}{|c|c|c|c|c|c|c|c|}
\hline & \multirow[b]{2}{*}{$n$} & \multicolumn{3}{|c|}{$\begin{array}{c}\text { Disinhtbitton * Condition } \\
\text { (no-cue and pizza-cue) }\end{array}$} & \multicolumn{3}{|c|}{$\begin{array}{l}\text { Restraint } * \text { Condition } \\
\text { (no-cue and pizza-cue) }\end{array}$} \\
\hline & & $B$ & $S E$ & p value & $B$ & $S E$ & $p$ value \\
\hline \multicolumn{8}{|c|}{ Changes in subjective appettte } \\
\hline Hunger & 52 & 265 & 132 & 0050 & -096 & 447 & 0830 \\
\hline Fullness & 52 & 079 & 156 & 0616 & 581 & 499 & 0251 \\
\hline Desire-to-eat pizza & 52 & 187 & 112 & 0100 & 082 & 393 & 0836 \\
\hline Desıre-to-eat chips & 52 & -117 & 110 & 0294 & -480 & 353 & 0180 \\
\hline Desire-to-eat cookues & 52 & 146 & 126 & 0254 & 038 & 433 & 0931 \\
\hline Craving for pızza & 52 & 435 & 150 & $0006^{*}$ & 163 & 541 & 0765 \\
\hline Craving for chips & 52 & 068 & 130 & 0603 & 028 & 435 & 0949 \\
\hline Craving for cookıes & 52 & 038 & 132 & 0776 & 569 & 433 & 0195 \\
\hline Pizza Intake & 52 & -575 & 618 & 0357 & -4673 & 2102 & $0031^{*}$ \\
\hline
\end{tabular}


A

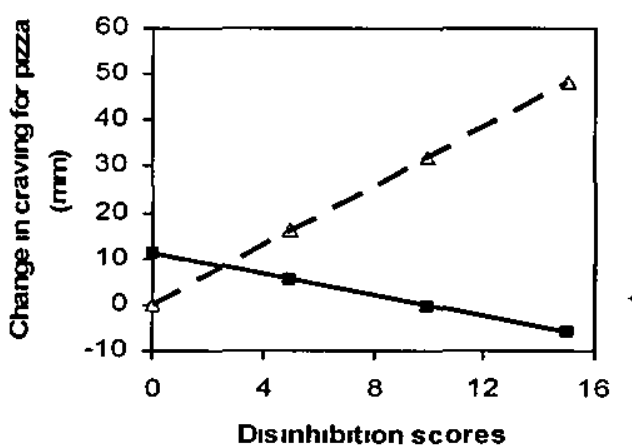

B

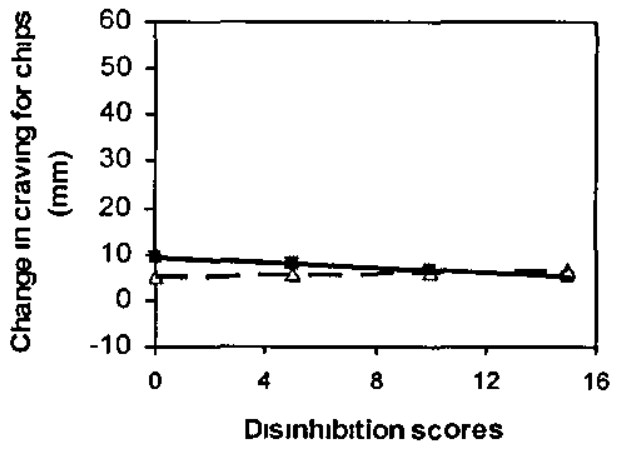

C

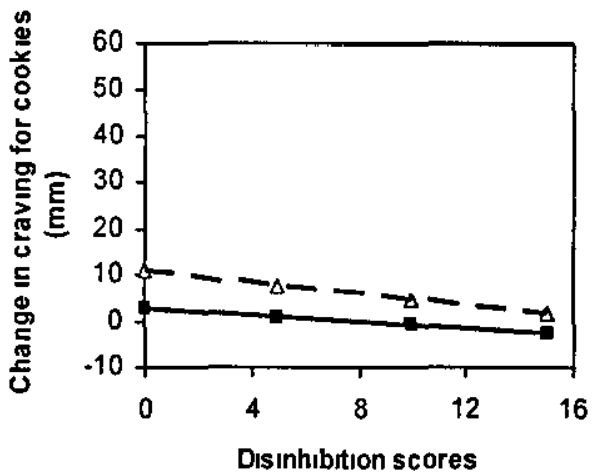

\begin{tabular}{cll}
$\Delta$ & $\begin{array}{l}\text { No-cue condition } \\
\text { Linear (Pizza-cue condition) }\end{array}-$ & - Lizza-cue condition \\
\hline
\end{tabular}

Figure 3.1 Predicted change in craving for pizza (A), chips (B), and cookles (C), (mm) for the no-cue (continuous lines), and pizza-cue condittons (dashed lines) separately, across disinhibition scores estimated using the parameter estimates from linear regression models ${ }^{5}$ for change in craving for chips, pizza, and cookies in the two conditions (no cue and pizza cue) ${ }^{6}$

${ }^{5}$ These were calculated using the following formula, $y=b x+b z+c$, where $b=$ the relevant parameter estımate from the regression model, $\mathrm{x}=$ disinhibition score, $\mathrm{z}=$ mean pre-exposure score, and $c=$ constant coefficient from the regression model

${ }^{6}$ In all models pre-exposure ratıngs are held at their mean value in the sample (see Table 31 for these values) and their parameter estımates are entered into the regression model 
A

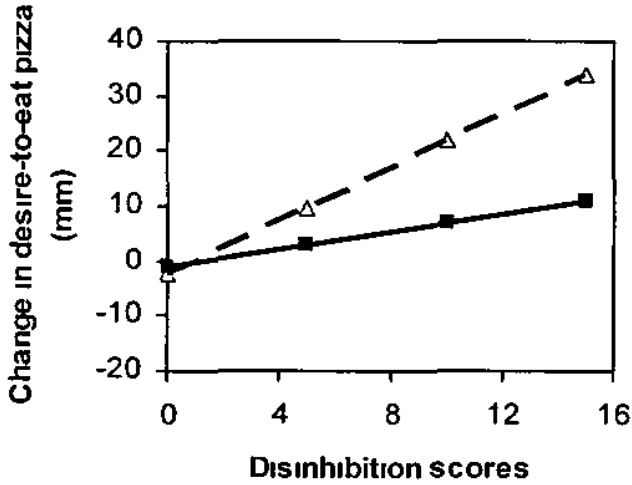

B

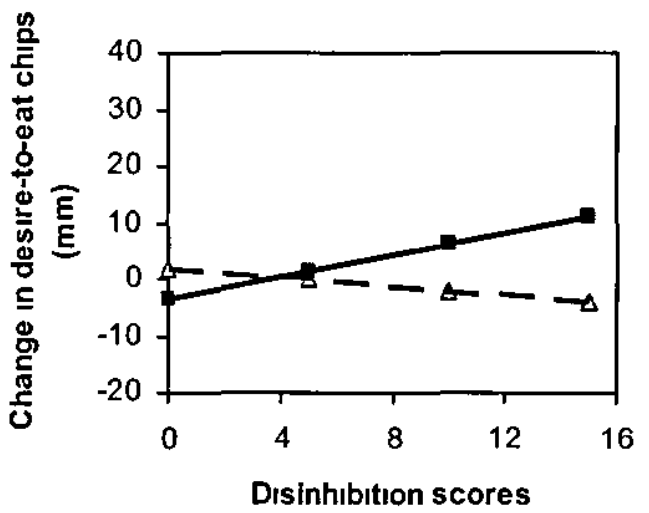

C

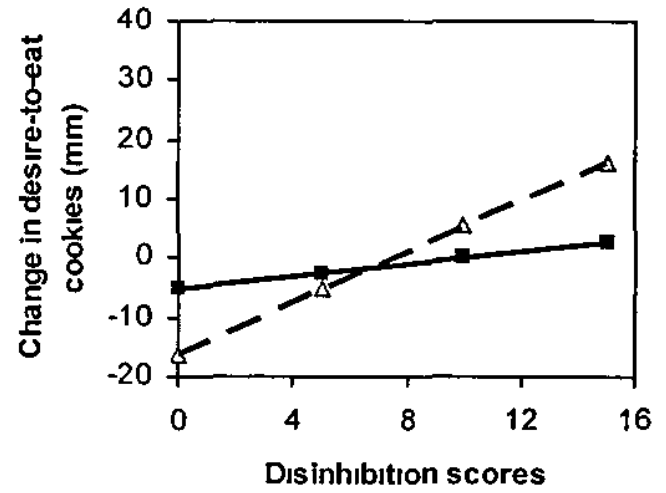

$\begin{array}{lll}\text { No-cue condition } & \Delta \quad \text { Pizza-cue condition } \\ \text { Linear (No-cue condition) } & - & - \text { Linear (Pizza-cue condition) }\end{array}$

Figure 32 Predicted change in desire-to-eat pizza $(A)$, chips $(B)$, and cookies $(C),(\mathrm{mm})$ for the no-cue (continuous lines) and pizza-cue conditions (dashed lines) separately, across disinhibition scores estimated using the parameter estımates from linear regression models for change desire-to-eat chips, pizza, and cooktes, in the two conditions (no cue and pizza (cue) $)^{7}$

${ }^{7}$ In all models pre-exposure ratıngs are held at their mean value in the sample (see Table 31 for these values) 


\subsubsection{Dietary restraint, disinhibition, and pizza intake}

There was little evidence to suggest condition interacted with disinhibition scores to predict pizza intake (Table 3.3) Rather, differences in intake were predicted by a significant interaction between DEBQ-restraint scores and condition (Table 3 3) As shown in Figure 3.3, highly restrained eaters consumed less in the pizza-cue condition than in the no-cue condition. In contrast, unrestrained eaters consumed slightly more after exposure to the pizza-cue. Even, after controlling for this association between restraint status and pizza intake, the interaction between disinhibition and condition was not statistically significant $(B=-532, \mathrm{SE}=6.17, p$ $=0393)$.

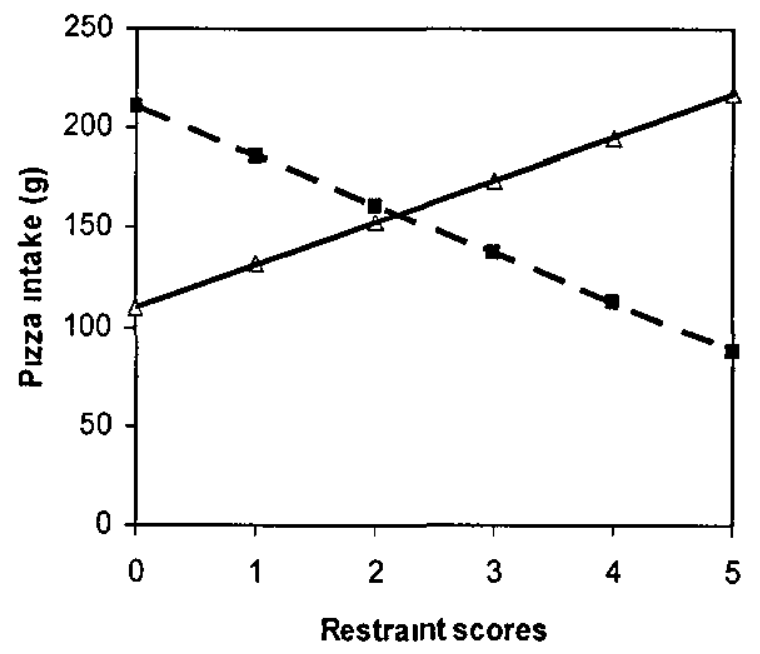

\begin{tabular}{|cll|}
\hline$\Delta \quad \begin{array}{ll}\text { No-cue condition } \\
\text { Linear (No-cue condition) }\end{array}$ & $-\quad-$ Pizza-cue condition \\
\hline
\end{tabular}

Figure 33 Predicted pizza intake in the no-cue (continuous lines) and pizza-cue conditions (dashed lines) separately, across restraint scores estimated using the parameter estımates from linear regression models for pizza intake in the two conditions (no cue and pizza cue) 


\subsubsection{Summary table of results}

To reduce the complexity of the results described here, a summary table of the observed interaction effects between dietary behaviour (dietary restraint and disinhibition) and condition (no cue and pizza cue) for each of the outcome measures is provided below. This suggests that restrained eaters did not expenence any greater subjective appetite after cue exposure, than unrestrained eaters. However, it does suggest that an interaction effect was observed between dietary restraint scores and pizza intake, indicating that restrained eaters consumed smaller amounts of pizza after exposure to this food It also suggests that an interaction effect was observed between dietary disinhibition and condition for change in craving for pizza This suggests that individuals with higher disinhibition scores experienced a greater change in craving for the cued food. All other interactions between dietary disinhibition and condition fatled to reach statistical significance.

Table 34 Stmmary table of the observed interactions between dietary behaviour (dietary restraint and disinhibition) and condition (no-cue and pizza-cue) for each of the outcome measures in this experiment

\section{Restraint * condition Disinhibition* condition \\ (no-cue and pizza-cue) (no-cue and pizza-cue)}

Outcome measure

Change in hunger

Change in fullness

Change in desire-to-eat pizza

Change in craving for pizza

Change in desire-to-eat chips

Change in craving for chips

Change in desire-to-eat cookies

Change in desire-to-eat cookıes

$A d-l t b$ pizza intake

Denotes where statistically significant interactions were observed 


\subsection{Discussion}

The primary aim of this expermment was to assess associations between food-cue reactivity and separate measures of dietary restraint and disinhibition It was expected that whilst levels of food-cue reactivity might not differ across an independent measure of dietary restraint, individuals with higher disınhibition scores might experience greater reactivity than individuals with lower disınhibition scores With regards to first part of this hypothesis, there was little evidence to suggest that food-cue reactıvity was associated with a restraned eatıng style. Restrained eaters did not report a greater motivation to eat than less restrained eaters after cue exposure, and in fact consumed significantly smaller amounts of the cued food These findings are important because they contradict previous suggestions (e g, Fedoroff et al 1997, 2003) that restrained eaters are highly reactıve to food cues. Notably, these findings are not the only results which contradict this notion. For example, it has been suggested that fastıng in obese individuals attempting to lose weight does not increase motivation to eat (hunger) after bref exposure to slides depıctıng food items (Lappalainen, Sjoden, Hurstı \& Vesa, 1990) Furthermore, it has also been suggested that pure dietary restrant (which does not conflate restrant with a tendency to disinhibit) is not associated with chocolate consumption after prolonged exposure to this food (e $\mathrm{g}$, participants keeping a bag of chocolate with them for 24 hours) (Stirlıng \& Yeomans, 2004)

The most interesting finding from this experiment relatıng to dietary restraint which requires further consideration was restrained eaters tendency to consume smaller amounts of food after pizza-cue exposure. As suggested above, restrained eaters were found to consume less than unrestrained eaters after pizza-cue exposure, and less than similarly restrained eaters consumed in the absence of cue exposure. The reason for this is unclear. However, one possibility is that in the presence of a food cue restraned eaters were explicitly forced to inhibit the desire to eat generated by this cue, and this caused them to consume smaller amounts of this food in the subsequent $a d-l b$ taste test. This explanation is adapted from Tiffany's (1990) model of drug-cue reactivity Tiffany's (1990) model was introduced in Chapter 2 
(see section 26.2 ). This model proposes that drug cues can automatically elicit drug use Thus, when exposed to a drug, drug users will automatically administer this drug. According to Tiffany (1990), to abstain from drug use, individuals must recruit non-automatic cognitive processes to inhibit automatic cued responses in the presence of drug cues. Thus, one possibility is that, as a consequence of actively inhibiting their food intake, restrained eaters might have reduced their food intake However, the extent to which Tiffany's (1990) model of cue reactivity can accurately account for the behaviour of restrained eaters in this experiment is unclear This is because, to date, this model has not been sufficiently tested Indeed, only two studies have provided evidence to suggest that restrained eaters might recruit non-automatic cognitive processes in an attempt to combat the automatic action plans to eat in the presence of food cues. Both these studies found that restrained eaters perform poorer on a concurrent cognitive task than unrestrained eaters when cued with the thought of their favounte food, but not when cued with the thought of their favourite holiday (Brunstrom \& Witcomb, 2004; Green, Rogers, \& Elliman, 2000,). This was presumably because, when cued with the thought of food, these individuals were recruitıng non-automatic cognitıve processes to inhibit automatic action plans to eat.

Given the minimal amount of evidence in support of using Tiffany's (1990) model to describe food-cue reactıvity, at present, the 1dea that restrained eaters recruit nonautomatic processes to inhibit their food intake in the presence of food cues is purely speculatıve. To provide support for this speculation, future studies are required to investigate the feasibility of generalising from Tiffany's (1990) model to explain food-cue reactıvity in restrained eaters. In particular, future studies are required to scrutınize exactly why restrained eaters expenence interference on a cognitive task when they are cued with the thought of food as observed in the studies by Green et al (2000) and Brunstrom and Witcomb (2004) Although Tiffany's (1990) model would suggest that this is to inhibit automatic action plans to eat triggered by food cues, at present there is no empirical support for this. If evidence for this is generated, the next step might be to evaluate the consequences of this. Tiffany (1990) suggests that non-automatic process recruited to inhibit drug use cause urges and cravings for the cued drug. However, there is little evidence from this experiment to suggest that after cue exposure restrained eaters 
experienced greater craving for, or a greater desire-to-eat, the cued food than unrestrained eaters. In addition to this, evidence should also be obtained to support the possibility suggested here, 1.e., that reduced intake after cue exposure in restrained eaters might result from recruiting these non-automatic cognitive processes.

Given that there is little evidence to support the proposal that reduced intake in restrained eaters after cue exposure is a result of inhibitory cognitions, alternatıve explanations for this observation must be considered. One alternative explanation is that exposure to the pizza cue threatens the dietary goals of restrained eaters, and consequently forces them to inhibit therr intake. Lowe and colleagues (Lowe, 1995, Lowe, Whitlow, \& Bellwoar, 1991) have found that dieters dramatically reduce their intake following forced consumption of a preload. Lowe (1995) interprets these findings as suggestıng that a high calone preload provides an obvious threat to these individuals' dietary goals and subsequently forces them to limit their intake. In a similar way, exposure to a pizza cue closely after a sandwich lunch might threaten restrained eaters' dietary goals, forcing them to limit their subsequent intake. However, again, this possibılity is purely speculatıve and requires future attention

Finding that dietary restraint was not associated with greater food-cue reactivity in this experiment was not particularly surpnising. This is because it was in fact hypothesised that food-cue reactivity might be more closely associated with a measure of dietary disinhibition, rather than with a pure measure of dietary restraint Partly consistent with this hypothesis, the results suggest that the TFEQdisınhibition scale was associated with change in craving for pizza after brief exposure to this food, such that individuals with the highest scores on this scale experienced the greatest changes in craving. However, somewhat surprisingly, this scale was not associated with change in desire-to-eat pizza after cue exposure. Given that craving is likely to reflect an intense desire to eat (PeIchat, 2002, Weingarten \& Elston, 1990;), it would be assumed that if change in craving was elevated in disinhibited eaters, change in desire-to-eat would also be greater in these individuals. One possible explanation for disinhibited eaters' tendency to report a greater change in craving, but not a greater change in desire-to-eat, might be that 
craving in fact reflects something other than an intense desire to eat For example, Rogers and Smit (2000) suggest it might represent the conflict between desire for that food because of the sensory pleasure it evokes, and attempts to resist consumption of it because of its perceived negative nutritional content (i.e., the conflict between 'naughty' but 'nıce') However, given that there was a trend for disinhibited eaters to experience a greater desire to eat after cue exposure (see Figure 32, Panel A), the most parsimonious explanation 1s perhaps that the experiment lacked power to detect a significant association between this measure of appetite and dietary disinhibition.

In this experiment, in addition to assessing changes in subjective appetite for the cued food across measures of disinhibition, changes in appetite for two non-cued foods was also assessed in an attempt to determine the specificity of any cued responses across this dietary measure. Notably, disinhibited eaters did not expenence greater subjective appetite (craving and desire to eat) for either of the non-cued foods (chips and cookıes) These findings are interestıng because they suggest that food-cue exposure might elicit a greater subjectıve appetite in disinhibited eaters, but that this motivation to eat is exclusive to the food which has been cued. This is consistent with Weingarten's proposals (Weingarten, 1985) regarding conditioned meal initiation He suggests that the effects of a food cue will be to exclusively motivate intake for the cued food.

Unfortunately, in this experiment it was impossible to determine the potential specificity of actual eatıng behaviour in disınhibited eaters This was because a measure of intake was only obtained for the cued food. However, using this measure it was possible to determine the extent to which food-cue exposure stimulated greater food intake in these individuals. Given that these disinhibited eaters experienced a greater change in subjective appetite for the cued food, it might be expected that these individuals would also consume larger amounts of this food than less disinhibited eaters. However, this expenment failed to provide any evidence for this One potential reason for this is that the measure of ad-lib intake used in this experiment was insensitive to the effects of cue exposure on food intake for disinhibited eaters In this experiment, the measure of $a d$-llb intake was 
obtained in a disguised taste test. Participants were instructed to taste the food and then rate its sensory characteristics. They were told that once these ratıngs were complete they could eat as much or as little of the food as they desired. However, this approach is problematic because it leads participant to believe that the aim of the phase is for them to merely taste and rate the food, rather than to eat as much as they desire. Thus, given this, it is unclear whether the taste test approach utilised in this experiment provided a valid measure of the amount individuals would really like to consume. This was not the only limitation associated with this measure. Another problem was that the pizza was presented in average-sized slices Therefore, one possibility is that the participants were controlled by the portion size of the pizza slices presented They might have felt that once intake of one pizza slice was initiated, the full slice had to be consumed. Given that these methodological issues might account for the fallure to observe greater food intake in disınhibited eaters, Experiment 2 utilised a different methodological approach which addressed these limitations

In summary, this experiment provided little evidence to suggest that food-cue reactivity is associated with dietary restraint when a measure of restraint is used which does not conflate dietary restriction with disinhibited eatıng. Rather, this experiment provided some evidence to suggest that food-cue reactivity might be associated with a measure of dietary disinhibition. Individuals with high disinhibition scores reported a greater change in appetite for the cued food. However, they did not consume greater amounts of this food. Given that the measure of $a d-l i b$ intake used in this experiment suffered several limitations, Experiment 2 aims to address these limitations 


\section{PART II: EXPERIMENT 2}

\subsection{Introduction}

The aim of Experiment 2 was to re-explore the hypothesıs tested in Experiment 1 using an improved version of the methodology. One concern in Experiment 1 was that the measure of $a d-l l b$ intake did not provide an adequate measure of participants desired intake. This was because, firstly, this phase was disguised as a taste test, thus participants believed that the aim of the phase was for them to merely taste and rate the food. Secondly, presenting the pizza in pre-defined slices might have served to control the amount of food that participants ate To address these concerns, in Experıment 2, a different approach to assess $a d$-ll $b$. intake was adopted. Rather than using a disguised taste test, in this experiment participants were merely told to eat as much or as little of the test food as they desired in the $a d-l l b$ intake phase. This approach was more appropriate because it signals to the participant that the aim of the phase $1 \mathrm{~s}$ for them to eat as much as they like In addition to this, foods were presented in bite-size pieces to eliminate the possibility that the portion size offered to participants controls the amount that they subsequently eat.

Potentially the greatest limitation associated with Experiment 1 was its fallure to adequately assess cue specificity across measures of restrant and disinhibiton. Measures of subjective appetite for the cued food and for the two non-cued foods made it possible to determine the extent to which cue exposure generated an exclusive subjective appetite for the food which had been cued. However, in the absence of a measure of intake of a non-cued food, it was impossible to determine whether food-cue exposure motivated greater intake of the cued food in these individuals but did not motivate greater intake of other non-cued foods To address this issue, Experiment 2 assessed $a d-l l b$ intake of both the cued, and a non-cued, food.

As suggested previously, Fedoroff et al, (2003) explored the specificity of cued intake in restrained eaters defined according to Herman and Polivy's Restraint 
Scale. However, as noted, one important feature of their study was that the cued and non-cued foods used were quite different (sweet and savoury). The implication of this is that these foods would not be served together within the same course of a meal. Therefore, cue-specific intake observed in this study might reflect the fact that individuals may have a tendency to select one or other of the foods almost exclusıvely. For example, if individuals have a desıre to eat a 'sweet' food they will consume the sweet food but are unlikely to consume any of the savoury food. Thus, this design might in fact exaggerate any cue-specific effects. Experiment 2 sought to address this issue by offering participants two foods that are likely to be consumed within the same course of a meal (pizza and chips). These foods were presented simultaneously to participants to allow them to choose between the two foods The foods chosen were chips and pizza. Participants were exposed to one of these foods (chip-cue or pizza-cue), or to the same environment in the absence of cue exposure (no-cue condition), and were then offered $a d-l l b$ access to both foods.

As in Experiment 1, a principle similar to that used by Fedoroff et al (2003) (see section 3.2) was employed in this experiment to assess the evidence for cue specificity across the measures of dietary restraint and disinhibition. To recap, this principle assumes that if food-cue reactivity reflects a cue-specific response then only appetite for the cued food should increase after cue exposure. Thus, intake of a particular food should be greater after cueing with that food but not after cueing with a different food. Applied to the current methodology, this would suggest that relative to intake in the absence of cue exposure (no-cue condition), intake of chips should be signtficantly greater after cueing with chips (chip-cue condition), but not after cueing with pizza (pizza-cue condition) In a similar way, it would suggest that relative to intake in the absence of cue exposure (no-cue condition), intake of chips should be significantly greater after cueing with chips (chip-cue condition), but not after cueing with pızza (pızza-cue condition).

In summary, this experıment sought to address the limitations associated with Experiment 1. Most importantly, it employed a methodology which allowed exploration of the effects of cue exposure on intake of not only the cued food, but also of non-cued foods This is important because it can determine the specificity of cue exposure on food intake. In addition to this, this experiment was designed to 
1mprove the measure of $a d$-llb intake Rather than using a disguised taste test, in this experiment participants were merely told to eat as much or as little of the test food as they desired in the $a d-l l b$ intake phase To avord influencing participants' intake by providing the test food in particular portion sizes, in this experiment test foods were presented in bite-size pieces.

\subsection{Method}

\subsubsection{Overview}

Following Experiment 1, cue reactivity was assessed in non-food deprived participants. Thus, to ensure that participants were replete prior to cue exposure, they were offered a buffet-style lunch at the outset. This allowed participants the freedom to consume as much food as they required to reach satiety. The decision to offer participants a buffet-style lunch in this experiment rather than a fixed lunch was motivated by the fact that in Experment 1 the fixed lunch was not sufficient to bring about satiety in some individuals.

In the exposure phase of this experiment, participants were exposed to, the sight and smell of pizza (pizza-cue condition), the sight and smell of chips (chip-cue condition) or the same environment in the absence of pizza or chips (no-cue condition). Both before and after this, participants rated their appetite for the food which had been cued (cued food) and the food which had not been cued (non-cued food), and rated their hunger and fullness After cue exposure all participants were offered $a d-l l b$ access to the two foods (pizza and chips) The final phase involved completing the various questionnaires. In addition to completing the DEBQrestraint scale and the TFEQ-disinhibition scale, this phase also involved completing an awareness questionnaire This measure was introduced in this experiment because it became apparent that it is important to ensure that any reactions to the food cues observed do not merely result from participants behaving in a way in which they feel they are expected to behave by the researcher. 


\subsubsection{Participants}

One hundred and twenty participants were recruted from the population of female undergraduate students at Loughborough University $(\mathrm{UK})$ (mean $\mathrm{BMI}=23.51, \mathrm{SD}$ $=370$ ). Thirty were recruited into the no-cue condition, 30 into the pizza-cue condition, and 30 into the chip-cue condition. All participants were aged between 18 and 30 , and were recruited via email. They received financial reimbursement for their participation (5 sterling pounds).

\subsubsection{Design}

Again, a between-subjects design was applied Partıcıpants were randomly assigned to one of three conditions, a pizza cue condition, a chip-cue condition, or a no-cue condition.

\subsubsection{Measures}

\section{Cue reactivity}

Appetite ratıngs used in this expenment were almost identical to those used in Experiment 1. Appetite ratıngs included measures of general appetite (hunger and fullness) and craving for, and desire-to-eat, pızza and chips (see Appendix A for examples of these).

$A d-l i b$ intake was assessed in this experiment by presentıng participants with chips and pizza simultaneously and asking them to eat as much or as little of the food as they desired. Pizza was presented in bite-size pieces heaped on a plate Chips were presented as manufactured on a separate plate. Participants were told they had as much time as they liked to consume the foods. Before and after consumption, the weight of the two foods was recorded and used to obtain a measure of intake of pızza and chips for each partıcıpant 


\section{Dietary restraint and disinhtbited eating}

Dietary restraint and disinhibition were assessed as in Expenment 1.

\section{Awareness questlonnalre}

An awareness questionnaire was issued at the end of the experiment to ensure that participants were not aware of the aims of this experiment. This questionnare asked 1) "What do you thınk was the purpose of this experiment?", 11 ) "In this experiment I measured your consumption of pizza and chips. Do you know why?" 111) "Did you feel you were expected to eat certann amounts of these foods?", 1v) "I did expect you to eat more food than you might usually do. Which food? pizza, chips, pizza and chips (please circle)," and v) "You were asked to rate your cravings for food at several points throughout the experment. Do you know why so many ratıngs were taken?". These questions were displayed on separate sheets of paper and participants were instructed to turn to the next page only when their answer to the previous question was complete.

\subsubsection{Procedure}

The procedure used in this experiment was different to that used in Experiment 1 in several ways Firstly, the sandwich-lunch stage was replaced by a buffet-style lunch. This buffet consisted of three sandwiches (ham, cheese, chicken), one and a half sausage rolls, six scotch eggs, three handfuls of original flavoured Pringles, two large oranges, six Jaffa cakes, and a glass of water. By asking partıcipants to eat until they felt 'comfortably full', we ensured that participants were non-food deprived prior to the cue/no-cue exposure.

Secondly, this experiment was not described as a taste perception study. This is because the $a d-l l b$ intake phase was no longer disguised as a taste test. Rather, this experiment was described as an investigation exploring the effect of appetite and eating on mood. The participants were told that they would be asked to rate their appetite and mood, and that they would be required to consume some food. 
Consistent with the cover story, the pre- and post-exposure ratıng included a set of mood ratıngs. Partıcıpants were asked how depressed ("How depressed (sad) do you feel right now?"), irritable ("How irritable do you feel right now?"), frustrated ("How frustrated do you feel nght now?"), angry ("How angry do you feel right now?") and anxious ("How anxious (nervous) do you feel right now?") they felt at that moment in time

Thirdly, in the exposure stage in this experiment, partıcıpants were exposed to the sight or smell of either cooked pizza (pızza-cue condition), or cooked chips (chipcue condition), or the same environment in the absence of food (no-cue condition), for three minutes. Again, in the food-exposure conditions, the food was placed directly in front the participant on the table at which they were sat. During this exposure phase, participants were instructed to sit and wait until the experimenter returned After completıng post-exposure ratıngs, participants were presented with both pizza and chips, simultaneously, during the $a d-l l b$ intake phase and asked to consume as much of these foods as they desired.

\subsubsection{Data analysis}

In this experiment the effect of cue exposure (no cue, pizza cue, or chip cue) on general subjectıve appetıte (hunger and fullness), subjectıve appetite (desire to eat and craving) for chips and pizza, and $a d-l l b$ intake of these foods was assessed. Since subjective appetite was assessed before and after cue/no cue exposure, change scores were derived from the measure of appetite taken before and after this exposure phase. As in Experiment 1, initially it was desirable to assess the descriptive statıstics (means and SD's) for the $a d-l ı b$ intake and change in subjective appetite across the three conditions. Each outcome measure was compared across the conditions using a series of one-way ANOVA's. Where significant differences were observed, Bonferroni post-hoc tests were used to assess the differences between the three conditions

To determine the extent to which food-cue reactivity was associated with dietary restraint and dietary disinhibition, and the extent to which this was specific to the 
cued food, interactions were explored between condition (no cue, pizza cue, chip cue) and the dietary measures (dietary restraint and disinhibition) for each of the outcome measures As in Experiment 1, regression analysis was used for this as it allows the dietary measures to be entered as contınuous variables. To compare the three experimental conditions (no-cue, pizza-cue, chip-cue) in this analysis the categones were converted into two dummy variables as described by Alken and West (1991) In dummy coding for three categones, one category is coded as a reference and the two other categones are compared with this reference category This creates two dummy variables. The reference category is assigned a value of ' 0 ' in both dummy variables, and the comparison group for each dummy variable is assigned a value ' 1 ' for that variable only (Aiken \& West, 1991) Given that it was important to compare the no-cue condition with both cued conditions (no-cue and pizza-cue) in this expenment, the no-cue condition was coded as the reference variable, and the two other conditions were coded as the comparison groups. This coding is system is shown in Table 3.5. The first dummy varable compared the nocue condition with the pizza-cue condition The second dummy variable compared the no-cue condition with the chip-cue condition Notably, both dummy variables and therr interaction effects (dummy variable * everyday dietary behaviour [dietary restraint and disinhibition]) are entered into the regression model simultaneously.

Using the analysis described above, interactions bctween each of the dummy variables and each of the measures of everyday dietary behaviour were observed for every outcome measure (change in hunger, change in fullness, change in desire-toeat pizza, change in desire-to-eat chips, change in craving for pızza, change in craving for chips, pizza intake and intake of chips). These interactions are described in the following section as the interaction between the comparison variable (pizzacue, or chip-cue, condition) and the measure of everyday dietary behaviour, when the reference is the no-cue condition.

As in Experiment 1, in the regression analyses used here, pre-exposure ratıngs for the measures of subjective appetite were controlled by entering the relevant preexposure variable as a covariate into the regression model Also, separate analyses were initially conducted to explore 1) the interactions with dietary restraint, and 11) the interactions with disinhibition However, since it was desirable to determine the 
extent to which any interactions between disinhibition scores and condition occurred irrespective of dietary restraint, the disinhibition model was repeated with dietary restraint scores entered as a covariate. 
Table 35 Dummy variable coding

\begin{tabular}{lll}
\hline No-cue condition $=$ Reference group & \\
\hline No-cue condition & Dummy variable 1 & Dummy variable 2 \\
Pizza-cue condition & 0 & 0 \\
Chip-cue condition & 0 & 0 \\
\hline
\end{tabular}

\subsection{Results}

\subsubsection{Participant characteristics and baseline measures}

To test that the three experimental groups did not differ in their appetite ratings prior to cue exposure ( $1 \mathrm{e}$, after the buffet-lunch), and to ensure that there were no differences in restraint and disinhibition scores across the three experimental groups, a serres of one-way between-subject ANOVA's were used The groups did not differ significantly in their DEBQ-restraint scores (Table 3.6). However, there was a significant difference between their TFEQ-disinhibition scores (Table 3.6) Post-hoc tests (Bonferron1) suggested that these scores were significantly higher in the pizza-cue condition relative to both the no-cue condition $(p=0009)$ and the chip-cue condition ( $p=0001)$ The implication of this difference is discussed later.

Across conditions, reported levels of fullness, and specific appetite (desire to eat and craving) for the two test foods (pizza, and chips), were not significantly different prior to cue exposure (all $p>0.05$ ). However, hunger levels did differ significantly across conditions (Table 3.6). Post-hoc tests did not highlight statıstically significant differences between any of the three conditions (all compansons $p>005$ ) However, visual inspection of the means suggests that hunger was greater in the no-cue condition relative to both the cued conditions For this reason, in the subsequent regression analys1s, pre-exposure hunger ratıngs were 
also controlled for statistically by enterng them as a covariate into the regression models for each of the independent variables

Table 36 One-way between-subject ANOVAs, means, and standard deviations, for baseline ratings (hunger, desire-to-eat pizza, destre-to-eat chips, craving for pizza, and craving for chips), and for participant characteristics (DEBQ-restraint scores TFEQ-disinhibition scores)

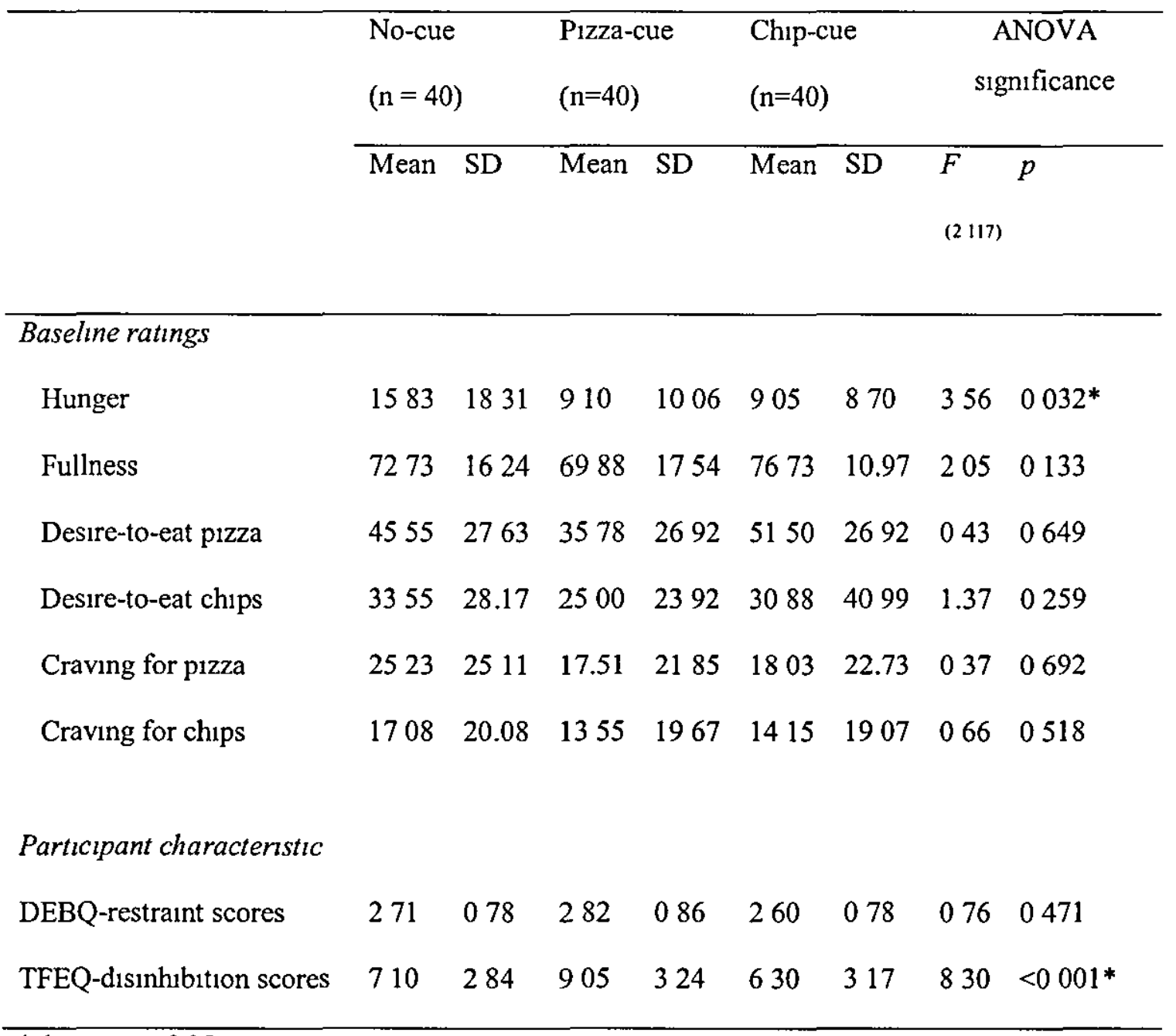

* denotes $\mathrm{p}<005$ 


\subsubsection{Descriptive statistics for measures of cue reactivity}

As suggested above, it was initially desirable to explore the descriptive statistics for the measures of cue reactivity across the three conditions. Therefore, the means and standard deviations, for changes in subjective appetite and for $a d-l l b$ intake are summarised in Table 3.7. The results of one-way between-subject ANOVAs used to compare these measures across the three conditions are also presented alongside these descriptive statıstics

Changes in hunger differed significantly across the three conditions (Table 3.7). Post-hoc tests (Bonferron1) suggested that change in hunger was significantly greater after exposure to the pizza cue relative to in the absence of cue exposure ( $p$ $<0001$ ). Changes in subjective appetite (desire to eat and craving) for both the test foods (chips and pizza) also differed significantly after cue exposure (Table 3.7) Post-hoc tests suggested that relative to the no-cue condition, change in desire-to-eat and craving for pizza were significantly greater after cueing with this food (both $p<$ 005 ), but not after cueing with chips (both $p>005$ ). Likewise, they suggested that changes in subjectıve appetite for chips were only greater after exposure to the chip cue (both $p<005$ ) After exposure to the pizza cue, these changes did not differ to changes observed in the absence of cue exposure (no-cue condition) (both $p>005$ ) By contrast, there was little evidence to suggest that intake of pizza or chips differed significantly across the three conditions (Table 3.7). 
Table 37 One-way between-subject ANOVAs, means, and standard deviations, for changes in subjective appettte, and for ad-lib intake in the no-cue, pizza-cue, and chip-cue, condition

\begin{tabular}{|c|c|c|c|c|c|c|c|c|}
\hline & \multicolumn{2}{|c|}{$\begin{array}{l}\text { No-cue } \\
(n=40)\end{array}$} & \multicolumn{2}{|c|}{$\begin{array}{l}\text { Pizza-cue } \\
(n=40)\end{array}$} & \multicolumn{2}{|c|}{$\begin{array}{l}\text { Chip-cue } \\
(\mathrm{n}=40)\end{array}$} & \multicolumn{2}{|c|}{$\begin{array}{c}\text { ANOVA } \\
\text { Significance }\end{array}$} \\
\hline & Mean & $\mathrm{SD}$ & Mean & SD & Mean & SD & $F_{(2117)}$ & $\mathrm{p}$ \\
\hline \multicolumn{9}{|l|}{ Changes } \\
\hline Hunger & 523 & 747 & 1538 & 16.57 & 7.38 & 1283 & 684 & $0002 *$ \\
\hline Fullness & -273 & 1586 & -265 & 1985 & -303 & 1680 & 001 & 0995 \\
\hline Desıre-to-eat pızza & -013 & 1947 & 2603 & 2928 & 1128 & 1992 & 1355 & $<0001 *$ \\
\hline Desire-to-eat chips & -063 & 1832 & 475 & 1432 & 1565 & 2105 & 839 & $<0001^{*}$ \\
\hline Cravıng for pızza & 728 & 2110 & 2368 & 2804 & 858 & 1483 & 687 & $0002 *$ \\
\hline Craving for chips & 388 & 1215 & 690 & 1266 & 1598 & 2306 & 567 & $0004^{*}$ \\
\hline \multicolumn{9}{|l|}{ Intake } \\
\hline Pizza & 8396 & 4641 & 7551 & 4383 & 6999 & 3623 & 107 & 0345 \\
\hline Chips & 4419 & 2666 & 4630 & 3788 & 5854 & 4586 & 165 & 0196 \\
\hline
\end{tabular}

* denotes $\mathrm{p}<005$

\subsubsection{Food-cue reactivity and dietary behaviour}

There was little evidence of significant interactions between either of the dietary measures and the pizza-cue condition (reference $=$ no-cue condition) for any of the changes in subjective appetite, or for $a d-l b b$ intake of etther of the test foods (Table $38)$. Likewise, interactions between the dietary measures and the chip-cue condition (reference $=$ no-cue condition) were not statistically significant for changes in hunger, fullness, subjective appetite for pizza, or chips, or for $a d-l l b$ pizza and chip intake (Table 3.8) 
Table 38 Adjusted' parameter estimates from linear regression models for interactions between the pizza-cue, or chip-cue, condition (Reference, no-cue condition) and dietary behaviour (dietary restraint and disinhibition) for changes in subjective appetite, and for pizza intake

\begin{tabular}{|c|c|c|c|c|c|c|c|c|}
\hline & & & $\begin{array}{l}\text { Disin } \\
\text { (no-c }\end{array}$ & hibition & $\begin{array}{l}\text { condition } \\
\text { 1zza-cue) }\end{array}$ & $\begin{array}{r}\text { Rest } \\
\text { (no-ct }\end{array}$ & $\begin{array}{l}\text { raint }{ }^{*} \text { co } \\
\text { e and } p\end{array}$ & $\begin{array}{l}\text { ition } \\
\text { a-cue) }\end{array}$ \\
\hline & $n$ & $\operatorname{Ref}$ & $B$ & $\mathrm{SE}$ & $p$ & $B$ & $\mathrm{SE}$ & $p$ \\
\hline Hunger & & & & & & & & \\
\hline Pizza-cue & 120 & No-cue & -084 & 0690 & 0225 & -218 & 254 & 0460 \\
\hline Chip-cue & 120 & No-cue & 003 & 0697 & 0957 & 081 & 265 & 0761 \\
\hline Fullness & & & & & & & & \\
\hline Pizza-cue & 120 & No-cue & 081 & 098 & 0409 & 215 & 356 & 0547 \\
\hline Chıp-cue & 120 & No-cue & 0003 & 099 & 0997 & 072 & 373 & 0847 \\
\hline Desire-to- & & & & & & & & \\
\hline Pizza-cue & 120 & No-cue & -005 & 148 & 0097 & 117 & 541 & 0829 \\
\hline Chıp-cue & 120 & No-cue & -030 & 149 & 0842 & -191 & 565 & 0735 \\
\hline Desire-to- & & & & & & & & \\
\hline P1zza-cue & 120 & No-cue & -193 & 118 & 0105 & 348 & 441 & 0431 \\
\hline Chip-cue & 120 & No-cue & -079 & 119 & 0507 & 438 & 460 & 0344 \\
\hline Craving fo & & & & & & & & \\
\hline Pizza-cue & 120 & No-cue & 007 & 124 & 0950 & 027 & 457 & 0953 \\
\hline Chıp-cue & 120 & No-cue & -025 & 125 & 0840 & -372 & -007 & 0437 \\
\hline Craving fo & & & & & & & & \\
\hline Pizza-cue & 120 & No-cue & -167 & 097 & 0088 & 232 & 358 & 0519 \\
\hline Chip-cue & 120 & No-cue & -028 & 097 & 0775 & 199 & 398 & 0519 \\
\hline Plzza Inta) & & & & & & & & \\
\hline Pizza-cue & 120 & No-cue & 330 & 304 & 0279 & 1906 & 1141 & 0098 \\
\hline Chıp-cue & 120 & No-cue & 301 & 311 & 0336 & 1907 & 1199 & 0115 \\
\hline Chips inta & & & & & & & & \\
\hline Pizza-cue & 120 & No-cue & 3.14 & 267 & 0242 & 226 & 1002 & 0822 \\
\hline Chip-cue & 120 & No-cue & 267 & 273 & 0330 & -556 & 1053 & 0598 \\
\hline
\end{tabular}

* denotes $p<005$

' Adjusted for pre-exposure hunger and for relevant pre-exposure ratıng 


\subsubsection{Awareness Questionnaire}

To explore the extent to which the results obtained in this experiment could be attributed to participants' awareness of the ams of the experiment, an awareness questionnarre was issued in the final phase of the experiment. Responses to this questionnaire are summarised in Table 39. These responses suggested that the majority of participants were unaware of the overall purpose of the expenment. Participants etther believed the cover story provided at the outset, or presumed the aim of the study was to explore dietary habits.

With regards to the more spectic alms of the study, approximately $27 \%$ of participants suggested that they were expected to eat certain amounts of the foods presented in the $a d-l l b$ phase. However, only seven out of 40 participants in the chip-cue condition felt that they were expected to eat more chips Slightly more participants (13 participants out of 40) in the pizza-cue condition suggested they were expected to consume larger amounts of pizza. By contrast, $25 \%$ of participants provided answers suggesting that they were aware of the interest in the effect of cue exposure on subjective appetite. 
Table 39 Summary of responses to the awareness questionnaire All total are given in percentages

\begin{tabular}{|c|c|c|c|c|}
\hline \multirow[b]{2}{*}{ Question } & \multicolumn{4}{|c|}{ Response (\%) } \\
\hline & $\begin{array}{l}\text { Yes/ } \\
\text { aware }\end{array}$ & $\begin{array}{l}\mathrm{No} / \\
\text { unaware }\end{array}$ & $\begin{array}{l}\text { Indicated pizza } \\
\text { in pizza-cue } \\
\text { condition }\end{array}$ & $\begin{array}{l}\text { Indicated } \\
\text { chips in chip- } \\
\text { cue condition }\end{array}$ \\
\hline $\begin{array}{l}\text { What do you think was the purpose of } \\
\text { this experiment? }\end{array}$ & 833 & 9167 & - & 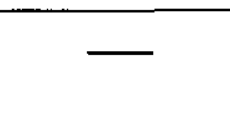 \\
\hline $\begin{array}{l}\text { In this experiment I measured your } \\
\text { consumption of pizza and chips Do } \\
\text { you know why? }\end{array}$ & 083 & 9917 & - & - \\
\hline $\begin{array}{l}\text { Did you feel you were expected to eat } \\
\text { certain amounts of food? }\end{array}$ & 2667 & 7333 & $\longrightarrow$ & $\longrightarrow$ \\
\hline $\begin{array}{l}\text { I did expect you to eat more food than } \\
\text { you might usually do Which food? }\end{array}$ & 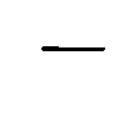 & - & 325 & 175 \\
\hline $\begin{array}{l}\text { You were asked to rate your craving } \\
\text { for food at several points throughout } \\
\text { the experiment. Do you know why so } \\
\text { many ratıngs were taken? }\end{array}$ & 2417 & 75.83 & & \\
\hline
\end{tabular}




\subsection{Discussion}

As in Experiment 1, food-cue reactivity was found to share little relationship with dietary-restraint status in this experiment. Restrained eaters did not differ in their subjective appetite or intake after exposure to the same food as that used in Experiment 1 (pizza), or after exposure to a different food (chips). These findings are important because they provide further support to suggest that, contrary to previously published work, restrained eaters are not any more reactive to food-cues than less restrained eaters

In Experiment 1, it was suggested that restrained eaters consume smaller, not greater, amounts of food than unrestrained eaters after cue exposure However, this finding was not replicated in the present study for either intake of pizza or chips One possibility is that this finding was particular to the method used to assess adlib intake in Experment 1 (1.e., the taste test methodology). However, an alternatıve possibility is that restrained eaters did not find it necessary to actively inhibit their pizza intake in this experment because they were relatıvely more satiated after lunch than in Experiment $1^{8}$. Indeed, Tiffany (1990) proposes that in the absence of physiological need for a cued substance, individuals attemptıng to abstain from use of the substance will not automatically be motivated towards it durng cue exposure, and therefore cognitive inhibition to prevent this automatic behaviour is unnecessary. Consistent with this, Brunstrom and Witcomb (2004) reported that restrained eaters do not cognitively suppress any automatic plans to eat in the presence of a cued food while satiated. These authors found that while cued with the thought of food, performance on a concurrent task was not significantly different in restrained, and unrestrained, eaters after they had recently consumed lunch. Thus, given that restrained eaters in the present study were relatively more satiated than in Experiment 1, it is possible that these individuals did not consume smaller amounts after cue exposure because food-cue exposure did not motivate this inhibited response in the absence of physiological need However, given that this

\footnotetext{
${ }^{8}$ In Experıment 2, mean fullness rating after the buffet lunch was 7311 By contrast in Experiment 1 , the mean ratıng after the fixed lunch was 4587
} 
possibility is purely speculative, future studies should consider this possibility further.

Notably, in Experiment 1, there was some evidence to suggest that food-cue reactivity might be associated with dietary disinhibition. Indeed, individuals with high disinhibition scores were found to experience greater craving for pizza after exposure to this food, but were not found to consume greater amounts of this food In the present study, using an improved measure of $a d-l l b$ intake, again individuals with high disinhibition scores did not consume greater amounts of a cued food, and in fact were not even found to experience any greater craving for this food than individuals with lower disinhibition scores The reason disinhibited eaters did not experience greater craving for the cued food in this experiment is unclear. However, participants did report being more satiated after lunch in this experiment. Therefore, this represents one difference relative to Experiment 1 which might account for the fallure to observe greater craving in these individuals However, this represents only one possibility and without empincal evidence to support this, it remains purely speculative

Before formulatıng firm conclusions regarding the associations between food-cue reactivity and the dietary behaviours, it is important to consider that there were several limitations associated with the present experiment The first limitation relates to the measure of $a d-l i b$ food intake, and also applies to Experiment 1. In both experiments, it has been assumed that the measure of $a d-l i b$ intake obtained in the no-cue condition provides a measure of intake of the test food in the absence of prior exposure to this food, 1.e., it provides a non-cued measure. However, one possibility which has not previously been considered is that intake in this condition is also cued, and therefore does not provide an adequate control measure. This cueing might occur as brief exposure to the sight and smell of a food in the ad-lib. intake cues appetite for this food. Indeed, there is no logical reason why even this bnef exposure should not cue appetite for a food. In fact, Weingarten (1985) suggested that there is no such thing as 'unsignalled meals.' This is because even the presentation of food immediately before a meal begins acts as a cue to stimulate intake. Furthermore, in addition to the sight and smell of food cueing appetite, there is also reason to suspect that the taste of the food as intake is initiated might cue 
appetite. Support for this comes from evidence suggesting that palatability, or the taste of a food, can stımulate food intake (Bobroff \& Kissıleff, 1986; Decke, 1971; Price \& Gnnker, 1973; Rodin, 1975a; Yeomans, 1996; Yeomans, Gray, Mitchell, \& True, 1997).

The possibility that $a d-l i b$ intake in a no-cue condition might also reflect a cued measure could account for the fallure to provide even basic evidence to suggest that food-cue exposure generally increases intake of the cued food in Experiments 1 and 2 , despite the fact that it increased subjective appetite for this food (see Sections 3.4.3 and 38 2). Although some previous studies (e g., Fedoroff et al, 1997, 2003; Jansen et $a l, 1991$,) have reported that $a d-l l b$ intake is stimulated by exposure to a food cue, they have typically used longer and more extensive exposure periods than used in Experiments 1 and 2. For example, Fedoroff et al (2003) exposed partıcipants to the smell of bakıng pizza for ten minutes while they were simultaneously asked to think about pizza and to write these thoughts on paper Therefore, as a result of this longer exposure period participants in the food-cue condition in these studies might be cued to an extent which cannot be achieved by brief cueing in the $a d-l l b$ intake phase However, using this intensive cueing period is problematic because it limits the applicability of these findings to occasions outside the laboratory where individuals are intensively exposed to a food cue for a relatively long period of time. Yet, withın everyday life, there are several occasions when participants are only briefly exposed to a food cue for a few minutes. For example, this brief exposure might occur when individuals are exposed to a poster advertising fast food. For this reason, it might be appropriate to avoid intensive cueing procedures.

Another limitation associated with Expenment 2 was that participants in the pizzacue condition had significantly higher TFEQ-disinhibition scores than participants in the other conditions. Consequently, similar groups of individuals were not being tested across the three conditions There are two possible explanations for these higher disinhibition scores in the pizza-cue condition Firstly, it may have simply resulted from a random sampling error However, an alternative possibility is that exposure to pizza inadvertently increased these individuals disinhibition scores While this latter possibility seems unlikely, partıcularly since disinhibition scores in 
the pizza-cue condition in Experiment 1 were not significantly higher than those reported in the no-cue condition, it does require further attention. To explore this 1ssue, all participants from the present study were contacted and asked to complete the disinhibition scale again. If these re-test scores were consistent with previous scores obtained during the experimental procedure, one would assume that higher scores in the pizza-cue condition were a result of a simple random sampling error. However, if these scores are significantly lower than those previously recorded, a re-analysis of the present data would be considered This is because, this might suggest that exposure to pizza in this experiment inadvertently increased these scores The results of this re-test are presented in the following section.

\subsection{Re-test of TFEQ-disinhibition scores}

Following the finding that disinhibition scores were elevated in the pizza-cue condition in Experıment 2, a decision was made to re-test partıcipants' disinhibition scores. If these re-test scores were consistent with the scores obtained during the Experiment 2, one would assume that higher scores in the pizza-cue condition were a result of a random sampling error. However, if these scores were significantly lower than those previously recorded a re-analysis of the data from Experiment 2 would be considered. This is because, this might suggest that exposure to pizza in this experıment inadvertently increased these scores.

\subsubsection{Method}

\subsubsection{Procedure}

Participants were contacted via email approximately five months after they had onginally participated in Experıment 2, and were asked to complete an on-line version of the TFEQ-disinhibition scale They were not told that they had completed this questionnaire previously. 


\subsubsection{Data Analysis}

Since the primary aim of this study was to determine the extent to which TFEQdisinhibition scores reported in the on-line follow-up questionnaire differed to those obtained in Experiment 2 in the pizza-cue condition, a within-subjects t-test was used to compare these two scores As a simple check of reliability, this test was also performed for the other two conditions (no-cue and pizza-cue condition).

\subsubsection{Results}

\subsubsection{Participant characteristics}

Thirty-one of the partıcipants who had previously partıcıpated in Experiment 2 had left the university Therefore, the questionnaire was received by 89 participants from the sample Sixty-five of these responded; 19 in the no-cue condition, 26 in the chip-cue condition, and 20 in the pizza-cue condition These respondents did not differ significantly from non-respondents in their TFEQ-disinhibition scores $(t=-$ $0370, d f=118, p=0.718)$, or in their DEBQ-restraint scores $(t=-1.61, d f=118, p$ $=0.110)$ reported in Experiment 2, or in their BMI $(t=-1.27, d f=118, p=0.207)$ (see Table 3.10 for means). 
Table 310 Means and standard deviations for participant characteristics (TFEQdisinhibition scores, DBEQ-restraint scores, and BMI)

\begin{tabular}{llclc}
\hline & \multicolumn{2}{c}{$\begin{array}{c}\text { Non-respondents } \\
(\mathrm{n}=24)\end{array}$} & \multicolumn{2}{c}{$\begin{array}{c}\text { Respondents } \\
(\mathrm{n}=65)\end{array}$} \\
\cline { 2 - 5 } & Mean & SD & Mean & SD \\
\hline TFEQ-disinhibition scores & 736 & 316 & 758 & 339 \\
DEBQ-restraint scores & 257 & 072 & 282 & 086 \\
BMI & 2299 & 374 & 2384 & 358 \\
& & & & \\
\hline
\end{tabular}

\subsubsection{TFEQ-disinhibition scores}

TFEQ-disinhibition scores were not found to be significantly different at follow-up for participants who had been assigned to the pizza-cue condition in Experiment 2 ( $t$ $=1.696, d f=19, p=0.109)$, or who had been assigned to the chip-cue $(t=0491, d f$ $=25, p=0629$ ), or to the no-cue, condition ( $t=0629$, $d f=18, p=0.537$ ) (see Table 311 for means). In fact, rather than being lower, disinhibition scores in the pizza-cue condition were in fact marginally higher at follow-up, albeit this increase was not statistrcally significant.

Table 311 TFEQ-disinhibition scores obtained via emall and in expertment 2, separately, for each condition (no-cue, pizza-cue, chip-cue)

\begin{tabular}{lllll}
\hline & $\begin{array}{l}\text { TFEQ-disinhibition score obtained } \\
\text { at follow-up }\end{array}$ & $\begin{array}{l}\text { TFEQ-disinhibition } \\
\text { expenment 2 }\end{array}$ & score from \\
\cline { 2 - 5 } & Mean & SD & Mean & SD \\
\hline No-cue & 7.74 & 078 & 742 & 306 \\
Pizza-cue & 1000 & 367 & 890 & 364 \\
Chip cue & 685 & 352 & 658 & 304 \\
\hline
\end{tabular}




\subsubsection{Discussion}

The present investigation re-examined the disinhibition scores of participants from Experiment 2 to determine the extent to which these scores were consistent with these reported in Experiment 2 The findings suggested that the disinhibition scores of participants assigned to the pizza-cue condition were not significantly different at follow-up, albeit the trend was for these scores to be marginally higher. On the basis of these findings, one can conclude, therefore, that the relatively high disinhibition scores reported in Experiment 2 in pizza-cue condition were a result of a random sampling error, rather than as a result of being exposed to pizza. The results of this re-test are also important because they highlight the re-test reliability of the disinhibition scores in the specific samples used for the research undertaken in this thes1s

\subsection{Chapter Summary}

Experiments 1 and 2 primarly sought to explore the extent to which food-cue reactivity is more closely associated with a tendency to disinhibit, rather than dietary restraint per se. In Experıment 1, using a basic cue reactivity paradigm, participants were exposed to the sight, and to the smell, of pizza for three minutes. Cue reactivity was then assessed using measures of subjective appetite and $a d-l l b$. intake. This experiment provided little evidence to suggest that food-cue reactivity was associated with dietary restraint. By contrast, individuals with high disinhibition scores were found to experience greater increases in craving after cue exposure than individuals with lower scores on this scale However, these individuals were not found to consume larger amounts of this food. One possible explanation for these inconsistent findings was that the measure of $a d-l ı b$ intake used in Experiment 1 lacked the sensitivity to detect differences in intake across disinhibition scores For this reason, Experiment 2 utilised an improved measure of $a d-l l b$ intake. The expenment was no longer disguised as a taste test and pizza was presented in bite-size pieces rather than in slices Yet, despite these changes, again 
there was little evidence of elevated food intake in individuals with high disinhibition scores after cue exposure Furthermore, in this experıment these individuals were not even found to expenence greater craving for the cued foods. 


\section{CHAPTER 4}

\section{IMPLICATIONS OF FOOD-CUE REACTIVITY FOR EVERYDAY PORTION-SIZE SELECTION}

\subsection{Chapter overview}

This chapter presents the findings from Experiment 3. The primary aim of this experiment was to consider the possibility that individuals who show elevated sensitivity to food cues in the laboratory consume larger amounts of food within therr everyday lives. To explore this possibility, associations between measures of food-cue reactivity and everyday portion-size selections were assessed. A secondary issue considered in this experiment was the extent to which food-cue reactivity is associated with measures of everyday dietary behaviour (dietary restrant and disinhibition). The remainder of this chapter provides further detalls of the issues addressed in this experment, the methodology apphed, and the observed results.

\subsection{Introduction}

Experiments 1 and 2 sought to determme the extent to which individual differences in dietary restraint and disinhibition can predict food-cue reactivity. Following from these expermments, the present experiment aimed to identify another characteristic which might explain variation in this reactivity to food cues. Specifically, this experiment sought to determine the extent to which greater food-cue reactivity in the laboratory is associated with the selection of larger everyday portion sizes Indeed, given that exposure to the sight and smell of food can increase food intake (e g., Fedoroff et al , 1997; 2003), and that this effect is more pronounced in some individuals (e g, Collıns, 1978; Rogers \& Hill, 1989), there is reason to suspect that 
greater sensitivity to food cues might be associated with greater everyday food consumption. To assess this possibility in this experiment, subjective and behavioural markers of cue reactivity were assessed in the laboratory, and compared with a measure of everyday portion-size selection It was hypothesised that those individuals who select larger everyday portions experience greater sensitivity to food cues (Hypothesis 1).

A secondary issue considered in this experiment was the extent to which food-cue reactivity is associated with measures of everyday dietary behaviour (dietary restraint and disinhibition). Again this was explored by comparng markers of foodcue reactivity in the laboratory with these dietary measures. As in Experiments 1 and 2, it was hypothesised that food-cue reactivity would be more closely associated with dietary disinhibition rather than restraint status (Hypothesis 2) Specifically, it was hypothesised that those individuals with high disinhibition scores would expenence greater cue reactivity than those individuals with lower disinhibition scores. By contrast, it was expected that restrained eaters would not expenence any greater cue reactivity than unrestrained eaters.

Food-cue reactıvity was assessed in this experiment using a methodology similar to that used in Experiments 1 and 2. However, the methodology adopted here sought to address concerns that the measure of intake used in Experiments 1 and 2 might have compromised ecological validity. In Experiments 1 and 2, desired food consumption after cue exposure was assessed using a measure of $a d-l l b$ intake This measure was chosen because it has previously been used to determine the effect of cue exposure on food intake (e g, Cornell et al , 1989, Fedoroff et al., 1997, 2003; Rogers \& Hill, 1989). However, measures used in the context of the laboratory should be able to explain behaviour outside the laboratory Yet, outside the context of the laboratory there are very few occasions when we are offered $a d-l l b$ access to food and able to eat as much or as little as we like. Rather, in these circumstances it is more typical for the size of a meal to be selected before a meal commences. This is because, we tend to pre-select an amount of food before preparing the food to eat, or select a portion size for consumption within a restaurant or a fast food 
establishment. These portion-size selections then dictate the amount of food that we consume (Dilibertı, et al , 2004; Rolls et al, 2002; Rolls et al 2004;). For this reason, it might be more relevant to explore the effect of food-cue exposure on portion-size selection of a cued food Thus, in Experiment 3, a measure of desired portion size replaced the measure of $a d-l y b$ food intake.

\subsection{Method}

\subsubsection{Overview}

In Experiment 3 a paradigm similar to that used in Experiments 1 and 2 was employed Thus, at the outset participants were offered a buffet-style lunch to ensure they were non-food depnved Following this, they entered an exposure phase where they were exposed to the sight and smell of pizza for three minutes. Both before and after this, they provided reactivity measures. In this experiment these included conventional appetite ratings used in Experiments 1 and 2, and a novel measure of portion-size selection as described in the preceding section. Following the procedure used in Experment 2, this expenment was disguised as a study exploring the relationships between appetite and mood.

\subsubsection{Design}

Contrary to Experiments 1 and 2, Experiment 3 did not include a no-cue condition This is because findings from Experiments 1 and 2 suggested that it is potentially difficult to achieve a truly non-cued condition since all participants might become prumed by the sight of the food in the $a d-l i b$. intake phase. Although Experiment 3 did not incorporate a measure of $a d-l l b$. intake per se, the inclusion of a measure of portion-size selection of the cued food required participant's to view the food in order to judge the portion size they would like to eat. Thus, the mere sight of pizza in this portion-size selection phase might cue appetite for pizza even in the absence of prior cue exposure For this reason, given that this was an initial attempt to 
explore the effect of cue exposure on desired portion size of the cued food, it was decided that all participants would be assigned to a pizza-cue condition. Therefore, all participants were primed with the sight and smell of pizza. This design allowed associations between the independent variables (everyday portion-size selection, dietary restraint, and dietary disinhibition) and the measures of cue reactivity (changes in subjective appetite for pizza, and portion-size selection) to be assessed across a group of individuals who had been cued with pizza.

\subsubsection{Participants}

Thirty participants were recruited from the population of female undergraduate students at Loughborough University $(\mathrm{UK})$ (mean age $=19.30, \mathrm{SD}=425$ ). These participants were recruited by emall and were financially reimbursed (5 sterling pounds). The decision to recruit 30 participants for this experiment was motivated by the fact that the experiment essentially involved only one condition. Following from Fedoroff et al's $(1997,2003)$ work, decisions regarding sample sizes in the experiments presented thus far in this thesis relied on their prnciple of approximately $30-40$ particıpants per condition

\subsubsection{Measures}

\section{Cue reactivity}

Again, hunger, and fullness, and craving for, and desire to eat, the cued food (pizza) were measured using 100-mm visual analogue ratıng scales (see Chapter 3 for details of these scales). Given that this was an initial attempt to explore the effect of food-cue exposure on desired portion size and its association with everyday portionsize selections, only measures of appetite (subjective, and portion size selection) for the cued food were included.

To obtain a measure of desired pizza portion size after cue exposure, participants were presented with a $420 \mathrm{~mm} \times 594 \mathrm{~mm}$ sheet of card. The card had a diagonal line running from the bottom left to the top right hand corner, and participants were told that the corner of their selected portion size should intersect this line (examples of 
this were provided) (see Appendix D for a picture of this card) Using the pizza presented during the exposure phase as a model, the participants were asked to select the amount of pizza that they would like to eat at that time The area of this selected portion size was then calculated.

\section{Everyday portion size}

To obtain a measure of everyday portion size, participants were shown sets of eight photographs, each set depicted a commonly consumed food (Nelson, Atkınson, \& Meyer, 1997). The series of pictures contained portion sizes ranging from the $5^{\text {th }}$ to $95^{\text {th }}$ centıle on a distribution of portion sizes observed in The Dietary and Nutritional Survey of British Adults (Gregory, Foster, Tyler, \& Wiseman, 1990) Participants were asked to use these photographs to indicate the amount of food that they typically consume. They were told that if the amount of a food corresponded exactly with the amount depicted in one of the pictures, then they should put a cross through the corresponding number on the scale However, if the amount was slightly larger or smaller then they should indicate this by placing a cross to the left or right of the corresponding number. This response was recorded using a 9-point visual analogue scale anchored with the numbers 0 and 8 . In total, nine foods were presented in this way (pasta, cornflakes, chocolate cake, potatoes, beans, lasagne, spaghettı bolognaise, chips, and cheesecake). A measure of everyday portion size was then defined as the average portion-size selection for these foods.

\section{Dietary restraint and disinhibited eatıng}

Measures of dietary restraint and disinhibition were measured in the same way as described in Experıments 1 and 2 (see Chapter 3)

\section{Awareness Questlonnaire}

An awareness questionnaire was 1ssued at the end of the experiment to ensure that participants were not aware of the alms of this experiment This questionnaire asked 1) what do you think was the purpose of this experiment? 11) I asked you to rate your mood and appetite twice durng the experiment. Do you know why? iii) In this experiment I asked you whether you would want to eat pizza and how much. Do you know why? These questions were displayed on separate sheets of paper and 
participants were instructed to turn to the next page only when their answer to the previous question was complete.

\subsubsection{Procedure}

Before arriving at the laboratory the participants were told that the aim of the experıment was to explore the relationship between 'appetıte and mood.' They were also told that they would have to rate their mood throughout the experiment and that they would be asked to offer an opinion on vanous foods. Finally, they were told that they would receive a buffet lunch.

Participants were scheduled for a 60-minute session between 11 am and 3pm. All were instructed to refrain from eating for three hours prior to the onset of the experiment. On arrival, participants gave written consent for their participation. Following this, they were presented with a buffet lunch and were asked to eat until they felt 'comfortably full.' The items that comprised this buffet lunch were 1dentıcal to those used in Experiment 2. After lunch, partıcıpants provided hunger and fullness ratıngs, and rated their appetite (desire to eat, and craving) for the pizza (pre-exposure appetite ratıngs) Consistent with the cover story, this initial set of measures also included a number of ratıngs relating to their current mood.

The participants were then exposed to the sight and smell of cooked pizza for three minutes. The pizza was presented in a rectangle slice, and weighed $300 \mathrm{~g}(810 \mathrm{kcal})$. It was placed on a table directly in front of the participant. Durng this exposure phase, participants were instructed to sit and wait until the experimenter returned. After exposure, the participants provided a second set of appetite ratıngs, and provided their portion-size selection of pizza. Following this, the participants completed measures of dietary restraint and disinhibited eatıng, and recalled their everyday portion size of nine commonly eaten foods. Finally, participants completed an awareness questionnaire. 


\subsubsection{Data analysis}

In Experiment 3, a measure of desired pizza size, and measures of subjective appetıte (hunger, fullness, desire-to-eat pızza, and craving for pızza) were obtained. Initially it was desirable to assess the descriptive statistics (means and SD's) for these measures and to assess the general effect of cue exposure on subjective appetite by companng pre- and post-cue exposure measures using within-subject $t$ tests. In addition to this, in this prelıminary part of the analyses it was desirable to calculate the descriptıve statıstıcs for partıcıpant characterıstics (dietary restraint, disinhibition, and everyday portion-size selection), and to calculate a series of Pearson Correlation Coefficients to assess the associations between each of these variables.

Following the prelıminary analyses, for each measure of subjective appetite, a change score was derived from the difference between the measure of reactivity before and after cue exposure. To determine the extent to which these change scores were associated with dietary restraint, disinhibition, and average everyday portion size, separate regression analyses were used. In each of these regression models the corresponding pre-exposure appetite ratıng was controlled for statıstically for each of the change scores by enterng the relevant pre-exposure vanable as a covariate into the model. To determine the extent to which any differences in subjective appetite across disinhibition scores were modulated by restraint status, further regression models were conducted for disinhibition scores which controlled statıstically for restraint status by entering it as a covariate into the model.

To determine the association between desıred portion size of pizza after cue exposure and the three measures of everyday dietary behaviour, a senes of simple Pearson's correlations were calculated. Again, for disinhibition, it was desirable to explore these associations after controlling for dietary-restraint scores. Accordingly, the association between these scores and portion-size selection was assessed in a second analysis using linear regression and controlling statıstically for restraint scores 


\subsection{Results}

\subsubsection{Participant characteristics}

Table 41 Mean and standard deviations for participant characteristics

\begin{tabular}{llll}
\hline & $\mathrm{n}$ & Mean & SD \\
\hline Characteristic & & & \\
BMI & 30 & 2272 & 249 \\
TFEQ-disinihibition score & 30 & 760 & 340 \\
DEBQ-restraint score & 30 & 281 & 086 \\
Everyday portion size & 30 & 567 & 088 \\
\hline
\end{tabular}

Means and SD's for each of the participant characteristics are summansed in Table 4.1 It was desirable to determine the extent to which the dietary measures (dietary restraint, disinhibition, and everyday portion size) were associated with each other. Thus, a series of Pearson's correlation coefficients were calculated. This analysis suggested that average everyday portion size was significantly associated with disinhubition scores $(r=0.464, p=0010)$, suggesting that individuals with higher disinhibition scores do report consuming larger amounts of food in their everyday lives However, in contrast to this, there was little evidence to suggest that individuals with high restraint scores select larger everyday portion sizes $(r=0.074$, $p=0697$ ). Furthermore, higher restraint scores were not significantly associated with higher disinhibition scores $(r=0168, p=0.376)$

\subsubsection{Baseline measures}

To eliminate the possibility that subjective appetite (hunger, fullness, desire-to-eat pızza, and craving for pizza) pror to cue exposure differed across the dietary measures, Pearson's correlation coefficients were calculated for each of the baseline measures of subjectıve appetite and each of the dietary behaviours. These analyses suggested that levels of fullness, hunger, desire-to-eat pizza, and craving for pizza 
did not differ significantly across disinhibition scores, or the measure of everyday portion size (all $p>005$ ) However, this analysis did suggest that restraned eaters had greater levels of hunger than unrestrained eaters prior to cue exposure $(r=$ $0.381, p=0038$ ) Thus, one possibility is that any greater reactivity observed in these individuals might result from this elevated hunger For this reason, it was decided that in circumstances where associations were observed between dietary restraint and measures of food-cue reactivity, hunger would be entered as a covariate into the regression model to determine whether the associations remained statıstıcally sıgnificant after controlling for these differences in baseline hunger.

\subsubsection{Descriptive statistics for measures of cue reactivity}

As suggested above it was initially desirable to explore the descriptıve statıstics for the measures of cue reactivity across the three conditions. The means and standard deviations for pizza intake after cue exposure and appetite ratıngs before and after cue exposure are therefore summarised in Table 4.2. The results of withın-subject ttests used to compare the measures of subjective appetite from before to after cue exposure are also shown. These findings suggest that levels of hunger and craving for pizza increased significantly after cue exposure (Table 4.2). By contrast, levels of fullness and desire-to-eat pizza were not significantly affected by cue exposure (Table 4.2). 
Table 42 Within-subject t-tests, means, and standard deviatons, for pre-exposure, and post-exposure, measures of cue reactivity

\begin{tabular}{|c|c|c|c|c|c|c|c|}
\hline & \multicolumn{3}{|c|}{ Pre-exposure } & \multicolumn{2}{|c|}{ Post-exposure } & \multicolumn{2}{|c|}{$\begin{array}{l}t \text {-value and } \\
\text { significance }\end{array}$} \\
\hline & $n$ & Mean & SD & Mean & $\mathrm{SD}$ & $t$ & $\bar{P}$ \\
\hline Hunger (mm) & 30 & 843 & 1090 & 1180 & 1454 & 236 & $0025 *$ \\
\hline Fullness (mm) & 30 & 7043 & 2352 & 6483 & 2483 & -102 & 0317 \\
\hline Desire-to-eat pizza $(\mathrm{mm})$ & 30 & 1227 & 1674 & 1653 & 2154 & 1454 & 0157 \\
\hline Craving for pizza (mm) & 30 & 607 & 897 & 1460 & 2158 & 262 & $0014^{*}$ \\
\hline $\begin{array}{l}\text { Pizza portion } \mathrm{mm}^{2} \\
(\mathrm{kcal})\end{array}$ & 30 & - & - & $\begin{array}{l}685212 \\
(18501)\end{array}$ & $\begin{array}{l}520920 \\
(14064)\end{array}$ & - & - \\
\hline
\end{tabular}

* denotes $p<005$

\subsubsection{Cue reactivity and everyday portion-size selection (Hypothesis 1)}

After controllıng for the relevant pre-exposure ratıngs, exposure to pizza was not found to stimulate greater feelıngs of hunger, desire-to-eat pizza, craving for pizza, or to significantly reduce feelings of fullness in individuals who recalled consuming larger everyday portion sizes (Table 4.3) However, after bnef exposure to pizza, individuals who typically consume larger everyday portion sizes desired larger portions of pizza ( $r=0521, p=0003)$ (these results are not shown in a table here) Using the parameter estimates from a regression model used to predict desired pizza portion after cue exposure from everyday portion size, the number of Kcalones an individual with a small (2.89), medium (3.73), and large (4.80), average everyday portion size (calculated as the average value in each tertile of the data) might consume after cue exposure was predicted. As Figure 4.1 suggests the number of Kcalories in the portion of pizza selected by individuals who on average consume the largest everyday portion sizes more than doubled compared to the portion size selected by individuals who on average select small everyday portion sizes 
Table 43 Adjusted $^{1}$ parameter estimates from linear regression models of associations between the three measures of dietary behaviour (TFEQ-distnhibition score, DEBQrestraint scores, and everyday portion stze) and change in generaltsed measures of appetite (hunger and fullness), and change in appetite (craving and desire to eat) for pizza

$n$

$B \quad S E \quad p$

\section{DEBQ-restraint scores}

$\begin{array}{llcll}\text { Change in hunger } & 30 & 1589 & 2000 & 0434 \\ \text { Change in fullness } & 30 & 2.196 & 6613 & 0742 \\ \text { Change in desire-to-eat pizza } & 30 & -5806 & 3084 & 0070 \\ \text { Change in craving for pizza } & 30 & -0363 & 4033 & 0929\end{array}$

\section{TFEQ}

Change in hunger

Change in fullness

Change in desire-to-eat pizza

Change in craving for pizza

\section{Everyday portion size}

\section{Change in hunger}

Change in fullness

Change in desire-to-eat pizza

Change in craving for pizza

$\begin{array}{llll}30 & 0.387 & 0474 & 0422 \\ 30 & -3422 & 1.527 & 0034^{*} \\ 30 & 1337 & 0767 & 0093 \\ 30 & 2324 & 0897 & 0015^{*}\end{array}$

* denotes $p<005$

${ }^{1}$ Adjusted for pre-exposure ratıngs 


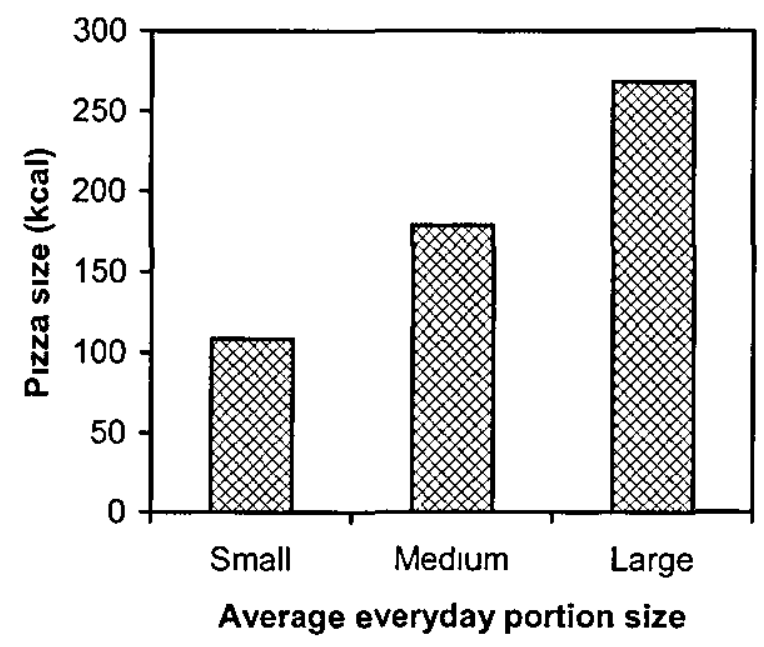

Figure 41 Predicted portion size of pizza in Kcalories (kcal) after cue exposure for individuals ho report consuming small (2 89), medium (3 73), and large (4 80), everyday portion sizes estimated using the everyday portion-size selection parameter estimate $(B=$ $309601)$ from the linear regression models for predicted portion size of pizza after cue exposure

\subsubsection{Cue reactivity, dietary restraint, and TFEQ-disinhibition scores} (Hypothesis 2)

After controlling for pre-exposure ratıngs, there was little evidence to suggest that change in hunger, fullness, desire to eat pizza, or craving for this food, were greater in individuals with higher restraint scores (Table 4.3) Furthermore, dietary restraint was unrelated to desired pizza-size $(r=009, p=0648)$ (these results are not shown in a table here), suggestıng that dietary restraint status shares little relationship with food-cue reactivity.

With regards to the association between disinhibition and food-cue reactivity, although disinhibition scores were unrelated to changes in hunger and desire-to-eat pizza (Table 4.3), they were significantly associated with a reduction in feelings of fullness, and an increase in craving for pizza (Table 4.3), even after controlling for dietary restraint scores (both $p<005$ ). Most 1mportantly, these scores were also associated with the selection of larger pizza sizes after cue exposure $(r=0.42, p=$ 
0020 ) (these results are not shown in a table here) and this was even the case after statistically controlling for restraint status $(B=64552, S E=270.85, p=0024)$ Again, using the parameter estımates from a regression model used to predict ideal portion size for disinhibition scores and controlling for restraint scores, the number of Kcalones an individual with a low (3.8), medium (77), and high (11.3), disinhibition score (calculated as the average value in each tertile of the data) might desire after cue exposure were predicted. These are shown in Figure 4.2. Visual inspection of this figure suggests that an individual with a high disinhibition score would be likely to consume over $100 \mathrm{kcal}$ more than an individual with a low disinhibition score after exposure to a food cue while non-food deprived

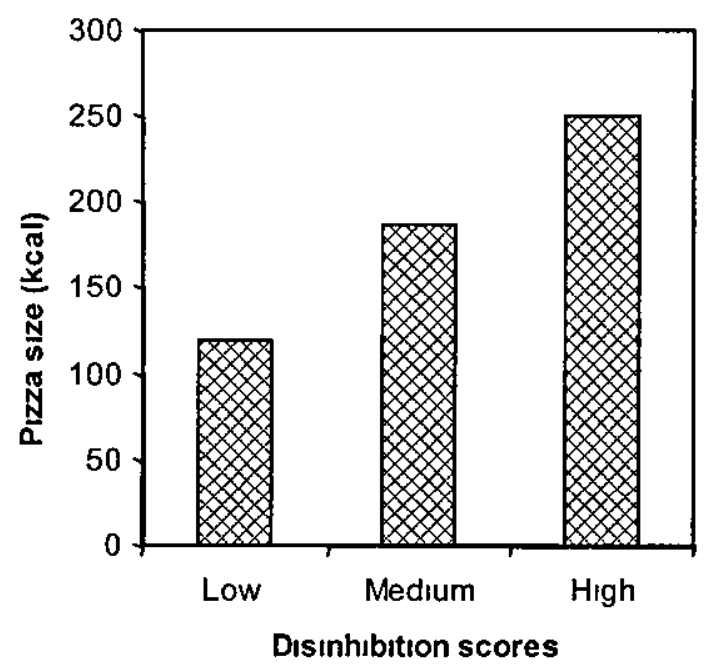

Figure 42 Predicted pizza size in Kcalories (kcal) after cue exposure for individuals with low (3 8), medium (7 7), and high (11 3), disinhibition scores estimated using the parameter estimate $(B=64969)$ from linear regression models for pizza portion size ${ }^{9}$

\footnotetext{
${ }^{9}$ In this model restraint scores were held at their mean value in the sample $(281)$ and the parameter estimate associated with restraint scores was included $(B=9806)$
} 


\subsubsection{Awareness questionnaire}

Following Experiment 2, in this expermment an awareness questionnare was administered at the end of the study to determine the extent to which the results observed could be attributed to an awareness of the aims of the study. The responses to this questionnaire are summarised in Table 44 . These responses suggest that the majority of the participants did not correctly guess the purpose of the study. Rather, most participants believed the cover story and suggested that the experiment was exploring the relationship between appetite and mood. However, a relatıvely small percentage $(167 \%)$ of the partıcipants guessed that appetite ratıngs were taken to explore the effect of exposure to pizza on appetite for this food A similar percentage $(20 \%)$ also guessed that portion-size selection was measured to determine the extent to which this exposure phase increased the amount of this food that participants wanted to eat. To determine the extent to which awareness of the study's interest in the effect of cue exposure on appetite ratings affected changes in these measures after cue exposure, regression analyses were used to explore associations between awareness of this aim and changes in subjective appetite. In this analysis the relevant pre-exposure ratings were controlled for by entering them as a covarnate into the analysis. To determine the extent to which awareness of the study's interest in the effect of cue exposure on desired portion size of pizza affected portion-size selections, between-subject t-tests were used to compare desired portion size in aware, and non-aware, participants All analyses provided little evidence to suggest that awareness of these aims predicted change in desired portion size of pizza, or changes in subjectıve appetıte (all $p>0.05$ ). Finally, to eliminate the possibility that awareness of the study aims did not account for the individual differences in cue reactivity observed, Pearson's correlation coefficients were calculated to determine the extent to which this awareness differed across the predictor vanables (dietary restraint, dietary disinhibition, and everyday portion-size selection). Again, this provided little evidence to suggest that awareness differed across the dietary measures (all $p>0.05$ ) 
Table 44 Summary of responses to the awareness questionnatre All total are given in percentages

\begin{tabular}{llc}
\hline \multicolumn{1}{c}{ Question } & \multicolumn{2}{c}{ Response (\%) } \\
\cline { 2 - 3 } & Aware & Not aware \\
\hline 1 What do you think was the purpose of this & 67 & 933 \\
experiment? & & 833 \\
2. I asked you to rate your mood and appetite twice & 167 & 80 \\
during the experiment. Do you know why? & \\
3 In this experiment I asked you whether you would & 20 & \\
want to eat pizza and how much Do you know why? & & \\
\hline
\end{tabular}

\subsubsection{Summary of results}

The aim of this section is to provide a summary of the significant associations observed in this experiment These associations are summarısed in Table 4 5. Visual inspection of this table suggests that dietary restraint shared little association with any of the outcome variables. Rather, it suggests that dietary disinhibition, and a measure of everyday portion-size selection might be associated with greater foodcue reactivity. Specifically, dietary disinhibition was associated with a greater reduction in fullness, greater increase in craving for pizza, and a greater increase in desired portion size of this food Likewise, the selection of larger everyday portion sizes was significantly associated with a greater change in desired portion size of pizza 
Table 45 Summary table to show the significant associations between the outcome variables and the predictor variables

Predictor variables

Restraint Disinhibition Everyday portion

size

Outcome measures

Change in hunger

Change in fullness

Change in desire-to-eat pizza

Change in craving for pizza

Change in desired pizza portion

Denotes where statıstically sıgnificant interactions were observed

\subsection{Discussion}

This experiment prediction that individuals who show elevated sensitıvity to food cues in the laboratory consume larger amounts of food within their everyday lives (Hypothesis 1) Consistent with this prediction, the results suggested that individuals who reported consuming larger everyday portion sizes selected the largest portions of pizza after cue exposure. Given that differences in awareness of the study arms, or in appetite for the cued food at the outset cannot explain these differences, it is important to consider potential explanations for this association. Perhaps the most obvious possibility is that those participants who reported consumıng the largest portion sizes within their everyday lives were unaffected by cue exposure in this experiment and were simply behaving in a similar way in the laboratory as they do in their everyday lives by selecting the largest portion sizes. In other words, the fact that these individuals had been cued by pizza was perhaps irrelevant. Indeed, it is possible that these individuals would have selected these larger portion sizes of the cued food even in the absence of this cue exposure.

Notwithstanding the possibility offered above, there are at least two other potential explanations for this observed association. One possibility is that the tendency to consume larger amounts of food after food-cue exposure in fact contributes to 
greater everyday portion-size selection, and for this reason an association was observed in this experment between desired portion stze of a cued food and everyday portion-size selection Consistent with this possibility, there have been speculations that food-cue reactivity might be responsible for overeating (Wardle, 1990) A second explanation is that the consumption of larger everyday portion sizes causes greater sensitivity to food cues, and for this reason the association reported here exists. This might occur as greater food intake, which occurs for whatever reason, becomes paired with environmental cues in a form of Pavlovian conditioning (Pavlov, 1927) Following this, subsequent presentation of these cues might reinforce the desire to consume greater amounts This explanation is based on the view taken by Jansen (1998) to explain food-cue reactivity in binge eaters. Jansen (1998) suggests that environmental cues become parred with consumption of largcr amounts of food during a binge episode. Therefore, subsequent exposure to these cues reinforces binge eating. According to this explanation, the present findings could suggest that food-cue reactivity might not initrally cause the consumption of larger everyday portion sizes, but rather might serve to maintain this tendency to consume larger amounts of food. Therefore, even according to this view, food-cue reactivity might be assumed to play an important role in overeating.

Notably, the basic premise of the two latter explanations offered here for the association between desired portion size of a cued food and everyday portion-size selections rely on the assumption that larger desired portion sizes of pizza were the direct result of food-cue exposure However, by not observing desired portion-size selection in the absence of cue exposure, it is impossible to determine whether the selection observed after pizza-cue exposure was in fact a result of this cue exposure. For this reason, it is impossible to eliminate the initial possibllity offered here suggesting that individuals were unaffected by cue exposure and were merely behaving in the same way they do outside the laboratory by selecting larger portion sizes Some support for this possibility comes from the fact that these individuals were not found to report significantly greater changes in subjective appetite after cue exposure. Thus, suggesting that these individuals appetite might not in fact have been affected by cue exposure Given the importance of this issue for our understanding of the association between food-cue reactivity and everyday portion size, it is considered further in Experiment 4. 
A secondary issue considered in this experiment was the extent to which food-cue reactivity is associated with measures of everyday dietary behaviour (dietary restraint and disinhibition) (Hypothesis 2). The results suggested that changes in subjective appetite, and desired pizza size, after cue exposure were not significantly associated with dietary-restraint status, despite the fact that restrained eaters were hungner prior to cue exposure than unrestrained eaters. These findings are in part consistent with the results reported in Experiments 1 and 2 In both these experiments, dietary restraint scores were also found to share little association with food-cue reactivity. Yet, it is important to note that the results reported here differ slightly to those reported in Experiment 1 This is because, in Expenment 1, restrained eaters were also found to inhibit their food intake after food-cue exposure Yet, the findings from the present experiment, and those presented in Experiment 2, have failed to replicate this finding. ${ }^{10}$ In these experiments, restrained and unrestrained eaters were not found to desire significantly different amounts after cue exposure irrespective of whether this was measured via $a d-l, b$ intake or using a measure of desired potion size Notwithstanding this modest difference between the findings reported here and those reported in Experiment 1, the importance of the results from the present experment is that again they dispute previous claims that dietary restraint presents a risk factor for greater reactivity to food cues.

Notably, in this thesis it was in fact hypothesised that food-cue reactivity might not be associated with an independent measure of dietary restraint (Hypothesis 2). This was because associations between dietary restraint and food-cue reactivity have been reported using a measure of restraint which conflates dietary restriction with disinhibited eating and weight fluctuation For this reason, it was predicted that heightened sensitivity to the effects of food-cue exposure on appetite might be associated with a measure of disinhibition (Hypothesis 2) Consistent with this hypothesis, the present findings suggest that the TFEQ-disinhibition scale shares an association with food-cue reactivity. Notably, disinhibited eaters were found to expenence greater food-cue reactivity irrespective of their restraint status.

\footnotetext{
${ }^{10}$ Potentıal reasons for this were highlighted in Experıment 2 and will not be discussed further here
} 
Restrained and unrestrained individuals with high disinhibition scores experienced a greater change in craving for pizza after cue exposure, and selected larger portions of this food.

Since individuals with high disinhibition scores were not found to differ in their appetite pror to cue exposure and did not have a greater awareness of the aims of the experiment than individuals with lower disinhibition scores, it seems reasonable to assume that greater reactivity observed in these individuals was in fact linked to their higher disinhibition scores However, understanding why dietary disinhibition might be associated with greater food-cue reactivity is relatively difficult. This is because it is not enturely clear what the disinhibition scale measures. Onginally, this scale was defined by Stunkard \& Messick (1985) as a measure of 'disinhibition of control ' More recently, it has been referred to as an 'overeating scale' (Brunstrom et al., 2005), a scale which assesses 'susceptibility to eating problems' (Westenhoefer et al, 1994), and a measure of 'uncontrolled eatıng' (de LauzonGullain, Basdevant, Romon, Karlsson, Borys, \& Charles, 2006). Exploration of the items on the scale suggests that one possibility is that it measures a susceptrbility to external triggers which promote food intake These triggers might be social situations, emotional states, or external food cues Therefore, individuals who obtain high scores on the disinhibition scale are likely to be unable to resist the temptation to eat offered by these cues. For individuals who obtain low scores on this scale some element of self-control must enable the temptation elicited by these external triggers to be resisted Indeed, consistent with this, it has been suggested that even non-dieters are likely to exert some self-control over their food intake (Herman \& Polivy, 2005) Based on this discussion, it is possible that in the present experment, disinhibited eaters were unable to resist the temptation offered by the pizza cues, and for this reason reported greater subjective appetite for this food and desired larger portion sizes of 1 t. By contrast, the individuals with lower disınhıbition scores were more likely to have been able to exert some self control in this situation, and for this reason selected smaller portion sizes of the food. 


\subsection{Chapter summary}

The experiment presented in this chapter considered the possibility that individuals who show elevated sensitivity to food cues in the laboratory consume larger amounts of food within their everyday lives The results provided some evidence for an association between everyday portion-size selection and desired portion size of a cued food. However, in the absence of a measure of desired portion of pizza pror to cue exposure, one possibility is that those individuals who typically select the largest portion sizes within their everyday lives were unaffected by cue exposure and behaved similarly in the laboratory as they do in therr everyday lives by selecting larger portion sizes. A secondary issue explored in this experiment was the extent to which food-cue reactivity is associated with measures of everyday dietary behaviour (dietary restraint and disinhıbition). Taken together, the findings suggest that food-cue reactivity shares little association with successful dietary restraint, but is related to a measure of dietary disinhibition. 


\section{CHAPTER 5}

\section{FOOD-SPECIFIC REACTIVITY AND EVERYDAY PORTION- SIZE SELECTION}

\subsection{Chapter overview}

This chapter discusses the fourth experiment in this thesis This experiment was designed primarily to re-consider associations between food-cue reactivity and everyday portion-size selection To improve upon the design used in Experiment 3, in this experiment desired portion-size selection was assessed in both a cued, and a non-cued, context. A secondary issue considered in this experiment was the extent to which food-cue reactivity is also associated with separate measures of dietary restraint and disinhibition. The remainder of this chapter presents details of the rationale, the methodology used, and analysis of the results, for this experiment.

\subsection{Introduction}

The primary aim of the precedıng Experiment (Experıment 3, see Chapter 4) was to determine the extent to which greater food-cue reactivity is associated with the selection of larger everyday portion sizes. The findings of that experiment suggested that the consumption of larger average everyday portion sizes was associated with a desire to eat larger portions of pizza after exposure to this food. However, without knowledge of desired pizza size in the absence of cue exposure, it was impossible to conclude that the desire for a larger portion of pizza in individuals who reported selecting the largest everyday portion sizes was in fact a direct result of pizza-cue exposure This is because it is possible that their desired portion of pizza after cue 
exposure represented the portion that they would select even in the absence of pizza-cue exposure.

In Experiment 3, portion-size selection was not measured in a non-cued context following the conclusions drawn from Experiments 1 and 2. In these experiments, $a d-l l b$ food intake was explored in the absence of cue exposure (no-cue condition) and after three-minute food-cue exposure (food-cue condition). However, it was suspected that the no-cue condition might in fact have become a 'cued condition' in the $a d-l ı b$ intake phase. This is because exposure to the sight and smell of food (as well as perhaps the taste of food) in this phase might have served to cue appetite for pizza. In Experıment 3, it was assumed that participants would be required to view the pizza to judge their desired portion size even in a presumably non-cued context. Thus, following from observations in Expenments 1 and 2 it was suspected that the sight and smell of the pizza in this apparent no-cue condition would be sufficient to cue appetite for this food, thus eliciting another 'cued' condition. On this basis, it was decided that a 'no-cue' condition would not be included in Experiment 3.

However, one possibility which was not considered in this experiment was that rather than viewing the food itself in order to indicate a desired portion-size in a 'no-cue condition,' participants could in fact view a model of this food. Indeed, the purpose of viewing the food is to give the participant an idea of its basic attributes. However, this could in fact be achieved using a food model. The advantage of this would be that the model would not elicit an olfactory cue, and if it was distinct from the food itself except for the basic characteristics, it would also not provide a strong visual cue for this food. Thus, using such models, it would be possible to explore portion-size selections in the absence of food-cue exposure. Following this reasoning, in Experiment 4, it was decided that a green cardboard model of pizza would be used to obtain a measure of desired pizza in the absence of exposure to this food. This model simply conveyed the base/crust of the pizza and gave some indication of the amount of topping on the pizza (see Appendix E for a picture of this) This measure of pizza size in the non-cued context could then be compared to desired pizza size after cue exposure, and the effect of pizza-cue exposure on portion-size selection of this food could be determined. Using this improved measure of portion-size selection and conventional measures of subjective appetite 
used in Experiments 1 and 2, this experiment sought to re-explore associations between food-cue reactivity and everyday portion size. Again, it was hypothesised that those individuals who select larger everyday portions will experience greater sensitivity to food cues (Hypothesis 1) As a secondary issue, this experiment also explored associations between food-cue reactivity and measures of everyday dietary behaviour (dietary restraint and disinhibition) Again, it was hypothesised that foodcue reactivity would be more closely associated with dietary disinhibition rather than restraint status (Hypothesis 2). Specifically, it was hypothesised that those individuals with high disinhibition scores would experience greater cue reactivity than those individuals with lower disinhibition scorcs. By contrast, it was expected that restrained eaters would not experience any greater cue reactivity than unrestrained eaters.'

As part of the present experiment, it was desirable to explore the extent to which any differences in motivation to eat across the three dietary measures (everyday portion-size selection, dietary restraint, and disinhibition) were specific to the cued food For example, it was useful to determine the extent to which those individuals who select larger everyday portions relative to those who select smaller everyday portion sizes expenence a greater motivation to eat the cued food, but do not experience a greater motivation to eat the non-cued foods As outlined previously in Chapters 2 and 3, specificity can be explored by determining the effect of food-cue exposure on measures of cue reactivity for both the cued food, and for non-cued foods Thus, in Experıment 4, desired portion-size selectıons and subjective appetite (desire to eat and craving) for pizza, and several other foods (peanuts, chips, garlic bread, chocolate, and chocolate cake), were assessed after brief exposure to the sight and smell of pizza. The non-cued foods were selected on the basis that they differed in the extent to which they would be served alongside the cued food (pizza) withın a meal. To ensure that a non-cued measure of portion-size selections of these food was obtained, participants indicated their portion selections both before and after cue exposure also using models of these foods (see Appendix $E$ for pictures of these foods) 
In previous cue reactivity studies, including those presented in this thesis, little consideration has been given to the potential effect that an individuals liking for a cued food has on their motivation to eat this food. This is surprising given that an individuals predilection towards particular foods must influence the effect that exposure to these food has on these individuals. For this reason, in the present experıment partıcipants likıng for the cued food, and their likıng for the non-cued foods, was measured This was then controlled for in the analyses exploring associations between the three dietary variables (everyday portion-size selection dietary restraint, and disinhıbition) and measures of food-cue reactivity. By doing this, the possibility that any association obscrved could be attributed to differences in likıng for the test food could be elıminated

In summary, using an improved methodology, Experiment 4 re-considered the association between food-cue reactivity and the selection of larger everyday portion sizes. It was hypothesised that those individuals who select larger everyday portions will expenence greater sensitivity to food cues (Hypothesis 1) As a secondary issue, this experiment also considered the relatıonships between food-cue reactivity and measures of everyday dietary behaviour (dietary restraint and disinhibition). Again, it was hypothesısed that food-cue reactivity would be more closely associated with dietary disinhibition rather than restraint status (Hypothesis 2).Unlike the methodology used in Experiment 3, the methodology used in this experiment allowed an assessment of the direct effect of cue exposure on portionsize selection by observing portion-size selection in a cued, and non-cued, context.

\subsection{Method}

\subsubsection{Overview}

Again in this experiment after access to a buffet-style lunch participants were exposed to the sight and smell of pizza for three minutes. Immediately before and after this, they rated their subjective appetite for the cued (przza), and non-cued, foods (chips, garlıc bread, peanuts, chocolate and chocolate cake), and indicated 
their desired portion size of these foods at that moment in time. A key feature of this methodology was that a measure of subjective appetite for the cued, and non-cued, foods was also obtained before and after participants' pre-exposure (baselıne) portion-size selections. These measures were included because it was desirable to ensure that the food models used to make portion-size selections did not cue appetite for these foods Thus, this could be assessed by comparng subjective appetite from before to after cue exposure

The questionnaire phase in this experiment was split across the experiment Participants reported their everyday portion-size selections at the outset pror to the buffet-style lunch, and completed the DEBQ-restrant, TFEQ-disinhibition questionnarre, and awareness questionnaire in the final stages of the experment. The reason the measure of average everyday portion size selection was obtaned at the outset in this experiment was to address the possibility that portion-size selections of the cued, and non-cued, foods made throughout the experment influences partıcipants' recall of therr everyday portion-sıze selections.

\subsubsection{Design}

The design employed in this experiment was a within-subject design Partıcipants provided a measure of subjective appetite, and portion-size selections, for the cued, and non-cued, foods both before and after food-cue exposure.

\subsubsection{Participants}

Thirty participants were recruted from the population of female students at Loughborough University (UK) (mean age $=2057, \mathrm{SD}=2.112$ ) (mean BMI $=$ 22.48, $\mathrm{SD}=2.19$ ) Partıcipants were recruited via emall and received seven pounds (sterling) for their partıcipation.

\subsubsection{Measures}

\section{Cue reactivity}


Hunger and fullness, and craving for, and desire to eat, the cued (pizza) and noncued foods (chips, garlic bread, peanuts, chocolate, and chocolate cake) were assessed using scales identical to those used in Experıment 1 (see Chapter 3)

Desired portion-size estımates were made for each of the non-cued foods before and after przza-cue exposure using a model of this food. For the cued food, pizza, this model was only used before cue exposure This is because after cue exposure partıcipants were able to use the pizza itself in order to judge their desired portion s1ze. These models and detalls of how portion-size selections were made and how they wcre measured are described separately for each food below (For pictures of these models see Appendix E)

\section{Food models}

Pizza was represented using a cardboard model of pizza $(150 \mathrm{~mm} \times 130 \mathrm{~mm} \times$ $32 \mathrm{~mm}$ ) This was identical in shape and size to the slice presented during cue exposure. Participants were told that this model represented a cheese and tomato pizza Using this model as a reference, the participants were asked to select their desired portion of pizza at that moment in time. They indicated this using the sheet of card described in Chapter 4. The area of the selected portion size was then calculated. This sheet of card was also used to measure desired pizza size after cue exposure. However, at this stage the participants were able to use the pizza presented durnng the exposure phase as a reference rather than the cardboard model

Chocolate was represented using a black and white photocopy of a $650 \mathrm{~g}$ bar of Cadbury's chocolate, which merely depicted the gnd-like pattern of a chocolate bar. For this food, participants were simply asked to indicate the number of pieces of chocolate they would like to eat at that time.

Peanuts were represented using silver metal hardware nuts which were presented to participants in a bowl. The partıcipants were asked to place their desired portion size in a smaller bowl which was later weighed 
Chips were represented using 40mm pieces of wood doweling Participants were asked to place their desired portion size on a plate and the amount selected was werghed.

Garlic bread was represented by a hand-drawn bird's eye view and side view of this food. Portion-size selection of this food was calculated by measuring the area of the portion selected on the side-view version.

Chocolate cake was represented using a circular piece of foam (crrcumference $30 \mathrm{~cm}$, depth $10 \mathrm{~cm}$ ) Again, portion-size selection of this food was calculated by measuring the area of the portion selected.

\section{Everyday portlon size}

Everyday portion-size selections were assessed using the same method as in Experiment 3. However, in this experiment partıcipants were asked to recall their typical portion sizes for a greater number of foods. These included the foods used in Experiment 3 (pasta, cornflakes, chocolate cake, potatoes, baked beans, lasagne, spaghettı bolognatse, chips, and cheesecake), and several new foods (sponge pudding, roast beef, battered fish, carrots, frutt salad, and quiche). By broadening the range, and number, of foods that comprised the measure of participant's average everyday portion size, it was assumed that this measure would provide a more valid assessment of participant's everyday portion size. This is because increasing the number of foods comprising the measure of average measure of everyday portion results in a more accurate reflection of a participants everyday portion size.

\section{Dietary restraint and disinhibited eating}

Again, these dietary behaviours were assessed using the restraint section of the Dutch Eating Behaviour Questionnaire (DEBQ; van Strnen et al, 1986) and the disinhibition section of the Three Factor Eatıng Questıonnaire (TFEQ; Stunkard \& Messick, 1985).

\section{Awareness Questionnaire}

An awareness questionnaire was issued at the end of the experment to ensure that participants were not aware of the aims of this experiment. This questionnarre asked 
1) what do you think was the purpose of this experiment? 11) I asked you to rate your mood and appetıte at three points during the experıment. Do you know why? 111) In this experiment I asked you to indicate the amounts of various foods that you would like to eat at that time Do you know why?, iv) I did expect you to want to eat greater amounts of the food than you might normally do at one time point. Which tıme point was this? (first or second), v) I expected you to want to eat greater amounts of food than you might normally do at the second time point. Which food (s)? These questions were displayed on separate sheets of paper and participants were instructed to turn to the next page only when therr answer to the previous question was complete.

\subsubsection{Procedure}

Before arnving to be tested the participants were told that the aim of the experment was to explore the relationship between 'appetite and mood.' They were also told that they would have to rate their mood throughout the experiment, that they would be asked to offer an opinion on various foods, and that they would receive a buffetstyle lunch.

Participants were tested between 11 am and $3 \mathrm{pm}$ All were instructed to refrain from eatıng for three hours pror to the onset of the experıment. On arrival, participants provided a measure of their everyday portion sizes. They were then presented with a buffet lunch which comprised the same items as Experiments 2 and 3, and were asked to eat untıl they felt 'comfortably full.' After lunch, participants provided a set of appetite ratıngs which served as a baselıne measure of subjective appetite prior to pre-exposure portion-size selections Immediately after completing these ratıngs, participants were invited to make their pre-exposure (baseline) portion-size selections. Following this, a second set of appetite ratings were taken These measures allowed exploration of the effects of makıng portion-size selections on appetite, and also served as a pre-exposure (baseline) measure of subjective appetite. Consistent with the cover story, these subjectıve measures of appetite also included a number of ratıngs relating to the participant's current mood. 
The next phase was the cue exposure stage. In this phase, participants were exposed to the sight and smell of cooked pizza for three minutes. The pizza was presented in a rectangle slice, and weighed $300 \mathrm{~g}(810 \mathrm{kcal})$ It was placed on a table directly in front of the participant. Dunng this exposure phase, participants were instructed to sit and watt untıl the experimenter returned. After exposure, the participants provided post-exposure portion-size selections and appetite ratıngs After this, the participants rated their liking for the cued and non-cued foods, and completed measures of dietary restraint and disınhıbited eatıng. Finally, partıcipants completed an awareness questionnaire

\subsubsection{Data Analysis}

In Expenment 4, a senes of cue reactivity measures were obtained before and after pızza-cue exposure. These included general measures of subjectıve appetite (hunger and fullness), measures of subjective appetite (desire to eat and craving) for the cued and non-cued foods, and measures of desired portion size of these foods. As in Expenment 3, preliminary analyses were used to assess the descriptive statistics (means and SD's) for these measures and to assess the general effect of cue exposure on appetite by companing pre- and post-cue exposure measures using within-subjects t-tests In addition to this, preliminary analyses were also conducted to ensure that the use of food models for the pre-exposure measures provided a noncued measure of participants' desired portion sizes To do this, within-subject t-tests were used to compare general subjectıve appette (hunger and fullness) and subjective appetite (desire to eat and craving) for the cued, and non-cued, foods If these food models were providing a non-cued measure, there would be little change in subjectıve appetite. Finally, as part of the prelıminary analyses, descriptive statıstıcs for partıcipant characterıstıcs (dietary restraint, disinhıbition, and everyday portion-size selection) were produced and a series of Pearson Correlation Coefficients were calculated to assess the associations between each of these variables

Following the vanous prelımmary analyses for each of the outcome measures (appetite ratıngs and desired portion sizes), a change score was derived from the 
difference between the measure of reactivity before and after cue exposure To determine the extent to which these change scores were associated with average everyday portion size, dietary restraint, and disinhibition scores, separate regression analyses were used. In each of these regression models liking for the food of interest, and the corresponding pre-exposure ratıng for each of the change scores, was controlled for statistically by entering it as a covarnate into the regression model To determine the extent to which any differences in subjective appetite across disinhibition scores were modulated by restraint status in these analyses, a second series of regression models were conducted for disinhibition scores which controlled for restraint status by entenng it as a covariate into the regression model

\subsection{Results}

\subsubsection{Participant characteristics}

Table 51 Means and standard deviatıons for participant characteristics

\begin{tabular}{llll}
\hline & $n$ & Mean & SD \\
\hline Charactertstic & & & \\
BMI & 30 & 2248 & 219 \\
TFEQ-disinhibition score & 30 & 713 & 346 \\
DEBQ-restraint score & 30 & 282 & 082 \\
Everyday portion size & 30 & 419 & 0.83 \\
\hline
\end{tabular}

Means and SD's for each of the participant characteristics are summansed in Table 5.1. It was desirable to determine the extent to which the dietary measures (everyday portion size, dietary restraint, and disinhibition) were associated with each other. Thus, a series of Pearson's correlation coefficients were calculated. Restrained eaters had significantly higher disinhibition scores $(r=0531, p=$ $0003)$, but did not select significantly larger everyday portion sizes $(r=-0302, p=$ 101) Contrary to the findings from Experiment 3, there was little evidence to suggest that individuals with higher disinhibition scores select significantly larger everyday portion sizes $(r=0.005, p=0.979)$. 


\subsubsection{Baseline measures}

Initially it was desirable to establish that there were no significant differences in hunger or fullness, subjective appetite for the test foods, or portion-size selections across the three dietary measures immediately prior to cue exposure. Pearson's correlation coefficients were calculated for this purpose and provided little evidence to suggest that any of these outcome measures differed significantly across the three dietary measures (all $p>005$ ).

\subsubsection{Descriptive statistics for measures of cue reactivity}

Initially, it was desirable to explore the descriptive statistics for the measures of cue reactivity before and after cue exposure The means and standard deviations for changes in subjective appetite and for portion-size selections for the cued and noncued foods are therefore summansed in Table 5.2 The results of within-subject ttests used to compare the pre- and post-exposure measures are also presented alongside these descriptive statistics. The results suggest that pizza-cue exposure significantly increased participants' ratings of hunger, craving for pizza, and desire to eat this food, and significantly decreased their reported fullness (Table 52 ). It also suggests that it increased participants' craving for peanuts and chips (Table 52 ). By contrast, there was little evidence to suggest that pizza-cue exposure significantly stimulated the selection of a larger portion of pizza, or of the non-cued foods (Table 5.2). 
Chapter 5

Table 52 Within-subject t-tests, means, and standard deviations, for pre-exposure and postexposure subjective appette and portion-size selections

Pre-exposure Post-exposure $t$-value and

slgnificance

\begin{tabular}{|c|c|c|c|c|c|c|c|}
\hline & $n$ & Mean & $\mathrm{SD}$ & Mean & $\mathrm{SD}$ & $t$ & $p$ \\
\hline Hunger & 30 & 1118 & 1180 & 1968 & 1738 & 339 & $0002 *$ \\
\hline Fullness & 30 & 7346 & 1778 & 6686 & 2184 & -306 & $0005^{*}$ \\
\hline \multicolumn{8}{|l|}{ Desire-to-eat } \\
\hline Pizza & 30 & 1360 & 1679 & 3247 & 3168 & 383 & $0001^{*}$ \\
\hline Chocolate & 30 & 3200 & 2808 & 2607 & 2490 & -152 & 0140 \\
\hline Peanuts & 30 & 980 & 1356 & 927 & 1429 & -025 & 0805 \\
\hline Chips & 30 & 1023 & 1412 & 920 & 953 & -048 & 0635 \\
\hline Garlıc bread & 30 & 1090 & 1668 & 1293 & 2190 & 063 & 0531 \\
\hline Chocolate cake & 30 & 2547 & 2611 & 2757 & 2550 & 065 & 0522 \\
\hline \multicolumn{8}{|l|}{ Craving } \\
\hline P1zza & 30 & 1407 & 23.03 & 3357 & 3105 & 318 & $0004 *$ \\
\hline Chocolate & 30 & 2387 & 2591 & 2660 & 2442 & 094 & 0357 \\
\hline Peanuts & 30 & 493 & 832 & 10.13 & 1697 & 255 & $0016^{*}$ \\
\hline Chips & 30 & 580 & 806 & 1057 & 1584 & 236 & $0025 *$ \\
\hline Garlıc bread & 30 & 680 & 14.83 & 763 & 1805 & 033 & 0741 \\
\hline Chocolate cake & 30 & 1893 & 2431 & 2223 & 2381 & 110 & 0279 \\
\hline \multicolumn{8}{|l|}{ Desired portion size } \\
\hline $\operatorname{Przza}\left(\mathrm{mm}^{2}\right)$ & 30 & 503770 & 681757 & 715355 & 643118 & 166 & 0107 \\
\hline Chocolate (pieces) & 30 & 523 & 431 & 463 & 445 & -084 & 0404 \\
\hline Peanuts (g) & 30 & 2753 & 3899 & 2207 & 4311 & -096 & 0343 \\
\hline Chrps (g) & 30 & 1536 & 1898 & 1649 & 2400 & 036 & 0.719 \\
\hline Garlic bread $\left(\mathrm{mm}^{2}\right)$ & 30 & 262000 & 394701 & 300000 & 549909 & 070 & 0489 \\
\hline $\begin{array}{l}\text { Chocolate cake } \\
\left(\mathrm{mm}^{2}\right)\end{array}$ & 30 & 2251.70 & 185098 & 167440 & 394701 & -085 & 0404 \\
\hline
\end{tabular}

* denotes $\mathrm{p}<005$ 


\subsubsection{Effect of food models on subjective appetite}

To substantrate the claim that the food models used in this expermment provided a non-cued measure of participants' desired portion sizes, the effect of these models on appetite was assessed by comparing ratıngs taken from before, to after, initial exposure to these models (1.e., when participants were indicatıng their pre-exposure desired portion sizes). These analyses suggested that being exposed to the food models significantly reduced hunger $(t=-3.78, d f=29, p=0001)$, and did not significantly affect any of the other appetite ratings (all $p>005$ ). This suggests that the food models did not affect appetite, and thereby can be accepted as providing a non-cued measure of portion-size selection.

\subsubsection{Cue reactivity and everyday portion size (Hypothesis 1)}

Average everyday portion-size selection was not significantly associated with a greater change in general measures of subjectıve appetıte (hunger and fullness), or with a greater change in appetite (desire-to-eat and craving) for pizza, or for the non-cued foods (all $p>005$ ). Furthermore, there was little evidence to suggest that changes in desired portion size of pizza, or of the non-cued foods differed significantly across average everyday portion sizes ( all $p>005$ ).

\subsubsection{Cue reactivity, dietary restraint, and disinhibition scores (Hypothesis 2)}

Changes in reported hunger and fullness were not found to differ significantly across restraint scores after pizza-cue exposure (Table 5 3). Furthermore, restrained eaters were not found to report a greater change in subjective appetite (desire to eat and craving), or portion-size selection for pizza, or for the several of the non-cued foods, (chips, garlic bread, peanuts, and chocolate cake) after cue exposure (Table 5.3). However, somewhat unexpectedly, restrained eaters were found to experience a greater change in desire-to-eat chocolate (Table 53 ) Yet, visual inspection of the data for this measure identified an outlier This data point represents a change in 
desire-to-eat chocolate which is 3.32 standard deviations below the mean With this outlier removed, the association between change in desire-to-eat chocolate and restraint scores was not statistically significant $(B=6.74, S E=3.28, p=0050)$.

For individuals with high disinhibition scores, exposure to pizza stimulated a significantly greater change in hunger, but failed to significantly reduce levels of fullness (Table 5 3) It also failed to stımulate a greater desire-to eat pızza, greater craving for this food, or a larger desired portion size in these individuals (Table $53)$. For the majority of the non-cued foods, subjective appetite and desired portion sizes also did not differ across disinhibition scores (Table 53). However, individuals with high disinhibition scores did experience a greater change in desireto-eat chocolate (Table 5.3), even after removal of the outlier associated with this variable (see above) ( $B=1.93, S E=081, p=0.025$ ). Yet, importantly, this association failed to reach statistical significance after controlling statistically for dietary-restraint status both with $(B=1.48, S E=120, p=0.190)$, and without, the outlier removed from the data set $(B=1.44, S E=093, p=0134)$ This suggests that disinhibition scores were not independently associated with change in desire-toeat chocolate, and that the vanance in this variable is in fact explained by dietaryrestraint status which is confounding the effect of the disinhibition scores.

Individuals with high disinhibition scores also experienced a greater change in desired portion-size selections of chocolate cake (Table 53 ). However, visual inspection of this data again revealed an outlier. The change in portion-size selection experienced by this participant was 4.35 standard deviations below the mean For this reason this participant's data was removed from this analysis. Yet, even after removing this outlier, the associations between disinhibition scores and desired portion size remained statistically significant $(B=118.77, S E=50.65, p=$ 0.027). This was even the case after controlling statistically for dietary-restraint status $(B=12582, S E=58.87, p=0043)$ 
Table 53 Adjusted $^{1}$ parameter estimates from linear regression models of assoctations between the two measures of dietary behaviour (TFEQ-disinhibition score, and DEBQrestraint scores) and the change in measures of cue reactivity (subjective appetite and destred portion size)

\begin{tabular}{|c|c|c|c|c|c|c|c|}
\hline & \multirow[b]{2}{*}{$n$} & \multicolumn{3}{|c|}{$T F E Q$-disininhibition scores } & \multicolumn{3}{|c|}{$\overline{D E B Q}$ restraint scores } \\
\hline & & $B$ & $\overline{S E}$ & $p$ & $B$ & $S E$ & $p$ \\
\hline \multicolumn{8}{|l|}{ Changes } \\
\hline Hunger & 30 & 405 & 302 & 0191 & 151 & 068 & $0034^{*}$ \\
\hline Fullness & 30 & -282 & 303 & 0360 & -088 & 067 & 0205 \\
\hline \multicolumn{8}{|l|}{ Destre-to-eat } \\
\hline Pizza & 30 & 1024 & 610 & 0105 & 234 & 155 & 0144 \\
\hline Chocolate & 30 & 1141 & 499 & $0030^{*}$ & 220 & 096 & $0030^{*}$ \\
\hline Peanuts & 30 & -101 & 292 & 0733 & -006 & 075 & 0939 \\
\hline Chips & 30 & 138 & 361 & 0705 & 054 & 082 & 0511 \\
\hline Garlic bread & 30 & -353 & 430 & 0419 & -048 & 107 & 0659 \\
\hline Chocolate cake & 30 & -028 & 778 & 0718 & 134 & 174 & 0450 \\
\hline \multicolumn{8}{|l|}{ Craving } \\
\hline Pizza & 30 & 993 & 666 & 0148 & 275 & 168 & 0112 \\
\hline Chocolate & 30 & 468 & 441 & 0180 & 124 & 111 & 0278 \\
\hline Peanuts & 30 & 314 & 224 & 0173 & 026 & 058 & 0.654 \\
\hline Chips & 30 & 082 & 259 & 0755 & -048 & 059 & 0417 \\
\hline Garlic bread & 30 & 100 & 352 & 0779 & -031 & 0850 & 0718 \\
\hline Chocolate cake & 30 & 624 & 437 & 0165 & 173 & 097 & 0086 \\
\hline \multicolumn{8}{|l|}{ Destred portion size } \\
\hline $\operatorname{P} 1 z z a\left(m^{2}\right)$ & 30 & 111445 & 132460 & 0408 & 35327 & 332.87 & 0.298 \\
\hline Chocolate (pieces) & 30 & -012 & 099 & 0906 & -024 & 025 & 0340 \\
\hline Peanuts (g) & 30 & 345 & 716 & 0634 & -081 & 183 & 0661 \\
\hline Chups (g) & 30 & -050 & 407 & 0903 & -066 & 092 & 0480 \\
\hline Garlic bread $\left(\mathrm{mm}^{2}\right)$ & 30 & 22189 & 68441 & 0748 & 19550 & 160.38 & 0234 \\
\hline $\begin{array}{l}\text { Chocolate cake } \\
\left(\mathrm{mm}^{2}\right)\end{array}$ & 30 & 53643 & 31806 & 0104 & 14887 & 70.39 & $0044^{*}$ \\
\hline
\end{tabular}

* denotes $\mathrm{p}<005$

1 Adjusted for relevant pre-exposure ratıng, and for likıng for that food (in models for specific foods) 


\subsubsection{Awareness Questionnaire}

Following the previous experiments demand awareness was assessed in the final stage of this experiment. This assessment suggested that none of the participants correctly guessed the purpose of this expenment (Table 5.4) However, when prompted with particular questions about specific elements of the experiment, some participants $(30 \%)$ did provide responses which suggested that they were aware of the experiments interest in changes in subjectıve appetite after cue exposure (Table 5.4, question 2) To determine the extent to which this awareness affected the changes in subjective appetite, a series of regression analyses were conducted to explore associations between these changes and awareness of this a1m In these analyses, pre-exposure ratıng was controlled for statıstıcally by entering it into the analysis as a covariate, and where appropriate likıng for the food was also controlled for. These analyses provided no evidence to suggest that awareness of the interest in the effect of cue exposure on subjective appetite affected the changes in these measures (all associations $p>0$ 05) In addition to this analysis, it was also desirable to determine the extent to which awareness of this aim differed across the dietary measures. Thus, a senes of between-subject $t$-tests were used to assess this. These provided little evidence of statistically significant associations (all $p>0.05$ ).

Although the responses to the awareness questionnaire suggested that only a small number of participants were aware of the interest in the effect of cue exposure on portion-size selection, when explicitly told that participants where expected to select larger portion sizes in this experment at the second time point $(1 \mathrm{e}$ after cue exposure), almost half the participants guessed that portion size of pizza was expected to increase. However, after controlling for likıng for pizza and preexposure portion-size selection of this food, there was little evidence to suggest that this awareness predicted the change in desired pizza size observed after cue exposure. Furthermore, this awareness did not differ significantly across the dietary measures (everyday portion size, dietary restraint, and disınhıbition) (all $p>005$ ) 
Table 54 Summary of responses to the awareness questionnaire All total are given in percentages

\begin{tabular}{lll}
\hline & \multicolumn{2}{c}{ Response (\%) } \\
\cline { 2 - 3 } Question & Aware & Not aware \\
\hline 1. What do you think was the purpose of this experiment? & 0 & 100 \\
2 I asked you to rate your mood and appetite twice during & 30 & 70 \\
the experiment Do you know why? & \\
3. In this experiment I asked you to indicate the amounts & 133 \\
of varnous foods that you would like to eat at that time Do & \\
you know why? \\
4. I did expect you to want to eat greater amounts of the \\
food than you might normally do at one time point. Which \\
time point was this? (first or second) \\
5 I expected you to want to eat greater amounts of food \\
than you might normally do at the second time point \\
Which food (s)?
\end{tabular}

\subsection{Discussion}

Expenment 4 primarly sought to explore associations between food-cue reactivity and everyday portion-size selection by considenng differences in portion-size selection in a cued, and a non-cued, context. Given that that the food models used in the non-cued context did not stimulate appetite, these measures can be confidently regarded as a non-cued assessment of portion-size selection However, despite the merits of the methodology employed here, the results provided little evidence of a significant association between change in desired portion size of the cued, and noncued, foods and reported everyday portion size-selections This suggests that cue exposure had a similar effect on the desired portion size of the cued, and non-cued, foods irrespectıve of participants' everyday portion-size selectıons.

In Experiment 3, the total desired portion-size selection observed in the cued context was significantly associated with everyday portion-size selections, such that those individuals who typically selected the largest everyday portion sizes also 
selected the largest portion sizes of the cued food However, one concern was that elevated portion-size selection in these individuals was not a result of the stımulation generated by the pizza cue, but was rather a reflection of their general tendency to select larger portion sizes. As a result of this concern, in the present experiment measures of desired portion-size selection were obtained in a cued, and non-cued, context. Yet, as suggested above, this provided little evidence to suggest that cue exposure had a significantly different effect on portion-size selection for individuals who typically select larger everyday portion sizes relative to those who select smaller everyday portion sizes.

Despite the findings from the present experiment, and the concern relating to the finding from Experiment 3, there is still reason to suspect that there might be an association between food-cue reactivity and everyday portion-size selection This is because, firstly, the present experiment has provided evidence to contradict the possibility that the association between desired portion size of a cued food and everyday portion-size selection observed in Experiment 3 was merely a reflection of individuals' general tendency to select larger portion sizes, and had little to do with the fact that they had just been exposed to a food cue. Indeed, in the present experiment there was little evidence to suggest that measures of desired portion size observed in the non-cued contexts were associated with reported everyday portionsize selections. Yet, if individuals who typically select the largest everyday portion sizes have a general predilection to select larger portion sizes withın the context the laboratory, they would have also been expected to select larger desired portion sizes even in the non-cued context. The second reason to be cautious about dismissing an association between food-cue reactıvity and everyday portion-size selection relates to the reliability of the findings in the cued context in the present experiment. To recap, in Experiment 3, desired portion sizes of the cued food in this context were significantly associated with everyday portion-size selections. However, in the present study, a post-hoc regression analysis of the total desired portion sizes in the cued context falled to reveal this significant association ( $p=0264)$.

The reason for the discrepancy between the findings from the present study and those reported in Experiment 3 is unclear. However, one possibility is that it is the result of methodological differences between the two studies One methodological 
difference in this experiment relative to Experiment 3 was that the measure of everyday portion size was obtained at the outset prior to the buffet lunch, rather than in the final stages of the experiment as in Expermment 3. Consequently, in the present study participants recalled everyday portion size after three-hour food deprivation when they would presumably have a greater motivation to eat $\mathrm{By}$ contrast, in Experiment 3, participants recalled their everyday portion size while satiated. This might be an important difference given that previous studies have suggested that levels of satiety can influence participants' recall of their everyday portion-size selection (Beasley, Hackett, Maxwell, \& Stevenson, 2004). Indeed, there was a substantial difference in recalled everyday portion-size selections between Experiments 3 and 4. In this experiment average everyday portion-size selection was 4.19, whilst in Experiment 3 it was 567 . The reason for changing the order of the procedure in the present experiment, such that participants recalled their everyday portion sizes at the outset, was to eliminate any effects of the experimental procedure on recall of everyday portion-size selection In Experiment 5, these issues were addressed by assessing everyday portion-size selections immediately after the buffet lunch This ensured that participants were satıated pror to this recall and eliminated any effects of the experimental procedure.

As in Experiment 3, a secondary issue considered in this study was the associations between food-cue reactivity and measures of everyday dietary behaviour (dietary restraint and dietary disinhibition) Again, the results provided little evidence to suggest that restrained eaters were more reactive to food cues than unrestrained eaters. These individuals were not found to expenence a greater change in subjective appetite, or portion-size selection, for pizza. Furthermore, in the most part, they were not found to expenence a greater change in appetite (subjectıve appetite and portion-size selection) for the non-cued foods. One exception to this was that dietary restraint was found to be associated with a greater change in desireto-eat chocolate. However, this association was no longer statistıcally significant after the removal of an outlier associated with this measure. Since this farlure to observe a difference in food-cue reactivity across restrained and unrestrained eaters cannot be attributed to differences in awareness of the aims of the experiment, differences in pre-exposure appetite, or liking for the test foods, this finding can be 
taken as further support for the proposition that food-cue reactivity shares little relationship with dietary-restraint status.

With regards to dietary disinhibition, in this study, individuals with high disinhibition scores did not experience a greater change in subjective appetite for pizza after food-cue exposure, or a greater change in portion size-selection of this food However, there were found to expenence a greater change in appetite for at least two of the non-cued foods (chocolate and chocolate cake) Given that appetite for the other non-cued foods did not increase after cue exposure, and that there is no theoretıcal justıfication for appetite for these specific foods to be stımulated by exposure to pizza, one possibility is that they were the result of a Type I error.

In Experiments 1 and 3 presented in this thesis, measures of cue reactivity were found to be associated with dietary disinhibition. After cue exposure, individuals will higher disinhibition scores reported a greater change in appetite for the cued food (Experiments 1 and 3), and selected larger portion sizes of this food (Experiment 3). Therefore, it is somewhat surprising that the present findings fall to provide support for an association between measures of food-cue reactivity and this dietary disinhibition However, notably, Experıment 2 also failed to provide evidence for such an association. One possible explanation for the discrepancy in the findings reported in separate experiments presented in this thesis is that where associations are found, another vanable is accounting for these relationships. After considenng the evidence from all six experiments presented in this thesis, Chapter 8 will discuss this possibility further.

\subsection{Chapter summary}

This chapter presented the findings from the fourth experiment conducted for this thesis. This experiment was designed to re-consider the associations between foodcue reactıvity and everyday portion size using an improved design to that employed in Experıment 3. This design allowed desired portion size (and subjective appetite) to be assessed in a cued, and a non-cued, context. The results from this experiment provided little evidence to support the hypothesis that food-cue reactivity plays an 
important role in everyday portion-size selection A secondary 1ssue considered in experiment 4 was the extent to which food-cue reactivity is also associated with measures of everyday dietary behaviour (dietary restraint and disinhibition). However, the results also provided little evidence to suggest that food-cue reactivity shares an association with either dietary-restraint status, or with disinhibition scores 


\section{CHAPTER 6}

\section{FOOD-CUE REACTIVITY AND BMI}

\subsection{Chapter overview}

This chapter presents the methods and findings from Experiment 5. The primary aim of this experiment was to assess the implications of being overweight for foodcue reactivity To do this, measures of cue reactivity were compared across overweight, and non-overweight, individuals. As a secondary 1ssue, this experiment also sought to explore associations between measures of food-cue reactivity and everyday portion-size selections and everyday dietary behaviour (dietary restraint and disinhibition) The remainder of this chapter presents details of the rationale for this experiment, the methodology used, and analysis of the results.

\subsection{Introduction}

After providing some evidence to suggest that heightened reactivity to food cues might be associated with the selection of larger everyday portion sizes (Experiment 3 ), the next step was to consider the potential influence of food-cue reactivity on BMI In the 1970's, it was suggested that overweight individuals might be more susceptible to the stimulatory effects of environmental food cues than nonoverweight individuals. For example, several studies suggested that cues, such as the time of day, the taste of food, the avallability and accessibility of food, and the prominence of food items, had a greater impact on the intake of overweight, relative to non-overwerght, individuals (see Chapter 2). These findings were explained by Schachter's (1968, 1971) externality hypothesis. In this hypothesis, Schachter (1968, 1971) suggested that overweight individuals eat primarily in response to immediate external cues associated with food, and ignore internal physiological stımulı signalling hunger and fullness By contrast, he suggested that the eatıng 
behaviour of normal-weight individuals is governed primarily by internal physiological signals of energy depletion

However, Schachter's (1968, 1971) externality hypothesıs came under severe criticism. In the most part, this was because overweight individuals' greater sensitivity to external cues was not reported consistently across studies (e.g, Rodin, et al., 1976, Rodin, et al, 1977) As a result of this, it was suggested that the externality hypothesis presented a rather simplistic account of the differences in eatıng behaviour between overweight, and non-overweight, individuals (Rodin, 1981). Prior to this criticism, Nisbett (1972) had already suggested that differences in external eatıng behaviour were in fact mediated by dietary restraint, rather than by BMI. According to Nisbett's (1972) hypothesis, individuals who have a tendency to restrict their dietary intake experienced a greater motivation to eat after exposure to a food cue Nisbett (1972) explained greater sensitivity to food cues previously observed in overweight individuals by suggesting that these individuals were more likely to engage in dietary restraint by dint of the fact that society places pressure on individuals to adhere to a slim ideal Therefore, Nisbett (1972) suggested that by restrictıng their dietary intake, overweight individuals were often found to be more sensitive to food cues than non-overweight individuals (see Chapter 2) However, contrary to Nisbett's (1972) hypothesis, the findings presented in this thesis suggest that dietary restraint per se is not the critical factor determining individuals' susceptibility to the stımulatory effects of a food cue Therefore, one possibility is that Schachter $(1968,1971)$ was indeed correct, and that being overweight might be an important factor for sensitivity to food cues The reason studies explonng this possibility have falled to consistently report associations between sensitivity to external cues and being overweight might in fact have been a result of methodological limitations.

More recently, Jansen et al (2003) have used a more modern food-cue reactivity paradigm (similar to that used in experiments presented in this thesis) to compare sensitivity to food cues in overweight, and non-overweight, children By doing this, the authors found that overweight children consumed greater amounts after foodcue exposure than they consumed in the absence of this exposure By contrast, they found that non-overweight children consumed greater amounts in the no-cue, 
relative to the food-cue, condition. Drawing on previous theorising by the primary author (Jansen, 1998), Jansen et al (2003) suggested that the reason they observed greater food intake in overweight children after cue exposure might be the result of a greater history of repeatedly overeating in the presence of food cues in these individuals. The authors suggested that over time, this parnng of overeating with the sight and smell of food, enables food cues to predict greater food intake in these children

Despite Jansen et al's (2003) study, there has been little attempt to explore sensitivity to food cues in overweight, and non-overweight, adults using a modern cue reactivity paradigm Yet, this issue is particularly important given the recent increases in the prevalence of obesity in both the UK (Health Survey for England, 2004), and in the US (Flegal, et al, 2002). For this reason, the primary aim of Experiment 5 was to explore the extent to which being overweight is associated with greater food-cue reactivity among adults.

One previously unconsidered possibility is the extent to which overweight individuals' greater sensitivity to food cues is manifest as a greater appetite for the cued food, or as a greater motivation to eat any food. For example, does brief exposure to the sight and smell of pizza simply stimulate greater appetite for this food in overweight, relative to non-overweight, individuals, or does it generate a greater appetite for any food. This issue is important because it has consequences for how we might conceptualise the effects of food-cue exposure on maintaining overeatıng in overweight individuals, and consequently how interventions might be designed to reduce cued overeatıng. Thus, given the importance of this issue, the present experiment compared the consequences of exposure to the sight and smell of pizza for appetite for this food, and for appetite for vanous other foods Given the success of the methodology employed in Experiment 4 to assess desired portionsize selections of various foods (chips, garlic bread, peanuts, chocolate, and chocolate cake) in a non-cued context, this approach was also adopted in the present experiment.

A secondary issue considered in this experiment was the extent to which food-cue reactivity is also associated with everyday portion-size selection, and separate 
measures of dietary restraint and disinhibition. In Experiment 4, there was little evidence of a statistically significant association between changes in desired portion size and everyday portion-size selections. One possibility considered in the previous part of this chapter was that the motivational state (three hours food deprived or satiated) in which partıcipants find themselves in when recalling everyday portion size selection might influence recall of their everyday portion-size selection, and thereby affect observed associations between this measure and food-cue rcactivity. Given that in Experiment 4, everyday portion-size selection was measured pnor to the buffet lunch ( $1 \mathrm{e}$, when participants were three hours food deprived), in the present experiment partıcıpants were asked to recall their everyday portion size after consuming items from the buffet lunch

\subsection{Method}

\subsubsection{Overview and procedure}

Given that the methodology used in Experiment 4 appeared to provide an adequate approach to testing food-cue reactıvity, an almost identical procedure was used in the present experiment The only methodological difference in this experiment was that participants were asked to recall therr everyday portion size of the selected foods after, rather than before, the buffet lunch This was because it was suggested in Experiment 4 that the motivational state in which participants find themselves in when recalling everyday portion size selection might influence this recall, and thereby affect observed associations between this measure and food-cue reactivity. All other elements of the procedure were identical to the procedure used in Experıment 4 (see Chapter 5) 


\subsubsection{Participants}

One hundred and twenty participants were recruited via email from the population of femalc undcrgraduate students at Loughborough Untversity (UK) (mean age = $2095, S D=2.52$ ) (mean $\mathrm{BMI}=2289, \mathrm{SD}=2.55$ ) The reason for recruiting a larger cohort of participants in this experiment than in the previous experiments ( 3 and 4) was motivated by two factors. Firstly, Field (2005) suggests that the required sample size for regression analysis with the number of predictors and control variables used in this experiment is at least 100 , achieving 80 percent power Secondly, in this experiment, participants were not recruited on the basis of whether they were normal weight or overweight. Rather, volunteers were recruited and then divided into an overweight, and normal weight, group Thus, to obtain a reasonable number of overwerght participants, and based on Field's (2005) instruction on sample sizes, it was decided that a sample size of 120 participants would be recruited All participants gave written consent to participate in the study and were informed that they could withdraw at any time during the expenment. All participants were paid seven pounds (Sterling) for their participation.

\subsubsection{Measures}

\section{Cue reactlvity and dietary behaviour}

Measures of cue reactivity, and dietary behaviours (dietary restraint, disınhibition, average everyday portion size) were identical to those used in Experiment 4 (see Chapter 5).

\section{$2 B M I$}

BMI was calculated in this expenment as weight $(\mathrm{kg}) /\left[\right.$ height $\left.(\mathrm{cm})^{2}\right]$ Particıpant's height was assessed using a stadıometer (Bodycare. Warwickshıre, UK) Weight was measured using a set of weighing scales (Soehnle, Germany). 


\subsubsection{Data Analysis}

The data analysis for this expenment was almost identical to that used in Experiment 4 (see Chapter 5) However, in this experiment there was an additional independent vanable, namely BMI. To explore associations between BMI and the measures of cue reactivity, BMI scores were used to dichotomise individuals into a normal weight, $(\mathrm{BMI} \leq 249)$, and an overweight (BMI > 24.9), group This resulted 1n 26 participants being classified as overweight (BMI > 249), and the remaining 94 as non-overweight (BMI $\leq 249)$ Changes in measures of cue reactivity from pre- to post-cue exposure were assessed as outcome measures (subjectıve appetite and portion-size selection) and were compared across the two groups using separate regression analyses for each of these outcome vanables Again, this analysis allowed the corresponding pre-exposure measure, and liking for that food, to be controlled for by entering these measures as covarnates into the regression model. The prelıminary analyses conducted for this experıment werc identıcal to those described in Experiment 4 (Chapter 5). However, when exploring the partıcipants characteristics, here, between-subject t-tests were also used to determine the extent to which these dietary behaviours were expressed to a greater extent in overweight, relative to non-overweight, individuals. 


\subsection{Results}

\subsubsection{Participant characteristics}

Table 61 Means and standard deviatıons for participant characteristics

\begin{tabular}{llll}
\hline & $n$ & Mean & SD \\
\hline Characteristic & & & \\
BMI & 120 & 2289 & 255 \\
TFEQ-disinhibition score & 120 & 815 & 326 \\
DEBQ-restraint score & 120 & 293 & 084 \\
Everyday portion size & 120 & 368 & 081 \\
\hline
\end{tabular}

Means and SD's for each of the participant characteristics are summansed in Table 6.1. It was desirable to determine the extent to which the dietary measures (dietary restraint, disinhibition, and everyday portion size) were associated with each other. Thus, a series of Pearson's correlation coefficients were calculated. The findings suggested that the individuals who obtained higher scores on the disinhibition scale selected larger everyday-portion sizes $(r=022, p=0015)$ and obtained higher scores on the DEBQ-restraint scale $(r=0.34, p<0.001)$. Individuals with higher restraint scores were also more likely to report selectıng smaller everyday portion sizes $(r=-021, p=0022)$

When exploring the extent to which these dietary behaviours were expressed to a greater extent in overweight, relative to non-overweight, individuals, the results of between-subject t-tests suggested that overweight individuals obtained significantly higher disinhibition scores $(t=271, d f=118, p=0008)$, reported consuming larger everyday portion sizes $(t=2.49, d f=118, p=0.014)$, but did not differ to nonoverweight indıviduals in their reported levels of dietary restraint $(t=0.33, d f=$ $118, p=0745)$. 


\subsubsection{Baseline measures}

It was desirable to establish that there were no significant differences in hunger or fullness, subjective appetite for the test foods, or portion-size selections across the three dietary measures (everyday portion-size selection, dietary restraint, and disinhibition) and BMI immediately prior to cue exposure Regression analyses were used to assess these associations. In these analyses liking for the test foods were controlled for in the models for specific foods by entering this variable as a covariate into the regression model These analyses suggested that nether subjective appetite, nor desired portion sizes, for any of the test foods differed across the predictor variables prior to cue exposure (all $p>0.05$ )

\subsubsection{Descriptive statistics for measures of cue reactivity}

Initially, it was desirable to explore the descriptive statistics for the measures of cue reactivity before and after cue exposure Therefore, the means and standard deviations for each of the changes in subjective appetite and portion-size selections for the cued, and non-cued. foods are summarised in Table 6.2. The results of within-subject t-tests used to compare the pre- and post-exposure measures are also presented alongside these descriptive statıstıcs. These analyses suggest that cue exposure significantly increased hunger, and significantly reduced fullness (Table 6.2) It also suggests that it increased desire-to-eat, and craving, for pizza, and chocolate, and increased craving for chips and garlıc bread (Table 6.2). Finally, these analyses suggest that pizza-cue exposure significantly decreased portion-size selection of peanuts and chocolate cake (Table 62 ) 
Table 62 Within-subject t-tests, means, and standard deviattons, for pre-exposure, and post-exposure, subjective appetite and portion -size selections

\begin{tabular}{|c|c|c|c|c|c|c|c|}
\hline & \multirow[b]{2}{*}{$n$} & \multicolumn{2}{|c|}{ Pre-exposure } & \multicolumn{2}{|c|}{ Post-exposure } & \multicolumn{2}{|c|}{$\begin{array}{l}\text { t-value and } \\
\text { significance }\end{array}$} \\
\hline & & Mean & $\mathrm{SD}$ & Mean & $\mathrm{SD}$ & $t$ & $p$ \\
\hline Hunger & 120 & 1513 & 16952 & 2058 & 18423 & 4.50 & $<0001^{*}$ \\
\hline Fullness & 120 & 7291 & 2211 & 6820 & 2315 & -321 & $0002^{*}$ \\
\hline \multicolumn{8}{|l|}{ Desire-to-eat } \\
\hline Pizza & 120 & 2055 & 22.33 & 3070 & 2722 & 558 & $<0001^{*}$ \\
\hline Chocolate & 120 & 3357 & 2870 & 2850 & 2666 & -321 & $0002 *$ \\
\hline Peanuts & 120 & 1132 & 1499 & 1001 & 1480 & -124 & 0218 \\
\hline Chips & 120 & 1573 & 1899 & 1457 & 1669 & -141 & 0256 \\
\hline Garlıc bread & 120 & 1456 & 1863 & 1521 & 1827 & 062 & 0534 \\
\hline Chocolate cake & 120 & 2558 & 2529 & 2380 & 2382 & -151 & 0133 \\
\hline Craving & 120 & & & & & & \\
\hline Pizza & 120 & 1733 & 2140 & 2697 & 2715 & 5.69 & $<0001^{*}$ \\
\hline Chocolate & 120 & 2852 & 2770 & 2599 & 2650 & -224 & $0027^{*}$ \\
\hline Peanuts & 120 & 897 & 1339 & 950 & 1444 & 063 & 0529 \\
\hline Chips & 120 & 11.78 & 1991 & 1460 & 1827 & 305 & $0003 *$ \\
\hline Garlıc bread & 120 & 1121 & 1567 & 1385 & 1737 & 2.13 & $0035^{*}$ \\
\hline Chocolate cake & 120 & 2429 & 2618 & 2211 & 2442 & -179 & 0076 \\
\hline \multicolumn{8}{|l|}{ Desired portion size } \\
\hline $\operatorname{Pizza}\left(\mathrm{mm}^{2}\right)$ & 120 & 645080 & 919413 & 6301.14 & 599884 & -021 & 0834 \\
\hline Chocolate (pieces) & 120 & 456 & 042 & 418 & 043 & -131 & 0193 \\
\hline Peanuts (g) & 120 & 2750 & 3540 & 2034 & 3083 & 364 & $<0001^{*}$ \\
\hline Chips (g) & 120 & 2319 & 2181 & 2090 & 2544 & -163 & 0.106 \\
\hline Garlic bread $\left(\mathrm{mm}^{2}\right)$ & 120 & 394475 & 410600 & 400475 & 405549 & 027 & 0791 \\
\hline $\begin{array}{l}\text { Chocolate cake } \\
\left(\mathrm{mm}^{2}\right)\end{array}$ & 120 & 194720 & 165130 & 165834 & 172946 & 331 & $0001^{*}$ \\
\hline
\end{tabular}




\subsubsection{Effects of food models on subjective appetite}

Again, to substantıate the claim that the food models used in this experiment provided a non-cued measure of participants' desired portion sizes, the effect of these models on appetite was assessed by companng ratıngs taken from before, to after, initial exposure to these models ( $1 \mathrm{e}$., when participants were indicating their pre-exposure desired portion sizes) These analyses suggested that using the food models to indicate pre-exposure portion-size selections significantly increased feelings of hunger ( $t=355, d f=119, p=0001$ ), and significantly reduced reported levels of fullness ( $t=-244, d f=119, p=0016)$. It also served to significantly increase craving, for chocolate $(t=366, d f=119, p<0001)$, peanuts $(t=2.46, d f=$ $119, p=0.015)$, and for chips $(t=200, d f=119, p=0048)$. However, visual inspection of the mean values for these changes suggests that they were modest at between $1 \mathrm{~mm}$ and $4 \mathrm{~mm}$ (see Table 6.3) on the 100mm VAS. All other measures of subjective appetite were not found to increase significantly (all $p<0.05$ ) after preexposure portion-size selections. This suggests that the food models had a minimal, if any, effect on appetite. Therefore, they can be regarded as providing a relatively non-cued measure of portion-size selection

Table 63 Means and standard deviations for hunger, fullness, craving for chocolate, craving for chips, and craving for peantits, before and after pre-exposure portion size selections using the food models

\begin{tabular}{llllll}
\hline & & \multicolumn{2}{c}{$\begin{array}{c}\text { Before portion-s1ze } \\
\text { selection }\end{array}$} & \multicolumn{2}{c}{$\begin{array}{c}\text { After portion-size } \\
\text { selection }\end{array}$} \\
\cline { 3 - 6 } & $n$ & Mean & SD & Mean & SD \\
\hline Hunger & 120 & 1133 & 11706 & 1513 & 1.547 \\
Fullness & 120 & 7674 & 1799 & 7291 & 22114 \\
Craving for chocolate & 120 & 2353 & 2469 & 28.52 & 27697 \\
Craving for peanuts & 120 & 7.18 & 10704 & 897 & 1339 \\
Craving for chips & 120 & 1001 & 1453 & 1178 & 1691 \\
\hline
\end{tabular}




\subsubsection{Cue reactivity and being overweight}

Overweight individuals were not found to expenence a greater change in hunger or fullness after cue exposure, or a greater change in subjective appetite (desire to eat and craving) for pizza (Table 64 ). However, being overweight was associated with a greater change in desired portion size of pizza (Table 6.4). Using the parameter estimates from the regression model for change in desired pizza size, this change was predicted in Kcalories for an overweight, and non-overweight, individual with an average likıng for pizza (average likıng for pızza $=7083 \mathrm{~mm}$ ) and average preexposure desıred pızza-size $\left(645080 \mathrm{~mm}^{2}\right.$ [174 $\left.\left.17 \mathrm{kcalones}\right]\right)$. These predıctions are displayed in Figure 6.1. Visual inspection of this figure suggests that after pizzacue exposure, overweight individuals increased their desired pizza size by 46.06 kcals. By contrast, the desired portion size of pizza selected by non-overweight individuals decreased by $17.22 \mathrm{kcals}$. To give some indication of how these changes affected the total amount that overweight and non-overwerght individuals might consume after cue exposure, pre-exposure portion size was predicted ${ }^{11}$ thus enabling the total number of calones that would be consumed by these individuals to be calculated through addition of the predicted change (Table 6.5).

It is also important to note that overwerght, and non-overweight, individuals did not differ in their change in subjective appetite (craving and desire to eat), or portionsize selection, for any of the non-cued foods (Table 64 ) This is interesting because, together with the findings reported for the cued food, it suggests that pizza-cue exposure was unable to stımulate subjective appetite for both the cued, and noncued, foods, but was able to elicit an exclusive increase in desired pizza size

\footnotetext{
"To predict pre-exposure portion size of pızza, this measure was modelled as an outcome variable in a regression analysis
} 
Table 64 Adjusted $^{1}$ parameter estımates from linear regression models for associations between changes in the measures of food-cue reactivity and BMI, and everyday portion-size selection

$\mathrm{BMI}>249$

Everyday portion size

(Reference $\mathrm{BMI} \leq 249$ )

Changes in measures of

cue reactivity

\begin{tabular}{|c|c|c|c|c|c|c|c|}
\hline Hunger & 120 & 362 & 297 & 0224 & -076 & 149 & 0612 \\
\hline Fullness & 120 & -518 & 361 & 0154 & -038 & 181 & 0833 \\
\hline \multicolumn{8}{|l|}{ Desire-to-eat } \\
\hline P1zza & 120 & 680 & 436 & 0122 & 218 & 222 & 0328 \\
\hline Chocolate & 120 & -683 & 363 & 0063 & -266 & 182 & 0148 \\
\hline Peanuts & 120 & -385 & 208 & 0066 & -245 & 102 & $0017^{*}$ \\
\hline Chips & 120 & -364 & 1.91 & 0059 & -184 & 097 & 0061 \\
\hline Garlıc bread & 120 & 331 & 226 & 0146 & 033 & 116 & 0.774 \\
\hline Chocolate cake & 120 & 085 & 290 & 0769 & 039 & 145 & 0.787 \\
\hline \multicolumn{8}{|l|}{ Craving } \\
\hline P1zza & 120 & 574 & 399 & 0153 & 179 & 203 & 0378 \\
\hline Chocolate & 120 & -015 & 279 & 0959 & -161 & 1.40 & 0253 \\
\hline Peanuts & 120 & -253 & 183 & 0169 & -195 & 089 & $0029^{*}$ \\
\hline Chrps & 120 & 322 & 237 & 0177 & 012 & 1.22 & 0925 \\
\hline Garlıc bread & 120 & -246 & 287 & 0393 & -002 & 1.46 & 0983 \\
\hline Chocolate cake & 120 & -276 & 294 & 0350 & -126 & 147 & 0392 \\
\hline \multicolumn{8}{|l|}{ Desired portion stze } \\
\hline $\operatorname{Pizza}\left(\mathrm{mm}^{2}\right)$ & 120 & 234313 & 107578 & $0031^{*}$ & 116165 & 54747 & $0036^{*}$ \\
\hline Chocolate (preces) & 120 & -0527 & 0681 & 0441 & -091 & 034 & $0008^{*}$ \\
\hline Peanuts (g) & 120 & 391 & 416 & 0350 & -048 & 209 & 0818 \\
\hline Chups (g) & 120 & -20775 & 52802 & 0695 & -097 & 171 & 0574 \\
\hline Garlic bread $\left(\mathrm{mm}^{2}\right)$ & 120 & -9839 & 53964 & 0856 & 26948 & 27154 & 0323 \\
\hline Chocolate cake $\left(\mathrm{mm}^{2}\right)$ & 120 & -6603 & 20292 & 0745 & -6809 & 108.33 & 0531 \\
\hline
\end{tabular}

* denotes $\mathrm{p}<005$

' Adjusted for the relevant pre-exposure ratıng for all outcome measures, and adjusted for liking for the cued/non-cued food for food-specific outcome measures (e g, change in craving for pizza, desired portion size of pızza) 


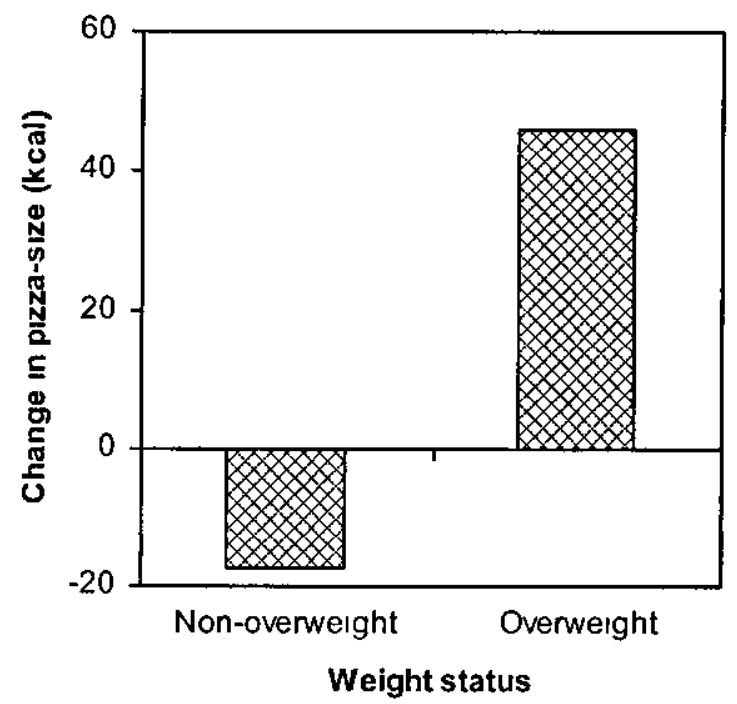

Figure 61 Predicted change in pizza-size in Kcalortes (kcal) for overweight and nonoverwetght individuals after cue exposure estimated using the parameter esttmates from the linear regression model $(B=234313)^{12}$

Table 65 Predicted values from the linear regression model for overweight, and normal wetght, individuals for pre-exposure portion-size selection, and the total amounts these individuals would be expected to consume ${ }^{1}$

\begin{tabular}{lll}
\hline & $\begin{array}{c}\text { Pre-exposure pizza size } \\
(\mathrm{kcal})\end{array}$ & $\begin{array}{c}\text { Post-exposure pizza size } \\
(\mathrm{kcal})\end{array}$ \\
\hline Non-overweight & 16623 & 14901 \\
Overweight & 20359 & 24963 \\
\hline
\end{tabular}

${ }^{1}$ Holding likıng for pizza, and pre-exposure pizza size, at their mean values for the sample (70 83mm, $645080 \mathrm{~mm}^{2}$ [174 17 kcalories], respectively)

${ }^{12}$ In this model likıng for pizza and pre-exposure pizza size were held at their average values in the sample (average likıng $=7083 \mathrm{~mm}$, average pre-exposure pızza sıze $=645080 \mathrm{~mm}^{2}[17417$ kcalories]), and their respective parameter estımates ( $B=7258, B=-068$, respectively) were used to predict the change in desired pizza size in Kcalories 


\subsubsection{Cue reactivity and everyday portion size}

The findings suggest that average everyday portion size was not associated with changes in generalised measures of subjectıve appetite (hunger and fullness) or subjectıve appetıte for pızza (craving and desıre to eat) (Table 6.4). However, average everyday-portion size was significantly associated with change in desired portion size of pizza (Table 6.4), such that those participants who reported consuming larger everyday portion sizes on average, selected larger pizza-sizes after cue exposure. Again, using the parameter estımates from the regression model, the change in portion-size selection (represented in Kcalones) for individuals who reported consuming small (2 82), medium (3 71), and large (4.52), everyday portion sizes (calculated as the average value in each tertile of the data) were predicted after holding likıng for pizza and pre-exposure portion-size selection at their mean values for the sample (70.83, and 174.17, respectively). These predictions are shown in Figure 6.2. To give some indication of how these changes affected the total amount that these individuals might consume, pre-exposure portion size selected by these individuals was again predicted ${ }^{13}$ thus enabling the total number of calories that would be consumed by these individuals to be calculated These are summarised in Table 66.

13 To predict pre-exposure portion size of pizza, this measure was modelled as an outcome variable in a regression analysis 


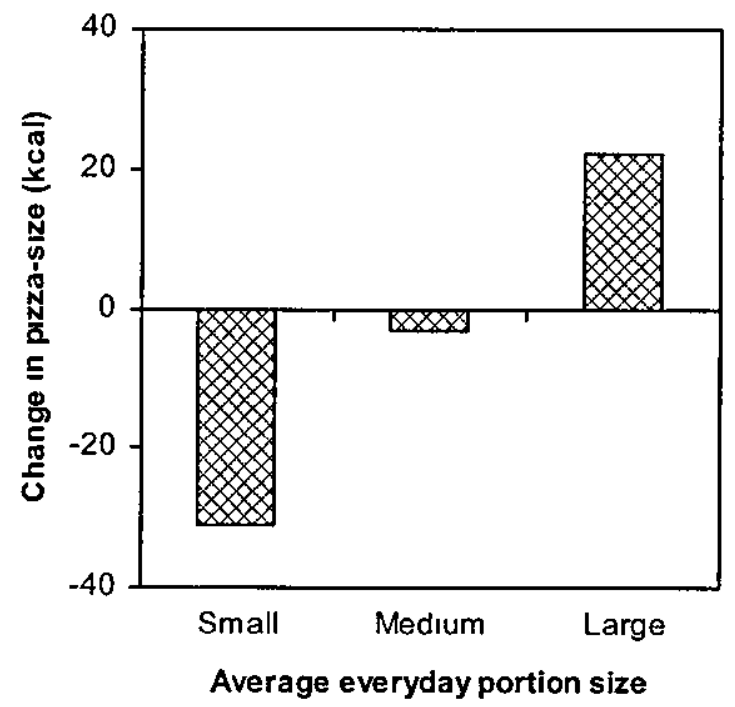

Figure 62 Predicted change in pizza size in Kcalones (kcal) for individuals with small (2 82), medium (3 71) and large (452) average everyday portion size (calculated as the average score in each tertile of the data) estimated using the parameter estimates from a linear regression model for change in pizza size $(B=1161.65)^{14}$

Table 66 Predicted values from the linear regression model for pre-exposure pizza size, and the total amounts individuals would be expected to consume in Kcalories for small, medium, and large, portion sizes (calculated as the average value in each tertile of the data) ${ }^{1}$

Pre-exposure pızza size

(kcal)
Post-exposure pizza sıze

(kcal)

Everyday portion size

Small

14140

11028

Medium

17509

17189

Large

20575

22795

\footnotetext{
1 Holding liking for pizza, and pre-exposure pizza size, at their mean values for the sample (70 83mm, $645080 \mathrm{~mm}^{2}$ [174 $17 \mathrm{kcalones}$, respectively)

${ }^{14}$ In this model pre-exposure pizza size and liking for pizza are held at their mean values in the sample (6450 80 $\mathrm{mm}^{2}$ [174 $17 \mathrm{kcalories]}$, and $7083 \mathrm{~mm}$ respectively) and their respective parameter estımates ( $B=-070, B=6452$, respectively) were used to predict change in desired pizza size in Kcalories
} 
With regards to the non-cued foods, changes in subjective appetite (craving and desıre-to-eat) for chips, garlıc bread, chocolate, and chocolate cake, did not differ significantly across average everyday portion size (Table 6.4). However, the consumption of larger everyday portion sizes was associated with a smaller change in desire-to-eat peanuts, and a smaller change in craving for this food (Table 6.4). Taken together therefore, these findings suggest that individuals who reported consuming larger everyday portion sizes did not experience greater subjective appetite for the cued, or non-cued, foods. Furthermore, desired portion-size selections of chips, garlic bread, peanuts, and chocolate cake did not differ significantly across average everyday-portion size (Table 6.4) However, the consumption of larger everyday portion sizes was associated with a decrease in desired portion size of chocolate

\subsubsection{Does being overweight act as a proxy measure of everyday portion size?}

Notably, both being overweight and everyday portion-size selections are associated with change in desired portion size after cue exposure, and were found to be related to each other (see above). Given this, one possibility is that being overwerght is associated with a greater change in desired portion size simply because overweight individuals have a tendency to select larger everyday portion sizes. To address this issue, post hoc, everyday portion-size selection was controlled for in the regression model assessing associations between change in desired portion size of pizza and being overweight by entering it as a covariate. If being overweight is associated with change in desired portion size independently of everyday portion size, then this variable should continue to be a significant predictor of this outcome variable. However, in this analysis, being overweight was no longer significantly associated with this change $(B=1917.82, S E=109708, p=0.083)$. This suggests that after the variation in change in desired portion size explained by everyday portion size selection is accounted for, being overweight fails to significantly predict this measure of cue reactivity. 


\subsubsection{Relationships between cue reactivity and dietary behaviour}

Dietary-restraint scores were not associated with change in subjective appetite (hunger, fullness, craving, and desire-to-eat, the cued, and non-cued, foods), nor were they associated with change in portion-size selection of pizza, or of the noncued foods (Table 6.7) This suggests that cue exposure did not have a differential effect for restrained, and unrestrained, eaters

For individuals with high disinhibition scores, there was little evidence to suggest that they experienced a greater change in hunger (Table 6.7) than those who obtained lower scores on this scale, and in fact these individuals were found to experience a smaller decrease in fullness (Table 67 ). There was also little evidence of statistically significant associations between change in reactivity measures (subjective appetite and portion size selection) for the non-cued foods and disinhibition scores (Table 6.7), suggesting that changes in motivation to eat the non-cued foods did not differ across disinhibition scores. By contrast, higher disinhibition scores were associated with a greater increase in desire-to-eat pizza, a greater change in craving for this food, and the selection of larger desired portions of it (Table 6.7). However, these associations were no longer statistically significant after controlling for restraint status (all $p>005$ ) This suggests that neither dietary restraint scores nor disinhibition scores were independently associated with changes in subjective appetite or desired pizza size, and that the vanance in these variables was in fact explained by the shared contribution of dietary-restraint status and disinhibition scores. 
Table 67 Adjusted ${ }^{1}$ parameter estimates from linear regression models of associations between the two measures of dietary behaviour (TFEQ-disinhibition score, and DEBQrestraint scores) and changes in measures of cue reactivity

\begin{tabular}{|c|c|c|c|c|c|c|c|}
\hline & \multirow[b]{2}{*}{$n$} & \multicolumn{3}{|c|}{ TFEQ-disinhibutton scores } & \multicolumn{3}{|c|}{$D E B Q$-restraint scores } \\
\hline & & $\bar{B}$ & $S E$ & $p$ & $B$ & $S E$ & $p$ \\
\hline \multicolumn{8}{|l|}{ Changes } \\
\hline Hunger & 120 & 140 & 144 & 0333 & 065 & 037 & 0085 \\
\hline Fullness & 120 & -050 & 175 & 0.778 & -092 & 046 & $0048^{*}$ \\
\hline \multicolumn{8}{|l|}{ Desire-to-eat } \\
\hline Pizza & 120 & 176 & 2.14 & 0413 & 115 & 054 & $0036^{*}$ \\
\hline Chocolate & 120 & -077 & 180 & 0670 & -032 & 046 & 0484 \\
\hline Peanuts & 120 & 159 & 101 & 0117 & 038 & 026 & 0147 \\
\hline Chips & 120 & -063 & 094 & 0503 & 007 & 025 & 0781 \\
\hline Garlic bread & 120 & 036 & 111 & 0747 & 039 & 029 & 0181 \\
\hline Chocolate cake & 120 & 058 & 1.40 & 0682 & 021 & 036 & 0570 \\
\hline \multicolumn{8}{|l|}{ Craving } \\
\hline P1zza & 120 & 352 & 194 & 0072 & 107 & 050 & $0034^{*}$ \\
\hline Chocolate & 120 & 132 & 137 & 0338 & 006 & 035 & 0856 \\
\hline Peanuts & 120 & 150 & 0.88 & 0092 & 034 & 023 & 0139 \\
\hline Chips & 120 & 085 & 116 & 0463 & 046 & 030 & 0128 \\
\hline Garlic bread & 120 & 209 & 138 & 0133 & 038 & 037 & 0.303 \\
\hline Chocolate cake & 120 & 220 & 142 & 0.124 & -046 & 036 & 0208 \\
\hline \multicolumn{8}{|l|}{ Destred portion size } \\
\hline $\operatorname{Przza}\left(\mathrm{mm}^{2}\right)$ & 120 & 28486 & 53370 & 0595 & 271.95 & 13499 & $0046^{*}$ \\
\hline Chocolate (pieces) & 120 & 064 & 034 & 0064 & -012 & 009 & 0172 \\
\hline Peanuts (g) & 120 & -179 & 203 & 0378 & -069 & 052 & 0.188 \\
\hline Chıps (g) & 120 & 169 & 165 & 0307 & -059 & 043 & 0171 \\
\hline Garlic bread $\left(\mathrm{mm}^{2}\right)$ & 120 & 17847 & 26102 & 0496 & 58.27 & 6765 & 0391 \\
\hline Chocolate cake $\left(\mathrm{mm}^{2}\right)$ & 120 & 9972 & 10514 & 0345 & -3242 & 2653 & 0224 \\
\hline
\end{tabular}

$*$ denotes $\mathrm{p}<005$

${ }^{1}$ Adjusted for the relevant pre-exposure ratıng for all outcome measures, and adjusted for likng for the cued/non-cued food for food-specific outcome measures (e g, change in craving for pizza, desired portion size of pizza) 


\subsubsection{Association between change in desired potion size and being overweight after controlling for disinhibition scores}

Notably, overweight individuals were found to have higher disinhibition scores than non-overweight individuals, and greater dietary disinhibition was associated with a larger change in desired portion size of pizza after cue exposure Given this, posthoc, it was decided to assess the associations between being overweight and change in desired portion size after controlling for disinhibition scores To do this, these scores were entenng as a covanate into the regression model assessing the association between change in desired portion size and being overweight This analysis suggests that after controlling for disinhibition scores, being overweight was not significantly associated with the change in desired portion size of pizza after exposure to this food $(B=192627, S E=1103.05, p=0083)$.

\subsubsection{Awareness questionnaire}

Observation of the responses to the awareness questionnaire suggested that only a small percentage of participants indicated that they had some awareness of the aims of this experiment (Table 6.8). However, when prompted with particular questions about specific elements of the experiment, some participants (25 8\%) did provide responses which suggested that they were aware of the experiments interest in changes in subjective appetite after cue exposure (Table 6.8, question 2) To determine the extent to which this awareness affected the changes in subjective appetite, a series of regression analyses were conducted to explore associations between these changes and awareness of this aim. In these analyses, pre-exposure rating was controlled for by entering it as a covariate into the regression model, and where appropriate liking for the food was also controlled for. These analyses provided little evidence to suggest that awareness of the interest in the effect of cue exposure on subjective appetite affected the changes in these measures (all associations $p>0.05$ ) In addition to this analysis, it was also desirable to determine the extent to which this awareness differed across the predictor variables (being overweight, everyday portion-size selection, dietary restraint, and dietary 
disinhibition) Thus, a series of between-subject t-tests were used to explore dietary restraint scores, disinhibition scores, and average everyday portion size selections of those individuals who were aware of the aims of the experiment and those who were unaware, and a chi-squared test was used to compare awareness in overweight individuals and non-overweight individuals. These analyses provided little evidence to suggest that this awareness differed across the predictor variables (all $p>0.05$ ).

Although the responses to the awareness questionnaire suggest that only a small number of participants were aware of the interest in the effect of cue exposure on portion-size selection, when participants were explictly told that they where expected to select larger portion sizes in this experiment at the second tıme point (i e., after cue exposure), over half the participants guessed that portion size of pizza was expected to increase. For this reason, again, it was desirable to determine the extent to which this awareness affected change in pizza portion size, and the extent to which it differed across the predictor vanables (being overweight, everyday portion-size selection, dietary restrant, and dietary disinhibition) After controlling for liking for pizza and pre-exposure portion-size selection of this food in regression analyses, there was little evidence to suggest that this awareness predicted the change in pizza size observed after cue exposure (all $p>005$ ). Furthermore, between-subject t-tests suggested that those individuals who were aware of this aim did not differ significantly in dietary restraint, average everyday portion size, or in their disinhibition scores (all $p>005$ ) Likewise, a chi-squared test suggested that awareness did not differ stgnificantly between overweight, and non-overweight, individuals $(p>0.05)$ 
Table 68 Summary of responses to the awareness questionnatre All total are given in percentages

\begin{tabular}{|c|c|c|}
\hline \multirow[b]{2}{*}{ Question } & \multicolumn{2}{|c|}{ Response } \\
\hline & Aware (\%) & Not aware (\%) \\
\hline 1 What do you think was the purpose of this experıment? & 158 & 842 \\
\hline $\begin{array}{l}2 \text { I asked you to rate your mood and appetite twice during } \\
\text { the experiment Do you know why? }\end{array}$ & 258 & 742 \\
\hline $\begin{array}{l}3 \text { In this experiment I asked you to indicate the amounts } \\
\text { of various foods that you would like to eat at that time Do } \\
\text { you know why? }\end{array}$ & 833 & 9167 \\
\hline $\begin{array}{l}4 \text { I did expect you to want to eat greater amounts of the } \\
\text { food than you might normally do at one time point Which } \\
\text { time point was this? (first or second) }\end{array}$ & 616 & 384 \\
\hline $\begin{array}{l}\text { 5. I expected you to want to eat greater amounts of food } \\
\text { than you might normally do at the second time point }\end{array}$ & 683 & 317 \\
\hline Which food $(s)^{?}$ & & \\
\hline
\end{tabular}

\subsubsection{Summary table of main results}

To summarise the main results from this experiment a summary table (Table 6.9) is provided below. This summanses where statistically significant associations were observed between the predictor variables and the outcome measures. This suggests that dietary-restraint status was not significantly associated with any of the measures of food-cue reactivity. However, importantly, it does highlight significant associations between measures of motivation to eat the cued food and everyday portion-sıze selection, being overwerght, and dietary disınhibition 
Table 69 Summary table of the significant associations between the predictor vartables and the outcome variables for this experiment

\begin{tabular}{|c|c|c|c|c|c|}
\hline \multicolumn{6}{|c|}{ Predictor variables } \\
\hline 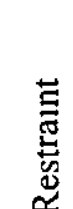 & 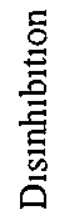 & 宽 & 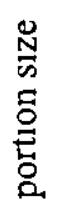 & $\stackrel{0}{\stackrel{0}{\Xi}}$ & 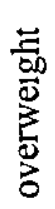 \\
\hline
\end{tabular}

Outcome measures

Change in hunger

Change in fullness

Change in desire-to-eat pizza

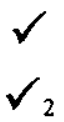

Change in desire-to-eat chocolate

Change in desire-to-eat garlıc bread

Change in desire-to-eat chips

Change in desire-to-eat peanuts

Change in desire-to-eat chocolate cake

\section{Change in craving for pizza}

Change in craving for chocolate

Change in craving for garlic bread

Change in craving for chips

Change in craving for peanuts

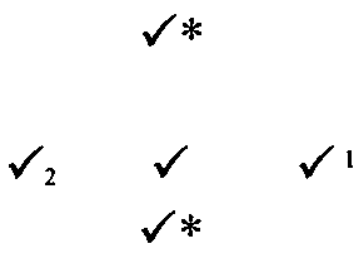

Change in craving for chocolate cake

\section{Change in desired pizza portion}

Change in desired chocolate portion

Change in desired portion of chips

Change in desired portion of peanuts

Change in desired portion of garlic bread

Change in desired portion of chocolate cake

$\checkmark$ Denotes where statistically significant interactions were observed

1 This association was no longer statıstically significant after controllıng for everyday portion-size selection and dietary disinhibition

2 This association was no longer statistically significant after controlling for dietary restraint scores

* Changes in these measures decreased as everyday-portion size increased 


\subsection{Discussion}

This experiment primarily sought to explore the association between food-cue reactıvity and being overweight. The results suggested that cue exposure did not have a greater effect on reported subjectıve appetite for pizza for overweight individuals relative to non-overweight individuals. However, it did have a differential effect on desired portion of pizza for these two groups of individuals. For overweight indıviduals, cue exposure served to increase desired pizza size By contrast, for non-overweight individuals, it reduced desired portion size. Immediately, these findings suggest that cue exposure has a greater effect on desired portion for overweight individuals

However, there are several other potential explanations for these findings. One possibility is that overweight individuals experienced a greater change in desired portion size in this experiment, because they had a greater awareness of the study's aims, and therefore were behaving in a way that they believed the researcher desired them to behave. Another possibility is that these individuals had a greater desire for the cued food prior to cue exposure, or that they were hungrier than the nonoverweight individuals. Indeed, several neuroimaginıng studies have suggested that overweight individuals might experience weaker, or delayed, satıety signals (Gautter, Chen, Salbe, Bandy, Pratley, Heıman, et al, 2000. Gautier, Del Parngi, Chen, Salbe, Bandy, Pratley, et al, 2001). Thus, one possibility was that the overweight individuals in this experiment selected larger portion sizes of the cued food because they perceived themselves as less satiated after the buffet lunch than non-overweight individuals. However, against these possibilities, overweight individuals in this experiment were not found to have a greater awareness of the study's aims, have a greater appetite for the cued food at the outset, or report different levels of hunger or fullness relative to the non-overweight participants. Given this, it is most likely that differences in the change in desired portion in overweight, and non-overweight, individuals were the result of differences in sensitıvity to foods cues between these two groups. 
Notably, finding that overweight individuals are more food-cue reactive than nonoverweight individuals is consistent with the results reported by Jansen et al (2003) These authors found that overweight children ingest larger amounts after pre-exposure to food, while non overweight children consume smaller amounts Taken together, the importance of Jansen et al 's (2003) findings and those reported in the present experiment is that they provide support for the proposition that the eating behaviour of overweight individuals might be influenced to a greater extent by external environmental cues than the eating behaviour of non-overweight individuals. This possibility has been outlined previously in the externality hypothesis of obesity (Schachter, 1968, 1971) However, this hypothesis was replaced by the proposal that sensitivity to food cues is mediated by dietary-restraint status, rather than differences in BMI. Yet, the findings from the five experiments presented in this thesis suggest that restrictıng ones dietary intake does not cause greater susceptibility to food cues, and the present study suggests that overweight individuals are more sensitive to food cues than non-overweight individuals Thus, perhaps Schachter's $(1968,1971)$ hypothesis was indeed correct and that being overweight is an important determinant of food-cue reactivity.

Given that the onginal proposals suggesting that being overweight might be an important determinant of sensitivity to food cues dates back to the 1970's, it is surprising that little consideration has been given to the exact consequences of cue exposure for food intake in these individuals. Specifically, there has been no attempt to determine the extent to which food-cue exposure is able to generate appetite for foods other than the one which has been cued in overweight individuals. Therefore, this experiment presents the first attempt to consider this issue by exploring changes in subjective appetite and desired portion size after cue exposure for the cued food, and for a series of non-cued foods. By doing this, the results of this experiment have provided little evidence to suggest that change in desired portion size, and subjective appetite, for the non-cucd foods differed significantly in overweight, relative to non-overweight, individuals. However, given that change in desired portion size of pizza was elevated in overweight individuals relative to nonoverweight individuals after cue exposure, this suggests that cue exposure is able to increase desired portion size of the cued food to a greater extent in overweight individuals, but is unable to similarly increase desired portion size of other foods 
It is important to consider why overweight individuals are specifically sensitive to food cues. There are several possible explanations for this The first possible explanation is related to overweight individuals' tendency to consume larger amounts of food In the present experiment, 1t was suggested that overweight individuals consume larger everyday portion sizes than non-overweight individuals This might be important in explaining their greater food-cue reactivity because Jansen's (1998) theory of cue reactivity suggests that consuming larger amounts of food is the key determinant of greater food-cue reactivity. Specifically, Jansen (1998) proposes that heightened cuc reactivity occurs because the consumption of larger portion sizes becomes associated with cues, such as the sight and smell of food Consequently, on each occasion when these cues are encountered, they promote the selection of these larger portion sizes. Consistent with Jansen's (1998) proposal, the findings from the present expenment suggest that food-cue reactivity does share an association with everyday portion-size selection. Thus, given this, it is possible that overweight individuals, by dint of the fact that they typically consume larger portion sizes, might be cued to select larger amounts of a particular food after exposure to its sensory characteristics (i e the sight and smell) Notably, finding that overweight individuals only selected larger portion sizes of the cued food in this expenment relative to non-overwerght individuals is in fact consistent with this possibility. This is because the sight and smell of pizza will only be associated with the selection of larger portion sizes of this food in overwerght individuals Thus, exposure to this cue will only be capable of stimulating the selection of larger portion sizes of this food.

The second potential explanation for the greater change in desired portion size of the cued food observed in overweight individuals relates to their tendency to obtain higher disinhibition scores. In this experiment, and in a series of previous studies (Bellisle et al, 2004; Lindroos et al, 1997), ovcrweight individuals have been found to score higher on the TFEQ-disinhibition scale than non-overweight individuals. Thus, given that dietary disinhibition was found to be an important predictor of food-cue reactivity in this experiment, one possibility is that overweight individuals are more sensitive to food cues because they tend to be more disinhibited than non-overweight individuals. Notably, in the present experiment, 
after controlling for disinhibition scores, being overweight was no longer significantly associated with change in desired portion size. Therefore, one possibility is that dietary disinhibition mediates the relationship between being overweight and change in desired portion size Given that high scores on the disinhibition scale might reflect an inability to resist the temptation to eat offered by external triggers (social situations, emotional states, and external food cues) (see Section 4.5 in Chapter 4), this suggests that overweight individuals might be more susceptible to external food cues because they suffer to a greater extent from an inability to resist the temptation to eat offered by external triggers

Unlıke the explanations offered here for greater food-cue reactıvity in overweight Individuals, Jansen et al (2003) have presented an account based upon the idea that overwerght individuals experience delayed satıety signals when consuming a food which has been cued, and for this reason consume larger amounts of this food Central to Jansen et al's (2003) explanation is the 1dea that a meal is terminated once the sensory characteristics of that meal ( $1 \mathrm{e}$, the taste, texture, sight, and smell) are no longer deemed desirable (Sensory-specific satıety [SSS], see Section 2.9, Chapter 2). Jansen et al (2003) suggest that for overweight individuals, during the intake of a cued food, this normal decline in the pleasantness of the sensory charactenstics of the food is attenuated. Subsequently, this delays the development of satiety, and a greater amount of food is consumed. By contrast, Jansen et al (2003) suggest that for non-overweight individuals the decline in the pleasantness of the foods sensory charactenstics (1.e, 1ts sight and smell) begins during the exposure phase. Consequently, these individuals require smaller amounts of this food when it is subsequently offered for consumption before they reach SSS. Similar explanations could account for the differences in change in desired portion size observed after cue exposure in overweight, and non-overweight, individuals in this experiment Indeed, the declining pleasantness of the sensory characteristics of the cued food in non-overweight individuals dunng cue exposure could account for the reduction observed in their desired portion size of the cued food For nonoverwerght individuals, knowledge of the attenuated decline in the sensory charactenstics of a cued food might have been gleaned from previous experiences of consuming cued foods. Thus, this knowledge might encourage these overweight individuals to select larger portion sizes of a cued food. However, it is important to 
note that at present, these ideas are purely speculative and should be tested in future studies

One final reason why overweight individuals were found to be more sensitive to food cues than non-overwerght individuals in this experiment might be related to differences in personality characteristics between these two groups of individuals Perhaps relevant is that overweight individuals are found to be more impulsive then non-overweight individuals (Nederkoorn et al., 2006; Nederkoorn et al, in press), and to have a greater sensitivity to reward (Franken \& Murs, 2005). Given that food-cue reactivity could conceivably be associated with a general inability to inhibit impulses generated by cues in the environment, and with a greater sensitivity to rewarding stimuli, such as a tasty food, one possibility is that these characteristics do in fact account for the greater food-cue reactivity observed in overweight individuals. However, to date, the potential role of these characteristics in food-cue reactivity has not been explored empirically. This is surprising given that such work might further develop our understanding of the fundamental processes which govern food-cue reactivity. For this reason, the associations between these characteristics and food-cue reactivity are considered in Experıment 6.

In addition to determining why overweight individuals might be more reactive to food cues than non-overweight individuals, it is equally important to consider the extent to which this greater reactivity might provide one explanation for why these individuals are overweight It is logical to expect that those individuals who consume larger amounts each time they are cued with food, over tıme, will gain weight. Indeed, given that in the present study overweight individuals were found to desire larger amounts after cue exposure, it is possible that this greater sensitivity to food cues contributed to them initially becoming overweight. Notably, the results from this expenment also provide some scope to speculate as to how this might occur Indeed, given that after controlling for everyday portion-size selections, the association between change in desired portion size and being overweight was no longer statistically significant, it is possible that everyday portion-size selection mediates the relationship between being overweight and the desire to consume greater amounts of a cued food In light of this, one possibility is that greater sensitivity to food cues causes greater everyday food consumption which over time 
results in individuals becoming overweight However, in a cross sectional study such as that presented here, this represents only a speculation To address this issue, studies are required which specifically assess the effect of greater sensitivity to food cues on weight gain. In the 1970's, Rodin, \& Slochower (1976) addressed this 1ssue by assessing weight gain durng a summer camp, where food cues were naturally abundant, in teenage girls who were more or less sensitive to such cues The authors found that teenage girls who were highly sensitive to food cues gained a larger amount of weight at summer camp than girls who were less sensitive to these cues Thus, their study provided some initial evidence to suggest that greater sensitivity to food cues might promote weight gain. However, future studies should aim to replicate this finding using samples from different populations in different contexts.

Despite the fact that the present study can only speculate as to the effect of greater sensitivity to food cues on weight gain, given that overweight individuals were found to select larger portion sizes of a cued food, it is possible to conclude that greater sensitivity to food cues is likely to represent one factor which at least serves to maintain these individuals degree of overweight. This alone is important because at present, obesity is a major concern for public health. Therefore, it is important that interventions are designed to reduce levels of body werght in obese, and overweight, individuals. Thus, if food-cue reactivity constitutes one factor which might at least be responsible for individuals sustaining excess weight, one intervention might be to attempt to reduce food-cue reactivity in overweight individuals. Since food-cue reactivity is assumed to result from learned associations between the sensory characteristics of a food (visual and olfactory) and food ingestion (Wardle, 1990; Weingarten, 1985), to reduce reactıvity it is feasıble to suggest that these learned associations need to be 'extınguished.' Jansen (1998) suggested one technique for this called 'response prevention.' This involves presentıng individuals with a food cue and preventıng them from eatıng in the presence of this cue A similar process has been successfully used to extinguish learned associations in bulimics (see Jansen, 1998 for details of this procedure) and alcoholics (Drummond \& Glaut1er, 1994; Mont1, Rohsenow, Rubon1s, Niaura, Sirota, Colby, et al 1993). Thus, it is plausible that a similar technique might be 
useful for extınguishing learned associations between the sensory charactenstics of a food (visual and olfactory) and food ingestion.

In addition to exploning the role of being overweight in food-cue reactivity, and the implications of food-cue reactivity for everyday portion-size selections, a secondary issue considered in this experiment was the extent to which food-cue reactivity is also associated with separate measures of dietary restraint and disinhibition. The findings suggested that disinhibition scores were associated with a greater change in subjective appetite (desire to eat and craving) for pizza and a greater change in desired portion size of this food. By contrast, these scores were not associated with a greater change in subjective appetite, or desired portion-size selection, for any of the non-cued foods Given that dietary disinhibition reflects a susceptibility to eat in the presence of external triggers, it is perhaps not surprising that disinhibited eaters expenence a specific appetite for the cued food after cue exposure. This is because the pizza cue is likely to generate a speclfic trigger to eat pizza

Consistent with results from the previous experiments presented in this thesis, in this experiment dietary-restraint status was not found to be associated with any of the measures of food-cue reactivity. Again this provides further support for the notion that restrained eaters have no greater sensitivity to food cues than unrestrained eaters. Notably, however, after controlling statistically for dietary restraint status when exploring associations between food-cue reactivity and disinibition scores, these associations failed to reach statistical significance. This suggests that dietary restraint status was in some way accountıng for the associations observed between dietary disinhibition and motivation to eat pizza. This finding is somewhat surprising given that dietary restraint has not been found to play any role in food-cue reactivity in any of the previous experiments presented throughout this thesis. The reason for this is also unclear. However, further ad-hoc inspection of the data suggested that a large proportion (75\%) of individuals with high disinhibition scores also had high restraint scores, while less than half of the individuals (41\%) with low disinhibition scores had high restraint scores. Therefore, one possibility is that this tendency for individuals with high disinhibition scores to have restraint scores resulted in associations between food-cue reactivity and 
disinhibition scores failing to reach statıstıcal significance after controlling for the effects of restraint on food-cue reactivity

\subsection{Chapter Summary}

The experiment presented in this chapter (Experiment 5) compared sensitivity to food cues in overweight, and non-overweight, individuals. Interestingly, the results suggested that overweight individuals experience the greatest change in desired portion size of the cued food This finding is important because it highlights the possibility that greater reactivity to food cues can promote weight gain. A secondary aim of this experiment was to re-consider associations between food-cue reactivity, and i) everyday portion-size selection, 11) dietary disinhibition, iil) and being overweight. Consistent with previous experiments reported in this thesis, there was little evidence to suggest that dietary restraint status was associated with greater food-cue reactivity. However, the findings did suggest that both dietary disinhibition, and everyday portion-size selection might be associated with this dietary phenomenon. Specifically, individuals with high disinhibition scores and those who reported selecting the largest portion sizes experienced the greatest changes in desired portion size of the cued food. 


\section{CHAPTER 7}

\section{INDIVIDUAL DIFFERENCES IN FOOD-SPECIFIC REACTIVITY IN FOOD-DEPRIVED AND NON-DEPRIVED INDIVIDUALS}

\subsection{Chapter overview}

This chapter discusses the final experiment presented in this thesis The primary atm of this experiment was to explore the extent to which individual differences in personality charactersstics, namely impulsivity and the BAS (Behavioural Activation System) tratt, can predict variation in food-cue reactivity. The secondary aim was to explore the extent to which these, and other individual differences (dietary restraint, dietary disinhibition, and body weight) in food-cue reactivity, differ across two motivational states, 1.e., when individuals were food-deprived and after they had eaten to satiety The first section of the chapter provides the background to these aims, and is followed by further sections outlining the methodology employed, the results observed, and a discussion of the findings

\subsection{Introduction}

In Experıment 5 it was found that overwerght individuals select relatıvely larger portion sizes of a cued food than non-overweight individuals. One potential explanation for this might be that differences in overweight individuals' personality render them more susceptible to the effects of food cues. In particular, these individuals tendency to be more impulsive (Nederkoorn et al., 2006; Nederkoorn et $a l$, in press), and to have a greater sensitivity to reward (Franken \& Muris, 2005), might account for their greater reactivity to food cues. Given this, the alm of the present experiment was to assess the potential role of characteristics such as impulsivity and sensitivity to reward in food-cue reactıvity. 
Different levcls of sensitivity to reward are assumed to be mediated by the Behavioural Approach system (BAS). The BAS was described in Chapter 2. Essentially, it is a hypothetical brain structure that responds to stımuli in the environment which are rewarding, or which are associated with a reward by actıvatıng behaviour (see Chapter 2 for further detalls). This activation system might be important for food-cue reactivity given that cue reactivity is likely to anse because a food cue has gained the capacity to signal the receipt of a tasty reward. Therefore, it follows that those individuals who have a highly reactive BAS and thereby are more sensitıve to cues signalling reward, might be more reactive to food cues (see Chapter 2 for further detals) Given this, one aim of the present study was to explore evidence for an association between activity of the BAS and food-cue reactivity. To do this, the BAS trait was assessed using the Sensitivity to Reward scale (SR) from the Sensitivity to Reward and Sensitıvity to Punishment Questionnaire (SRSPQ, Torrubia, Avıla, Molto, \& Caseras, 2001)

As suggested in Chapter 2, impulsivity is defined as an inclination to act in a rash, and unplanned, manner, towards environmental stımulı. Therefore, individual differences in this trait might also be associated with sensitivity to environmental stimulı associated with food ingestion Put simply, impulsive individuals would be expected to execute a rash response to food cuss, giving little consideration to the consequences of this action By contrast, less impulsıve individuals might consider the implications of consuming larger amounts of cued food, and as a consequence refrain from selectıng these larger portion sizes. Given that this possibility has not previously been considered, the present study also sought to explore associations between food-cue reactivity and impulsivity To do this, impulsivity was assessed using a self-report measure of impulsivity, namely the impulsivity scale from the Eysenck Personality Questionnaire (1.e., Eysenck \& Eysenck, 1975), and by assessing inhibitory control Since impulsivity reflects a deficit in inhibitory control, 1t was desirable to obtain a measure of this deficit. This was achieved by using the Stop-Start task (Logan, Schachar, \& Tannock, 1997). This task was recently utılised by Nederkoorn, et al (2004) in a study of food-cue reactivity However, rather than assessing the association between measures of food-cue reactivity and inhibitory control, the authors explored the extent to which food-cue exposure promotes 
deficits in inhibitory control Thus, the present expenment constitutes the first attempt to assess associations between food-cue reactivity and trat impulsivity and inhibitory control

A secondary aim of this experiment was to compare individual differences in foodcue reactivity when individuals are food deprived and when they are non-food deprived In the experiments presented thus far in this thesis individual differences in food-cue reactivity have been assessed in the absence of food deprivation The initial decision to test individuals in this state was motivated by Weingarten's (1985) proposals regarding conditioned meal initiation. Weingarten (1985) suggested that if food-cue reactivity reflects a learned response it should be evident even when individuals are non-food deprived. However, as suggested in the opening chapters of thrs thesis when exploring individual differences in food-cue reactivity it might also be important to ascertain that the same individual differences exist when individuals are in fact modestly deprived of food. This is particularly important given that there is reason to suspect that some associations between the predictor vanables used in this thesis and food-cue reactivity might be exclusive to a satrated state. Indeed, it is suspected that overweight, and non-overweight, individuals might only respond differently to food cues when they are satiated. When modestly deprived of food, these two groups of individuals might in fact behave in a similar way. Evidence for this possibility comes from the externality hypothesis devised by Schachter $(1968,1971)$ This hypothesis suggests that overweight individuals rely exclusively on external food cues to control therr food intake. Thus, these individual are likely to react consistently to an external food cue irrespective of their internal motivational state By contrast, the hypothesis suggests that non-overweight individuals rely on internal physiological signals, and thus, would be expected to respond to a food cue only when they are hungry. Given this, it follows that reactivity to food cues might be simtlar in overweight, and non-overweight, individuals when they are deprived of food, but differ when these individuals are satıated. This is because when satiated non-overweight individuals are unlıkely to react to food cues given that their internal physiological signals do not promote the intake of food By contrast, for non-overweight individuals, even when satıated, external food cues will offer a tempting reward. In light of this, the present experment also sought to explore individual differences in food-cue reactivity when 
individuals were food-deprived, and in the absence of hunger. In addition to explonng how individual differences in BAS activity and impulsivity are associated with food-cue reactivity in these deprived, and non-deprived, states, it was also 1mportant to explore how differences in body weight, dietary restraint, and dietary disinhibition relate to food-cue reactivity in these states.

To summarise, the objective of this experiment was to explore associations between the measures of cue reactivity used in the preceding experiments (subjective appetite and portion-size selection) and 1) dietary restraint, 11) disinhibition, 1i1) being overweight, iv) BAS activity, and v) impulsıvity, when individuals were fooddeprived and in the absence of food deprivation Food deprivation was manipulated by asking participants to refrain from eating for four hours prior to initial pizza-cue exposure, and then by asking them to consume items from a buffet lunch until they felt comfortably full prior to a second identical pizza-cue exposure phase. This allowed associations between the measures of cue reactivity and the five predictor variables (dietary restraint, dietary disinhibition, body weight, BAS trait, and ımpulsıvity) to be explored after four hours food deprivation and immediately after eatıng to satıety

\subsection{Method}

\subsubsection{Overview}

This experıment comprised five phases; 1) pizza-cue exposure before lunch, 11) buffet-style lunch, i1) pizza-cue exposure after lunch, iv) Stop Start task, and v) a questionnaire phase (TFEQ-disinhibition scale, DEBQ-restraint scale, Impulsıvity scale, SR scale, and awareness questionnaire). Phases 1) and 111) (the exposure phases) were identical to each other except that in phase (1) participants had been deprived of food for at least four hours, while in phase (111) they were satiated after the buffet lunch As in Experiments 4 and 5, in these exposure phases, participants were exposed to the sight and smell of pizza for three minutes Immediately before and after this exposure they rated their subjectıve appetite for the cued (pızza), and 
non-cued (chips and chocolate cake), foods and indicated their desired portion size of these foods. Again, portion sizes were assessed using food models identical to those used in Experiments 4 and 5 Measures of general subjectıve appetite (hunger and fullness) and measures of specific appetite (desire to eat and craving) were taken before and after each of the pre-exposure measures made using these models to ensure that these models were providing a non-cued assessment of portion-size selection.

\subsubsection{Design}

This experiment employed a within-subjects design Changes in motivation to eat elicited by the food cue were observed in each participant after four-hour deprivation, and following lunch The reason this approach was employed was because it increases the power of the design since cue reactivity is observed in each participant in both a food-deprived, and non-deprived, state.

\subsubsection{Participants}

One hundred and twenty participants were recruited from the population of female students at Loughborough University (mean age $=2008, \mathrm{SD}=2.24$ ). In the most part, the sample was self-selected. Participants who wished to take part volunteered for the study after receiving an emall advertisement. However, in the final stages of recruitment, non-overweight participants were not recruited, and overweight participants were actively selected using the details provided on a pre-screening health questionnaire (see Appendix F). This was because fewer overweight participants initially volunteered for this expenment relative to the number of overweight volunteers recruited in Experiment 5. Therefore, to ensure that a similar number of overweight participants were recruited in this expenment these individuals were actıvely selected 


\subsubsection{Measures}

\section{Cue reactlvity}

The measures of cue reactivity used in this experiment were identical to those used in the previous experiments Full descriptions of these measures are presented in the preceding chapters The only difference was that in this experiment measures of appetite (subjective appette and desired portion size) were only assessed for two non-cued foods These were chips and chocolate The reason for this was to reduce the complexity of the design because there were two exposure phases. It was decided that this would not be detrimental to the study given that in previous studies there has been little differential effect of cue exposure on appetite for non-cued foods

\section{Being overweight, dietary disinhibition, and dietary restraint}

These characteristics were assessed and defined in the same way as in the earlier experiments described in this thesis

\section{Sensitlvity to reward}

Activity of the BAS was assessed in this experiment using the SR scale from the SRSPQ (Torrubia, et al , 2001) This scale has good internal consistency, test-re-test reliability, and construct valıdity (see Torrubia et al, 2001). An alternative measure of the BAS are the BAS scales (BAS-fun seeking, and BAS-reward responsiveness) developed by Carver \& White (1994) However these scales are less desirable than the SR scale of the SRSPQ scale because the items relate to the non-specific concept of reward. By contrast the items on the SR scale relate to specific rewards and appraisal, and therefore can be interpreted with less ambiguity.

The SR scale comprises 24 items which assess sensitivity to rewards such as money, sex, social power, and approval, and appraisal (e g, Does the good prospect of obtaining money motivate you strongly to do some things?) (See Appendix G for the full list of the items included in this questionnaire ) Participants are requested to respond with etther a 'yes' or 'no' to each 1tem 'Yes' responses score one point, 
and 'no' responses score zero points Points are totalled across the 24 items resultıng in a single measure of sensitivity to reward out of a total score of 24 .

\section{Impulsivity}

Self-report impulsivity was assessed using the Impulsivity scale from the EPQ (Eysenck \& Eysenck, 1975) This scale comprises 19 1tems which assess a tendency to act on impulse without sufficient forethought (See Appendix $\mathrm{H}$ for the specific items included in this questionnaire.) Again, participants are requested to respond with either a 'yes' or 'no' to each 1tem. For most 1tems, 'yes' responses score one point, and 'no' responses score zero points. However, for some ttems this scoring is reversed. For example, the scoring of the ttem 'Before making your mind up, do you consider all the advantages and disadvantages?' would be scored backwards By totalling the points scored across the nineteen items an impulsivity score can be denved.

Response inhibition was assessed in this experiment using the Stop Signal task (Logan, et al, 1997). This task has been used extensively to assess deficits in inhibitory control in individuals with Attentional Deficit Hyperactıve Disorder (ADHD) (e g., Bekker, Overtoom, Kenemans, Koo1j, De Noord, Buitlaar et al, 2005; Schachar, Tannock, Marriot, \& Logan, 1995) In this experıment, the task was copied from Logan et al (1997) and was created using E-prime software. Durıng this task partıcipants were required primanly to respond to a choice reaction-time task ('go' task). The letter ' $\mathrm{O}$ ' and ' $\mathrm{X}$ ' were presented for 1000 miliseconds (ms) on the centre of a computer screen. Participants were asked to respond to the ' $\mathrm{X}$ ' by pressing the ' $\mathrm{x}$ ' key on a standard keyboard and to respond to an ' $O$ ' by pressing the ' $o$ ' key on the same keyboard. They were also told to press the keys as quickly as possible. On $25 \%$ of the 'go' trals, however, a $1000 \mathrm{~Hz}$ tone would sound. Participants were told that when they heard this sound they should not respond to the 'go' task. This was defined as the 'stop' task' Initially, on trials where the 'stop' sound signalled, it occurred $250 \mathrm{~ms}$ after the 'go' signal, 1 e., $250 \mathrm{~ms}$ after the letter appeared on the screen. If the participants falled to inhibit their response, the 'stop' signal was produced 50ms earlier, thereby makıng it easier for particıpants to inhibit their response when the next 'stop' signal occurred In contrast, if the participant successfully inhibited their response, the delay of the stop signal was reduced by 
$50 \mathrm{~ms}$ making it more difficult to inhibit the next 'stop' signal trial The two variables measured in this task are reaction time (RT) and the stop delay. The stopsignal reaction time (SSRT) is calculated by subtractıng the stop delay from the reaction time for these trials where the participant provided the correct response to the reaction-time choice task ( 1 e., by pressing ' $o$ ' or ' $x$ ' correctly in response to the letter observed on the screen). The task consists of one block containing 32 trals There were an equal number of ' $X$ 's' and 'O' $\mathrm{s}$ ' across the trials. Partıcipants were given an opportunity to familianse themselves with the task before these trials began

\section{Awareness Questionnalre}

Agarn, an awareness questronnaire was issued at the end of the experiment to ensure that participants were not aware of the aims of this experiment This questionnaire asked 1) What do you think was the purpose of this experiment?, 2) I asked you to rate your mood and appetite during the experiment. Do you know why?, 3) I asked you to indicate the amounts of przza, chocolate cake, and chips, that you would like to eat at various points during the experiment Do you know why? 4) I expected that you would want to eat greater amounts of these foods than you might normally do at certain times during the experiment, a) Which time(s) do you think this/these was/were?, b)Which food(s)?, and 5) Do you know why you were offered lunch in this expenment?

\subsubsection{Procedure}

As in other expenments presented in this thesis, before arriving to be tested the participants were told that the aim of the experiment was to explore the relationship between 'appetite and mood.' They were also told that they would have to rate their mood throughout the experiment, that they would be asked to offer an opinion on various foods, and that they would receive a buffet-style lunch

Partıcipants were tested between $11 \mathrm{am}$ and $3 \mathrm{pm}$. All were instructed to refrain from eatıng for four hours prior to the onset of the experiment. To check compliance with this, participants were asked to record their intake prior to their test session On 
arrival at the laboratory, participants provided a set of appetite ratings which served as a baseline measure of subjective appetite prior to pre-exposure portion-size selections. Immediately after completıng these ratıngs, partıcıpants were invited to make their pre-exposure portion size selections. Following this, a second set of appetite ratings was taken This measure allowed exploration of the effects of makıng these portion-size selections on appetite, and also served as a pre-exposure measure of subjective appetite. Consistent with the cover story, these subjective measures of appetite also included a number of ratıngs relatıng to the participant's current mood After this, the participants were then exposed to the sight and smell of cooked pizza for three minutes. The pizza was presented in a rectangle slice, and weighed $300 \mathrm{~g}(810 \mathrm{kcal})$ It was placed on a table directly in front of the participant. During this exposure phase, participants were instructed to sit and wait until the expenmenter returned After exposure, the participants provided post-exposure portion-size selections and appetite ratıngs They were then presented with a buffetlunch and were asked to eat unt1l they felt 'comfortably full.' After lunch, the same procedure as that described above was repeated to provide a measure of the effects of pizza-cue exposure on motivation to eat while individuals were non-food deprived. Following this, partıcipants completed the Stop Signal task, the TFEQdisinhibition scale, the DEBQ-restraint scale, the SR scale, the impulsivity questionnaire, the awareness questionnaire, and rated their liking for the cued (pizza), and non-cued (chips and chocolate cake), foods. Finally, a measure of height and weight was taken, and BMI was calculated.

\subsubsection{Data Analysis}

The aim of this experiment was to explore associations between the measures of cue reactivity and 1) dietary restraint, 11) dietary disınhibitıon, 111) being overweight, 1v) BAS activity, v) self-report impulsivity, and v1) response inhibition (assessed using scores on the Stop Signal task) in two different motivational states, 1.e., when individuals were food deprived, and immediately after they had eaten to satiety. Measures of cue reactivity taken in this experiment included two measures of general subjectıve appetite (hunger and fullness), two measures of specific 
subjectıve appetite (desire-to-eat and craving) for the cued (pizza), and non-cued (chips and chocolate cake), foods, and a measure of desired portion size of these foods To assess cue reactivity, four sets of these measures were taken One set was taken prior to cue exposure, in both the first (before lunch), and second exposure (after lunch), phases (pre-exposure sets), and one set was taken following cue exposure, in both the first, and second, exposure phases Initially, descriptive statistics (means and SD's) for these outcome measures were assessed and withinsubject t-tests were calculated to determine the extent to which they differed from before, to after, pizza-cue exposure In addition to this, preliminary analyses also sought to ensure that the use of food models for the pre-exposure measures provided a non-cued measure of participants' desired portion sizes. To do this, within-subject t-tests were used to compare general subjective appetite (hunger and fullness) and subjective appetite (desire to eat and craving) for the cued, and non-cued, foods If these food models were providing a non-cued measure, there should be little change in subjective appetite. Finally, as part of the prelımınary analyses, descriptive statıstıcs for partıcipant characteristıcs (sensitıvity to reward, impulsıvity, BMI, dietary restraint, and dietary disinhibition) were produced. Following from this, a senes of Pearson Correlation Coefficients were calculated to assess associations between the linear measures (1 e, sensitivity to reward, impulsivity, dietary restraint, and dietary disinhibition), and between-subject t-tests were used to assess the extent to which these linear charactenstics differed across overweight, and nonoverweight, participants.

After conductıng these prelıminary statıstıcs, change scores for each of the cue reactıvity outcome measures (general appetıte, subjectıve appetite, and desired portion size) after cue exposure were denved from the difference between the measure of reactivity taken before, and after, p1zza-cue exposure. These change scores were derived for the measures taken when participants were hungry and when they were satiated. Separate regression models were used to explore the associations between these change scores and each of the predictor variables (dietary restraint, dietary disinhibition, BMI, impulsıvity, and the BAS trait). As in previous experiments, in each of these models, pre-exposure reactivity measures were controlled for by entering these measures as covariates into the regression model. In addition to this, where food-specific outcome measures were being 
modelled, liking for the cued/non-cued food was also controlled for. Importantly, all predictor variables were entered into the regression model as continuous variables except BMI. As in Experiment 5 (Chapter 6), BMI scores were used to dichotomise individuals into a normal weight, $(\mathrm{BMI} \leq 24.9)$, and an overweight, $(\mathrm{BMI}>24.9)$, group, and compansons were made between these two groups. Twenty-six partıcipants were classified as being overweight (BMI > 249), and the remaining 94 as non-overweight (BMI $\leq 24.9)$. Again, as in previous experıments presented in this thesis it was important to determine the extent to which any associations between the outcome measures and disinhibition scores occurred irrespective of restraint status. Thus, where significant associations were reported for disinhibition, a second regression model was run which controlled statıstıcally for restraint scores. Similar to this, since sensitivity to reward and impulsivity are likely to be related to each other, it was important to explore the extent to which these charactenstics were independently associated with cue reactivity. For this reason, where significant associations were reported between either of these variables and one of the outcome measures, the regression model was re-run controlling for the other variable by entering it as a covariate into the regression model. Where outliers were observed in the data, the analysis is reported with these outliers in the data set and with them removed.

As in the previous experiments, statistically significant associations between an outcome variable and the predictor variables are depicted graphically by using the parameter estımates from the appropriate regression model to predict the change in the outcome measure for different values of the predictor variable after controlling for the effect of any confounding variable, such as pre-exposure measures of reactıvity Where the predictor varrable was a contınuous measure this variable is split into tertiles. An average measure of this variable was then calculated for each tertile of the data, yielding a low, medium, and high, score. After predicting the changes in the outcome measures, where changes were observed in portion-size selection, it was also desirable to gain some insight into the effect of this change on the total portion size likely to be consumed after cue exposure. To do this, initially, a regression model was constructed to model pre-exposure portion size controlling for likıng for the food across the tertiles of the relevant predictor variable. The parameter estımates from this model were then used to predict pre-exposure size 
across the three levels By summing this pre-exposure portion-size prediction to the change in this measure observed after cue exposure, the total portion size which would be consumed after cue exposure was calculated.

\subsection{Results}

\subsubsection{Outliers}

One participant was removed from the data set as she had a BMI of 13 , which indicated that she was severely undernourished. Another participant expenenced a change in desired pizza size when hungry which was 557 standard deviations above the mean change in this measure. Inspection of the data suggested that this change equated to a change of 2376 Kcalones This change in of itself exceeds the recommended daly Kcalone intake for women, suggestıng that this measure was likely to have been an error Since it is possible that if this participant made an error in estımatıng therr desired pizza size, they also made errors in other measurements provided throughout the expermment, this participant's data was also removed from the data set.

A further two participants appeared to be incorrectly completing the rating scales. This is because initially they rated their hunger as relatively high $(83 \mathrm{~mm}$ and $94 \mathrm{~mm}$ ) and their fullness as relatively low ( $1 \mathrm{~mm}$ and $7 \mathrm{~mm}$ ), but then following the first pre-exposure portion-size selections using the food models, their hunger ratıngs decreased to a level which would indicate that they were not hungry $(1 \mathrm{~mm}$, and $24 \mathrm{~mm}$ ) and their fullness increased to level which would suggest they were in fact satıated $(99 \mathrm{~mm}$, and $72 \mathrm{~mm})$ However, after exposure to the pizza, therr high levels of hunger $(99 \mathrm{~mm}$ and $96 \mathrm{~mm})$ and reduced levels of fullness $(1 \mathrm{~mm}$, and $3 \mathrm{~mm}$ ) returned. One possibility is that in the second set of ratings these participants confused the hunger and fullness ratings. Since it is also possible that these participants made other errors throughout the experiment, the analysis was run with, and without, these participants included Any differences in the findings which occur as a result of these participants benng included in the analysis will be reported 
in the following sections. Where the inclusion of their data did not alter the statistical significance of the findings, the results are presented with these data points excluded

\subsubsection{Participant characteristics}

Characteristics of the participants are summarised in Table 7.1. Mean values for the majonty of these charactenstics are similar to those observed in previous experıments However, mean stop start signal scores were much greater than would be expected. This is because the mean score was approximately $100 \mathrm{~ms}$ greater than that reported in previous studies (e.g., Nederkoorn et al, 2004).

Table 71 Mean and standard deviatıons for participant characteristics

\begin{tabular}{llll}
\hline & $n$ & Mean & SD \\
\hline Characteristic & & & \\
BMI & 118 & 2288 & 334 \\
TFEQ-disinihibition score & 118 & 842 & 302 \\
DEBQ-restraint score & 118 & 268 & 085 \\
Sensitivity to reward score & 118 & 1137 & 395 \\
Impulsivity score & 118 & 760 & 4.34 \\
Stop start signal task score [ms] & 118 & $26534(44405)$ & 20163 \\
(reaction time [ms]) & & & $(10113)$ \\
\hline
\end{tabular}

Exploration of the association between each of the participant characteristics suggested that higher disinhibition scores were associated with higher EPQimpulsivity scores $(r=0.24, p=0.008)$, higher DEBQ-restraint scores $(r=0.44, p<$ $0.001)$, and higher sensitivity to reward scores $(r=0.22, p=0019)$ Furthermore, higher EPQ-1mpulsivity scores were associated with higher scores on the sensitivity to reward scale $(r=039, p<0.001)$. Finally, overweight individuals had higher TFEQ-disinhibition scores $(t=3.18, d f=114, p=0.002)$ and higher DEBQrestraint scores $(t=3.33, d f=114, p=0.001)$ than non-overweight individuals 
While overweight individuals obtained scores of 3.18 and 10.12 respectively on the restraint and disinhibition scales, non-overweight individuals obtained scores of 256 and 804 respectıvely.

\subsubsection{Baseline measures}

Prior to the initial cue exposure phase, there was little evidence to suggest that hunger, fullness, or appetite (desire to eat and craving) for the cued, and non-cued, foods differed across the predictor variables (dietary restraint, disinhibition, body werght, Impulsivity, BAS trait). However, after lunch, prior to the second cue exposure phase, desire-to-eat pizza $(r=019, p=0.039)$ and craving for this food $(r$ $=0.26, p=0005$ ), were significantly greater in individuals with high impulsivity scores However, since pre-exposure measures were controlled for statistically in the regression analyses explonng changes in the measures of cue reactivity and impulsivity, these differences should not have any impact on the observed results All other associations between pre-exposure measures before lunch and the predictor varıables were not statıstically significant (all $p>005$ ).

\subsubsection{Lunch manipulation}

To ensure that the lunch manipulation was effective and that individuals were relatıvely hungry prior to cue exposure before lunch, and relatively satiated prior to cue exposure after lunch, mean ratıngs of baselıne hunger and fullness were assessed before and after lunch. These are displayed in Table 7.2. Within-subject ttests suggested that hunger levels were significantly greater before lunch $(t=-25.66$, $d f=116, p<0.001)$ and levels of fullness were significantly greater after lunch $(t=$ $2831, d f=116, p<0.001)$. 
Table 72 Means and standard deviations for baseline hunger ( $\mathrm{mm})$ and fullness $(\mathrm{mm})$ before, and after, lunch

\begin{tabular}{llllll}
\hline & & \multicolumn{3}{c}{ Before lunch } & \multicolumn{2}{c}{ After lunch } \\
\cline { 2 - 6 } & $n$ & Mean & SD & Mean & SD \\
\hline Hunger & 118 & 6482 & 2088 & 11.91 & 1181 \\
Fullness & 118 & 1396 & 1697 & 7304 & 1678 \\
\hline
\end{tabular}

\subsubsection{Descriptive statistics for measures of cue reactivity}

Within-subject t-tests exploring measures of motivation to eat obtained both before, and after, pizza-cue exposure are shown in Tables 7.3 (hungry state before lunch) and 7.4 (satiated state after lunch), respectively. The statistics in parenthesis (brackets) represent the findings after the removal of outliers associated with these variables These outliers were between 4 and 7 standard deviations away from the mean However, they had little impact on the statistical significance of the observed results.

Inspection of Table 73 suggests that before lunch, hunger was significantly increased after cue exposure, and that fullness was significantly reduced. It also suggests that subjective appetite (desire-to-eat, and craving) for pizza was significantly greater after cue exposure. By contrast, appetite for the non-cued foods (chips and cookıes) was significantly reduced after pizza-cue exposure, suggesting that cueing with pizza did little to stimulate appetite for these foods A similar pattern of results was also evident for portion-size selections before lunch. Only desired portion size of pizza increased significantly after cue exposure. The mean desired portion size of pizza pnor to cue exposure comprised $825.74 \mathrm{kcal}$ ( $S D=$ $531.98 \mathrm{kcal}$ ), whilst the mean desired portion size after cue exposure comprised $92678 \mathrm{kcal}(S D=629.55)$.

After lunch, the findings revealed that hunger significantly increased from before to after cue exposure and fullness decreased significantly (Table 7.4). Appetite (desire to eat and craving) for pizza, and desired portion size of this food, again were also 
significantly greater after cue exposure, whilst appetite (desire to eat and craving) and desired portion size for the non-cued foods did not differ significantly (Table 74). Prior to cue exposure, the mean desired portion size of pizza comprised 175.75 $\mathrm{kcal}(S D=224.87 \mathrm{kcal})$. By contrast, after cue exposure it comprised $291.17 \mathrm{kcal}$ $(S D=338.08 \mathrm{kcal})$

Table 73 Within-subject t-tests, means, and standard deviations, for changes in hunger ( $\mathrm{mm}$ ) and fullness ( $\mathrm{mm}$ ) and changes in appettte ratings (desire to eat and craving) ( $\mathrm{mm}$ ) and portion-size selection, for the cued (pizza,) and non-cued, foods (chips, and chocolate cake) before lunch

\begin{tabular}{|c|c|c|c|c|c|c|c|}
\hline & \multirow[b]{2}{*}{$n$} & \multicolumn{2}{|c|}{ Pre-exposure } & \multicolumn{2}{|c|}{ Post-exposure } & \multicolumn{2}{|c|}{$\begin{array}{l}\text { t value and } \\
\text { significance }\end{array}$} \\
\hline & & Mean & SD & Mean & SD & $t$ & $p$ \\
\hline \multicolumn{8}{|l|}{ Changes } \\
\hline Hunger (mm) & 118 & 6687 & 2348 & 7221 & 2302 & 344 & $0001 *$ \\
\hline Fullness (mm) & 118 & $\begin{array}{l}1687 \\
(1677)\end{array}$ & $\begin{array}{l}1751 \\
(1755)\end{array}$ & $\begin{array}{l}1361 \\
(1259)\end{array}$ & $\begin{array}{l}1641 \\
(1527)\end{array}$ & $\begin{array}{l}-408 \\
(-544)\end{array}$ & $\begin{array}{l}<0001^{*} \\
(<0001)^{*}\end{array}$ \\
\hline $\begin{array}{l}\text { Desire-to-eat pizza } \\
(\mathrm{mm})\end{array}$ & 118 & 5780 & 2971 & 69.70 & 27.99 & 645 & $<0001^{*}$ \\
\hline $\begin{array}{l}\text { Desire-to-eat chips } \\
(\mathrm{mm})\end{array}$ & 118 & 4988 & 2942 & 4435 & 2821 & -384 & $<0001^{*}$ \\
\hline $\begin{array}{l}\text { Desire-to-eat } \\
\text { chocolate cake (mm) }\end{array}$ & 118 & 5297 & 2964 & 4651 & 2908 & -394 & $<0001^{*}$ \\
\hline $\begin{array}{l}\text { Craving for pizza } \\
(\mathrm{mm})\end{array}$ & 118 & 5156 & 3147 & 6459 & 2961 & 645 & $<0001^{*}$ \\
\hline $\begin{array}{l}\text { Cravıng for chıps } \\
\text { (mm) }\end{array}$ & 118 & 4474 & 3001 & 3903 & 2869 & -304 & $0003 *$ \\
\hline $\begin{array}{l}\text { Craving for } \\
\text { chocolate cake (mm) }\end{array}$ & 118 & 5023 & 2943 & 43.78 & 2812 & -382 & $<0001^{*}$ \\
\hline Pizza size $\left(\mathrm{mm}^{2}\right)$ & 118 & 3058291 & 1907360 & 3423519 & 2331681 & 303 & $0003 *$ \\
\hline Portion of chips (g) & 118 & 7295 & 4351 & 6915 & 4581 & -1.42 & 0158 \\
\hline $\begin{array}{l}\text { Portion of chocolate } \\
\text { cake }\left(\mathrm{mm}^{2}\right)\end{array}$ & 118 & 555272 & 4554.26 & 436068 & 410710 & -554 & $<0001^{*}$ \\
\hline
\end{tabular}

* denotes $p<005$

() Statistics once outliers are removed from the data set The outlier was 561 standard deviations above the mean 
Table 74 Within-subject t-tests, means, and standard deviations, for changes in hunger ( $\mathrm{mm})$ and fullness $(\mathrm{mm})$, and changes in appetite ratıngs (desire to eat, and craving) ( $\mathrm{mm}$ ) and portion-size selection, for the cued (pizza), and non-cued (chips, and chocolate cake), foods after lunch

\begin{tabular}{|c|c|c|c|c|c|c|c|}
\hline & \multirow[b]{2}{*}{$n$} & \multicolumn{2}{|c|}{ Pre-exposure } & \multicolumn{2}{|c|}{ Post-exposure } & \multicolumn{2}{|c|}{$\begin{array}{l}\text { T-value and } \\
\text { significance }\end{array}$} \\
\hline & & Mean & SD & Mean & SD & $t$ & $p$ \\
\hline \multicolumn{8}{|l|}{ Changes } \\
\hline Hunger (mm) & 118 & 1409 & 1399 & 2059 & 1700 & 527 & $<0001^{*}$ \\
\hline Fullness (mm) & 118 & $\begin{array}{l}7235 \\
(7213)\end{array}$ & $\begin{array}{l}1959 \\
(1953)\end{array}$ & $\begin{array}{l}6827 \\
(6882)\end{array}$ & $\begin{array}{l}2138 \\
(2061)\end{array}$ & $\begin{array}{l}-278 \\
(-264)\end{array}$ & $\begin{array}{l}0006^{*} \\
(0010)^{*}\end{array}$ \\
\hline $\begin{array}{l}\text { Desire-to-eat pizza } \\
(\mathrm{mm})\end{array}$ & 118 & $\begin{array}{l}1599 \\
(1530)\end{array}$ & $\begin{array}{l}2004 \\
(1867)\end{array}$ & $\begin{array}{l}2666 \\
(2670)\end{array}$ & $\begin{array}{l}2536 \\
(2547)\end{array}$ & $\begin{array}{l}612 \\
(713)\end{array}$ & $\begin{array}{l}<0001^{*} \\
(<0001)^{*}\end{array}$ \\
\hline $\begin{array}{l}\text { Desire-to-eat chips } \\
(\mathrm{mm})\end{array}$ & 118 & $\begin{array}{l}1327 \\
(1331)\end{array}$ & $\begin{array}{l}1861 \\
(1868)\end{array}$ & $\begin{array}{l}1297 \\
(1259)\end{array}$ & $\begin{array}{l}1766 \\
(1727)\end{array}$ & $\begin{array}{l}034 \\
(090)\end{array}$ & $\begin{array}{c}0737 \\
(0.368)\end{array}$ \\
\hline $\begin{array}{l}\text { Desire-to-eat } \\
\text { chocolate cake (mm) }\end{array}$ & 118 & $\begin{array}{l}1933 \\
(1882)\end{array}$ & $\begin{array}{l}2165 \\
(2104)\end{array}$ & $\begin{array}{l}1747 \\
(1759)\end{array}$ & $\begin{array}{l}2088 \\
(2093)\end{array}$ & $\begin{array}{l}137 \\
\left(\begin{array}{ll}1 & 01\end{array}\right)\end{array}$ & $\begin{array}{l}0175 \\
\left(\begin{array}{ll}0 & 316\end{array}\right)\end{array}$ \\
\hline $\begin{array}{l}\text { Craving for pizza } \\
(\mathrm{mm})\end{array}$ & 118 & $\begin{array}{l}1476 \\
(1404)\end{array}$ & $\begin{array}{l}2067 \\
(1926)\end{array}$ & $\begin{array}{l}2443 \\
(2449)\end{array}$ & $\begin{array}{l}2656 \\
(2667)\end{array}$ & $\begin{array}{l}535 \\
(633)\end{array}$ & $\begin{array}{l}<0001^{*} \\
(<0001)^{*}\end{array}$ \\
\hline $\begin{array}{l}\text { Craving for chips } \\
(\mathrm{mm})\end{array}$ & 118 & 1123 & 1706 & 1153 & 1623 & 048 & 0632 \\
\hline $\begin{array}{l}\text { Craving for } \\
\text { chocolate cake (mm) }\end{array}$ & 118 & $\begin{array}{l}1776 \\
(1730)\end{array}$ & $\begin{array}{l}2225 \\
(2178)\end{array}$ & $\begin{array}{l}1609 \\
(1617)\end{array}$ & $\begin{array}{l}1909 \\
(19.15)\end{array}$ & $\begin{array}{l}142 \\
(106)\end{array}$ & $\begin{array}{l}0160 \\
0290\end{array}$ \\
\hline Pizza size $\left(\mathrm{mm}^{2}\right)$ & 118 & 650936 & 832846 & 1078421 & 1252133 & 561 & $<0001^{*}$ \\
\hline Portion of chips (g) & 118 & 2533 & 3843 & 2183 & 2626 & -120 & 0232 \\
\hline $\begin{array}{l}\text { Portion of chocolate } \\
\text { cake }\left(\mathrm{mm}^{2}\right)\end{array}$ & 118 & 3056 & 3635 & 2962 & 36.52 & 082 & 0415 \\
\hline
\end{tabular}

* denotes $p<005$

() Statistics once outliers are removed from the data set The outhers were between 4 and 7 standard deviations above, and below, the mean

\subsubsection{Effects of food models on subjective appetite}

To substantiate the claim that the food models used in this experiment provided a non-cued measure of participants' desired portion sizes, the effect of these models 
on appetite was assessed by comparing ratings taken from before, to after, initial exposure to these models $(1 \mathrm{e}$, when participants were indicating their pre-exposure desired portion sizes) In this experiment, this analysis was undertaken for the measures obtained both before, and after, lunch. Before lunch, the act of making pre-exposure portion-size selections using the food models significantly reduced fullness, increased desire-to-eat chips and pizza, and increased craving for all three test foods (Table 75 ) After lunch, although hunger increased significantly by approximately $3 \mathrm{~mm}$ after indicating pre-exposure desired portion size of the test foods, desire-to-eat all the test foods was sigmificantly reduced as was craving for pizza and chips (Table 76 ). By contrast, craving for chocolate cake and levels of fullness were not significantly different. Taken together, these findings suggest that the food models used in this experiment can in fact stımulate subjective appetite when participants have been deprived of food, but not after partıcipants have recently eaten to satiety

Table 75 Within-subject t-tests, means and standard devattons, for changes in hunger ( $\mathrm{mm}$ ) and fullness ( $\mathrm{mm}$ ), and changes in appette rattngs (destre to eat, and craving) ( $\mathrm{mm}$ ) for the cued (pizza), and non-cued (chips, and chocolate cake), foods after pre-exposure portion-size selections, whlle participants were hungry

\begin{tabular}{|c|c|c|c|c|c|c|c|}
\hline & \multirow[b]{2}{*}{$n$} & \multicolumn{2}{|c|}{$\begin{array}{l}\text { Before portion- } \\
\text { size selection }\end{array}$} & \multicolumn{2}{|c|}{$\begin{array}{c}\text { After portion-size } \\
\text { selection }\end{array}$} & \multicolumn{2}{|c|}{$\begin{array}{l}t \text {-value and } \\
\text { significance }\end{array}$} \\
\hline & & Mean & SD & Mean & $\mathrm{SD}$ & $t$ & $p$ \\
\hline \multicolumn{8}{|l|}{ Changes } \\
\hline Hunger (mm) & 118 & 6457 & 2079 & 6687 & 2348 & 176 & 0081 \\
\hline Fullness (mm) & 118 & 1402 & 1703 & 1687 & 17.51 & 266 & $0009^{*}$ \\
\hline \multicolumn{8}{|l|}{ Destre-to-eat } \\
\hline Pizza (mm) & 118 & 5397 & 2926 & 5780 & 29.71 & 245 & $0016^{*}$ \\
\hline Chıps (mm) & 118 & 43.78 & 2950 & 4988 & 2942 & 323 & $0002^{*}$ \\
\hline Chocolate cake (mm) & 118 & 5181 & 2665 & 5297 & 2965 & 0743 & 0459 \\
\hline \multicolumn{8}{|l|}{ Craving } \\
\hline $\operatorname{Pizza}(\mathrm{mm})$ & 118 & 4253 & 2989 & 5156 & 3147 & 572 & $<0001^{*}$ \\
\hline Chıps (mm) & 118 & 3646 & 2848 & 4474 & 3001 & 471 & $<0001^{*}$ \\
\hline Chocolate cake $(\mathrm{mm})$ & 118 & 4358 & 2896 & 5023 & 2943 & 430 & $<0001^{*}$ \\
\hline
\end{tabular}


Table 76 Within-subject t-tests, means, and standard deviations, for changes in hunger $(\mathrm{mm})$ and fullness $(\mathrm{mm})$, and changes in appettte ratings (destre to eat, and craving) $(\mathrm{mm})$ for the cued (pizza), and non-cued (chips, and chocolate cake), foods after pre-exposure portion-size selections in the absence of hunger

\begin{tabular}{|c|c|c|c|c|c|c|c|}
\hline & \multirow[b]{2}{*}{$n$} & \multicolumn{2}{|c|}{$\begin{array}{l}\text { Before portion- } \\
\text { size selection }\end{array}$} & \multicolumn{2}{|c|}{$\begin{array}{l}\text { After portion-size } \\
\text { selection }\end{array}$} & \multicolumn{2}{|c|}{$\begin{array}{l}\text { t-value and } \\
\text { significance }\end{array}$} \\
\hline & & Mean & $\mathrm{SD}$ & Mean & $\mathrm{SD}$ & $t$ & $p$ \\
\hline \multicolumn{8}{|l|}{ Changes } \\
\hline Hunger (mm) & 118 & $\begin{array}{l}1181 \\
(1161)\end{array}$ & $\begin{array}{l}1181 \\
(1167\end{array}$ & $\begin{array}{l}1409 \\
(1347)\end{array}$ & $\begin{array}{l}1399 \\
(1232)\end{array}$ & $\begin{array}{l}254 \\
(232)\end{array}$ & $\begin{array}{l}0013^{*} \\
(0022)^{*}\end{array}$ \\
\hline Fullness (mm) & 118 & 7312 & 1687 & 7279 & 1910 & -031 & 0754 \\
\hline \multicolumn{8}{|l|}{ Desire-to-eat } \\
\hline Pızza (mm) & 118 & 2045 & 2106 & 1599 & 2004 & -517 & $<0001^{*}$ \\
\hline Chips (mm) & 118 & 1625 & 1795 & 1327 & 1861 & -335 & $0001^{*}$ \\
\hline Chocolate cake $(\mathrm{mm})$ & 118 & 2100 & 2074 & 1933 & 2165 & -517 & $<0001^{*}$ \\
\hline \multicolumn{8}{|l|}{ Craving } \\
\hline Pizza (mm) & 118 & $\begin{array}{l}1797 \\
(1743)\end{array}$ & $\begin{array}{l}21.24 \\
(20.52)\end{array}$ & $\begin{array}{l}1476 \\
(1473)\end{array}$ & $\begin{array}{l}2067 \\
(2075)\end{array}$ & $\begin{array}{l}-3.34 \\
(-328)\end{array}$ & $\begin{array}{l}0001^{*} \\
(0001)^{*}\end{array}$ \\
\hline Chips (mm) & 118 & 1433 & 1881 & 1123 & 1706 & -340 & $0001^{*}$ \\
\hline Chocolate cake (mm) & 118 & 1807 & 2068 & 1776 & 2225 & -028 & 0780 \\
\hline
\end{tabular}

* denotes $p<005$

() Statistics once outliers are removed from the data set The outhers were over 513 standard deviations above the mean

\subsubsection{Associations between food-cue reactivity and sensitivity to reward}

Before lunch, pizza-cue exposure was not found to significantly stimulate greater hunger, a greater subjectıve appetite for the test foods (pizza, chips, or chocolate cake), or to increase desired portion size of any of the foods in individuals with a high sensitivity to reward (Table 77 ). In addition to this, a higher reward sensitivity was not associated with greater decreases in fullness following cue exposure before lunch This was the case even after the removal of an outler from the data set which was 5.61 standard deviations above the mean and 634 standard deviations above the predicted value from the linear regression model. 
Again, after lunch, there was little evidence to suggest that individuals with higher reward sensitivities experienced greater changes in hunger, or fullness, or in subjective appetite (desire to eat and craving) for the pizza or for non-cued foods after cue exposure (Table 78). However, there was a statistically significant association between change in desired pizza size and sensitıvity to reward scores when individuals were tested in the absence of hunger. Individuals with high sensitivity to reward scores expenenced a change in desired pizza size of approxımately $170 \mathrm{kcal}$ while those with lower scores on this scale experienced a change of approximately only $60 \mathrm{kcal}$ (see Figure 7.1 ). Table 79 provides estımates of how these changes might affect the total amount of pizza in Kcalones that individuals with different reward sensitivities might consume after cue exposure.

To determine the extent to which the association between sensitivity to reward scores and change in desired pizza size was independent of impulsivity scores, these scores were entered as a covariate into the regression model. This analysis suggested that the association between change in desired portion size and sensitivity to reward remained statistically significant even after controlling for impulsıvity scores $(B=393.15, S E=19503, p=0046)$. This suggests that individuals with high reward sensitivities experienced a significantly greater change in desired portion after cue exposure irrespective of their tendency to act on impulse. 
Table 77 Adjusted parameter estımates ${ }^{1}$ from linear regression models for associations between sensitivity to reward scores and measures of cue reactivity before lunch

\begin{tabular}{lllll}
\hline & \multicolumn{4}{c}{ Sensitvity to reward } \\
\cline { 5 - 5 } & $n$ & $B$ & $S E$ & $p$ \\
\hline Cue reactivtty measure & & & & \\
Change in hunger & 118 & 023 & 026 & 039 \\
Change in fullness & 118 & 005 & 022 & 080 \\
& & $(-077)$ & $(-013)$ & $(044)$ \\
Change in desire-to-eat pizza & 118 & -001 & 041 & 098 \\
Change in desire-to-eat chips & 118 & 003 & 035 & 092 \\
Change in desire-to-eat chocolate & 118 & 016 & 037 & 066 \\
cake & & & & \\
Change in craving for pizza & 118 & -008 & 048 & 087 \\
$\begin{array}{l}\text { Change in craving for chips } \\
\text { Change in craving for chocolate cake }\end{array}$ & 118 & 0.14 & 043 & 075 \\
Change in desired portion of pizza & 118 & -054 & 037 & 015 \\
Change in desired portion of chips & 118 & -082 & 064 & 020 \\
Change in desired portion of & 118 & -066 & 064 & 031 \\
chocolate & & & & 010 \\
\hline
\end{tabular}

\footnotetext{
Adjusted for the relevant pre-exposure ratıng for all outcome measures, and adjusted for likıng for the cued/non-cued food for food-specific outcome measures (e g, change in craving for pizza, desired portion size of pizza)

() Statistics once outliers are removed from the data set The outlier was 561 standard deviations above the mean and 634 standard deviations above the predicted value

* denotes $\mathrm{p}<005$
} 
Table 78 Adjusted parameter estimates ${ }^{1}$ from linear regression models of associations between sensitivity to reward scores and measures of cue reactivity after lunch

\begin{tabular}{lllll}
\hline & \multicolumn{4}{c}{ Sensitivity to reward } \\
\cline { 4 - 5 } & $n$ & $B$ & $S E$ & $p$ \\
\hline Cue reactivity measure & & & & \\
Change in hunger & 118 & 037 & 031 & 0234 \\
Change in fullness & 118 & -019 & 032 & 0567 \\
& & $(-007)$ & $(026)$ & $(0779)$ \\
Change in desire-to-eat pizza & 118 & 034 & 044 & 0433 \\
& & $(042)$ & $(040)$ & $(0293)$ \\
Change in desire-to-eat chips & 118 & 020 & 021 & 0361 \\
& & $(012)$ & $(019)$ & $(0539)$ \\
Change in desire-to-eat chocolate & 118 & 055 & 032 & 0089 \\
cake & & $(047)$ & $(029)$ & $(0109)$ \\
Change in craving for pizza & 118 & 019 & 044 & 0275 \\
& & $(013)$ & $(040)$ & $(0156)$ \\
Change in craving for chips & 118 & 016 & 014 & 0271 \\
Change in craving for chocolate cake & 118 & 024 & 026 & 0365 \\
Change in desired portion of pizza & 118 & 44161 & 18849 & $0021 *$ \\
Change in desired portion of chips & 118 & 004 & 037 & 0922 \\
Change in desired portion of & 118 & 3537 & 1997 & 0079 \\
chocolate & & & & $(0477)$ \\
\hline
\end{tabular}

\footnotetext{
TAdjusted for the relevant pre-exposure ratıng for all outcome measures, and adjusted for liking for the cued/non-cued food for food-specific outcome measures (e g, change in craving for pizza, desired portion size of pizza)

() Statistics once outliers are removed from the data set These outliers were between 4 and 7 standard deviations above and below the mean and between 35 and 65 standard deviations above and below the values predicted from the regression model

$*$ denotes $\mathrm{p}<005$
} 


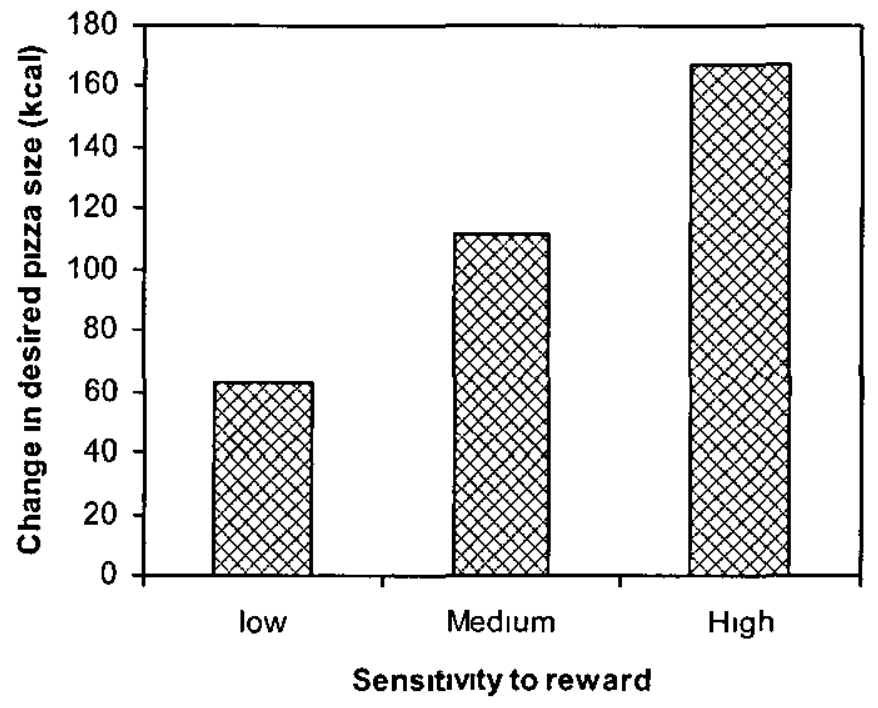

Figure 71 Predicted changes in desired pizza size (kcal) after lunch for individuals with low (723), medium (11 28), and high (1595), sensitivity to reward scores from a regression model used to predict this measure $(B=44161)^{15}$

Table 79 Predicted pre-exposure pizza size and calculated post-exposure portton size after lunch for individuals with low (7 23), medium (11 28), and high (1595), sensittvity to reward scores ${ }^{16}$

\begin{tabular}{lll}
\hline & Pre-exposure (kcal) & Post-exposure (kcal) \\
\hline Sensitivity to reward scores & & \\
Low & 14417 & 20780 \\
Medium & 17423 & 28616 \\
High & 20880 & 37629 \\
\hline
\end{tabular}

${ }^{15}$ Liking for pizza and pre-exposure desired pizza size were held at their average values in the sample $\left(7305 \mathrm{~mm}\right.$ and $650936 \mathrm{~mm}^{2}$ [175 $\left.\left.75 \mathrm{kcal}\right]\right)$ and therr respectıve parameter estımates from the regression model $[B=9535$ and $B=0095$, respectively] were used to predict desired portion size of pizza for individuals with a low, medium, and high sensitivity to reward

${ }^{16}$ Pre-exposure size is predicted from a regression model used to predict this measure $(B=27483)$ Average liking for pizza was held at its average value in the sample $(7305)$ and its parameter estumate from the regression model was used to predict pre-exposure portion size $(B=4910)$ Postexposure portion size was calculated from this measure by summing the predicted pre-exposure portion sizes to the predicted change in desired pizza size 


\subsubsection{Associations between food-cue reactivity and impulsivity}

\subsubsection{Stop start task}

There was little evidence to suggest that stop start signal scores were associated with changes in any of the measures of subjective appetite, or portion-size selection, after cue exposure etther in the absence of hunger (after lunch), or after four hours food deprivation (all $p>005$ ) (Results not shown here because they all falled to reach statistical significance) However, there were limitations associated with this measure These will be discussed further in the discussion (Section 7.5)

\subsubsection{EPQ-impulsivity scores}

Before lunch, there was little evidence to suggest that impulsivity scores were associated with changes in general subjective appetite (hunger and fullness) after cue exposure, or with increased motivation-to-eat (subjective appetite and desired portion size selections) the non-cued foods (Table 7.10). However, there was evidence of a statistically significant association between these scores and change in craving for pizza (Table 7.10). As Figure 7.2, Panel A suggests change in craving for pizza was greater in individuals who reported greater impulsivity. Before lunch, these individuals were also found to select significantly larger pizza sizes after cue exposure (see Table 7 10, and Figure 72 , Panel B) Table 7.11 provides estımates of the effect of these increases on the total amount of pizza that these individuals might consume after cue exposure.

To determine the extent to which these associations observed between impulsivity scores and the two measures of cue reactivity (change in craving and change in portion-size selection) before lunch were independent of sensitivity to reward both predictor vanables were entered simultaneously into two separate regression models to predict change in craving for pizza/ change in pizza portion size as outcomes. This analysis suggested that the association between change in craving and 
impulsivity scores remained statistically significant $(B=1.05, S E=0.45, \mathrm{p}=$ 0022 ), suggesting that individuals with higher impulsivity scores experienced a greater change in craving for pizza after cue exposure irrespective of their sensitivity to reward However, the association between impulsivity scores and change in desired portion size was no longer statistically significant when sensitivity to reward was also entered into the regression model $(B=556.82, S E=$ $29589, p=0062$ ). This suggests that impulsivity scores were not independently associated with the changes in desired pizza size observed and that these changes were in fact explained by some shared variance between impulsivity and sensitıvity to reward scores Indeed, visual inspcction of Figure 7.3 suggests that although individuals with high impulsivity scores in the absence of a high sensitivity to reward did experience greater changes in desired pizza than those with lower scores on both scales, individuals who had simultaneously high scores on the impulsivity and sensitivity to reward scales experienced the greatest increase in desired pizza after cue exposure. 
Table 710 Adjusted parameter estimates ${ }^{1}$ from linear regression models for assoctations between impulsivity scores and measures of cue reactivity before lunch

\begin{tabular}{lllll}
\hline & \multicolumn{3}{l}{ Impulsivity } \\
\cline { 2 - 5 } & $n$ & $B$ & $S E$ & $p$ \\
\hline Cue reactivity measures & 118 & 033 & 024 & 0164 \\
Change in hunger & 118 & -025 & 024 & 0302 \\
Change in fullness & & $(026)$ & $(022)$ & $(0237)$ \\
& 118 & 059 & 037 & 0111 \\
Change in desire-to-eat pizza & 118 & -044 & 033 & 0184 \\
Change in desire-to-eat chips & 118 & -004 & 034 & 0897 \\
Change in desire-to-eat chocolate cake & 118 & 088 & 042 & $0039^{*}$ \\
Change in craving for pizza & 118 & -059 & 0.40 & 0142 \\
Change in craving for chips & 118 & -37 & 006 & 0856 \\
Change in craving for chocolate cake & 118 & 64772 & 27139 & $0019^{*}$ \\
Change in desired portion of pizza & 118 & -032 & 058 & 0589 \\
Change in desired portion of chips & 118 & 1584 & 4562 & 0.729 \\
Change in desired portion of chocolate & 118 & & & \\
cake & & & & \\
\hline
\end{tabular}

\footnotetext{
TAdjusted for the relevant pre-exposure rating for all outcome measures, and adjusted for liking for the cued/non-cued food for food-specific outcome measures (e g, change in craving for pizza, desired portion size of pizza)

() Statistics once outhers are removed from the data set The outlier was 561 standard deviations above and the mean and 488 standard deviations above the values predicted from the regression model

$*$ denotes $\mathrm{p}<005$
} 
A

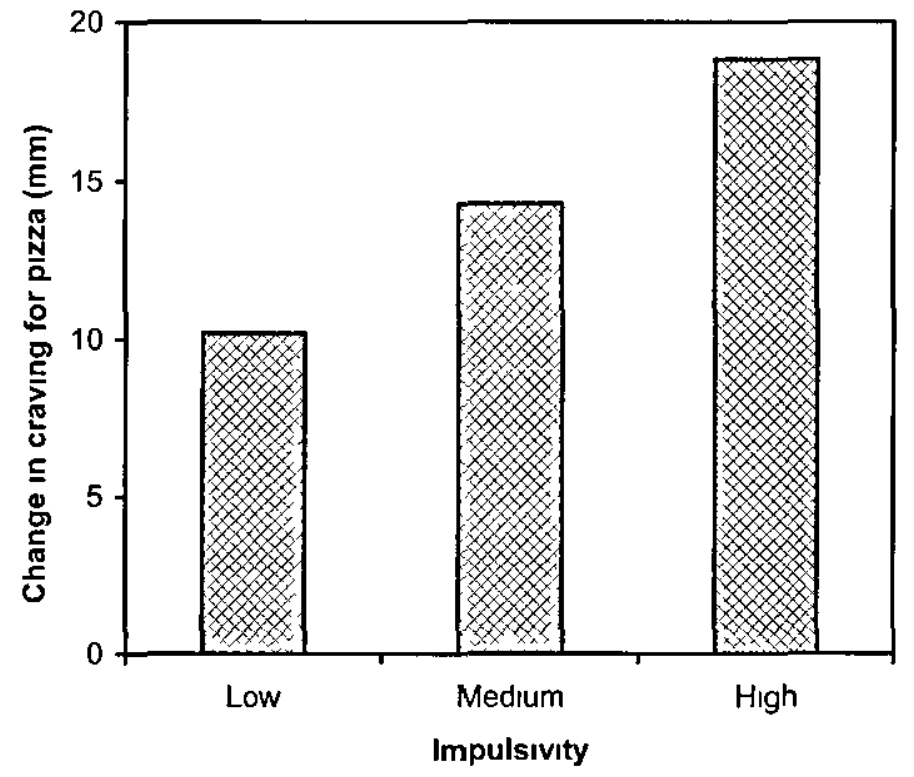

B

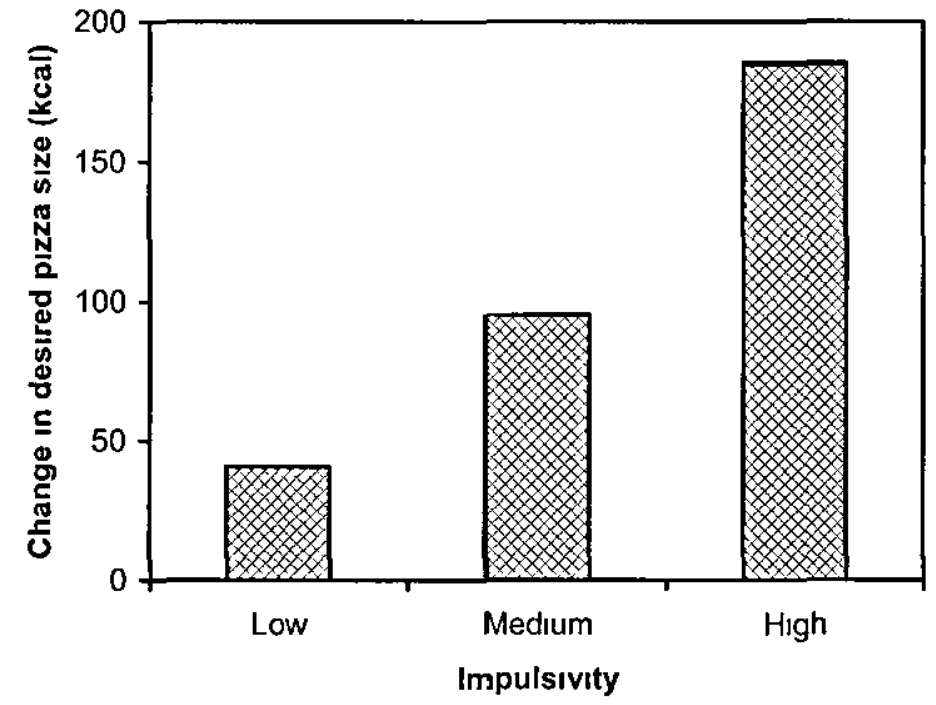

Figure 72 Predicted changes in craving for pizza ( $\mathrm{mm})$ (A) and desired pizza size (kcal) (B) before lunch for individuals with low (2 82), medium (7 49), and high (12 65), impulsivtty scores from a regression model used to predict these measures $(B=088, B=$ 64772 , respectively) $)^{17}$

${ }^{17}$ Likung for pizza $(7305 \mathrm{~mm})$, and pre-exposure craving for pizza $(5056 \mathrm{~mm})$, were held at their average values in the sample for predicted changes in craving for pizza and their parameter estimates from the regression model were used to predict pre-exposure portion size $(B=014, B=-029$, respectively) For predicted changes in desired pizza size likıng for pizza $(7305 \mathrm{~mm})$ and preexposure desired pizza size (3058291 [82574 kcal]) were held at their average value in the sample 
Table 711 Predicted pre-exposure pizza size and calculated post-exposure portion size after lunch for individuals with low (2 82), medium (7 49), and high (12 65), impulstvity scores $^{18}$

\begin{tabular}{lll}
\hline Impulsivity scores & Pre-exposure (kcal) & Post-exposure $(\mathrm{kcal})$ \\
\hline Low & 80760 & 84843 \\
Medium & 82211 & 91715 \\
High & 83815 & 102343 \\
\hline
\end{tabular}

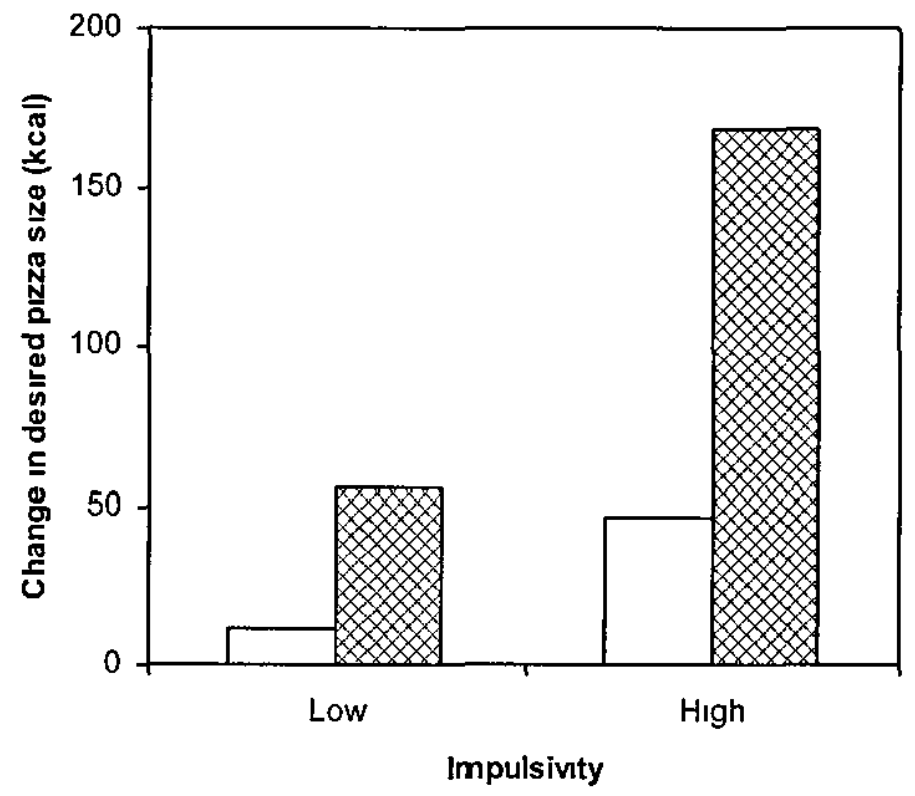

Low sensitivity to rew ard $\square$ High sensitivity to rew ard

Figure 73 Predicted changes in desired pizza size (kcal) for individuals with low (3 93)/high (11 25) impulsivity and low (8 17)/high (14 43) sensitivity to reward from a regression model used to predict change in desired pizza size before lunch ${ }^{19}$

and their parameter estımates from the regression model were used to predict pre-exposure portion size $(B=7809, B=-004$, respectively)

${ }^{18}$ Pre-exposure size is predicted from a regression model used to predict this measure while holding average liking for pizza at its average value in the sample (7305) Post-exposure portion size was calculated from this measure using predicted change in desıred pizza size after controlling for likıng for pizza and pre-exposure portion size

${ }^{19}$ Liking for pizza and pre-exposure desired pizza size were held at their average values in the sample (73 05mm and $3058291 \mathrm{~mm}^{2}$ [825 $\left.74 \mathrm{kcal}\right]$ ) 
After lunch, individuals with high impulsivity scores expernenced greater changes in desire-to-eat pizza, craving for this food, and hunger (see Table 7.12 and Figure 7.4) These associations remained statistically significant after controlling for sensitivity to reward (all $p<005$ ) However, it is important to note that after including the two outliers described earlier in the analysis (see data analysis section, 7.36 ), the association between change in hunger and impulsivity was no longer statistically significant after controlling for sensitıvity to reward $(B=-0.57, S E=$ $0.30, p=0063$ )

Visual inspection of the association between impulsivity scores and change in desired portion size of pizza revealed a curved rather than linear association. For this reason, impulsivity scores were split at their median value in the sample and entered into the regression model as a discrete vanable. However, this model provided little evidence to suggest that impulsıve individuals experienced a greater change in desired portion of the cued food than less impulsive individuals (Table 7.12). 
Table 712 Adjusted parameter estimates ${ }^{1}$ from linear regression models for associations betw'een impulsivity scores and measures of cue reactivity after lunch

\begin{tabular}{|c|c|c|c|c|}
\hline & \multirow[b]{2}{*}{$n$} & \multicolumn{3}{|c|}{ Impulsivity } \\
\hline & & $B$ & $S E$ & $p$ \\
\hline \multicolumn{5}{|l|}{ Cue reactivity measures } \\
\hline Change in hunger & 118 & 063 & 028 & $0028^{*}$ \\
\hline \multirow[t]{2}{*}{ Change in fullness } & 118 & -0154 & 029 & 0602 \\
\hline & & $\left(\begin{array}{ll}-0 & 15\end{array}\right)$ & $(024)$ & $(0520)$ \\
\hline \multirow[t]{2}{*}{ Change in desire-to-eat pizza } & 118 & 105 & 039 & $0008^{*}$ \\
\hline & & $(106)$ & $(036)$ & $(0004)^{*}$ \\
\hline \multirow[t]{2}{*}{ Change in desıre-to-eat chıps } & 118 & 007 & 019 & 0725 \\
\hline & & $(009)$ & $(050)$ & $(0618)$ \\
\hline Change in desire-to-eat chocolate & 118 & 004 & 030 & 0991 \\
\hline cake & & $\left(\begin{array}{lll}0 & 03\end{array}\right)$ & $(027)$ & $(0905)$ \\
\hline \multirow[t]{2}{*}{ Change in craving for pizza } & 118 & 1.16 & 040 & $0004 *$ \\
\hline & & $\left(\begin{array}{ll}1 & 16\end{array}\right)$ & $(036)$ & $(0002)^{*}$ \\
\hline Change in craving for chips & 118 & 011 & 013 & 0371 \\
\hline Change in craving for chocolate & 118 & 003 & 024 & 0989 \\
\hline cake & & $\left(\begin{array}{lll}0 & 01\end{array}\right)$ & $(022)$ & $(0948)$ \\
\hline $\begin{array}{l}\text { Change in desired portion of } \\
\text { pizza }^{2}\end{array}$ & 118 & 233351 & 153772 & 0132 \\
\hline Change in desired portion of chips & 118 & 024 & 024 & 0478 \\
\hline $\begin{array}{l}\text { Change in desired portion of } \\
\text { chocolate cake }\end{array}$ & 118 & -568 & 1855 & 0760 \\
\hline
\end{tabular}

\footnotetext{
TAdjusted for the relevant pre-exposure rating for all outcome measures, and adjusted for liking for the cued/non-cued food for food-specific outcome measures (eg, change in craving for pizza, desired portion size of pizza)

${ }^{2}$ Impulsivity scores were split at their median value in the sample to explore the association with this outcome measure because this association was not linear

() Statistics once outliers are removed from the data set These outliers were between 4 and 7 standard deviations above and below the mean and between 35 and 65 standard deviations above and below the values predicted from the regression model

* denotes $\mathrm{p}<005$
} 
A

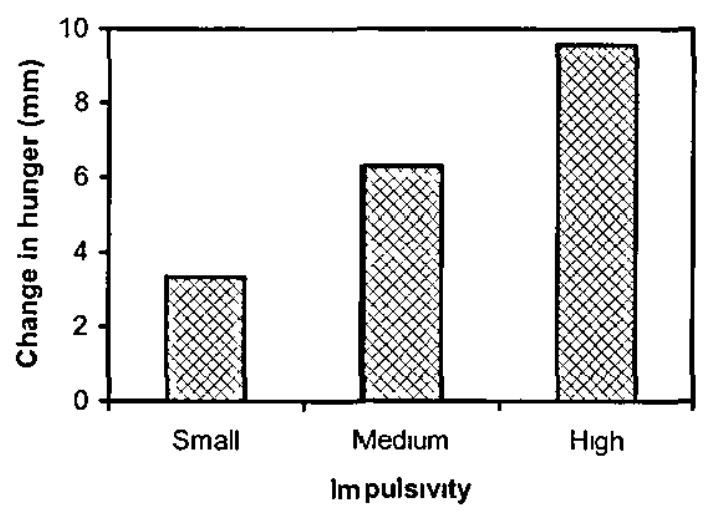

B
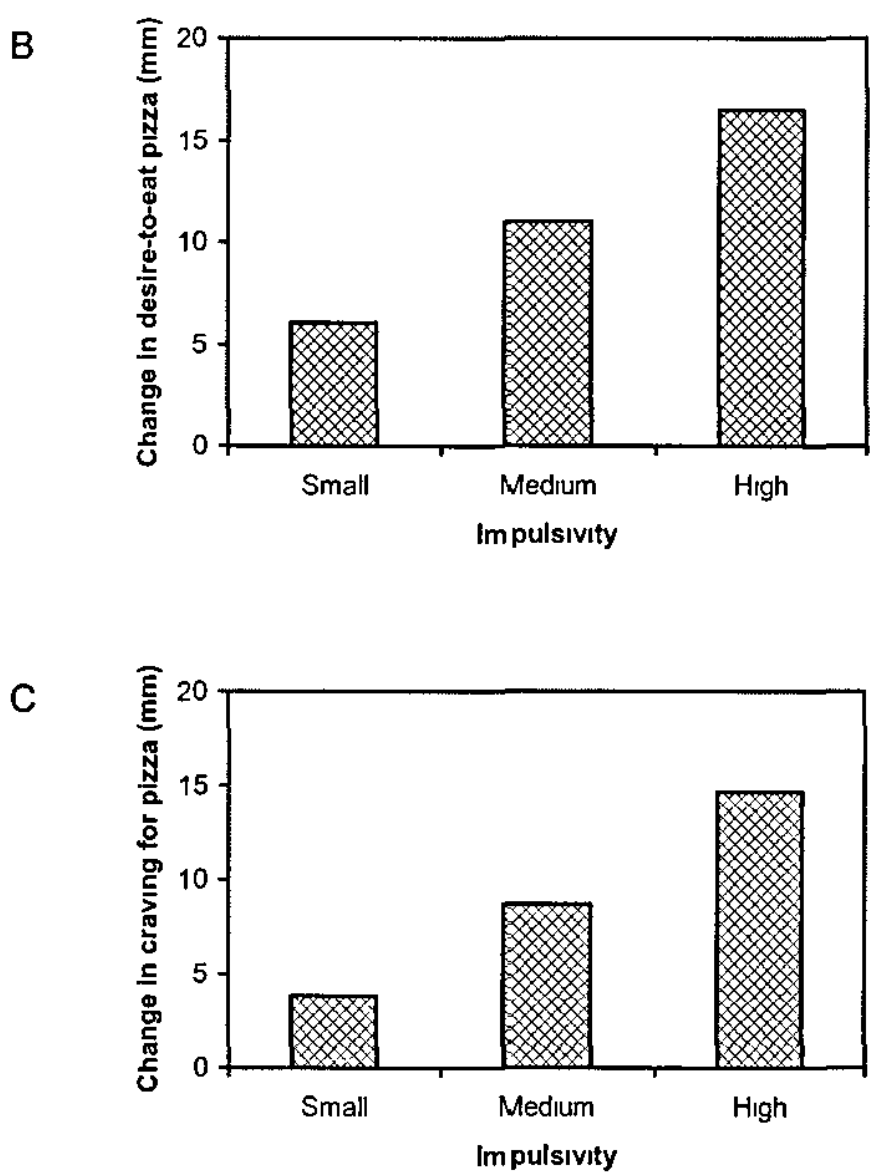

Figure 74 Predicted changes in hunger $(\mathrm{mm})(A)$, desire-to-eat pizza $(\mathrm{mm})(B)$, and craving for pizza ( $\mathrm{mm})(C)$ after lunch for individuals with small (2 82), medium (7 49), and high (12 65), impulsivity scores from three regression models used to predict these measures $\left(B=-0633,1049,1159\right.$, respectively) ${ }^{20}$

\footnotetext{
${ }^{20}$ Pre-exposure hunger $(1409)(B=-0247)$, desire-to-eat $(1599 \mathrm{~mm})(B=-0264)$, and craving for pizza $(1476 \mathrm{~mm})(B=-0244)$ were held at their average value in the relevant models Liking for pizza $(7305 \mathrm{~mm})$ was held at his average value in the sample when predicting change in desire-toeat, and craving for, pizza $(B=0236, B=0288$, for change in desire to eat, and craving for, pizza, respectrvely)
} 


\subsubsection{Associations between cue reactivity, everyday dietary behaviour, and body weight}

There was little evidence to suggest that changes in general measures of subjective appetite (hunger and fullness), changes in subjectıve appetite for the cued and noncued foods, and changes in desired portion sizes of these foods were associated with DEBQ-restraint scores, TFEQ-disinhibition scores, or being overweight (all $p>$ $005)$.

Notably, preliminary observations of the association between change in desired pizza size and TFEQ-disinhibition scores suggested that the relationship was curved rather than linear. For this reason, TFEQ-disinhibition scores were split at their median value in the sample for the subsequent regression analysis. Notably, these preliminary observations also suggested that the variance in change in desired portion size increased as TFEQ-disinhibition increased (homoscedascity) Thus, some individuals with high disınhibition scores were selectıng much larger portions of pizza after cue exposure than those selected by individuals with lower scores on this scale, while other individuals with high disinhibition scores where selecting portion sizes similar to those selected by less disinhibited individuals. This suggested that another variable might be interacting with disinhibition scores to explain elevated cue reactivity in a subsection of the individuals with high disinhibition scores. To explore this possibility, interactions between disinhibition scores (high/low) and 1) dietary restraint, 11) BMI, i11) sensitivity to reward, and 1v) impulsıvity (high and low) were assessed using regression analyses which controlled for liking for pizza and pre-exposure desired portion size. However, the only interaction which reached statistical significance was that between disinhibition scores (high/low) and impulsivity scores (high/low) ( $B=7908.11, S E$ $=317425, p=0014$ ) As Figure 75 suggests cue exposure had a much greater effect on desired portion size for individuals with simultaneously high scores on the disinhibition scale and impulsivity scale. For all other individuals, change in desired portion size was relatively similar although individuals with low impulsivity and low disinhibition scores did experience a modestly greater change in desired pizza 
size $^{21}$ It is important to note that this interaction remained statistically significant even after controlling for restrant status $(B=8942.94, S E=323465, p=0007)$ and after controlling for sensitivity to reward $(B=831562, S E=313316, p=$ 0009 ). This suggests that change in desired pizza size was elevated in individuals with simultaneously high impulsivity and disinhibition scores irrespective of their restraint status or their sensitivity to reward scores.

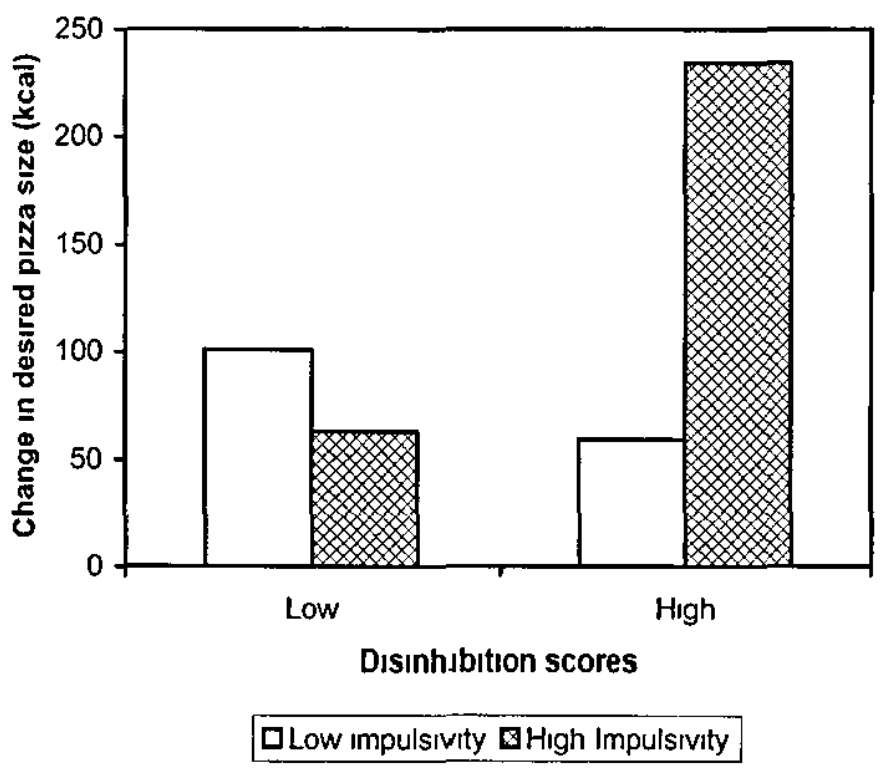

Figure 75 Predicted changes in desired pizza size (kcal) after lunch for individuals with different combinations of TFEQ-disinhibition scores and impulsivity scores based on parameter estimates from regression models ${ }^{22}$

\footnotetext{
${ }^{21}$ This interaction was not evident when individuals were hungry $(p>005)$

${ }^{22}$ In these models likıng for pizza and pre-exposure desired pizza size were held at their average values in the sample (73 05mm and $650936 \mathrm{~mm}^{2}$ [175 $\left.\left.75 \mathrm{kcal}\right]\right)$
} 
Again it was desirable to determine the effect of these changes experienced by individuals with simultaneously high disinhibition, and impulsivity, scores on total desired portion in Kcalones after cue exposure Estımates of these post-exposure portion sizes were calculated from the sum of the pre-exposure portion-size selections and the change in these portion sizes (see section 73.6 data analysis for further details of this procedure). This calculated post-exposure total portion size and the predicted pre-exposure portion size are displayed in Table 7.13. This table suggests that after cue exposure the total desired portion size was almost identıcal for individuals with high disinhibition scores irrespective of their impulsıvity scores This implies that the greater change experienced by individuals with simultaneously high scores on the disinhibition scale and impulsivity scale did not result in these individuals selecting a larger portion size in total after cue exposure. The reason these individuals' greater change in portion did not result ultımately in the selection of a larger total portion size after cue exposure is because they selected much smaller portion sizes prior to cue exposure (see Table 7.13) After controlling statistically for liking for pizza, the interaction effect between disinhibition scores (high and low) and impulsıvity scores (high and low) for these preexposure measures reached statistical significance $(B=-1060750, S E=2999.91, p=$ $0001)$. This suggests that individuals with high disinhibition scores selected much smaller pre-exposure portion sizes if they had high impulsıvity scores relative to if they had lower impulsivity scores. By contrast, individuals with low scores on this scale selected much larger pre-exposure portion sizes if they had high impulsivity scores relative to if they had lower impulsivity scores. The reason for these differences in preexposure portion-size selections is unclear. However, one possibility is that this interaction effect results from the fact that those individuals who selected larger preexposure portion sizes did so because they were relatively hungrier following the buffet lunch. To explore this possibility, the interaction between impulsivity and disinhibition scores was assessed for hunger ratıngs made immediately prior to these portion-size selections This analysis revealed a significant interaction effect $(B=-10.66, S E=4.47$, $p=0019$ ). As suggested by Table 714 the interaction effect was identical to that observed for pre-exposure portion size. Thus, individuals with high disinhibition scores reported lower hunger levels if they had high impulsıvity scores relative to if they had 
lower impulsıvity scores. By contrast, individuals with low scores on this scale reported greater levels of hunger if they had high impulsivity scores relative to if they had lower impulsıvity scores In Table 7.14 the pre-exposure portion-size selections for these groups of individuals can be seen in brackets. Direct comparison of these portion sizes suggests that those individuals who selected the larger pre-exposure portion sizes were in fact hungrier. Given the fact that individuals across the four groups appeared to differ in hunger prior to cue exposure, it was recognized that it was important to control statistically for hunger levels prior to cue exposure in the regression model used to explore the interaction between impulsivity (high and low) and disinhibition scores (high and low) This interaction remained statıstıcally significant even after controlling for this pre-exposure hunger $(B=7521.19, S E=321290, p=0021)$

Table 713 Predicted pre-exposure pizza size and calculated post-exposture portion size for individuals with different combinations of TFEQ-disinhibition scores and tmpulsivity scores ${ }^{23}$

\begin{tabular}{lcccc}
\hline & Low Impulsivity & 3 & High Impulsivity \\
\cline { 2 - 5 } & $\begin{array}{c}\text { Pre-exposure } \\
(\mathrm{kcal})\end{array}$ & $\begin{array}{c}\text { Post-exposure } \\
(\mathrm{kcal})\end{array}$ & $\begin{array}{c}\text { Pre-exposure } \\
(\mathrm{kcal})\end{array}$ & $\begin{array}{c}\text { Post-exposure } \\
(\mathrm{kcal})\end{array}$ \\
\hline Low Disinhibition & 7843 & 17925 & 21437 & 27344 \\
High Disinhibition & 30509 & 36782 & 13297 & 367.46 \\
\hline
\end{tabular}

\footnotetext{
${ }^{23}$ Pre-exposure size is predicted from a regression model used to predict this measure while holding average likıng for pizza at its average value in the sample $(7305 \mathrm{~mm})$ Post-exposure size was than calculated by adding the change in desired portion size predicted from the linear regression after controlling for likıng for pizza and the pre-exposure portion size
} 
Table 714 Predicted hunger ratings $(\mathrm{mm})$ prior to the pre-exposure portion-size selection based on the parameter esttmates from the regresston model ${ }^{24}$

\begin{tabular}{ccc}
\hline & Low Impulsıvity & High Impulsıvity \\
\hline Low Disinhibition & 8381 & 1651 \\
& $(7843)$ & $(214.37)$ \\
High Disinhibition & 1339 & 1086 \\
& $(30509)$ & $(13297)$ \\
\hline
\end{tabular}

\subsubsection{Awareness Questionnaire}

The responses from the awareness questionnaire issued in the final stages of the experiment are summarised in Table 7.15. These responses indicate that there were a small number of participants who provided responses to a general question enquiring about the aims of the study which indicated they might have some awareness of the purpose of this experiment (13 7\%), and an even smaller percent (6\%) were aware of the reason for the lunch manıpulation. However, approxımately a quarter of the sample appeared to be aware of the experiments alm to assess the effect of cue exposure on appetite ratungs and desired portion-sıze selectıons, In light of this finding, a series of regression analyses were conducted in which awareness was entered as a predictor of the key outcome measures considered in this experiment (change in an appetite ratings and portion-size selection) when individuals were hungry and satiated ${ }^{25}$. However, these analyses did not provide evidence to suggest that the outcome measures differed across aware, and non-aware, participants (all associations $p>005$ ). Furthermore, a series of between-subject t-tests and a chi-squared test for the categorical variable BMI

\footnotetext{
${ }^{24}$ Predicted pre-exposure portion sizes were based on the parameter estımates from a regressıon model used to predict this measure

${ }^{25}$ In these analyses corresponding pre-exposure measures were controlled for statıstıcally, as was likıng for pizza where the outcome measure was pizza specific
} 
provided little evidence to suggest that awareness differed across the six predictor varıables (dietary restraint, disınhıbitıon, body weıght, BAS-trait, EPQ-ımpulsıvity, or the stop start signal task).

Table 715 Summary of responses to the awareness questionnatre All totals are given in percentages

\begin{tabular}{|c|c|c|}
\hline \multirow[b]{2}{*}{ Question } & \multicolumn{2}{|c|}{ Response (\%) } \\
\hline & Aware & Not aware \\
\hline $\begin{array}{l}\text { 1. What do you think was the purpose of this } \\
\text { experiment? }\end{array}$ & 13.7 & 86.3 \\
\hline $\begin{array}{l}\text { 2. I asked you to rate your mood and appetite durıng } \\
\text { the experiment Do you know why? }\end{array}$ & 215 & 78.5 \\
\hline $\begin{array}{l}3 \text { I asked you to indicate the amounts of pizza, } \\
\text { chocolate cake, and chips that you would like to eat at } \\
\text { various time during the experiment. Do you know } \\
\text { why? }\end{array}$ & 215 & 785 \\
\hline $\begin{array}{l}\text { 4. I expected you to want to eat greater amounts of } \\
\text { these foods than you might normally do }\end{array}$ & & \\
\hline a) Which time (first, second, third, fourth)? & 49.1 & 50.9 \\
\hline b) Which food (pızza, chips, chocolate cake)? & 698 & 302 \\
\hline $\begin{array}{l}\text { 5. Do you know why you were offered lunch in this } \\
\text { experiment? }\end{array}$ & 6 & 94 \\
\hline
\end{tabular}




\subsubsection{Summary table of main results}

Given the complexity of the results described here, this section provides a tabular summary of the observed associations between the predictor, and the outcome, variables This table (Table 7.16) suggests that dietary restraint, dietary disinhibition, and being overwerght were not significant predictors of any of the measures of foodcue reactivity. However, it does suggest that sensitivity to reward, impulsivity, and an interaction effect between dietary disinhibition and impulsivity might be important predictors of some of the measures of change in appetite for the cued food. 
Table 716 Summary of the significant assoctations between the predictor vartables and the main outcome variables

\section{Predictor variables}

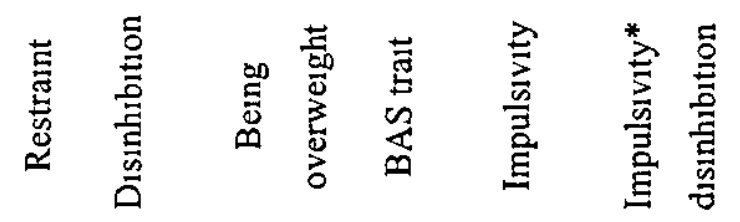

Outcome measures

Change in hunger

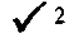

Change in fullness

Change in desire-to-eat pizza

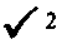

Change in desire-to-eat chips

Change in desire-to-eat chocolate cake

Change in craving for pizza

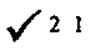

Change in craving for chips

Change in craving for chocolate cake

Change in desired pizza portion

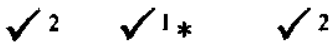

Change in desired portion of chips

Change in desired portion of chocolate

cake

$\checkmark$ Denotes where statıstically significant interactions were observed

${ }^{1}$ Association observed before lunch

${ }^{2}$ Association observed after lunch

* This was no longer statıstıcally significant after controllıng for sensitıvity to reward (t e, BAS trait)

\subsection{Discussion}

The primary aim of this expermment was to determine the extent to which individual differences in the functioning of a hypothesised brain system, the BAS, and differences in impulsivity, might be associated with food-cue reactivity in two different motıvational states (food deprived and non-food deprived) Given that the BAS is assumed to respond to stımuli associated with a reward, it was hypothesised that greater 
reactivity of this system might predict the occurrence of greater appetitive motivation elicited by a food cue The results from this experiment suggested that in a non-food deprived state there was little evidence that those individuals with a high BAS trait (1 e., a high sensitivity to reward), expenenced greater changes in subjective appetite for cued, or non-cued, foods or selected larger portions of these foods after cue exposure. However, after lunch, although individuals with a high BAS trait were not found to experience a greater increase in subjective appetite for the cued food relative to those individuals with a lower BAS trait, they did experience a greater change in desired portion stze of this food.

Therefore, in part, the findings from the present study are consistent with Gray's (1970, 1976, 1981, 1987a, 1987b) predictions regarding the functioning of the BAS. This is because Gray $(1970,1976,1981,1987 \mathrm{a}, 1987 \mathrm{~b})$ would predict that individuals with a high BAS trait experience greater appetitive motıvation for cued stımulı which are associated with a reward Notably, however, the present findings are not the first to provide support for this theory. Rather, two recent studies have also suggested that after exposure to a drug cue, motivation to use drugs is greater in those individuals with a higher BAS trait (Kambouropoulos, \& Sta1ger, 2001; 2004) The 1mportance of this accumulating evidence in support of a BAS-like system is that it raises the possibility that all behaviour that is motivated by external cues signaling a reward is the result of reactivity of one universal system. This possibility implies that individual differences in food-cue reactivity (and drug-cue reactivity for that matter) do not result from individual differences specific to that particular behaviour (1.e., eatıng, or drug use), but rather result from a more general tendency to experience a greater appetitıve motivation in the presence of cues signaling a potential reward An important, yet obvious, consequence of this is that individuals who experience greater sensitivity to food cues are also likely to experience greater sensitivity to other cues in the environment that signal a reward.

Given that food-cue reactivity might result from activation of a universal approach system sensitive to cues signalıng a reward, it is important to begin to understand the 
mechanism underlyıng this system One possibility is that greater sensitivity to stımuli associated with rewards in those with highly reactive BAS's results from stronger associations between these stımulı and the primary reinforcer (or reward) (Pickering \& Gray, 2001). For example, indıviduals who are more reactive to food cues might form stronger associations between the sight and smell of food and a tasty reward However, empincal support for this possibility has been weak For example, several studies have found that those with higher BAS reactivity do not form associations between a stimuli and a primary reward at a greater rate than those with a lower BAS reactivity. Rather, these studies have found that once these responses are learnt, individuals with a high BAS trait perform them faster (Corr, Pickerıng, \& Gray, 1995, Pıckerıng, Diaz, \& Gray, 1995) For this reason, Pickernng and Gray (2001) suggest that rather than forming stronger learned associatıons between external stımulı (e g., a food cue) and a reward (i e., the tasty reward), those with higher BAS activity might in fact attribute greater 'incentive salience' to a conditioned stimulus (CS). The implication of this is that when these individuals are exposed to this stimulus on subsequent occasions the salience of the incentive offered by this stimulus is greater for these individuals.

The notion of motivated responses relying on incentive salience is consistent with Berridge and Robınson's (1998) Incentıve Salience hypothesıs. To recap, this hypothesis was described in Chapter 2 and suggests that the ability of an external cue (such as a food cue) to motıvate behaviour is the result of three psychological processes. Initial contact with an unconditioned stimulus (1.e., a tasty food) produces a hedonic liking for the food and thereby leads to the acquisition of new incentives. A correlation is then identified between this hedonic activation and the external stımulus that predicted it. Finally, this external stımulus acquires incentive salıence, and thereby is able to command attention and elicit a motivational state This final stage is the most important stage and is necessary for food-cue reactivity to occur Initral contact with a food cue alone will not result in greater reactivity. Thus, it is this final stage which Pickering and Gray (2001) suggest might differ in those individuals with a highly reactive BAS This is because those with a higher BAS are assumed to attribute greater incentıve salience to a food cue. 
Importantly, in their Incentıve Salience hypothesıs, Berridge and Robinson (1998) suggest that incentive salience is attributed via dopamine activation Put simply, it is assumed that when individuals are presented with a stımulus that predicts a reward, dopamınergic actıvity begins and thereby incentive salıence is attributed to this stımulus. Berridge and Robınson (1998) present a review of evidence suggestıng that disruption of dopaminergic activity (which has been found to occur in anticipation of a reward) does not affect learned associations themselves, but rather disrupts appetitive motıvation for the CS The authors use this evidence to suggest that dopamine is required for incentive salience, but is not necessary for the formation of associations between an external stımul and the reward it predicts. This is potentrally relevant to understanding the mechanism underlying the BAS because it is also assumed that the functioning of the BAS depends on firing of dopamine cells (P1ckerıng \& Gray, 2001). Thus, one possibility is that those individuals with a highly reactive BAS experience greater dopamine firng in the presence of stımuli associated with rewards, thereby they attribute greater incentive salience to these stımul, and for this reason are more motivated to obtain the reward associated with this cue Given that evidence implicates dopamıne as the determınant of cue-elıcited behaviour (see Berridge \& Robınson, 1998 for a review), it does follow that individual differences in dopamine activation might determine reactivity to environmental cues. However, the extent to which a high BAS trait predicts greater dopamine activation remains to be established To date, evidence has only shown that behaviours associated with BAS activity are related to neurological disruptions which elicit greater dopamine activation (Comings, Gade, Wu, Chiu, Dietz, Muhlemann et al 1997). Therefore, future work is required to determine the extent to which a high BAS trait is associated with greater dopamine activation in the presence of cues associated with a reward. There is also a need to understand the extent to which these differences in dopamine actıvation determine appetitive motivation elicited by these stımuli.

Implicit in the preceding discussion is the notion that a high BAS trait is indiscriminately associated with a greater appetitive motivation in the presence of food 
cues. However, the results from the present study suggest that a highly reactive BAS was not in fact associated with greater motivation to eat a cued food while individuals were food deprived This suggests that individual variation in the BAS might only predict greater food-cue reactıvity when individuals are satıated The reason for this might not be that the BAS functions differently in different physiological states, but rather that a highly reactive BAS is not required to experience appetitive motivation for a stımulı associated with a food reward when a physiological drive to eat is present. Consistent with this possibility, it has been suggested that an entirely separate neural system (1.e., the tegmental pedunculopontıne, TPP) mediates the incentıve value of rewards when anımals are in a deprived state (Bechara \& van der Kooy, 198, 1992), thus suggesting that attribution of incentive salience is not required in order for a cue to motıvate behavıour while food deprived. Berridge and Robınson (1998) suggest that this is because a motivational drive to eat is sufficient to motivate greater appetitive motivation in the absence of a high BAS trait Therefore, following from this, in circumstances where individuals are deprived of food it is expected that physiological drive rather than a high BAS trait will predict food-cue reactivity By contrast, on occasions where individuals are non-food deprived, $1 \mathrm{e}$, satıated, the BAS would be expected to predict reactivity to food cues. Therefore, the implication of having a high BAS is that overeatıng will occur in the presence of food-related cues when energy from food is least required.

At this point it might also be worth noting further findings from this experiment which define the implications of having a high BAS trait for food-cue reactıvity. Firstly, even in circumstances where individuals with a high BAS trait selected larger portions of the cued food relative to those individuals with a lower BAS trait, they did not select larger portions of the non-cued foods. This finding is perhaps not surprising given that when individuals with a highly reactive BAS are exposed to a food cue, the salience of the incentive offered by this food will increase, but the salience of the incentive offered by other foods will remain unchanged. Secondly, it is worth considering the implication of finding that the only measure of motivation-to-eat the cued food to increase to a greater extent in individuals with a high BAS trait relatıve to those with a lower BAS trait, was 
the measure of desired portion size Neither ratıngs of subjectıve appetite for this food, nor hunger, increased to a greater extent in these individuals. One possibility is that this greater appetitive motivation was not consciously experienced to a greater extent in these individuals and therefore was not reported. Berridge and Robinson (1998) suggest that the attribution of incentive salience is an unconscious process which can later become conscious. Thus, it is possible that the increased salience of the incentive offered by a food cue was also not consciously experienced An alternative possibility, however, is that these appetite ratıngs were insensitive to the greater changes in appetitive motivation experienced by these individuals.

In addition to considering the role of the BAS trait in sensitivity to food cues, this experiment also explored the association between food-cue reactivity and impulsivity. Impulsivity was assessed using the EPQ-impulsivity scale, and using the Stop start signal task (a measure of inhibitory control) The results provided little evidence to suggest that higher scores obtained on the Stop start signal task were associated with a greater motivation to eat after cue exposure. Therefore, initially, this finding suggests that deficits in inhibitory control (i e, deficits in the ability to inhibit impulses to act) are not implicated in food-cue reactivity However, it is important to note that this task was not executed well in this experiment. Indeed, as suggested in the previous section, the mean score obtained on the task across the sample was relatively high in comparison to means obtained in a similar samples of participants by Nederkoorn et al. (2004). Inspection of the scores obtained in this study suggested that a proportion of the participants had been ignoring the stop signal and merely responding to the choice reaction-time task (go signal) To recap, the stop signal originally sounds $250 \mathrm{~ms}$ after the go signal. If participants fall to inhibit their response to the go task, the sound is produced $50 \mathrm{~ms}$ earlier in order to make it easier for the participants to inhibit their response. If the response is still not inhibited the delay of the stop signal will be reduced by a further $50 \mathrm{~ms}$ on the subsequent trial This reduction in the delay of the stop signal continues until the individual is able to inhibit their response to the choice reactıon-tıme task ('go' task). However, if a partıcıpant is ignoring the stop signal and responding to the go signal on all trials, then the delay between the go signal and the 
stop signal will be contınuously reduced such that the stop signal in fact occurs before the go signal This is the pattern of responses which were observed in a proportion of the participants in this experiment. One potential reason for the poor execution of this task might have been because the instructions were not well understood. Therefore, future studies which aim to use this task might benefit from ensuring that task instructions are well understood proor to the test phase, and by training participants on the task if deemed necessary.

In addition to using the stop start signal task as a measure of impulsivity in this experiment, the EPQ-impulsıvity scale was also used. Unlike the stop start signal task, this scale provides a more general measure of tendencies to act on impulse across different situations Using this scale, the results from this experiment suggest that impulsıvity does play a role in food-cue reactıvity. With regards to subjectıve appetite, after four hours food deprivation, individuals with a high degree of impulsivity experienced a greater increase in craving for pizza after cue exposure, irrespective of their sensitivity to reward. Likewise, immediately after eatıng to satiety, these individuals experienced a greater change in hunger, desıre-to-eat pızza, and craving for this food The results relating to change in desired portion size were slightly more complicated Before lunch, although impulsivity was associated with change in desired portion size, this association was not statistically significant after controlling for sensitivity to reward scores. Observation of the data suggests that this might be because it is only those individuals who have simultaneously high sensitivity to reward and impulsivity scores who experience the greatest change in desired portion-size selection after cue exposure when deprived of food. Notably, a different pattern of results emerged after lunch for change in desired portion size of the cued food In these circumstances, an interaction effect between impulsıvity and dietary disinhibition suggested that only impulsive individuals who also have high disinhibition scores experience a greater change in desired portion-size selection after cue exposure. Therefore, taken together, these findings suggest that impulsivity alone is able to motıvate greater subjectıve appetite for a cued food when individuals are both hungry and when they are satiated. However, they suggest that impulsivity might have to be 
coupled with sensitivity to reward to motivate a greater change in desired portion size when individuals are hungry, and with high dietary disinhibition when individuals are satiated.

To interpret the observed role of impulsivity in food-cue reactivity, it is perhaps important to understand the implications of being impulsive. Recently, impulsivity has been defined as a predisposition towards rapid, unplanned, reactions to internal or external stımulı (Moeller, Barratt, Dougherty, Schmitz, \& Swann, 2001). Thus, given that a food cue constitutes an external stimulus, perhaps it is not surprising that impulsıvity might be an important determınant of food-cue reactivity. Indeed, after food-cue exposure, impulsive individuals might make a rash decision to eat the cued food.

Previously, impulsivity has been found to share associations with everyday smoking (Grano et al, 2004; Mitchell, 1999), smokıng relapse following 48-hours of nicotıne abstinence (Doran et al., 2004), frequency of alcohol consumption and the quantity consumed (Grau \& Ortet, 1999, Grano et al , 2004, Waldeck \& Miller, 1997), alcohol dependence symptoms, and methamphetamine abuse symptoms (Simons et al, 2005). However, this is the first study to associate impulsivity with greater reactivity to food cues. Therefore, the importance of these findings is that they suggest that, like substance use, food-cue reactıvity might also be contingent upon a more general inability to resist reactıng to external stımuli in the environment

It is interesting that the present findings perhaps suggest that impulsivity is not the sole factor that drives the desire to consume larger amounts after food-cue exposure. Indeed, one important finding was that suggesting that impulsıve individuals with a greater sensitıvity to reward appear to experience the greatest changes in desired portion size after cue exposure when they are mildly food deprived (1.e., four-hour food deprived). This is a particularly interesting result given that previously in this discussion it was suggested that sensitivity to reward is unable to motıvate a desire for larger portion sizes of a cued food when individuals have been deprived of food. However, perhaps 
paired with greater impulsivity, a greater sensitıvity to reward is able to elicit a desire for a larger portion size of a cued food when individuals are food deprived. Indeed, given that individuals with a heightened sensitivity to reward presumably attribute greater incentive salience to food cues (Pickering \& Gray, 2001), it is possible that in the presence of stımulı signaling a tasty reward, impulsıve individuals with a high sensitivity to reward are unable to resist the temptation offered by the tasty reward Therefore, these individuals desire the largest portion size of the cued food. By contrast, in the absence of a high BAS tratt, a food cue is unlikely to predict the same intense indication of a tasty reward for these individuals because it has been attributed less incentive salience. For this reason, impulsive individuals without a high BAS trait are perhaps less likely to desire the largest portion sizes of this food.

Another important finding from this experiment which is worthy of consideration was that only impulsıve individuals with high disinhibition scores were found to experience the greatest changes in desired portion size of the cued food when individuals were tested whilst satıated. This suggests that in the absence of hunger, impulsive individuals might also require a specific inability to resist the temptation to eat offered by external cues in order to desire larger portions of a food after being exposed to it briefly. This perhaps makes sense because it seems plausible that some bias towards food-related cues is essential to elicit an initial impulse to eat when individuals are satiated Given that dietary disinhibition reflects a greater susceptibly to triggers in the environment which promote food intake, it seems that this dietary characteristic would constitute a bras towards food-related stımulı. For impulsive individuals, this initial bias is likely to prompt these individuals to make the rash decision to select a larger portion size of the cued food. However, in the absence of a tendency to act on impulse, individuals with high dietary disinhibition perhaps consider the consequences of selecting a larger portion size of their desired food, and thereby regulate the portion size that they select

As an aside, whilst discussing the joint role of dietary disınhibition and impulsivity in food-cue reactivity, it is important to note that in this experiment, the greater change in desired pizza sıze experienced by individuals with simultaneously high impulsıvity and 
disinhibition scores did not result in the selection of the largest total portion sizes of this food after cue exposure This is because they selected the smallest portion sizes of przza proor to cue exposure, thus, their greater change in desired portion size was unable to stımulate the largest portion-size selection in the cued context The reason these individuals selected the smallest portion sizes prior to cue exposure is likely to be because they had lower levels of hungry than the other groups prior to cue exposure If, however, these individuals had had similar hunger levels at the outset, they would have been expected to select similar pre-exposure portion sizes, and as a result of their greater change in desired portion size they would have selected the largest portion sizes after cue exposure.

In addition to exploring associations between food-cue reactivity and impulsivity and sensitivity to reward, another alm of this experiment was to consider the extent to which associations between food-cue reactivity and 1) dietary restraint, and 11) being overweight differ when participants are deprived of food, relative to when they are nonfood deprived. Previous experiments presented in this thesis have suggested that dietary restraint shares little relationship with food-cue reactivity when participants are tested immediately after lunch. The results from the present experiment confirm this finding and also suggest that restrained and unrestrained eaters do not differ in their reactivity when individuals are tested while food deprived. Therefore, taken together, this suggests that restrained eaters do not expenence any greater reactivity to food cues than unrestrained eaters irrespective of whether they are food deprived or have recently eaten to satiety This is perhaps not surprising given that relative to unrestrained eaters, restrained eaters would be expected to be exerting greater levels of restriction over their intake urrespective of their motivational state.

With regards to the associations observed between food-cue reactivity and being overweight, the findings were less expected To recap, in Experment 5 , change in desired pizza size after cue exposure was found to be associated with being overweight whılst individuals were tested whilst satıated However, in this experıment, not only was elevated reactivity not associated with being overweight when individuals were 
food-deprived, but, contrary to the findings from Experiment 5, it was also not associated with food-cue reactivity when individuals were satıated. One difference in this experiment which might account for this is that overwcight individuals were more restrained than the non-overweight individuals. Indeed, the mean restraint scores observed in this experiment for the overweight, and non-overweight, groups suggest that the overweight group in fact reflected a group of restrained eaters, whilst the nonoverweight group reflected a group of unrestrained eaters Thus, since comparisons were being made between restrained and unrestrained groups perhaps it is not surprising that there was little evidence of an association between food-cue reactivity and being overweight.

Another reason for the fallure to report greater food-cue reactivity in overweight individuals might be because the sample of overweight participants recruited for this study did not have a higher BAS-related trait, or higher impulsivity scores, than nonoverweight individuals. Indeed, the findings from this experiment have suggested that both these characteristics are important predictors of food-cue reactivity, Thus, following from this, one possibility is that the reason previous studies (e g., Jansen et al, 2003; Tom \& Rucker, 1975) have reported greater reactıvity in overweight individuals is because they have recruited a group of overweight individuals with a high sensitıvity to reward and high impulsivity. Indeed, previously, randomly selected groups of overweight have been found to score higher on these particular characteristics (Franken \& Muis, 2005; Nederkoorn et al, 2006; Nederkoorn et al, in press). However, unfortunately, for the groups of overweight indıviduals previously found to experience greater cue reactivity there is no record of their levels of impulsivity or sensitivity to reward, making it impossible to explore this speculation However, future studies might wish to consider this possibility further.

In light of the fallure to report any overweight/non-overweight differences in food-cue reactivity in this study, little can be concluded regarding differences in food-cue reactıvity in overweight, and non-overweight, individuals across different motivational states. This is disappointing because previous work suggests that such a difference 
might in fact occur For example, several studies have found that overweight individuals purchase greater amounts of food at a supermarket than non-overweight individuals when satiated, but that normal weight individuals in fact consume greater amounts as the time since previous meal increases (Mela, Aaron, \& Gatenby, 1996, Nisbett \& Kanouse, 1969; Tom, 1983) Since supermarket shopping exposes an individual to an array of food cues, these findings might therefore suggest that overweight individuals only expenence greater reactivity to food cues than nonoverweight individuals when satiated Furthermore, another study conducted in the 1970's by Tom and Rucker (1975) suggested that overwerght partıcipants consumed larger amounts of food, and were willing to purchase more food, relative to nonoverweight individuals, after exposure to food slides, but only when they had recently eaten to satiety. In fact, simılar to the supermarket studies, after viewing the food slides while food-deprived, non-overweight indıviduals consumed greater amounts of food, and were willing to purchase modestly more of this food than overweight individuals. In light of this initial evidence in support of a difference in the extent to which overweight individuals experience greater food-cue reactivity than non-overweight individuals, future studies should explore this possibility further.

Finally, in this discussion it is important to address some of the limitations associated with the present experiment. One limitation is that in the first cue-exposure phase $(1 \mathrm{e}$, food-deprived phase) the portion-size selections made using the food models in the non-cued context might have reflected modestly cued selections. The reason for suspecting this is because subjective appetite for these foods was found to increase after making these selections in this motivational state. This is problematic because if the changes were cued to some extent, then they might have been modestly conservative with respect to the actual change that would be stimulated by exposure to such a cue when hungry. A second limitation associated with this experiment was that the compliance check (i e., food diary) admınıstered to ensure that partıcıpants were in fact food deprived prior to the first cue exposure penod was not optimal A more appropriate check may have been to collect salvia samples whıch partıcıpants believed 
would be analysed to determine that they had not ingested any food in the previous four hours.

A further potential limitation of this experiment was that despite attempts to minimise awareness of the aims of the study, a modest proportion of the participants did have some awareness that the expermment sought to investigate the effect of pizza-cue exposure on appetite ratıngs and desired portion size However, post-hoc analyses did suggest that this awareness did not predict changes in these measures after cue exposure Thus, even if some participants were aware of the aims of the experiment this did not appear to influence their responses throughout the experiment.

Finally, this experiment might be limited by the fact that two assessments of cue reactivity were made essentially within the same test session, $1 \mathrm{e}$, one while participants were deprived of food, and one immediately after they had eaten to satiety. The most obvious implication of this is that by the second assessment participants were aware of the aims of the study. However, as suggested here, even if they were, this did not affect their subsequent reactivity. Another implication is that their responses in the second cue-reactivity assessment were affected by the fact that participants had already made these same assessments in the first phase of the experiment. This might explain why there were several outliers observed for the second set of reactivity measures. One possibility is that due to the large numbers of measures obtained in this experiment, partıcipants became fatigued and began to make mistakes in the second set of measures. Another potential problem might have been that partıcipants' assessments were influenced by those made previously Particularly, this might have been the case for the measures of desired portion size. Evidence for this comes from the fact that in this experiment the mean change in pizza size observed after being cued with the pizza while satıated was much larger than that observed in Experiment 5 . Therefore, one possibility is that these portion sizes were guided to some extent by the portions sizes made whilst participants were hungry. Thus, to assess the possibility that the results reported here might be an artıfact of repeated testıng, future studies should attempt to replicate these findings using a methodological design whereby cue exposure in the two 
different motivational states is assessed in two separate test sessions In these studies, participants should be randomised to a motivational state condition for the first set of testing sessions so that half the partıcipants undertake the initial testing session while satiated and the other half while hungry

\subsection{Chapter summary}

The experiment presented in this chapter explored associations between food-cue reactivity and 1) dietary restraint, 11) dietary disinhibition, 111) body weight, 1v) BAS activity and v) impulsıvity, in two different motivational states (1 e, while individuals were food-deprived and in the absence of food deprivation). The results provided little evidence to suggest that food-cue reactivity was associated with individual differences in dietary restraint, or body weight in either of the motivational states However, they did provide some evidence to suggest that impulsivity might be an important predictor of food-cue reactivity when food deprived and after recently eatıng to satiety. This trait was found to interact with disinhibition scores to predict greater changes in desired portion sizes of a cued food when individuals were satiated Furthermore, in conjunction with a heightened sensitivity to reward, there was some evidence to suggest that impulsivity might also predict greater food-cue reactivity when individuals were hungry. Finally, sensitivity to reward (the BAS trait) was also found to be an independent predictor of changes in desired portion size of a cued food when individuals were satıated Therefore, taken together, the findings from this experıment suggest that food-cue reactivity might be heightened in the most part due to the overactivity of a universal system which reacts to stimul in the environment associated with rewards, and as a result of a general inability to resist impulses. 


\section{CHAPTER 8}

\section{GENERAL DISCUSSION}

\subsection{Chapter Introduction}

The six experıments presented in this thesis have considered individual differences in food-cue reactivity. Importantly, several findings have emerged from these experiments that further our understanding of this dietary phenomenon. Specifically, the findings suggest that dietary restraint shares little association with food-cue reactivity, but that dietary disinhibition, impulsivity, and a greater sensitıvity to reward (BAS trait) might be important predictors of this reactivity In addition to this, potential links have also been highlighted between reactivity to food cues and everyday portion-size selections and being overweight. This chapter discusses these findings and considers their implications for food-cue reactıvity, and for preventıng, and reducing, overeatıng.

A secondary issue considered in this chapter is the limitations and methodological issues arising from the work presented in this thesis These are discussed in the later sections of the chapter and future methodological innovations are proposed. The final section of this chapter considers the future for food-cue reactivity research, and proposes ideas relating to how research in this area can progress.

\subsection{Food-cue reactivity and dietary restraint}

Previously, it has been suggested that food-cue reactivity is associated with dietary restraint (e g, Fedoroff et al , 199, 2003; Rogers \& Hill, 1989) However, given that the measure of restraint (i e, the Restraint Scale) used in these studies does not provide a 
pure measure of this dietary behaviour, this thesis began with an exploration of associations between food-cue reactıvity and a purer measure of dietary restriction (i.e., the restraint scale from the DEBQ, van Strien et al, 1986). Using this purer measure, there was little evidence to suggest that food-cue reactivity shares a relationship with dietary-restraint status across six separate experiments After food-cue exposure, restrained eaters did not expenence greater subjectıve appetite for either the food which had been cued, or for the non-cued foods In addition to this, they were not found to consume larger amounts of these foods (Experiments 1 and 2), or to desire larger portions of 1t (Experiments 3 to 6) Furthermore, this fatlure to observe greater cue reactıvity in restrained eaters occurred when partıcıpants were tested while satiated and after four-hour food deprivation Taken together, these findings suggest that dietary restraint does not place individuals at any greater risk of overeatıng in the presence of a food cue This is important because it contrasts previous conclusions drawn from associations observed between the Restraint Scale and food-cue reactivity suggesting that restrained eaters overeat in the presence of food cues (e g., Fedoroff et al, 1997, 2003, Rogers \& Hill, 1989)

Finding that dietary restraint is not associated with food-cue reactivity is perhaps not surprising This is because it is unclear why merely attempting to restrict ones dietary intake should result in an individual desinng larger amounts of a food which has been cued. Indeed, individuals who are attempting to inhibit a partıcular behaviour would not be expected to engage in that behaviour to a greater extent that those who are unconcerned with inhibition of that behaviour. Fenichel (1999) in his discussion of psychoanalytical theory explains why this is the case. He suggests that when tendencies to act in a partıcular way, and tendencies to inhibit that behaviour, are equally strong, there will be no motivated activity Fenıchel's (1999) explanation is important because it can in fact be used to provide an explanation of the behaviour of restrained eaters. Indeed, restrained eaters are likely to experience a motivation to eat in the presence of a food cue. However, their attempted restriction should counteract this motivation. Consistent with this, there is evidence to suggest that restrained eaters are motivated to eat after exposure to a food cue. For example, two separate studies have suggested that 
restrained eaters (identıfied using pure measures of dietary restraint) experience greater salivary responses in the presence of a food cue (Brunstrom et al , 2004; Tepper, 1992). Yet, evidence from the experiments presented in this thesis also implies that restrained eaters are able to counteract this motivation because they do not indicate a desire to overeat a cued food This successful mhibition might be the result of restraned eaters ability to actively avert therr attention away from food cues (see Kemmotsu \& Murphy, 2006; Pracentını, Schell, \& Vanderweele,1993).

Notably the idea that dietary restraint does not inadvertently cause greater reactivity to food is not consistent with all accounts of cued behaviour. For example, Tiffany (1990) suggests that inhibiting a particular behaviour can encourage initiation of this behaviour in the presence of enabling stımulı. Specifically, he suggested that inhibiting drug use can motivate further drug use in the presence of cues associated with this behaviour However, the findings from the experiments presented here do not suggest that this is the case for food-cue reactivity. This is an important finding because it implies that the theoretical account of drug urges provided by Tiffany (1990) might not constitute an approprate model for explaining food-cue reactıvity.

Given that the findings presented here suggest that measures of pure dietary restriction fail to predict food-cue reactivity, it becomes important to ask what it is about the Restraint Scale (Herman \& Polivy, 1980) that promotes associations with this dietary phenomenon. One possibility is that the Restraint Scale acts as a proxy measure for obesity-proneness (Lowe \& Kral, 2006), and that it is this predisposition towards obesity which is associated with greater food-cue reactivity. However, an alternative possibility is that individuals who obtain high scores on the Restraint Scale oscillate between periods of intense calorie restriction and bouts of disinhibited eating (Lowe, 1993). Thus, put simply, rather than reflecting a measure of obesity proneness, the Restraint Scale might reflect the cyclic history of dietary restriction and excessive food intake (1 e., weight fluctuation) (Lowe, 1993). Given this, it is possible that weight cycling (e.g., Brownell, \& Rodin, 1994, Foreyt, Brunner, Goodrıck, Cutter, Brownell, \& Stjeor, 1995, Kajıka, Tsuzuku, Shımokata, \& Sato, 2002) accounts for associatıons 
between the Restraint Scale and food-cue reactivity. An explanation for this potential association has been provided by Lowe (1993) He suggests that a single cycle of overeatıng, followed by a strict diet, will leave individuals at a greater risk for disinhıbitory eating This is because dietıng has caused these individuals to become unresponsive to hunger cues, while the preceding overeatıng phase rendered these individuals insensitive to satiety cues. Consequently, these individuals are left to rely on external cues to guide their eating behaviour. Some support for this assertion comes from a study by Heatherton, Polıvy, and Herman (1989) In this study, the authors gave partıcıpants a pill and told them that it had made a previous group of partıcipants feel etther more hungry, or feel more satiated. By doing this, Heatherton et al (1989) found that individuals who obtained higher scores on the Restraint Scale (and thereby are assumed to be weight cycling) ate greater amounts when told that the pill made the previous group feel hungry, than when they were told that it made them feel more satıated These findings were therefore taken to suggest that these individuals rely on external cues to gurde their food intake Thus, given this, it is possible that individuals who obtain high scores on the Restraint Scale also rely to a greater extent on external food cues to guide their intake, and in the absence of satiety signals, overeat in the presence of these cues

Unfortunately, the extent to which food-cue reactivity shares an association with obesity-proneness, or weight cycling, was not considered in the experiments presented here Rather, in this thesis it has been assumed that the Restraint Scale acts as a proxy measure for dietary disinhibition. This is because the Restraint Scale is known to conflate dietary restraint with disinhibited eating (Blanchard \& Frost, 1983, Drewnowski et al., 1982; Heatherton et al, 1988; Johnson et al, 1983; Laessle et al, 1989; Lowe, 1984). For this reason, it was initially hypothesised that food-cue reactivity might in fact be more closely associated with the disinhibition subscale from the TFEQ (Stunkard \& Messick, 1985) The following section discusses the findings from this thesis relevant to this hypothesis. It also consıders related findings suggesting that impulsivity and sensitivity to reward are also important determinants of food-cue reactivity. 


\subsection{The role of dietary disinhibition, impulsivity, and sensitivity to reward, in food-cue reactivity}

As suggested above, initially in this thesis it was hypothesised that dietary disinhibition might be an important predictor of food-cue reactivity Thus, throughout the six experiments, associations between food-cue reactivity and dietary disınhibition were explored. However, across these experıments, support for this association was relatively weak Although Experiments 1,3, and 5 provided some support for such an association, Experıments 2 and 4 provided little evidence for this However, interestingly, in the final experiment, this dietary behaviour was found to interact with impulsıvity to predict greater food-cue reactıvity when individuals were satıated. Thus, impulsive individuals with high levels of dietary disinhibition experienced the greatest change in desired portion size of pizza after brief exposure to this food. Given this, one possibility is that those experiments which previously reported associations between dietary disinhibition and food-cue reactivity did so because the disinhibited eaters in these studies were more likely to also have a high degree of impulsivity.

To understand the implications of an interaction between dietary disinhibition and impulsivity for food-cue reactivity, it is important to consider the impact of these separate tratts on behaviour. With regards to impulsivity, it has been suggested that this trait reflects a blind obedience to internal drives, behaviour actıvated by an impulse, rather than by controlled and reasoned deliberation, or behaviour that is poorly conceived, prematurely expressed, unduly risky, or inappropriate to the situation (Evenden, 1999) Based upon this definition, and inspection of the items which comprise the EPQ-1mpulsıvity scale, it appears that impulsivity reflects a general inability to consciously control ones behaviour. Thus, impulsive individuals might be described as falling to have the same levels of self control as less impulsive individuals. By contrast, dietary disinhibition perhaps reflects a more specific inability to exert control over ones food intake. Indeed, after inspection of the items that comprise the TFEQ-disinhibition scale, it has been suggested here that this dietary behaviour reflects an increased susceptibility to external triggers which promote food intake (see Section 


\section{5, Chapter 4).}

Based upon these definitions of impulsivity and disinhibition, it appears that impulsive individuals with high levels of dietary disinhibition experience greater reactivity to food cues when satıated because they are highly susceptıble to external triggers, such as food cues, and are also because they are more generally unable to execute sufficient self control over their behaviour Thus, when faced with food cues these individuals are motivated to eat by the presence of this cue, and in the absence of sufficient self control, they experience the greatest change in desired portion size. The implication of this finding is that it suggests that when individuals are satıated, one potential cause of greater food intake after exposure to food cues might be a greater susceptibility to external triggers which promote food intake paired with a more general inability to control ones behaviour.

It is important to note that the findings from Experiment 6 did not provide any evidence of a statıstically significant interaction between dietary disinhıbition and impulsıvity when partıcipants were tested whilst hungry. However, in this motıvational state, impulsivity was found to be a significant predictor of food-cue reactivity. This suggests that a greater susceptibility to external cues which promote intake (1.e, dietary disinhibition) might not be responsible for greater food-cue reactivity when individuals are mildly food deprived. Yet, in these circumstances an inability to generally maintain control over ones behaviour might contınue to be an important predictor of this dietary phenomenon. It is important to note, however, that after controlling statistically for sensitıvity to reward scores, Impulsıvity was no longer a sıgnificant predictor of greater reactivity to food cues whilst individuals were hungry. Exploration of this finding suggested that one possibility is that only impulsive individuals with a high sensitivity to reward expenenced greater changes in desired portion size of the cued food. The reason for this is unclear and it might therefore be useful perhaps for attempts to be made to replicate this finding with larger sample sizes. Notwithstanding this, it is important to note that sensitivity to reward is most definitely an important predictor of food-cue reactivity. This is because when individuals were satiated this charactcristic 
was found to be associated with greater food-cue reactivity irrespective of individuals' levels of impulsıvity

To recap, sensitivity to reward is mediated by the BAS (Behavioural Activation System). This is a hypothetical brain structure that responds to rewards or cues signalling reward by actıvatıng behaviour. In the previous chapter it was suggested that individuals with a higher BAS trait more readily approach environmental cues associated with a reward because they assign greater incentive salience to these cues (P1ckerıng \& Gray, 2001). The 1dea that assigning greater incentive value to an environmental cue might result in this cue eliciting an appetitive motivation is consistent with Berridge and Robınson's (1998) 'Incentıve Salience' hypothesis To recap, Berridge and Robinson (1998) suggest that environmental stımulı are assigned incentive salience after they have been associated with a reward. According to Berridge and Robinson (1998), as a result of this attribution these cues become capable of demanding attention and motıvating behaviour towards acquiring the reward which they have become associated with Importantly, consistent with the sentiment of Berridge and Robinson's (1998) theory, a number of other theories of motivated behaviour have also suggested that environmental stımulı come to elicit an appetitıve motivation because they gain incentive motivation, or incentive value (e.g., Bindra, 1974, Bolles, 1972) (See section 1.4.3, Chapter 1) Thus, the findings from this thesis are also more generally consistent with these theories

By suggestıng that the Incentive Salience hypothesis can be used to describe food-cue reactıvity, it implies that that the mechanism which governs food-cue reactivity is in fact the same mechanism that governs other cued behaviours. This is because the Incentive Salience hypothesis can be regarded as a theoretical account for all motivated behaviours elıcited by environmental cues. Indeed, sensitivity to drug cues is also assumed to result from the attribution of incentive salience to these cues. Robinson and Berndge (1993) in their 'Incentive Sensitızation Theory' suggest that addictive drugs enhance the mesolımbic dopamine transmission responsible for the attribution of Incentive Salience, and consequently greater incentive salience is attributed to external 
cues encountered immediately prior to drug use. Support for this theory comes from two recent studies which have suggested that reactivity to drug cues is associated with greater reactivity of the BAS (Kambouropoulos \& Staiger, 2001, 2004).

The possibility that the same mechanism governs all cued behaviour is important because it suggests that individuals who have a highly reactive BAS are susceptible to all environmental stımuli which predict the receipt of a reward. However, it is important to note that these individuals are perhaps most vulnerable to greater sensitivity to food cues This is because, for example, individuals must engage in drug use in order for drug-related cues to motivate further drug use Thus, those individuals with a highly reactive BAS who never use drugs will not develop a greater sensitivity to drug cues. However, since eating is essential to sustain life, individuals cannot avord this behaviour. Consequently, all individuals with a highly reactive BAS will unfortunately tend to develop a greater sensitivity to the stımulatory effects of food cues

Thus, given that the BAS trait might be fundamental to food-cue reactivity, it is important to consider the mechanısm which governs this system Notably, individuals with a highly reactive BAS are assumed to attribute greater incentive salience to external stımul This attribution is guided by dopamıne actıvation (Pickering \& Gray, 2001 ). Given this, it would appear that a more reactive BAS is the result of greater dopamine actıvation One possibility suggested by Ptckering and Gray (2001) is that dopamine cells themselves might be more reactive to their incoming signals in high BAS, relatıve to low BAS trait, indıviduals. A high BAS trait would then be manifest as a more intense dopamine cell firing in response to positıve reinforcers, or rewards. Consequently, external stımulı which predict these reinforcers would be attributed greater incentive salıence on subsequent encounters. However, an alternative possibility is that BAS functioning might vary across individuals because of a variation in the number and/or functioning of dopamine receptors (Pickering \& Gray, 2001). Findings from Wang, Volkow, Logan, Pappas, Wong, Zhu et al. (2001) suggest that the number of dopamine receptors might be lower in some individuals $(1 \mathrm{e}$, overweight 
individuals). These authors suggest that this deficit in dopamine receptors causes a 'reward deficiency syndrome.' As a consequence of this syndrome, individuals seek out rewards to counteract their deficiency. Consequently environmental stımuli that predict a reward might create a greater motivatıonal state in these individuals

In addition to the mechanism by which individuals with a high BAS trait attribute greater incentive salience being unclear, it is also unclear exactly why this attribution stımulates a greater motivation to obtain the reward associated with that cue when it is presented on subsequent occasions. The Incentive Salience hypothesis suggests that this motıvated behaviour occurs because once incentıve salıence has been attributed to a stimulus, this stımulus commands attention. This suggests that attribution of incentive salience to environmental cues by individuals with a highly reactive BAS leads to an attentional bias for these stimul. Since an attentional bias, at least in part, is involuntary and unintentional, it is indeed likely that this bias provides an automatic pathway for greater motivation to obtain the rewards associated with these environmental cues.

There are at least two pieces of evidence consistent with the notion that cue reactivity more generally might be the result of an attentional bias caused by the attribution of greater incentıve salience. Firstly, several studies have reported that drug users have an attentional bias for drug cues (e g., Bradley, Mogg, Wright, \& Field, 2003; Hogarth, Mogg, Bradley, Duka, \& Dickınson, 2003; Mogg \& Bradley, 2002; Munafo, Mogg, Roberts, Bradley, \& Murphy, 2003), and that this is associated with a highly reactive BAS (Munafo, et al, 2003). Secondly, reports suggest that increasing levels of the neurotransmitter responsible for the attribution of incentıve salience, 1.e., dopamine, creates an attentıonal bias for drug cues (Franken, Hendriks, Stam, \& Brink, 2004). Thus, taken together, it appears that reactivity to environmental cues predicting a reward might ultimately reflect the allocation of greater attention to these cues guided by incentive salience. However, at present, there is little formal evidence within the domain of food-cue reactivity to affirm that it is in fact this process which guides this dietary phenomenon. Only tentative support for this possibility can be taken from the 
fact that the Restraint Scale, which is associated with food-cue reactıvity (e g, Fedoroff et al, 1997, 2003), has also been associated with an attentional bias for food cues (Franc1s, Stewart, \& Hounsell, 1997; Israel1 \& Stewart, 2001) Therefore, given this possibility that food-cue reactivity might result from a greater attentional bias, future research should address this further

As an aside, it is important to acknowledge the fact that models other than Berridge and Robinson's (1998) Incentive Salience hypothesis have been proposed to explain cue reactivity. One particular alternative theory has been proposed by Tiffany (1990) Although this model was primarily devised to account for drug use, it is in fact applicable to other behaviours motivated by environmental cues, such as food intake According to Tiffany (1990), drug use is controlled by habit More specifically, he suggests that drug use is controlled by automatic action plans which require little conscious control. Thus, according to Tiffany (1990), when a smoker is cued by the sight of a c1garette packet, for example, he/she will automatically reach for the packet, take out a cigarette, light it, and begin to smoke it, without even realising that they have engaged in this behaviour.

Initially, it appears very difficult to reconcile Tiffany's (1990) account of cue reactivity with the Incentive Salience hypothesis adhered to here. However, one possibility is that these theories do not present competing accounts of cue reactivity. Rather, it may be that they account for different stages in the process by which environment cues come to motıvate behaviour. Durıng the early stages of learning, incentıve learning might primarily control reactivity to cues. However, after this response has been learned and repeatedly performed, the behaviour might become automatically initiated by triggering stımuli, thus a habit is formed (Mogg, Field, \& Bradley, 2005). Notably, Dı Chiara (2000) has suggested that this process governs drug-cue reactivity. According to $D_{1}$ Chiara (2000) in the early stages of micotine dependence, smoking behaviour is controlled by incentive learning processes. This is because, as a result of dopamine release, smoking-related cues acquire positive motivational properties. However, after extensive experience of smokıng, incentıve learning processes no longer play a primary 
role in determining smoking behaviour, as there is a switch from incentive responding to a mode of habit-based responding The findings from a study by Mogg et al (2005) provide some support for this model In the rationale for this study, the authors suggested that if the Incentive Salıence hypothesis only describes the initial stages of learning about the incentive properties of a drug cue, then predictions from this theory should only hold true in these initial stages. Consequently, Mogg et al (2005) hypothesised that only low levels of nicotine dependence should be associated with an attentional, and approach, bias for smoking cues. Consistent with this, the authors found that compared to moderate levels of nicotine dependence, low levels of nicotine dependence were associated with a bias towards approachıng smokıng-related cues, and an attentional bias for these cues Consequently, these authors provided some support for the two-stage process of cue reactivity proposed by $D_{1}$ Chiara (2000)

Since food-cue reactivity shares many parallels with drug-cue reactivity one possibility is that the same two-stage model might also account for the initiation, and maintenance, of food-cue reactivity. Initially, individuals with a highly reactive BAS might select larger portions of food after they have been cued with this food because they have attributed greater incentive salience to food cues and thereby have an attentional bias for these cues. However, after repeatedly selecting these larger portion sizes in the presence of a food cue, this response might become an automatic behaviour elicited whenever this cue is encountered. Thus, rather than heightened BAS reactivity being associated with food-cue reactivity because incentıve salience consistently governs food-cue reactivity, it might in fact be that those with the BAS trait initially assign greater incentive saltence to food cues, and therefore, this trait is associated with greater food-cue reactivity However, over time these individuals might in fact become habitually more cue reactive.

If, as suggested, reactıvity to food cues does become an automatic process, this might explain why individuals with a more reactive BAS, experience greater changes in portion-size selection of a food after food-cue exposure, but do not report greater changes in subjective appetite This is because, subjectıvely wantıng a reward is likely 
to be a non-automatic cognitive process Indeed, Tiffany (1990) suggests that cravings and urges for cued objects require non-automatıc cognitıve processes. Furthermore, Kavangh, Andrade, and May (2005) in their 'Elaborated Intrusion theory (EI),' have suggested that for an individual to experience a conscious desire for an object which has been cued, they must cognitively elaborate on the thought of that object. In support of these theoretical proposals, several studies have confirmed the need for cognitive capacity in subjective appetite by suggesting that craving for an imagined food is reduced if participants are required to complete a concurrent task (Kemps, Tiggeman, \& Hart, 2005, Kemps, Tiggeman, Woods, \& Soekov, 2004; Steel, Kemps, Tiggeman, 2006) On the basis of this evidence it is possible that subjective appetite does in fact require non-automatic cognitive processing. Thus, if food-cue reactıvity has become an automatic process in individuals with more reactive BAS's it follows that these individuals are unlikely to experience greater appetite for the cued food

To summanise, this section has suggested that dietary disınhibition, impulsivity, and sensitivity to reward (BAS trait) might be important determinants of food-cue reactivity. These findings are important because they allow us to begin to understand the mechanisms which might govern reactıvity to food cues. However, in addition to understanding these underlying mechanisms, it is also important to begin to understand the consequences of greater cue reactivity for overeatıng. Thus, the following section discusses findings from this thesis which suggest that food-cue reactivity might contribute to greater everyday food consumption and being overweight.

\subsection{Potential consequences of greater food-cue reactivity for everyday food consumption and being overweight}

One aim of this thesis was to consider the extent to which greater food-cue reactivity is associated with the consumption of larger everyday portion sizes and being overweight. Given that exposure to a food cue can increase $a d-l l b$ food intake (e $g$, Cornell $e t a l$, 1989; Rogers \& Hill, 1989), it follows that those individuals who are particularly 
reactive to food cues might consume larger amounts of food within their everyday lives. This possibility was considered in Experiments 3 to 5 using a measure of everyday portion-size selection. The results from two of these experiments (Experiment 3 and 5) suggested that individuals who showed elevated sensitivity to food cues in the laboratory consumed larger amounts of food within their everyday lives. However, given the cross-sectional nature of these experiments, it is impossible to ascertain the extent to which susceptibility to food cues is directly responsible for the selection of larger everyday portion sizes. Yet, it is possible to conclude from these findings that greater food-cue reactivity might at least maintain overeatıng in highly responsive individuals

Notwithstanding the importance of these findings, it is useful to note that there are several limitations associated with the measure of everyday portion size used in these experiments. In partıcular, this measure comprised of an average indication of everyday portion sizes across only nine (Experiment 3), or 15 (Experıments 4 and 5), foods Thus, this measure is likely to have provided only a very rough estımate of participants' everyday portion sizes This is particularly true given that it will also have been influenced ultımately by liking for these foods. Furthermore, it is not even certain that recalled portion sizes of the nine to 15 foods were accurate recalls of the amounts that individuals would typically consume This is because there is no evidence to suggest that portion-size estımations of everyday consumption made using the Food Atlas provide a valid indication of everyday portion-size selections. Evidence merely suggests that individuals are able to use pictures of food to indicate portion sizes of the food itself with modest accuracy (Lucas, Nitavong, Villeminot, Kaaks, \& ClavelChapelon, 1995; Nelson, Atkınson, \& Darbyshıre, 1994, Venter, Macıntyre, \& Vorster, 2000). However, in the absence of evidence to suggest that participants are able to provide accurate assessments of their everyday portion size, this measure is in some respects limited Its limitations are further increased by the fact that there is also reason to suspect that recall might be affected by the degree to which individuals are hungry when recalling these portion sizes. For example, Beasley et al (2004) found that everyday portion sizes were recalled as larger when individuals were hungry 
relative to when they were satıated Furthermore, here it was suggested in Experiment 4 that the inability to highlight an association between everyday portion size and foodcue reactivity might have been a result of the fact that in this experiment, unlike in Experıments 3 and 5, partıcipants were asked to recall their everyday portion sizes prior to the buffet lunch while they were food deprived

Given that the measure of everyday portion-size selections used in the experiments presented here might not in fact provide a valid indication of everyday consumption, it may be useful for future studies to devise a more valid test of everyday food consumption. Rather than assessing associations between reactivity to food cues and everyday portion size specifically, it might be more desirable to assess associations with daily calone intake This issue might be addressed by using validated measures such as the 24-hour dietary recall methods, or food record methods (see Buzzard, 1998 for a detalled account of these methods) Twenty-four hour recall methods are based upon an in-depth interview conducted by a trained dietary interviewer. This allows collection of specific information regarding consumed foods, preparation methods, recipe ingredients, and brand names. This information can then be analysed using computer software to provide a measure of daily Kcalone intake. The food record measure also allows a measure of dally Kcalorie intake to be obtained, but uses a slightly different method Specifically, this technique asks participants to keep their own record of their food intake over a 24-hour period. Using these methods, information regarding an individual's intake could be obtained over several days, and then compared with the level of food-cue reactivity observed in the laboratory. This research would be particularly important because evidence of greater daily intake in cue reactıve individuals, after controlling for other relevant variables, would confirm the assumption that heıghtened reactıvity to food cues presents a risk factor for overeatıng.

If, as assumed here, greater food-cue reactivity is a risk factor for overeatıng, one possibility is that susceptibility to food cues is also associated with being overweight. In Experiments 5 and 6, this possibility was explored The findings from Experiment 5 suggested that overweight indıviduals experienced a greater change in desired portion 
size of a cued food than non-overweight individuals However, in Experiment 6 there was little evidence to suggest that measures of food-cue reactivity differed between overweight, and non-overweight, individuals. The reason for this inconsistency across the two studies is unclear However, it is not unusual. In the 1970's, there were a series of studies which confirmed the association between sensitivity to food cues and being overweight (e.g., Nisbett, 1968a, Abramson \& Stınson, 1977), and a separate groups of studies which failed to replicate these results (e g, Rodın et al., 1976; Rodin et al., 1977).

The reason why only some groups of overweight individuals are found to experience greater sensitivity to food cues than non-overweight individuals is unclear However, perhaps relevant to this, the group of overweight individuals who were not found to experience any greater reactivity to food cues than non-overweight individuals in this thesis (i e., those in Experiment 6) were not found to be more impulsive, or to have a greater sensitivity to reward than the non-overweight group, but they were found to be more restrained. These might be important observations given that impulsivity, and sensitivity to reward, appear to be important determinants of food-cue reactivity (Experiment 6), and that dietary restraint could potentially suppress reactivity to food cues. Indeed, in light of these observations, one possibility is that greater impulsivity and a higher sensitivity to reward can render some overweight individuals more susceptible to food cues than non-overweight individuals. Thus, this might explain why the overweight group in Experiment 5 were found to be more cue reactive than nonoverweight individuals. However, unfortunately, in Experiment 5 levels of impulsivity and sensitivity to reward were not measured making it is impossible to ascertain the extent to which this is in fact the case

Finding that greater food-cue reactıvity is not consistently observed in overweight individuals is perhaps not surprising. This is because, firstly, obesity is a multifaceted disease with a magnitude of potential causal factors including such things as a genetic predisposition (for a review see Loos, \& Bouchard, 2003), greater snack consumption (e g , Francis \& Birch, 2003), and more frequent fast food consumption (e.g., Pereıra, 
Kartashov, Ebbeling, Van Horn, Slattery, Jacobs et al, 2005) etc.. Thus, it is extremely unlikely that all individuals who are overweight became overweight because they are more sensitive to the effects of food-cue exposure on appetite The second reason for not consistently observing greater food-cue reactivity in overwerght individuals is because some individuals who became overweight because they were more reactive to food cues might now be using dietary restriction to inhibit this heightened reactivity. Thus, greater food-cue reactivity may no longer be observed in these individuals.

Thus, although food-cue reactivity might cause weight gain, this does not necessarly mean that an association will be found between being overweight and food-cue reactivity. This is because not all overwerght individuals will experience a greater sensitivity to food cues. Some may have become overweight for reasons other than being more susceptible to food cues, and some might now be attempting to inhibit their reactivity by consciously restricting their dietary intake Thus, given this, to successfully investigate the role of food-cue reactivity in weight gain, future studies might seek to adopt a longitudinal approach Specifically, reactive and non-reactive individuals could be identıfied and their weight gain montored over several months This work would be particularly important because it would further enhance our understanding of obesity, and inform the design of interventions aimed to reduce, or prevent, overeating The work presented here provides a first step towards doing this However, future work is required to further investigate this issue.

\subsection{Implications of this research for interventions designed to reduce obesity}

In light of the recent increases in obesity, it is desirable to identıfy interventions which might reduce body weight in overweight individuals. Although the extent to which food-cue reactivity promotes weight gain is not entırely clear from the experiments presented in this thesis, it is likely to present one causal factor. Thus, given this, it might be important to reduce heightened reactivity to food cues. In Chapter 6 it was suggested that one method to achieve this might be to prevent individuals from eating 
in the presence of food cues (Response Prevention) This technique was originally proposed by Jansen (1998). Jansen (1998) suggests that overeating in the presence of a food cue becomes associated with cues encountered immediately prior to this act. Thus, when these environmental cues are subsequently encountered they motivate overeating Although the result from the experiments presented in this thesis provide a rather different theoretical accounts of the process by which food cues come to motivate eatıng behaviour (see Section 8.3), a response prevention technique might still be important for reducing elevated food-cue reactivity. This is because it has been suggested that food-cue reactivity eventually reflects a habit to overeat in the presence of food cues (see Section 8.3). Thus, this technique would serve to break this habit.

Notwithstanding the fact that this response-prevention technique is attractive, the feasıbility of it might in fact be compromised. Essentially, this is because individuals must eat to sustain life Thus, even if established cued responses can be extınguished, new cued responses will be immediately re-established as individuals contınue to eat in the presence of environmental stımuli This will occur because these individuals will re-attribute greater incentive salıence to these stimulı. The reason a Response Prevention technique is able to extınguish drug-cued responses after administration of the treatment is because patients no longer have any reason to use drugs. Yet, after administering this treatment to reduce food-cue reactivity, individuals would still be required to eat to sustain life. Thus, as a consequence of this, cued responses would be re-established. In light of this inefficiency of the Response Prevention method to permanently eliminate over-reactivity to food cues, other techniques need to be establıshed. Given that attribution of incentive salıence to food cues and a lack of inhibitory control are likely to be responsible for contınued reactivity to food cues after the administration of a Response Prevention technique, it is perhaps these behaviours which require treatment to permanently inhibit food-cue reactivity. However, since it would be extremely difficult to intervene in the attribution of incentive salıence because this is guided by dopamine activation, it might be more feasible to attempt to train individuals to inhıbit their tendency to overeat in the presence of a food cue. This might be achieved by teaching individuals to consciously control the amounts of food that 
they eat after food-cue exposure. However, it is important to note that the feasibility of this intervention is not known and for this reason future studies might seek to consider this further.

\subsection{Limitations and methodological considerations}

The preceding sections have sought to discuss the findings from the experiments presented in this thesis Notwithstanding these findings, it is important to note that there were several limitations associated with the experiments presented here. Some of these limitations were addressed as the thesis progressed. Howcver, there are several limitations which remain unresolved This section provides a chronological account of the methodological approaches adopted in the experiments presented here, their limitations, and where applicable how these methods were improved upon. This begins by considering the methodologies employed in the initial experiments

In the early experiments ( $1 \mathrm{e}$, Experiments 1 and 2) the methodological design followed those typically used in previous studies exploring food-cue reactivity Consequently, a between-subjects design was employed Participants were randomly assigned to a nocue, or a pizza-cue, condition. The effect of cue exposure on appetite ratıngs and $a d-l l b$ intake was then compared across the two conditions. The reason this approach has been used in expermments exploring food-cue reactivity is likely to be because it reduces demand awareness. Indeed, if participants had participated in two identical test sessions which only differed in the extent to which they were cued with pizza, they would almost certainly have deduced the aims of the study Consequently, it is likely that the participants would have felt inclined to behave in the way they felt they were expected to by the researcher. For these reasons, this between-subjects approach appears advantageous. However, it is not without limitations. For example, it is less powerful than a between-subjects design This is because the same participant cannot be compared across the two conditions. 
In later experiments presented in this thesis (Experiments 4-6), a within-subject methodology was employed. Thus, rather than some participants providing cued measures and others providing non-cued measures, cach participant provided both measures within a single test session The measure taken in the non-cued context was then treated as a baseline measure, or a pre-exposure measure, and the cued measure served as a post-exposure measure. This allowed the difference (change score) between these two measures to be calculated and thereby the effect of cue exposure could be assessed This approach was advantageous because it was more powerful than a between-subjects design. This is because it allowed compansons between the effects of food-cue exposure on appetite to be made within each participant. However, this approach does introduce a greater risk of partıcipants becoming aware of the experimental aim. An attempt was made to assess this awareness by issuing an awareness questionnaire in the final stages of the experıments. These questionnaires provided evidence to suggest that a proportion of the participants were aware of the experiments interest in the effects of food-cue exposure on appetite ratıngs and food intake. However, importantly, post-hoc analysis suggested that this did not promote greater food-cue reactivity and did not vary across the predictor vanables (1.e, dietary restraint, dietary disinhıbition, everyday portion sizes, being overweight, impulsivity, and BAS trait). Nevertheless, it is impossible to entirely eliminate the possibility that demand awareness played some role in the responses that were observed. This is because, firstly, it is possible that the questions designed to assess the study aims lacked sensitivity to detect awareness in all individuals. Secondly, some participants may have been aware of the experiments aims but did not articulate this well in their responses to the questions.

Typically, when utılising a withın-subjects design such as that employed in the later experiments, conditions should be randomised to avoid order effects This is because fatigue factors might contribute to performance in later conditions, and novelty factors might be implicated in performance in earlier conditions However, it was impossible to randomise the order in which participants completed the no-cue, and pizza-cue, conditions in the experiments presented here. This is because this would elicit a greater 
awareness of the study aims in those individuals who initially completed the pizza-cue condition Furthermore, to randomise the order of the conditions, the study would have had to be run over two separate sessions This is because the pizza-cue condition could not precede the no-cue condition in a single test session. However, this approach is problematic because it is impossible to ensure that participants are in identical motivational states prior to cue exposure in the two separate sessions. For example, it would be impossible to ascertain whether an individual was satiated or hungry to the same extent prior to cue exposure in each of the test sessions

In food-cue reactivity studies, it is essential to obtain measures of cue reactivity in the absence of food-cue exposure. This is because by doing this the exact effect of cue exposure on appetite can be established. However, as suggested earlier in this thesis (see Section 3.9, Chapter 3), obtaining a measure of food intake in a non-cued context is particularly difficult This is because even very brief exposure to a food cue is likely to act as a cue. In the original methodology employed in this thesis (e g, Experiments 1 and 2), participants in the no-cue condition were presented with pizza in the ad-llb intake phase. However, it was suspected that the sight, smell, and taste, of the test food in this phase cued participants' appetite for this food, thereby creating another cued condition. In light of this, in subsequent experiments it was decided that a measure of desired portion size using food models which reflected only the very basic elements of the food would be used to assess reactivity in a non-cued context. To ensure the suitability of this approach, appetite ratıngs were taken before and after participants had indicated their desired portion size using the food models These ratıngs suggested that the models had little effect on subjective appetite when participants were tested immediately after eating to satiety However, in Experiment 6, there was some evidence to suggest that these models were able to cue appetite for the foods they represented when participants had been deprived of food for four hours. This finding is important because it suggests that food models might not in fact provide a non-cued measure of food-cue reactivity when individuals are hungry. For this reason, the findıngs from Experıment 6 must be interpreted in light of this. 
The fact that food models might reflect cued measures in some circumstances is not the only limitation associated with the use of these models Another limitation is that these models provide very little information about the food they represent. Thus, as a consequence of this, participants are required to draw upon other resources to indicate their desired portion size. This is problematic because these resources will differ from participant to participant. The most unrepresentative food model used in the experıments presented here was pizza This is because it was rectangular in shape rather than circular. As a consequence of this, participants almost certainly had to rely to some extent on their imagination of what this pizza might be like to indicate their desired portion size. Thus, this introduces a bias into this measure as different participants will have been imagining different pizzas For this reason, it might be useful to replicate the findings presented here using more descriptive food models. This would ensure that all participants are using the same information in order to indicate their desired portion sizes.

A further limitation of the pizza model was that it did not allow the participants to see the actual three-dimensional size of pizza that they were selecting. To recap, for the pızza-sıze selections partıcipants were provided with a three-dimensional model of pizza which was identical in size to the slice of pizza they were exposed to in the exposure phase. They then made their portion size selections on a one-dimensional sheet of card As a consequence of this, they had to imagine how the one-dimensional slice that they selected would look if it was a three-dimensional pizza. Again, this introduces some aspect of error into this measure. Therefore, in retrospect, a less biased measure of desired pizza slice might have been obtained by providing a very large three-dımensional pızza and askıng partıcıpants to indicate their desıred portion size using this model.

In light of the limitations associated with obtainıng direct measures of intake after foodcue exposure perhaps it might be useful for future studies to consider other methods by which to assess likely food intake after food-cue exposure. One approach might be to rely solely on appetite ratıngs to assess reactivity to food cues However, this is not 
advisable because these measures assess subjectıve appetite and cannot be relied upon as providing a reliable measure of potentral intake. For example, Mattes (1990) reported discrepancies between hunger ratings and reported intake in a 7-day study Furthermore, after a comprehensive review of the literature, Stubbs, Hughes, Johnstone, Rowley, Rerd, Elia et al (2000) concluded that although visual analogue scales correlate with energy intake, they do not reliably predict energy intake to the extent that they could be used as a proxy for this. Given this, an alternative option might be to assess the likelihood of participants initiating intake after food-cue exposure In other words, identıfying those individuals, who after food-cue exposure, actively decide to obtain the cued food. Besides providing an alternative to the potentrally flawed behavioural measures used in the experments presented here, this approach would in fact provide a more reliable assessment of those individuals who are most likely to engage in food intake after exposure to a food intake. This is because, outside the context of the laboratory, individuals will be exposed to food cues, such as the sight of food, and then will etther continue their normal activity or will actively decide to obtain that food. Thus, perhaps it is not important to assess the portion size that individuals select after food-cue exposure, but rather the likelihood that this exposure motivates individuals to obtain and consume the cued food. Indeed, in many circumstances, after being exposed to a food cue individuals perhaps do not have a chorce over the portion size they select. This might be because the food which has been cued happens to only be avallable in a pre-determined size. For example, if individuals are cued by a poster advertısement depicting a McDonalds Big Mac those individuals who are highly sensitive to this cue and would therefore like to consume this food would have almost no choice over the portion size of food which they eat. This is because the portion sizes of these varieties of food are pre-determined by the fast food establishments. Thus, on the basis of this discussion, future studies might wish to devise a measure to assess the likelihood that a cued food will be actively obtained. Tom \& Rucker (1985) used one approach which was designed to do this After brefly exposing participants to a food cue, these authors asked them to indicate whether they would like to consume crackers. However, the specific approach used in this study was flawed by the fact that the food offered for consumption was not that which had been 
cued Future studies might therefore wish to adopt an approach similar to that used by Tom \& Rucker, but should improve upon this methodology by enquiring about future consumption of the cued food.

Apart from these specific limitations associated with the design of the experiments presented here, there are several other more general limitations. Firstly, each study tested a cohort of female students aged between 18 and 30 The decision to recruit from this specific population was motivated entirely by the fact that in recent studies exploring food-cue reactivity participants have been recruited from this specific population. Thus, it was useful to adhere to recruitıng from this population to ensure that the findings obtained for the experiments were easily comparable to those of previous studies However, despite this, this strategy is not without limitations. Indeed, as a result of this decision, the sample constituted a group of individuals who were of a particular gender, came from a narrowly defined age group, were of a particular educational level, and most likely were over-representatıve of a partıcular social class. Thus, the findings from the experiments presented here cannot be used to describe the behaviour of the population as a whole. Rather, the conclusions formulated as a result of the findings can only be confidently used to describe the behaviour of the subsection of the population which the sample is recruited from.

Secondly, the same cued food was used in the most part throughout the six experiments. The decision to use pizza as the cued food was motivated by the fact that it is a popular fast food and that it is foods such as these which are likely to be having a sufficient impact on the obesity epidemic. In addition to this, this food has been used in previous studies exploring food-cue reactıvity (e.g., Fedoroff et al, 1997, 2003). Therefore, again, to ensure that the findings from the experiments presented here could be easily compared with previous studies, it was desirable to use pizza as the cued food. However, 1t might be useful for future studies to replicate the findings from the experıments presented here using different foods. This would ensure that the findings reported here are not specific to pizza 
A third more general limitation of the work conducted here is that some of the experıments presented within it might not comprise sample sizes sufficient to use regression analyses incorporating the number of predictor variables and controlling variables that were used. For example, in both Experıment 3 and Experiment 4, 30 participants were recrutted. The decision to use samples of this size was motivated by the sample sizes used in previous cue reactivity studies. For example, in a study comprising three conditions, Fedoroff et al (1997) used a sample size of approximately 90 partıcipants Thus, in experıments such as Experıments 3 and 4, which comprised essentially only one condition, it was decided that a sufficient sample would comprise 30 participants. However, according to Field (2005), with the three predictors used in these experiments and the two controlling variables, to achieve $80 \%$ power, using regression analysis a sample size of approximately 50 participants would be required. Thus, in retrospect, larger sample sızes should have been used in these experiments

The fourth limitation of this thesis is that an identical cue reactivity paradigm was employed in each study. As a consequence of this, in each of the six experiments participants were exposed to the food cues for three minutes. However, it might be useful to assess individual differences in food-cue reactivity when individuals are exposed to a food cue for a much shorter penod of time. This is because, outside the context of the laboratory, participants might be exposed to a food cue for only a matter of seconds. Therefore, it might be useful to determine the effects of cue exposure in these circumstances.

The final limitations of the research presented here relate to the $a d-l i b$ lunch used in each experiment, and the failure to acknowledge human variation in smell With regards to the $a d-l l b$ lunch, one possibility is that this lunch served to cue participants appetite and this in some way affected the later changes that were observed in their cue reactıvity. In an attempt to address this issue, the methodology applied in each experiment aimed to ssolate the effects of cue exposure on appetite by exploning participants change in motıvation to eat from immediately before, to immediately after, cue exposure However, despite this, it remains possible that the ad-lib lunch cued 
participants appetite and this in some way impacted on their later reactivity to the cued food ( 1 e., pizza or chips). A further limitation associated with the ad-lib lunch was that participants intake in this phase of the experiment was not measured This is problematic because intake at this lunch may also have affected partıcipants' reactivity in the later cue exposure phase. Given this, in retrospect, intake in this phase should have been measured for each participant and entered as a covariate into the analyses of cue reactıvity. In addition to fallng to acknowledge the potential effect of the $a d-l l b$ lunch on food-cue reactivity, this research also falled to address the possibility that individual variation in sense of smell might predict food-cue reactivity when olfactory stımuli are used as a cue To address this limitation, future studies might attempt to implement a measure of sense of smell and also include this as a covariate in any analyses of cue reactivity.

In summary, there are several limitations associated with the experiments presented in this thesis These relate to the experimental design, the measures that were employed, the materials used, and also the sample selection. Given these limitations, it would be desirable for future studies to replicate the findings presented here using improved methodological designs which consider these limitations

\subsection{Directions for future research}

Following from the research presented in this thesis, there are two main areas which future studies might wish to pursue Firstly, it is important to determine the exact effect of food-cue exposure on daily Kcalorie intake, and to explore the extent to which those indıviduals who are partıcularly cue reactive are at a greater risk of developing obesity This area of research is particularly worthy of consideration given that it might further enhance our understanding of obesity. To address this 1ssue, future studies might consider using 24-hr recall, and food record, methods to assess associations between food-cue reactivity and dally intake (see Section 84 ), and by using longitudinal methods to monitor any weight gain in cue reactive, and non-cue reactıve, individuals. 
The second series of questions which require further attention following from the research presented in this thesis are those related to the potential roles of sensitivity to reward and impulsivity in food-cue reactivity. The findings from the experiments presented here suggest that elevated food-cue reactivity might result from attributing greater incentive salience to foods. Given this, a first task for future research might be to further substantiate the role of incentive salience in the initiation of food-cue reactivity by addressing some of the limitations associated with the experiments conducted here. After this, it might also be desirable to test the extent to which the attribution of greater incentıve salience transforms food cues into stımul capable of demanding attention This particular question warrants scrutiny because it has been suggested that the attribution of incentive salience transforms food cues into attractive, and attention grabbing, stimuli To address this issue, attentional biases for food cues could be explored in the same way that attentional biases are assessed for drug cues, 1 e., using techniques such as the adapted versions of the Stroop task. The Stroop effect (Stroop, 1935) is demonstrated by asking participants to name the colour in which colour words (e g., red) are printed. Typically, individuals attend to the word itself and therefore find it very difficult to simply name the colour the word is printed in. In the literature on dietary control, there have been several studies which have adapted this task to explore attentıonal biases for food words (e g, Braet \& Combez, 2003; Lattımore, Thompson, \& Halford, 2000) However, there have been no attempts to explore the associations between food-cue reactivity and attentional bias for food cues. Thus, it is important to now use these tasks to address this issue

Another avenue for future research might involve determining the extent to which, over tıme, food-cue reactivity does indeed become an automatic process governed by automatic action plans and is therefore exempt from cognitive control. It is important to address this issue because it has been suggested that, over time, cued responses might become habitual and controlled by automatic action plans (see section 83 ) To address this issue, performance on a cognitive task could be assessed in both a cued, and a noncued, context. If performance is not impaired in the cued context, but reactivity to the 
food cue is observed, it can be concluded that food-cue reactivity requires little cognitive resource and is therefore controlled by automatic action plans The reason for this is that if food-cue reactivity requires cognitıve processing, performance on a task whilst being cued with food would be expected to be impaired because fewer cognitive resources would be avallable for the task Similar approaches have been used previously to determine the extent to which attempts to restrict ones dietary intake in the presence of a food cues consumes cognitive resource (e g, Brunstrom et al, 2004, Green et al , 1999; , see section 3.5, Chapter 3). Such approaches are based on a singlecapacity model of cognitive resource. This model suggests that there is a limit on cognitive capacity (Kahneman, 1973). Thus, once all cognitive resource has been allocated, performance on a second task is impaired (dual-task methodology).

In addition to testıng the three hypotheses outlined above it might also be desirable for future research to provide further evidence for the role of impulsivity in food-cue reactivity. One way in which future studies might do this is by experimentally manipulatıng impulsivity. For example, one group of individuals might be trained to feel more impulsive, than a second untrained group. This might be an important study because it would confirm the causal role of this characteristic in this dietary phenomenon A similar procedure has already been employed in a more general study assessing the role of impulsıvity in overeatıng (e g, Guerrıen, Nederkoorn, \& Jansen, 2006).

\subsection{Final remarks and conclusions}

Previous studies have suggested that bref exposure to food-related stimuli, such as the sight and smell of food, can stimulate food intake (e g, Fedoroff et al, 1997, Nederkoorn et al, 2004). However, despite this basic research, very few studies have sought to identify those individuals who are particularly reactive to food cues, or to explore the potential implications of this phenomenon for everyday dietary intake, and for being overweight In light of this, the research presented in this thesis sought to 
explore this issue Specifically, it considered associations between food-cue reactivity and everyday dietary behaviour (dietary restraint and disınhibition), everyday portionsize selections, being overweight, and personality characteristics, such as impulsivity and sensitivity to reward. Importantly, by doing this, this thesis has advanced current understanding of food-cue reactivity in two main ways. Firstly, it has suggested that restricting ones dietary intake does not render an individual more susceptible to the effects of food-cue exposure Rather, it has identified the importance of characteristics such as sensitivity to reward ( 1 e., BAS trait), impulsivity, and dietary disinhibition, for food-cue reactivity. Specifically, it has suggested that those individuals who possess these particular characteristics are likely to be more sensitıve to the effects of food-cue exposure. Acknowledging the role of these characteristics is important because it implies that food-cue reactivity can result from the attribution of greater incentive value to food cues, and from a general inability to inhibit responses when a reward is imminent, or when a susceptibility towards external triggers which promote food intake exists (i e, dietary disinhıbition) The second way in which the research presented in this thesıs has advanced understanding of food-cue reactıvity is by identıfying potential links between this dietary phenomenon and everyday food consumption and being overweight. Specifically, this thesis suggests that food-cue reactıvity might present one factor which contributes to overeating, and weight gain. To move forward within this research area, studies should contınue to investigate the role of food-cue reactivity in overeating, and should seek to further identify the mechanısms which promote greater reactivity to food cues in an attempt to design interventions to alleviate the current obesity ep1demic 


\section{REFERENCES}

Abramson, E. E., \& Stınson, S. G. (1977) Boredom and eatıng in obese and non-obese individuals. Addictive Behaviors, 2, 181-185

Alken, L S, \& West, S G (1991) Multtple regression Testing and interpreting interactions. Sage Publications.

Alsese, K M, Chaverneff, F., \& de Wit, H. (2003) Role of abstinence and visual cues on food and smokıng craving. Behavioural Pharmacology, 14 (2), 145-151.

Aluja, A (2004) Sensitivity to punishment, sensitıvity to reward and sexuality in females. Personality and Individual Differences, 36 (1), 5-10

Aluja-Fabregat, A , \& Torrubia-Beltı, R. (1998). Viewing of mass media violence, perception of violence, personality and academic achievement. Personality and Individual Differences, 25, 973-989.

Baker, B J., Booth, D. A., Duggan, J. P., \& Gibson, E. L. (1987) Protein appetite demonstrated - learned specificity of protein-cue preference to protein need in adultrats. Nutrition Research, 7 (5), 481-487.

Balleine, B (1992) Instrumental performance following a shift in primary motivation depends upon incentıve learning. Journal of Experımental psychology* Anımal Behavior Processes, 18, 236-250.

Balleine, B, \& Dickinson, A. (1994). Role of cholecystokının in the motıvatıonal control of instrumental action. Behavioral Neturoscience, 108, 590-605. 
Balleine, B W , \& Dickınson, A (1998). The role of incentive learnıng in instrumental outcome revaluation by sensory-specific sat1ety. Animal Learning \& Behavior, 26, 4659.

Bechara, A, \& van der Kooy, D. (1989) The tegmental pedunculopontıne nucleus: a brain-stem output of the limbic system critical for the conditioned place preferences produced by dopamine and amphetamine Journal of Netiroscience, 9, 3400-3409

Baeyens, F., Crombez, G., Vandenbergh, O , \& Eelen, P. (1988) Once in contact always in contact - evaluative conditioning is resistant to extinction. Advances in Behaviour Research And Therapy, 10 (4), 179-199.

Baeyens, F., Eelen, P, Vandenbergh, O , \& Crombez, G. (1990). Flavor-flavor and color-flavor conditioning in humans Learning and Mottvation, 21 (4), 434-455

Baeyens, F., Crombez, G , Dehouwer, J., Eelen, P. (1996). No evidence for modulation of evaluative flavor-flavor associations in humans. Learning and Motvvation, 27 (2), 200-241.

Beasley, L. J , Hackett, A. F., Maxwell, S M., \& Stevenson, L (2004). The effect of a dietary preload on estımation of usual food portion size by photograph in female volunteers. Journal of Human Nutrition and Dietetics, 17 (3), 219-225.

Bekker, E M., Overtoom, C C. E., Koolj, J. J S , Buitelaar, J K, Verbaten, M. N., \& Kenemans, J. L. (2005). Disentangling deficits in adults with attentiondeficit/hyperactıvity disorder. Archives of General Psychıatry, 62 (10), 1129-1136

Bellisle, F, Clement, K., Le Barzıc, M., Le Gall, A., Guy-Grand, B., \& Basdevant, A (2004). The eating inventory and body adıposity from leanness to massıve obesity a study of 2509 Adults. Obesity Research, 12, 2023-2030 
Berridge, K. C. (2004). Motivation concepts in behavioral neuroscience Physiology \& Behavior, 81 (2), 179-209

Berridge, K. C , \& Robinson, T. E (1998) What is the role of dopamine in reward. hedonic impact, reward learnıng, or incentive salıence? Brain Research Reviews, 28 (3), 309-369

Bindra, D (1974). A motivational view of learnıng performance, and behavior modification. Psychological Review, 81, 199-213.

Birch, L. L, \& Deysher, M. (1985). Conditioned and unconditioned caloric compensation - evidence for self-regulation of food-intake in young-children Learning and Motivation, $16(3), 341-355$

Birch, L. L., McPhee, L, Sulivan, S , \& Johnson, S. (1989). Conditioned meal initiation In young children. Appetzte, 13 (2), 105-113.

Bobroff, E. M., \& Kıssileff, H R (1986) Effects of changes in palatability on foodintake and the cumulatıve food-intake curve in man Appettte, 7 (1), 85-96

Boddy, J., Carver, A, \& Rowley, K. (1986). Effect of positıve and negative reinforcement on performance as a function of introversion-extraversion some tests of Gray's theory Personality and Individual Differences, 7, 81-88.

Bolles, R. C. (1972) Reinforcement, expectancy, and learning Psychological Review, 79 (5), 394-409

Booth, D. A. (1972). Conditioned satiety in rat. Journal of Comparative and Physiological Psychology, 81 (3), 457-471. 
Booth, D A , Stoloff, R , \& Nicholls, J. (1974). Dietary flavor acceptance in infant rats established by association with effects of nutrient composition Physiological Psychology, 2 (NA3), 313-319

Booth, D. A (1977) Satiety and appetite as conditioned reflexes Psychosomatic Medicine, 39 (2), 76-81.

Booth, D. A, Mather, P, \& Fuller, J (1982). Starch content of ordınary foods associatıvely conditions human appetite and satıation, indexed by intake and eating pleasantness of starch-paired flavors Appetite, 3 (2), 163-184.

Booth D A., \& Grınker, J A (1993). Learned control of meal size in spontaneously obese and nonobese bonnet macaque monkeys. Physiology \& Behavior, 53 (1), 51-57.

Bordnıck, P. S , Graap, K. M., Copp, H. L., Brookes, J., \& Ferrer, M (2005) Virtual reality cue reactivity assessment in cigarette smokers. Cyberpsychology \& Behavior, 8 (5), 487-492.

Blanchard, F. A., \& Frost, R O (1983) Two factors of restraint: concern for dietıng and weight fluctuation Behaviour Research and Therapy, 21, 259-267.

Blundell, J. E , \& Halford, J. C. G. (1994) Regulation of nutrient supply-the brain and appetite control. Proceedings of the Nutrition Society, 53 (2) 407-418.

Bradley, B. P., Mogg, K, Wright, T , \& Field, M. (2003). Attentional bias in drug dependence Vigilance for cigarette-related cues in smokers Psychology of Addictive Behaviors, 17 (1), 66-72.

Braet, C , \& Combez, G. (2003). Cognitive interference due to food cues in childhood obesity Journal of Clintcal Child and Adolescent Psychology, 32, 32-39. 
Breteler, J. A., Schippers, C M, De Jong, C. A. J, van der Stark, C. P. F. (2000). No effect of negatıve mood on the alcohol cue reactıvity of in-patient alcoholics. Addictive Behaviors, 25 (4), 619-624.

Brownell, K D , \& Rodin, J (1994) Medical, Metabolic, and psychological effects of weight cycling. Archives of Internal Medicine, 154 (12), 1325-1330

Brunstrom, J M, Downes, C. R., Higgs, S. (2001) Effects of dietary restraint on flavour-flavour learnıng. Appettte, 37 (3), 197-206

Brunstrom, J. M., Yates, H M, \& Witcomb, G L (2004) Dietary restraint and heightened reactivity to food Physiology \& Behaviour, 81 (1), 85-90.

Brunstrom, J M , \& Witcomb, G L. (2004) Automatic and nonautomatic processed in dietary restraint Further evidence for a commonality between food and drug abstınence. Eatıng Behaviors, 5, 365-373.

Brunstrom, J. M, Mitchell, G L, Baguley, T. S. (2005) Potential early-lıfe predictors of dietary behaviour in adulthood a retrospective study International Journal of Obesity, 29 (5), 463-474.

Burton, S. M., \& Tiffany, S T. (1997). The effect of alcohol consumption on craving to smoke. Addiction, 92 (1), 15-26.

Buzzard, M (1998) 24-hour dietary recall and food record methods. In W. Willet (Eds.), Nutritıonal Epıdemiology (2 ${ }^{\text {nd }}$ Editıon) (p. 50-73). Oxford: Oxford University Press

Calle, E. E, Thun, M J., Petrell, J M , Rodrıguez, C , \& Heath, C.W. (1999). Body mass index and mortality in a prospectıve cohort of US adults. New England Journal of Medicine, 341 (15), 1097-1105. 
Calvin, J. S., Bıcknell, E. A., \& Sperlıng, D S (1953). Establishment of a conditioned drive based on the hunger drive. Journal of Comparative and Physiological Psychology, 46 (3), 173-175

Cannon, W.B. (1932). The W1sdom of the Body New York: Norton

Capaldı, E. D., Davidson, T L, \& Myers, D. E. (1981) Resistance to satiation: Reinforcing effects of food and eatıng under satiation Learning and Mottvation, 12, $171-195$.

Carbonnel, F., Lemann, M, Rambaud, J. C , Mundler, O, Jian, R (1994). Effect of the energy density of a solid-liquid meal on gastric emptyıng and satiety. American Journal of Clinical Nutrition, 60, 307-311.

Carter, B. L., \& Tiffany, S T. (1999). Meta-analysis of cue reactivity in addiction rescarch Addlction, 94 (3), 327-340

Carver, C. S., \& White, T. L. (1994). Behavioral inhibition, behavioural activation, and the affective responses to impending reward and punıshment: The BIS/BAS scale. Journal of Personality and Soctal Psychology, 67, 319-333

Castella, J., \& Perez, J. (2004). Sensitıvity to punıshment and sensitıvity to reward and traffic violations. Accident Analysts and Prevention, 36 (6), 947-952.

Claes, L. Vandereycken, W., \& Vertommen, H. (2002). Impulsive and compulsıve traits in eating disordered patients compared with controls. Personality and Individual Differences, 32, 707-714. 
Clonınger, C. R, Sigvardsson, S , Bohman, M. (1988). Chıldhood personality predicts alcohol-abuse in young-adults Alcoholssm-Clintcal and Experimental Research, 12 (4), 494-505

Collıns, J. E. (1978) Effects of restraint, monıtorıng, and stımulus salıence on eatıng behaviour Addictlve Behaviors, 3, 197-204.

Comıngs, D. E, Gade, R., Wu, S , Chiu, C., Dietz, G, Muhlemann, D., Saucier, G, Ferry, L, Rosenthal, R J , Lesieur, H. R, Rugle, L J , MacMurray, P. (1997) Studies of the potential role of the dopamine D-1 receptor gene in addictive behaviours Molecular Psychiatry, 2, 44-56.

Conns, E E. \& White, H A. (1977). Tonic properties of orosensation and the modulation of intracranial self-stımulation The can weighting of external and internal factors governing reward. Annals of the New York Academy of Sciences, 290, 158-179.

Cooney, N. L, Gillespie, R. A, Baker, L.H., \& Kaplan, R. F. (1987) Cognitive changes after alcohol cue exposure. Journal of Consultting and Clintcal psychology, 55, 105-155.

Cooney, N L., Litt, M. D., Morse, P. A , Bauer, L O., \& Gaupp, L. (1997). Alcohol cue reactivity and relapse in treated alcoholic men Journal of Abnormal Psychology, $106(2), 243-250$.

Corbit, L H., \& Balleıne, B. W. (2003). Instrumental and Pavlovian incentive processes have dissociable effects on components of a heterogeneous instrumental chain. Animal Behavior Processes, 29 (2), 99-106.

Cornell, C. E., Rodın, J., \& Weıngarten, H. P. (1989). Stımulus-ınduced eatıng when satiated. Physiology \& Behaviour, 45, 695-704. 
Corr, P. J., Pıckerıng, A. D., \& Gray, J A (1995). Personality and reınforcement in associatıve and instrumental learnıng. Personality and Individual Differences, 19, 47 71

Costanzo, P R, \& Woody, E. Z. (1979). Externality as a function of obesity in children' Pervasıve style or eatıng-specific attribute. Journal of Personality and Social Psychology, 37, 2286-2296

Cuilso, R. Z, Toyoshıma, H., Date, C, Yamamoto, A., Kıkuchı, S, Kondo, T, Watanabe, Y, Kolzuma, A, Wada, I., Inaba, , Y \& Tamakoshi, A (2005). Body mass index and mortality from cardiovascular disease among Japanese men and women The JACC study Stroke, 36 (7), 1377-1382

Davidson, T L (1993) The nature and function of interoceptive signal to feed - toward integration of physiological and learning perspectıves. Psychological Review, 100, 640-657.

Davis, J D , \& Campbell, C S (1973). Peripheral control of meal size in rat - effect of sham feeding on meal size and drinking rate. Journal of Comparative and Physiological Psychology, 83 (3), 379-387.

De Castro, J M , \& Brewer, E. M (1992). The amount eaten in meals by human is a power function of the number of people present. Physiology \& Behavior, 51, 121- 125.

Decke, E. (1971). Effects of taste on the eatıng behavior of obese and normal persons In S. Schachter Emotıon, Obesity, \& Crime New York, Academıc Press, 1971.

de Lauzon-Gullain, B, Basdevant, A., Romon, M., Karlsson, J., Borys, J M., \& Charles, M A. (2006). Is restrained eatıng a risk factor for weight gain in a general population? American Journal of Clinical Nutritıon, 83 (1): 132.138 
Di Chiara, G. (2000). Role of dopamine in the behavioural actions of nicotıne related to addiction. European Journal of Psychopharmacology, 393, 295-314.

Dıckınson, A, Balleıne, B., Watt, A, Gonzalez, F., \& Boakes, R. A. (1995) Motivational control after extended instrumental training Anımal Learning \& Behavior, 23 (2), 197-206.

Dickınson, A, \& Balleıne, B. (1994). Motıvational control of goal-directed action Anımal Learning \& Behavior, 22, 1-18

Dickınson, A, \& Balleıne, B. (2002) The role of learnıng In the operation of motivational systems. In Steven's handbook of experımental psychology, Ed 3 (Pashler $H$, Gallistel, R, EDS), PP497-533. New York: Wiley.

Dilıbertı, N , Bordı, P. L., Conklın, M T, Roe, L S., \& Rolls, B. J. (2004) Increased portion size leads to increased energy intake in a restaurant meal Obesity Research, 12 (3), 562-568.

Doran, N., Spring, B., McChargue, D, Pergadia, M, \& Rıchmond, M. (2004). Impulsıvity and smoking relapse. Nicotıne and Tobacco Research, 6, 641-647.

Drewnowskı, A., Rıskey, D , \& Desor, J. A (1982). Feelıng fat yet unconcerned selfreported overweight and the restraint scale. Appetıte, 3, 273-279.

Dritschel, B., Cooper, P. J , \& Charnock, D. (1993). A problematic counterregulation experıment - implications for the link between dietary restraint and overeating. International Journal of Eating Disorders, 13 (3), 297-304 
Drobes, D J , \& Tiffany, S. T. (1997) Induction of smoking urge through imaginable and in vivo procedures Physiological and self-report manifestations. Journal of Abnormal Psychology, 106 (1), 15-25.

Droungas, A, Ehrman, R N, Childress, A R, \& O'Brien, C. P (1995). Effect of smoking cues and cigarette avallability on craving and smoking behaviour. Addictive Behaviours, 20 (5) 657-673

Drummond, D. C., \& Glautier, S. T. (1994). A controlled trial of cue exposure treatment in alcohol dependence Journal of Consulttng and Clinical Psychology, 62, 809-817.

Edgar, D., Hall, G, \& Pierce, J. M. (1981). Enhancement of food-rewarded instrumental responding by an appetitive conditioned-stımulus Quarterly Journal of Experimental Psychology Section B-Comparattve and Phystological Psychology, 33, 319.

Elizalde, G., \& Sclafani, A. (1990). Fat appetite in rats - flavor preferences conditioned by nutritıve and nonnutritıve oll-emulsions. Appettte, 15 (3), 189-197.

Eysenck, H. J. (1957). The Dynamics of Anxzety and Hysteria. , Praeger, New York.

Eysenck, H J. (1965). Extraversion and the acquisition of eyeblink and GSR conditioned responses Psychological Bulletın, 63, 258-270

Eysenck, H. J (1966). Conditioning, introversion-extraversion and the strength of the nervous system. Proceedings of Eighteenth International Congress of Experimental Psychology, 33-34 Moscow. Ninth Symposium .

Eysenck, H. J (1967) The Biological Basis of Personaltty. Sprngfield, Illınois. 
Eysenck, H J., \& Esyenck, S. B. G. (1975) Manual of Personalty Questıonnatre San Diego, CA: EDITS

Evenden, J. L. (1999). Varieties of impulsıvity. Psychopharmacology, 146 (4), 348361.

Fedoroff, I, Polivy, J , \& Herman, C P. (1997). The effects of pre-exposure to food cues on the eatıng behaviour of restrained and unrestrained eaters. Appetite, 28, 33-47

Fedoroff, I, Polivy, J., \& Herman, C P (2003). The specificity of restrained versus unrestrained eaters' responses to food cues: general destre to eat, or craving for the cued food? Appettte, 41, 7-13

Fenıchel, O. (1999) Psychoanalytical theory of neurosts Routeledge

Field, A (2005). Discovering statistics using SPSS (2 ${ }^{\text {nd }}$ Edition) London Sage publications.

Field, M , \& Duka, T. (2005). Cue reactivity in smokers: the effects of perceived avallability and gender. Pharmacology, Btochemistry, and Behaviour, 78 (3), 647-652.

Flatt, P R., \& Ba1ley, C. J. (1983) Glucose and insulin-response to conditioned feeding in lean and genetically-obese hyperglycemic (ob ob) mice. Metabolism-clinical and experimental, 32 (5), 504-509.

Flegal, K. M., Carroll, M D , Ogden, C. L., \& Johnson, C L. (2002). Prevalence and trends in obesity among US adults, 1999-2000, JAMA-Journal of the American Dietetıc Assoctation, 288 (14), 1723-1727. 
Foreyt, J. P., Brunner, R. L, Goodrıck, G. K, Cutter, G, Brownell, K. D., \& Stjeor, S. T. (1995) Psychological correlations of weight fluctuation. International Journal of Eatıng Disorders, 17 (3), 263-275.

Francis, J A, Stewart, S H , \& Hounsell, S. (1997) Dietary restraint and the selective processing of forbidden and nonforbidden food words in restrained eater Cognitive Therapy and Research, 21 (6), 633-646

Francis, L, \& Birch, L. (2003) Links among television viewing, snacking and dietary intake in 11-year-old gurls Obesity Research ,12, (Suppl) A74-A74

Franken, H. A, de Haan, H A., van der Meer, A. W , Haffmans, P. M. J., \& Hendrick, V .M (1999). Cue reactivity and effects of cue exposure in posttreatment drug users. Journal of Substance Abuse, 16 (1).81-85

Franken, I. H. A (2002). Behavioral approach system (BAS) sensitivity predicts alcohol craving Personality and Individual Differences, 32 (2), 349-355

Franken, I. H. A , Hendrıks, V. M, Stam, C. J., \& Van den Brınk, W. (2004). A role for dopamine in the processing of drug cues in heroin dependent patients European Neuropsychopharmacology, 14, 503-508.

Franken, I. H. A., \& Murıs, P. (2005). Indıvidual differences in reward sensitivity are related to food craving and relative body weight in healthy women. Appetite, 45, 198201.

Gautıer, J. F, Chen, K. W., Salbe, A D, Bandy, D., Pratley, R E, Heıman, M, Ravussin, E , Reıman, E. M , \& Tatarann, P A. (2000). Differentıal brain responses to satiation in obese and lean men Diabetes, 49 (5), 838-846. 
Gautıer, J. F., Del Parıi, A, Chen, K W., Salbe, A. D., Bandy, D., Pratley, R. E., Ravussin, E., Reıman, E M, Tatarannı, P A. (2001) Effect of satıation on brain activity in obese and lean women. Obesity Research, 9 (11), 676-684.

Glautier, S , \& Drummond, D. C. (1994) Alcohol dependence and cue reactivity. Jotırnal of Studies on Alcohol, 55 (2), 224-229.

Glautier, S \& Remington, B (1995) The form of responses to drugs. In D. C. Drummond (Eds) Addictive Behaviour Cue exposture theory and practice. Wiley.

Gibson, E L, Wainwright, C. J , \& Booth, D. A. (1995). Disguised protein in lunch after low-protein breakfast conditions food-flavor preferences dependent on recent lack of protein-1ntake. Physiology \& Behavior, 58 (2), 363-371.

Gibson, E. L., \& Booth, D A (2000) Food-conditioned odour rejection in the late stages of the meal, medıatıng learnt control of meal volume by aftereffects of food consumption Appettte, 34 (3), 295-303.

Goldman, D., Jaffa, M., \& Schachter, S. (1968) Yom Kippur, Arr France, dormitory food, and eatıng behaviour of obese and normal persons Journal of Social psychology, 10, 117-123.

Grano, N, Vırtanen, M, Vahtera, J., Elovaını, M, \& Kıvımakı, M (2004) Impulsivity as a predictor of smoking and alcohol consumption. Personality and Individual Differences, 37 (8), 1693-1700

Grau, E. \& Ortet, G (1999) Personality traits and alcohol consumption in a sample of non-alcoholic women. Personality and Indivedual Differences, 27, 1057-1066.

Gray, J. A. (1970). The psychophysiological basis of introversion-extraversion. Behaviour Research and Therapy, 8, 249-266. 
Gray, J. A. (1976). The behavioural inhibition system: a possible substrate for for anxiety. In M. P. Feldman \& A. M. Broadhurst (Eds) Theoretical and Experimental Bases of Behaviour Modificatton. London: Wiley.

Gray, J. A. (1981). A critıque of Eysenck's theory of personality. In H J. Eysenck (Ed ) A Model for Personality Berlın Springer.

Gray, J A. (1987a) The psychology of fear and stress Cambridge Cambridge University

Gray, J A. (1987b) Perspectives on anxiety and impulsıvity A Commentary. Journal of Research in Personality, 21, 493-509.

Green, M W., Rogers, P. J., \& Ellman, N. A. (2000) Dietary restraint and addıctive behaviours: The generalisability of Tiffany's cue reactıvity mode International Journal of Eatıng Disorders, 27, 419-427.

Greenley, J. D, Swıft, W., Prescott, J , \& Heather, N. (1993). Reactıvity to alcoholrelated cues in heavy and light drinkers. Journal of Studies on Alcohol, 54 (3), 359-368.

Gregory, J , Foster, K., Tyler, H., \& Wiseman, M. (1990). The dietary and nutrittonal survey of British adults. London HMSO

Guinard, J. X, \& Brun, P. (1998). Sensory-specific satiety: Comparison of taste and texture effects. Appettte, 31 (2), 141-157.

Gupta, B S. (1996). Extraversion and reinforcement in verbal operant conditioning. Britısh Journal of Psychology, 67, 47-52.

Gupta, B S., \& Nagpal, M (1978) Impulsıvity/sociabılity and reinforcement in verbal operant conditioning. Britısh Journal of Psychology, 68, 203-206. 
Gupta, B. S \&. Shukla, A. P. (1989). Verbal operant conditioning as a function of extraversion and reinforcement. Brittsh Journal of Psychology, 80, 39-44.

Guerrierı, R , Nederkoorn, C , \& Jansen, A. (2006) Do impulse control problems cause obesity? Conference presentation, Britısh Feedıng and Drınkıng Group (BFDG), Unıversity of Birmıngham, Abstract publıshed in Appettte, 47, 264

Guthrie, E. R. (1934) Pavlov's theory of conditioning, Psychologıcal Review, 41, 199206.

Guthrie, E. R. (1952). The psychology of learning (Rev ed) New York: Harper

Haynes, C., Lee, M. D., \& Yeomans, M. R (2003) Interactive effects of stress, dietary restraint, and disınhibition on appette, Eating Behaviours, 4, 369-383.

Health Survey for England, 2004 Updating of trend tables to include 2004 data. http //www ic nhs uk/pubs/hlthsvyeng2004upd

Heatherton, T. F., Herman, C. P , Polivy, J, Kıng, G. A., \& McGree, S. T. (1988) The (mis)measurement of restraint - an analysis of conceptual and psychometric 1 ssues. Journal of Abnormal Psychology, 97 (1), 19-28

Heatherton, T F., Polivy, J., \& Herman, C. P. (1989). Restrant and internal responsiveness: Effects of placebo manpulation of hunger state on eatıng. Journal of Abnormal Psychology, 98, 89-92.

Herman, C. P. (1974) External and internal cues as determınants of smoking behaviour of light and heavy smokers Journal of Personality and Social Psychology, 30 (5), 664672. 
Herman, C. P, \& Mack D. (1975) Restrained and unrestranned eatıng. Journal of personality, 43, 647-660.

Herman, C. P , \& Polıvy, J. (1980) Restrained eatıng In A B. Stunkard (Ed.), Obestty, Philadelphia Saunders

Herman, C. P., Polıvy, J, Klajner, F , \& Esses, V. M. (1981) Salıvation in dieters and non-dieters. Appette, 2 (4), 356-361.

Herman, C.P., \& Polıvy, J (1984). A boundary model for the regulation of eatıng. In A.B. Stunkard \& E. Stellar (Eds.), Eating and tts Disorders (pp. 141-156). New York: Raven Press.

Herman, C. P., Ostovich, J. M , \& Polıvy, J (1999). Effects of attentional focus on subjectıve hunger ratıngs. Appettte, 33 (2), 181-193.

Herman, C. P , \& Polivy, J. (2005). Normative influences on food intake. Physiology and Behavior, 86 (5), 762-772.

Herrman, M J., Weyjers, H. G., Wiesbeck, G. A., Bonıng, J., \& Fallagatter, A. J. (2001). Alcohol cue-reactivity in heavy and light social drinkers as revealed by eventrelated potentials. Alcohol \& Alcoholssm, 36 (6), 588-593.

Hogarth, L. C., Mogg, K., Bradley, B. P, Duka, T., \& Dickinson, A. (2003). Attentional orientatıng towards smokıng related stımulı Behavioural Pharmacology, 14 (2), 153-160.

Hibscher, J. A., \& Herman, C. P. (1977) Obestty, dieting, and expression of obese characteristics. Journal of Comparative and Physiological Psychology, 91 (2), 374-380 
Hodgson, R. J , \& Greene, J B (1980). The salıva prımıng effect, eatıng speed and the measurement of hunger. Behaviour Research and Therapy, 18 (4), 243-247.

Holman, G L. (1969). Intragastric reinforcement effect. Journal of Comparative and Phystological Psychology, 69 (3), 432.

Howard, M. O., Kıvlahan, D , \& Walker, R. D. (1997) Clonınger's trıdımensıonal theory of personality and psychopathology Applications to substance use disorders Journal of Studies on Alcohol, 58 (1), 48-66.

Hu, G., Tuomilehto, J., Silventoinen, K., Barebgo, N. C , Peltonen, M , \& Jousililaht1, P. (2005). The effects of physical activity and body mass index on cardiovascular, cancer and all-cause mortality among 47,212 middle-aged Finnish men and women. International Journal of Obesity, 29 (8), 894-902.

Hugdahl, K, \& Ternes, J. W (1981). An electrodermal measure of arousal in oprate addicts to drug-related stımulı. Biological psychology, 12 (4), 291-298.

Hull, C L. (1935). Thorndike's fundamentals of learnıng Psychological Bulletın, 32, $807-823$.

Hull, C L (1943). Principles of behavior. New York. Appleton.

Hutchınson, K. E, Niaura, R., \& Swift, R. (1999). Smoking cues decrease prepulse inhibition of the startle response and increase subjective cravings in humans. Experimental and Clinical Psychopharmacology, 7 (3), 250-256

Israel, A. L., \& Stewart, S. H (2001). Memory bias for forbidden food cues in restrained eaters. Cognitive Therapy and Behaviour, 25 (1), 37-47. 
Jain, M. G., Miller, A B, Rohan, T E, Rehm, J T, Bondy, S. J., Ashley, M. J., Cohen, J. E, Ferrence, R G (2005) Body mass index and mortality in women: followup of the Canadian National Breast Screening Study Cohort International Journal of Obesity, 29 (7), 792-797.

Jansen, A, \& van den Hout, M. (1991). On being led into temptation “counterregulation" of dieters after smelling a "preload." Addictıve Behaviors, 16, 247253

Jansen, A , Vandenburg, J., \& Bulten, K. (1992) No counterregulation after breaking the external restraint of children Behaviour Research and Therapy, 30 (1), 59-62

Jansen, A (1998). A learning model of binge eatıng Cue reactıvity and cue exposure. Behaviour Research and Therapy, 36 (3), 257-272.

Jansen, A, Theunissen, N., Slechten, K., Nederkoorn, C., Boon, B, Mulkens, S , \& Roefs, A. (2003). Overwe1ght children overeat after exposure to food cues. Eating behaviours, 4, 197-209.

Johnson, W. G. (1974). The effects of cue prominence and obesity on effort to obtain food. In Schachter, E., \& Rodın, J. (1974) Obese humans and rats. Washington, DC Erlbaum

Johnson, W G, Lake, L, \& Mahan, J. N. (1983). Restrained eatıng: measuring an elusive construct. Addictlve Behaviour, 8, 413-418.

Johnson, S L., McPhee L., \& Birch, L. L. (1991). Conditioned preferences - youngchildren prefer flavors associated with high dietary-fat. Physiology \& Behavior, 50 (6), 1245-1251. 
Jorm, A F, Christensen, H., Henderson, A. S., Jacomb, P.A, Korten, A E., \& Rodgers, B (1999). Usıng the BIS/BAS scales to measure behavioural inhibition and behavioural activation: factor structure, validity and norms in a large community sample Personality and Individual Differences, 26, 49-58.

Kahneman, D. (1973). Attention and Effort Englewood Cliffs (New Jersey), London: Prentice Hall.

Kajıka, T, Tsuzuku, S, Shımokata, H., \& Sato, Y. (2002) Effects of intentional weight cycling on non-obese young women Metabolısm-Clinical and Experimental, $51(2), 149-154$.

Kambouropoulos, N , \& Staiger, P K. (2001). The influence of sensitivity to reward on reactivity to alcohol-related cues. Addiction, 96 (8), 1175-1185.

Kambouropoulos, N., \& Staiger, P K (2004) Reactivity to alcohol-related cues. Relationship among cue type, motivational processes, and personality. Psychology of Addictive Behaviors, 18 (3), 275-283

Kane, T. A., Loxton, N. J , Staiger, P. K , \& Dawe, S (2004). Does the tendency to act impulsıvely underlie binge eatıng and alcohol use problems? An empirical investıgation. Personality and Individuals Differences, 36, 83-94.

Kavangh, D. J., \& Andrade, J., \& May, J. (2005) Imagınary relish and exquisite torture: The elaborated intrusion theory of desire Psychological Review, 112 (2), 446467

Kemmotsu, N., \& Murphy, C. (2006). Restrained eaters show altered brain responses to food odor. Physiology \& Behavior, 87 (2), 323-329. 
Kemps, E, Tiggeman, M, Woods, D, \& Soekov, B. (2004). Reduction in food cravings through concurrent visuo-spatial processing International Journal of eating Disorders, 36, 31-40

Kemps, E., Tiggeman, M , \& Hart, G. (2005) Chocolate cravings are susceptible to visuo-spatıal interference. Eatıng Behaviours, 6, 101-107.

Kennedy, G C (1953) The role of depot fat in the hypothalamic control of food intake in the rat. Proceedings of the Royal Soclety, London Serles B, 140, 578-592.

Kern, D. L., McPhee, L, Fisher, J, Johnson, S, \& Birch, L L. (1993). The postingestive consequences of fat condition preferences for flavors associated with high dietary-fat. Phystology \& Behavior, 54 (1), 71-76

Klajner, F., Herman C. P, Polıvy, J , \& Chhabra, R. (1981) Human obesity, dietıng, and anticipatory salivation to food Physiology \& Behaviour, 27 (2), 195-198

Kranzler, H R , \& Baller, L. O (1992) Bromocriptıne and cocaine cue reactıvity in cocame-dependent patients Britlsh Journal of Addictıon, 87 (11), 1537-1548.

Knyazev, G. G (2004) Behavioural activation as predictor of substance use: mediatıng and moderating role of attitudes and social relationships. Drug and Alcohol Dependence, 75 (3), 309-321. 
Knyazev, G. G , Slobodskaya, H. R , Kharchenko, I. I., \& Wilson, G. D (2004)

Personality and substance use in Russian youths: The predictıve and moderatıng role of behavioural actıvation and gender. Personality and Individual Differences, 37 (4), 827 843

Laessle, R G , Tuschl, R. J., Kotthaus, B. C., \& Prrke, K. M. A (1989) Comparison of the validity of three scales for the assessment of dietary restraint. Journal of Abnormal Psychology, 98 (4), 504-507

Lambert, K G, Neal, T, Noyes, J., Parker, C , \& Worrel, P. (1992). Food-related stımuli increase desire to eat in hungry and satıated human-subjects. Current Psychology-Research and Reviews, 10 (4), 297-303.

Lappalainen, R, Sjoden, P. O., Hursti, T., \& Vesa, V. (1990). Hunger/craving responses and reactıvity to food stımulı durıng fastıng and dietıng International Journal of Obesity, 14, 679-688

Lappalainen, R., Sjoden, P. O., Karhunen, L, Gladh, V., \& Lesinska, A. D. (1994). Inhibition of anticipatory salivation and craving in response to food stımuli. Physiology \& Behavior, 56 (2), 393-398.

Lattımore, P. J., Thompson, G. M., \& Halford, J C G. (2000) Developmental onset of eatıng related color naming inference: The role of restraint and eatıng psychopathology. International Journal of Eating Disorders, 28, 27-32.

LeGoff, D B , \& Spıgelman, M N (1987). Salıvary response to food stımuli a function of dietary restraint and body-werght. Appette, 8 (1), 29-35.

Leon, G R, \& Roth, L. (1977) Obesity - psychological causes, correlations, and speculations. Psychological Bulletin, 84 (1), 117-139. 
Le Magnen, J (1955) La satıeteındutte par lea stımulı sucres chez le reat blanc Comptes Rendus des Seances de las Soctete de Blolgie, Parts, 149, 1339-1342.

Levitsky, D. A. (2002). Puttıng behaviour back into the feedıng behavıour. A tribute to to George Collier. Appetite, 38 (2), 143-148

Lindroos, A. K., Lıssner, L, Mathiassen, M E., Karlsson, J, Sullıvan, M, Bengtsson, C , \& Sjostrom, L. (1997). Dietary intake in relation to restrained eatıng, disınhibition, ad hunger in obese and nonobese Swedish women Obesity Research, 5, 175-182

Logan, G. D., Schachar, R. J., \& Tannock, R. (1997). Impulsıvity and inhibitory control Psychological Sclence, 8, 60-64.

Logue, A. W , Ophır, I, \& Strauss, K E (2002) The acquisition of taste aversıons in humans. Behaviour Research and Therapy, 19, 319-333.

Loos, R. J., \& Bouchard, C (2003) Obesity-is it a genetic disorder? Journal of International Medicine, 254, 401-25.

Lopez, M., Balleıne, B., \& Dickınson, A. (1992). Incentive learning and motivational control of instrumental performance by thirst. Animal Learning \& Behavior, 20, 322 328.

Lovibond, P. F. (1980). Effects of long-duration and variable-duration signals for food on actıvity, instrumental responding, and eatıng. Learning and mottvation, 11 (2), 164184.

Lovibond, P. F. (1983). Facilitation of instrumental behavior by a pavlovian appetitive conditioned-stımulus Journal of Experımental Psychology-Animal Behavior Processes, 9 (3), 225-247. 
Lowe, M. R. (1984). Dietary concern, weight fluctuation, and weight status further explorations of the Restraint Scale. Behaviour research and Therapy, 22, 243-248

Lowe, M. R., \& Kleıfield, E. I. (1988) Cognitive restraint, weight suppression, and the regulation of eatıng Appettte, 10 (3), 159-168

Lowe, M R, Whitlow, J. W., \& Bellwoar, V. (1991). Eatıng regulation: The role of restraint, dietıng, and weight Internatıonal Journal of Eatıng Disorders, 10, 461-471.

Lowe, M R. (1993). The Effects of dietıng on eating behavior: A three-factor model. Psychological Bullettn, 114 (1), 100-121.

Lowe, M R, (1995). Restrained eatıng and dietıng: Replication of their divergent effects on eatıng regulation. Appettte, 25, 115-118.

Lowe, M , \& Kral, T. V. E. (2006). Stress-ınduced eatıng in restrained eaters may not be caused by stress or restraint Appetıte, 46, 16-21.

Loxton, N. J , \& Dawe, S (2001). Alcohol abuse and dysfunctional eatıng in adolescent girls The influence of individual differences in sensitivity to reward and punishment. International Journal of Eatıng Disorders, 29, 455-462

Lucas, F., Nitavong, M., Villeminot, S., Kaaks, R , \& ClavelChapelon, F. (1995) Estımation of food portion sıze using photographs - validity, strengths, weaknesses, and recommendations. Journal of Human Nutrition and Dietetics, 8 (1), 65-74.

MacCallum, R. C , Zhang, S B., Preacher, K. J., \& Rucker, D. D. (2002) On the practice of dichotomization of quantıtatıve variables. Psychological Methods, 7, 19-40.

MacFarlane, S. J., \& White, J M (1989). Acquisition and extunction of an alcoholopposite conditioned-response in humans. Psychopharmacology, 97 (3), 355-357. 
Marcelıno, A. S., Adam, A. S., Couronne, T., Koster, E. P., S1efferman, J. M. (2001). Internal and external determinants of eating initiation in humans Appettte, 36 (1), 9-14

Mattes, R., 1990. Hunger ratıngs are not a valıd proxy measure of reported food intake in humans. Appettte, 15, 103-113.

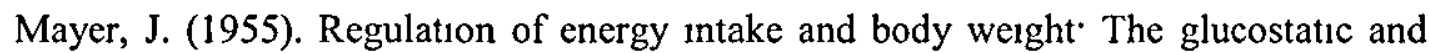
lipostatic hypotheses. Annals New York Academy Science, 63, 15-43

McArthur, L. Z, \& Bustein, B (1975) Field-dependent eatıng and perception as a function of weight and sex Journal of Personality, 43 (3), 402-420

McCaul, M E., Turkkan, J. S., \& Stıtzer, M. L. (1989) Conditioned opponent responses - effects of placebo challenge in alcoholic subjects. Alcoholism-clinical and experimental research, $13(5), 631-635$

Mela, D J, Aaron, I, \& Gatenby, S J. (1996) Relationships of consumer characteristics and food deprivation to food purchasing behavior. Physiology and Behavior, 60 (5), 1331-1335.

Michael, J (1982) Distınguishing between discriminatıve and motivational functions of stımuli. Journal of the Experimental Analysis of Behavior, 37 , 149-155.

Michael, J. (1993) Establishıng operatıons. Behavior Analyst, 16, 191-206

Michael, J. (2000) Implications and refinements of the establishing operation concept. Journal of Applied Behavior Analysis, 33, 401-410.

Mitchell, S. H. (1999) Measures of impulsivity in cigarette smokers and non-smokers Psychopharmacology, 146, 455-464 
Moeller, F. G, Barratt, E. S., Dougherty, D. M., Schmıtz, J. M., \& Swann, A. C. (2001). Psychiatric aspects of impulsivity American Journal of Psychiatry, 158, 17831793

Mogg, K, \& Bradley, B. P. (2002) Selective processing of smoking-related cues in smokers manipulation of deprivation level and comparison of three measures of smokıng bias. Journal of Psychopharmacology, 16 (4), 385-392

Mogg, K, Field, M , \& Bradley, B P. (2005). Attentıonal and approach biases for smokıng cues in smokers: an investıgation of competıng theoretıcal views of addiction Psychopharmacology, 180, 333-341.

Montı, P M., Rohsenow, D J, Rubonıs, A V, Niaura, R S., Sirota, A D, Colby, S M, Goddard, P , \& Abrams, D. B (1993) Cue exposure with coping skills treatment for male alcoholics. A preliminary investıgation Journal of Consulting and Clinical Psychology, 61, 1011-1019

Munafo, M, Mogg, K, Roberts, S., Bradley, B. P , \& Murphy, M. (2003). Selectıve processing of smokıng-related cues in current smokers, ex-smokers, and never-smokers on the modified Stroop task Journal of Psychopharmacology, 17 (3), 310-316.

Nagpal, M , \& Gupta, B S. (1979) Personality, reinforcement and verbal operant conditıoning British Journal of Psychology, 70, 471-476

Nasser, J. A., Gluck, M. E., \& Geliebter, A. (2004), Impulsivity and test meal intake in obese binge eatıng women Appettte, 43, 303-307.

Naurı, R. S., Rohsenow, D. J , Blinkoff, J A , Montı, P. M., Pedraza, M., \& Abrams, D. B. (1988). Relevance of cue reactivity to understanding alcohol and smoking relapse Journal of Abnormal Psychology, 97 (2), 133-152 
Nederkoorn, C, Smulders, F. T. Y., \& Jansen, A. (2000) Cephalıc phase responses, craving and food intake in normal subjects Appetite, 35 (1), 45-55.

Nederkoorn, C, \& Jansen, A (2002). Cue reactivity and regulation of food intake Eatıng Behaviors, 3, 61-72

Nederkoorn, C, Smulders, F., Havermans, R., Jansen, A (2004) Exposure to bıngefood in bulımıa nervosa finger pulse amplitude as a potentıal measure of urge to eat and predictor of food intake. Appetıte, 42 (2), 125-130.

Nederkoorn, C., van El]s, Y, \& Jansen, A. (2004) Restrained eaters act on impulse. Personaltty and Individual Differences, 37 (8), 1651-1658

Nederkoorn, C., Smulders, F, Havermans, R., Roefs, A., \& Jansen, A. (2006). Impulsivity in obese women. Appetite, 47, 253-256

Nederkoorn, C., Braet, B., Van Eıs, Y, Tanghe, A., \& Jansen, A Why obese children cannot resist food: The role of impulsivity. Eatıng Behaviors, in press

Nelson, M., Atkınson, M., \& Darbyshıre, S (1994) Food photography I - The perception of food portion size from photographs. British Journal of Nutritton, 72 (5), 649-663.

Nelson, M., Atkınson, M., \& Meyer, J (1997). A photographic Atlas of Food Portıon Sizes MAFF Publications, London.

Neuringe, A. J (1969). Anmals respond for food in presence of free food. Sclence, 166 (3903), 399. 
Newlin, D. B. (1985). Human conditioned compensatory response to alcohol cuesinitial evidence. Alcohol, 2 (3), 507.509

Nisbett, R E (1968a). Determinants of food intake in human obesity. Sclence, 159, 1254-1255.

Nisbett, R. E (1968b). Taste, deprivation and weight determınants of eatıng behavior. Journal of Personality and Social Psychology, 10, 107-16

Nisbett, R. E (1972). Hunger, obesity, and the ventromedial hypothalamus. Psychological Review, 79, 433-453

Nisbett, R. E , \& Kanouse, D. E (1969). Obesity, food deprivation, and supermarket shopping behavior Journal of Personalty and Soctal Psychology, 12, 289-294.

Oakes, M. E , \& Slotterback, C S. (2000) Self-reported measures of appetite in relation to verbal cues about many foods Current Psychology, 19 (2), 137-142

O'Brien, C. P. (1976). Experimental analysis of conditioning factors in human narcotıc addiction Pharmacological Reviews, 27, 533-543.

O'Conner, R., M , \& Colder, C R. (2005). Predictıng alcohol patterns in frst-year college students through motivational systems and reasons for drinkıng. Psychology of Addictlve Behaviors, 19, 10-20.

Osbourne, S. R. (1977). Free food (contrafreeloading) phenomenon - review and analysis Animal Learning \& Behavior, 5 (3), 221-235.

Ouwens, M. A, van Strien, T., \& van der Stark, C. P. F. (2003). Tendency toward overeatıng and restraint as predictors of food consumption Appettte, 40 (3), 291-298. 
Overduin, J, Jansen, A., \& Ellkes, H. (1997). Cue reactıvity to food- and body-related stımulı in restrained and unrestrained eaters. Addictive Behaviors , 22 (3), 395-404.

Payne, T. J , Rappaport, N. B , Smith, P O., Etscheidt, M , Brown, T. A., \& Johnson, C A (1992). Reactivity to alcohol-relevant beverage and imaginable cues in alcoholics Addictive Behaviors, 17 (3), 209-217

Pavlov, I P. (1927) Conditioned reflexes London and New York Oxford Unıversity press

Pelchat, M L (2002). Of human bondage. Food craving, obsession, compulsion, and addiction. Physiology and Behavior, 76, 347-352.

Pereira, M. A., Kartashov, A. I., Ebbelıng, C. B , Van Horn, L, Slattery, M , Jacobs, D. R, Ludwig, D. S. (2005) Fast-food habits, weight gain, and insulin resistance (the CARDIA study): 15-year prospective analysis. Lancet, 365 (9453), 36-42.

Perez, C., Ackoff, K, \& Sclafant, A. (1996) Carbohydrate- and proteın-conditioned flavor preferences: Effects of nutrient preloads Physlology \& Behavior, 59 (3), 467474.

Perez, C , Fanızza, L J, \& Sclafanı, A. (1999) Flavour preferences conditioned by intragastric nutrient infusions in rats fed chow or a cafeteria diet Appetite, 32 (1), 155170.

Pracentını, A, Schell, A. M, \& Vanderweele, D A. (1993). Restrained and nonrestrained eaters onentating responses to food and non-food odours. Physiology \& Behavior, 53 (1), 133-138. 
Pıckerıng, A. D., \& Gray, J. A. (2001). Dopamıne, appetitıve reınforcement and neuropsychology of human learning An individual differences approach. In A. Eliaz, \& A Angleitner (Eds), Advances in individual differences research Lengerich. PABST Science Publishers

Pickerıng, A. D., Diaz, A., \& Gray, J. A (1995). Personality and reinforcement: An exploration usıng a maze-learning task. Personality and Individual Differences, 26, 357-365.

Polıvy, J. (1976) Perception of calones and regulation of intake in restrained and unrestrained subjects Addictive Behaviors, 1 (3), 237-243.

Pomerlau, O F., Fertıg, J., Baker, L, \& Conney, N. (1983) Reactivity to alcohol cues in alcoholics and non-alcoholics Implications for a stımulus control analysis of drınkıng Addictıve Behaviors, 8, 1-10.

Powel, J., Gray, J., \& Bradley, B. P (1993) Subjective craving for opıates: evaluation of a cue exposure protocol for use with detoxified opiate addicts. British Journal of Clinical Psychology, 32, 39-53

Powell, J H., AlAdawı, S , Morgan, J., Greenwood, R. J. (1996) Motivational deficits after brain injury: Effects of bromocriptıne in 11 patients Journal of Neurology and Psychatry, 60 (4), 416-421.

Price, J. M , \& Grinker, J. (1973). Effects of degree of obesity, food deprivation, and palatability on eating behavior of humans Journal of Comparative \& Phystological Psychology, 85, 265-271.

Pudel, V. E , Metzdorff, M., \& Oettıng, M. X. (1975) Persoehnlıchkeıt Adıpoeser in psychologischen Tests unter Beruecksichtıgung latent Fettsuechtıger $Z$ Psychosom Med Psychoanalyse, 21, 345-350. 
Rescorla, R. A (1990). Instrumental responses become associated with reinforcers that differ in one feature. Animal Learning \& Behavior, 18, 206-211

Revusky, S H (1967). Hunger levels durıng food consumption' Effects on subsequent preference Psychonomic Science, 7, 109-110.

Revusky, S. H. (1968) Effects of thirst level during consumption of flavoured water on subsequent preference Journal of Comparative \& Physiological Psychology, 66, 777 779

Rezek, M \& Kroeger, E. W. (1976). Glucose antmmetabolites and hunger. Journal of Nutrition, 106, 143-157

Richardson, N J., Rogers, P J, \& Ellıman, N. A. (1996) Conditioned flavour preferences reinforced by caffeıne consumed after lunch Physiology \& Behavior, 60 (1), 257-263.

Ridgeway, P. S., \& Jeffrey, B (1998) A comparıson of the Three-Factor Eatıng Questionnaire and the Restraint Scale and consideration of Lowe's three-factor model. Addictive Behaviors, 23, 115-118.

Rikard-Figuero, K., \& Zeichner, A. (1985) Assessment of smoking urge and its concomitants under an environmental smokıng cue manipulatıon Addictlve Behaviors, 10, 249-256.

Robinson, T E, \& Berridge, K. C. (1993). The neural basis of drug craving - An incentive sentization theory of addiction. Brain Research Reviews, 18 (3), 247-291.

Rodin, J (1975a). The effects of obesity and set point on taste responsiveness and intake in humans Jotirnal of Comparative \& Physiological Psychology, 89, 1003-1009. 
Rodin, J (1975b). Causes and consequences of time perception differences in overweight and normal weight people. Journal of Perspectives on Social Psychology, 31, 898-910.

Rodın, J, Moskowitz, H R, \& Bray, G. A. (1976). Relationshıp between obesity, weight loss, and taste responsiveness. Physiological behaviour, 17, 591-597

Rodin, J, \& Slochower, J. (1976) Externality in nonobese The effects of environmental responsiveness on weight Journal of Personality and Social Psychology, 29, 557-565

Rodın, J., Slochower, J , \& Flemıng, B. (1977). The effects of degree of obesity, age of onset, and energy deficit on external responsiveness Journal of Comparattve Physiological Psychology, 91, 586-597

Rodin, J. (1981). Current status of the internal-external hypothesis for obesity - what went wrong American Psychologist, 36 (4), 361-372.

Rogers, P. J., \& Hill, A. (1989) Breakdown of dietary restraint following mere exposure to food stimulı: Interrelationships between restraint, hunger, salıvation and food intake Addictive Behaviors, 14, 387-397.

Rogers, P. J , \& Smit, H. J. (2000). Food craving and food "addiction": A critical review of the evidence from a biopsychosocial perspective Pharmacology Biochemistry and Behavior, 66 (1), 3-14.

Rolls, B. J., Rowe, E. A., Rolls, E. T., Kingson, B., \& Megson, A (1981) Variety in a meal enhances food-intake in man. Physılogy \& Behaviout, 26 (2), 215-221. 
Rolls, E T, Rolls, E. T, \& Rowe, E. A. (1983). Sensory-Specific and motivationspecific satiety for the sight and taste of food and water in man. Physiology \& Behaviour, 30 (2), 185-192

Rolls, E T., \& Rolls, J H (1997) Olfactory sensory-specıfic satiety in humans.

Physiology \& Behavior, 61 (3), 461-473.

Rolls, B. J., Morris, E. L, \& Roe, L. S (2002). Portion size of food affects energy intake in normal-weight and overwerght men and women American Journal of Clinical Nutrition, 76 (6), 1207-1213.

Rolls, B J , Roe, L S , Meeıngs, J S., \&Wall, D. E. (2004). Increasıng the portion size of a sandwich increases energy intake Journal of American Dietetic Assoctation, 104 (3), 367-372.

Ross. L. (1974). Effects of manipulating the salıence of food upon consumption of obese and normal eaters. In S. Schachter \& J. Rodin, Obese humans and rats Washıngton, D C. Erlbaum/Halstead

Rubonis, A. V., Colby, S. M, Montı, P M, Rohsenow, D. J., Gullıver, S. B., Sirora, A. D. (1994) Alcohol reactıvity and mood induction in male and female alcoholics Journal of Studies on Alcohol, 55 (4), 487-494

Ruderman, A. J., \& Wilson, G T (1979) Weight, restraint, cognition, and conterregulation Behaviour Therapy and Research, 17, 581-590.

Ruderman, A. J., \& Christensen, H. (1983) Restraint theory and its applicability to overwerght individuals. Journal of Abnormal Psychology, 92 (2), 210-215 
Sahakıan, B J., Lean, M. E. J, Robbıns, T W, \& James, W. P. T (1981) Salivation and insulin secretion in response to food in nonobese men and women Appetite, 2 (3), 209-216.

Schachar, R, Tannock, R, Marriot, M , \& Logan, G (1995). Deficient inhıbitory control in attention deficit hyperactivity disorder Journal of Abnormal Child Psychology, 23, 411-437

Schachter, S (1968) Obesity and eating. Sclence, 161, 751-756.

Schachter, S , Goldman, R., \& Gordan, A. (1968) Effects of fear, food deprivation and obesity on eating. Journal of Personality and Social Psychology, 10 (2), 91-97.

Schachter, S., \& Gross, L. (1968). Manıpulated tıme and eatıng behaviour. Journal of Personality \& Social Psychology, 10, 98-106

Schachter, S. (1971). Some extraordinary facts about obese humans and rats. American Psychologist, 26, 129-144.

Schachter, S., \& Friedman, L. N. (1974). The effects of work and cue prominence on eatıng behaviour. In S Schachter \& J. Rodın Obese humans and rats. Washıngton, DC:Erlbaum.

Schachter, E , \& Rodın, J. (1974). Obese humans and rats. Washıngton, DC Erlbaum

Schwartz, K. S., \& Cunningham, C. L. (1990). Conditıoned-stımulus control of morphine hyperthermia. Psychopharmacology, 101 (1), 77-84.

Schumaker, J. F., \& Wagner, M. K. (1977). External-cue responsively as a function of age at onset of obesity. Journal of American Dietetıc Associatıon, 70, 275-279. 
Sclafanı, A, \& Nissenbaum, J. W (1988). Robust conditioned flavor preference produced by intragastric starch infusions in rats. American Journal of Physiology, 255 (4), R672-R675.

Seeley, R J., \& Schwartz, M W. (1997) The regulation of energy balance: Perıpheral hormones signals and hypothalamic neuropeptides. Current Directions in Psychological Science, 6, 39-44.

Shriffrın, R. M , \& Schnetder, W. (1977). Controlled and automatıc human information processing II Perceptual learning, automatic attending and a general theory Psychological Review, 84 (2), 127-190.

Sideroff, S. I , \& Jarvik, M. E (1980). Conditioned-responses to a videotape showing herom-related stımul1. Internatıonal Journal of Addictıons, 15 (4), 529-536

Siegel, S. (1999) Drug antıcıpation and drug addiction The 1998 H. David Archibold Lecture. Addiction, 1999, 94 (8), 1113-1124.

Simons, J. S, Olıver, M. N I, Gaher, R M, Ebel, G, \& Brummels, P. (2005). Methamphetamine and alcohol abuse and dependence symptoms: Assoctations with affect liability and impulsıvity in a rural treatment population. Addictive Behaviors, $\mathbf{3 0}$, 1370-1381

Singh, D., \& Sikes, S. (1979). Role of past experience on food-motıvated behaviour of obese humans. Journal of Comparatıve and Phystological Psychology, 86, 503-508.

Skınner, B. F. (1938). The behavior of organtsms, an expertmental analysts. New York: Appleton 
Skınner, B F (1953) Science and human behavior. New York. Macmıllan.

Smith, G. P , Gıbbs, J , Strohmayer, A , \& Strokes, P E. (1972). Threshold doeses of 2deoxy-D-glucose for hyperglycemıa and feeding in rats and monkeys. American Journal of Physiology, 222, 77-81

Sobık, L , Hutchison, K , \& Craighead, L. (2005) Cue-elıcited craving for food a fresh approach to the study of binge eatung Appetite, 44 (3), 253-261.

Spencer, J. A., \& Fremouw, W. J. (1979) Binge eatıng as a function of restraint and weight classification. Journal of Abnormal Psychology, 88 (3), 262-267.

Staiger, P. K., \& White, J. M. (1988). Conditıoned alcohol-like and alcohol-opposite responses in humans. Psychopharmacology, 95 (1), 87-91

Staiger, P. K, \& White, S. M. (1991). Cue reactıvity in alcohol abusers Stimulus specificity and extınction of the response Addlctive Behaviors, 16, 211-221.

Steel, D., Kemps, E., Tiggeman, M. (2006) Effects of hunger and visuo-spatial interference on imagery-induced food cravings Appetite, 46 (1), 36-40

Steere, J., \& Cooper, P. J. (1993). The effects on eatıng of dietary restraint, anxiety, and hunger International Journal of Eating disorders, 13, 211-219.

Stewart, J , de Wit, H , \& Eikelboom, R. (1984). Role of unconditioned and conditioned drug effects in the self-administration of opiates and stımulants. Psychological Review, 91 (2), 251-268. 
Stırlıng, L. J., \& Yeomans, M R (2004) Effect of exposure to a forbidden food on eating in restrained and unrestrained women. International Journal of Eatıng Disorders, 35 (1) 59-68.

Stroop, J. R (1935) Studies of interference in serial verbal reactions Journal of Experimental Psychology, 18, 743-762.

Stubbs, R. J., Hughes, D. A., Johnstone, A. M., Rowley, E., Re1d, C, Elıa, M, Strattopon, R, Delargy, H, King, N , \& Blundell, J E. (2000). The use of visual analogue scales to assess motivation to eat in human subjects: a review of their reliability and validity with an evaluation of new hand-held computerized systems for temporal trackıng of appetite ratıngs Britısh Journal of Nutrition, 84 (4), 405-415.

Stunkard, A., \& Koch, C. (1964). The interpretation of gastric motility. 1. Apparent bias in the reports of hunger by obese persons Archives of General Psychatry, 11 (1), 74.

Stunkard, A. (1975). Satiety as a conditioned reflex. Pychosomatıc Medicine, 37 (5), 383-387.

Stunkard, A , \& Messick, S (1985) The Three-Factor Eatıng Questionnatre to measure dietary restraint, disinhibition and hunger. Journal of Psychosomatıc Research, 29 (1), 71-83.

Tapper K. (2005). Motıvatıng operations in appetite research Appetite, 45 (2), 95-107.

Teasdale, J. D. (1973). Conditioned abstınence in narcotic addicts. International Journal of Addictions, 8 (2), 273-292. 
Tepper, B J (1992) Dietary restraint and responsiveness to sensory-based food cues as measured by cephalıc phase salıvation and sensory spectfic satiety Physiology \& Behavior, 52 (2), 305-311

Thewissen, R, van der Hout, M, Havermans, R. C., \& Jansen, A. (2005) Contextdependency of cue-elicited urge to smoke. Addiction, 100 (3) 387-396.

Thomas, S E, Drobes, D. J., \& Deas, D (2005). Alcohol cue reactivity in alcoholdependent adolescents Journal of Studies on Alcohol, 66 (3), 354-360.

Thorndike, E. L. (1905) The elements of psychology. New York. Seller.

Thorndike, E. L (1908). A pragmatic substitute fir free will In essays philosophical and psychological in honour of William James. New York: Longmans, Green, pp. 587610.

Thorndike, E. L (1911) Antmal Intelligence. New York Macmıllan

Tiffany, S. T. (1990). A cognitive model of drug urges and drug-use behaviour - Role of automatıc and nonautomatic processes Psychologıcal Review, 97 (2), 147-168.

Toates, F. M. (1981). The control of ingestive behaviour by internal and external stimuli-A theoretıcal review. Appettte, 2, 35-50.

Tolman, E. C (1932) Purpostve behaviour in antmals and men. New York : Appleton.

Tom, G , \& Rucker, M (1975). Fat, full, and happy: Effects of food deprivation, external cues, and obesity on preference ratıngs, consumption, and buyıng intentions. Journal of Personality and social psychology, 32 (5), 761-766 
Tom, G (1983). Effect of deprivation on the grocery shopping behavior of obese and nonobese consumers. International Journal of Obesity, 7 (4), 307-311

Torrubia, R , Avila, C., Molto, J , \& Caseras, X (2001). The Sensitıvity to Punıshment and Sensitivity to Reward Questionnaire (SPSRQ) as a measure of Gray's anxiety and impulsivity dimensions Personality and Individual Differences, 31, 837-862.

van Strien, T, Friıters, J. E, Bergers, G P. A., \& Defares P. B (1986). The Dutch Eatıng Behaviour Questionnaire (DEBQ_ for assessment of restrained, emotional and external eatıng behaviour Internatıonal of Journal of eatıng Disorders, 5, 747-755

van Strien, T. (1997) On the relationship between dieting and "obese" and bulımic eatıng patterns. Internatıonal Journal of Eatıng Disorders, 19, 83-92.

van Strien, T, Cleven, A, \& Shıppers, G (2000). Restraint, tendency toward overeatıng and ice-cream consumption. International Journal of Eatıng Disorders, 28 (3), 333-338.

Venter, C. S., Macintyre, U. E., \& Vorster, H H. (2000). The development and testıng of a food portion photograph book for use in an African population Jotirnal of Human Nutrition and Dietetics, 13 (3), 205-218

Vettor, R , Fabris, R , Pagano, C., \& Federspll, G (2002) Neuroendocrine regulation of eatıng behaviour. Journal Of Endocrinological Investıgatıon, 25 (10), 836-854.

Waldeck, T. L, \& Miller, L. S. (1997) Gender and impulsıvity differences in elicit substance use Journal of Substance Abuse, 9, 269-275.

Wang, G-J, Volkow, N. D, Logan, J, Pappas, N. R., Wong, C. T , Zhu, W, Netusıl, N , \& Fowler, J. S. (2001). Brain dopamine and obesity The Lancet, 357, 354-357. 
Wardle, J. (1987) Eatıng style - a valıdatıon-study of the Dutch Eatıng Behavior Questionnatre in normal subjects and women with eating disorders. Journal of Psychosomatic Research, 31 (2), 161-169.

Wardle, J , \& Beales, S. (1987) Restraint and food-intake - an experımental-study of eating patterns in the laboratory and in normal life Behaviour Research and Therapy, 25 (3), 179-185

Wardle, J (1990) Conditioning processes and cue exposure in the modification of excessive eatıng Addictive Behaviors, 15 (4), 387-393

Warwıck, Z. S, \& Weingarten, H P. (1996). Flavor-postıngestıve consequence associations incorporate the behaviorally opposing effects of positive reinforcement and anticıpated satıety: Implications for interpretıng two-bottle tests Physiology \& Behavior, 60 (3), 711-715

Weingarten, H. P. (1983) Conditıoned cues elıcit feedıng in satiated rats. A role for learning in meal initiation Science, 220, 431-433.

Weingarten, H. P. (1984) Meal initiation controlled by learned cues: Basıc Behavioural Properties. Appettte, 5, 147-158

Weingarten, H P. (1985) Stımulus control of eating; Implications for a two-factor theory of hunger Appettte, 6, 387-340.

Weingarten, H, \& Elston, D. (1990) The phenomenology of food cravings. Appetite, 15, 231-246. 
Westenhoefer, J., Broeckmann, P, Munch, A. K, \& Pudel, V. (1994). Cognitıve control of eatıng behaviour and the disinhibition effect Appette, 23, 27-41.

WHO (1998). Obesity Preventıng and managing the global epidemic. Report of WHO consultation on obesity Geneva: World Health Organızatıon.

Wiesbeck, G. A., Weijers, H G., \& Gross, J. P. (2000). Craving for alcohol and dopamine receptor sensitivity in alcohol dependent men and women and control subjects Journal of Neural Transmission, 107 (6), 691-699.

Wigmore, S. W , \& Hinson, R E. (1991) The influence of setting on consumption in the balanced placebo design Brttssh Journal of Addiction, 86 (2), 205-215

Wikler, A. (1948) Recent progress in research of the neurophysiologic basis of morphine addiction. American Journal of Psychiatry, 105, 329-338

Wikler, A , \& Pescor, F. T. (1967). Classical conditıoning of a morphine abstınence phenomenon, reinforcement of opıoid-drinking behavior and "relapse" in morphineaddicted rats Psychpharmacologia, 10, 255-284

Wirtshafter, D. \& Davis, J D. (1977). Set points, settling points, and the control of body weight. Physiology \& Behavior, 19, 75-78.

Woods, S. C. (1991) How we tolerate food. Psychological Revew, 98, 488-505.

Woods, S. C., \& Strubbe, J. H. (1994) The psychology of meals. Psychonomic Bullettn \& Review, 1, 141-155

Woods, S. C., \& Ramsey, D. S. (2000). Pavlovian influences over food and drug intake. Behavioural Brain Research, 110, 175-182 
Woody, E Z., Costanzo, P. R, Leifer, H., \& Conger, J. (1981). The effects of taste and caloric perceptions on the eatıng behaviour of restrained and unrestrained subjects. Cognitive Therapy and Research, 5 (4), 381-390

Wooley, S (1972) Physiologic versus cognitive factors in short term food regulation. Psychosomatic medicine, 34, 62.

Yeomans, M. R. (1996). Palatability and the micro-structure of feeding in humans The appetizer effect. Appetite, 27 (2), 119-133.

Yeomans, M. R., Gray, R W, Mitchell, C J , \& True, S. (1997) Independent effects of palatability and withın-meal pauses on intake and appetite ratıngs in human volunteers Appetite, 29 (1), 61-76.

Yeomans, M. R, Spetch, H., \& Rogers, P. J (1998) Conditioned flavour preference negatively reinforced by caffeıne in human volunteers Psychopharmacology, 137 (4), 401-409

Yeomans, M. R, Jackson, A, Lee, M. D, Nesic, J, \& Durlach, P. J. (2000a). Expression of flavour preferences conditioned by caffeine is dependent on caffeine deprivation state. Psychopharmacology, 150 (2), 208-215

Yeomans, M R., Jackson, A., Lee, M. D., Steer, B., Tinley, E., Durlach, P , \& Rogers, P J (2000b). Acquisition and extinction of flavour preferences conditioned by caffeine in humans. Appetite, 35 (2), 131-141.

Yeomans, M. R., Tovey, H M, Tinley, E M., \& Haynes, C. J. (2004). Effects of manipulated palatability on appetite depend on restraint and disinhibition scores from the Three-Factory Eating Questionnarre Internatıonal Journal of Obesity, 28 (1), 144151. 
Yeomans, M. R., Durlach, P J , \& Tinley, E. M (2005) Flavour lıkıng and preference conditioned by caffeine in humans. Quarterly Journal of Experimental Psychology Section B - Comparative and Physiological Psychology, 58 (1), 47-58.

Zahorik., D M , \& Maier, S F (1969). Appetitive conditionıng with recovery from thiamıne deficiency as the unconditioned stımulus. Psychonomic Science, 17, 309-310.

Zellner, D. A., Rozın, P., Aron, M., \& Kulish, C. (1983). Conditioned enhancement of humans liking for flavor by pairng with sweetness. Learning and Motivation, 14 (3), 338-350.

Zentall, T R , Hogan, D E., Compomızzı, K., \& Compomızz1, C. (1976) Responding to a positıve stımulus by satıated pigeons. Learning and motivation, 7 (1) 141-159. 


\section{APPENDIX A}

The following questions involve ratıng scales On each scale please mark a vertical line to indicate your response to the question and please ensure that you use the full range of the scale.

How HUNGRY do you feel RIGHT NOW?

NOT AT

ALL HUNGRY
EXTREMELY

HUNGRY

How FULL do you feel RIGHT NOW?

NOT AT

EXTREMELY

ALL FULL FULL

How STRONG is your desıre to eat pizza/chıps/cookıes RIGHT NOW?

NOT AT

ALL STRONG
EXTREMELY

STRONG 
Appendices

How much do you CRAVE pızza/chıps/cookıes nght now RIGHT NOW?

NOT AT

ALL

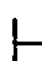

VERY MUCH 


\section{APPENDIX B}

The restraint scale from The Dutch Eatıng Behavıour Questıonnaire (DEBQ, van Strien et al, 1986)

\begin{tabular}{|c|c|c|c|c|c|c|}
\hline $\begin{array}{l}\text { When you have put on weight do you } \\
\text { eat less than you usually do? }\end{array}$ & $\begin{array}{l}\text { not } \\
\text { relevant }\end{array}$ & never & seldom & sometımes & often & $\begin{array}{l}\text { very } \\
\text { often }\end{array}$ \\
\hline $\begin{array}{l}\text { Do you try to eat less at mealtimes } \\
\text { than you would like to eat? }\end{array}$ & & never & seldom & sometımes & often & $\begin{array}{l}\text { very } \\
\text { often }\end{array}$ \\
\hline $\begin{array}{l}\text { How often do you refuse food or } \\
\text { drink offered to you because you are } \\
\text { concerned about your weight? }\end{array}$ & & never & seldom & sometımes & often & $\begin{array}{l}\text { very } \\
\text { often }\end{array}$ \\
\hline Do you watch exactly what you eat? & & never & seldom & sometımes & often & $\begin{array}{l}\text { very } \\
\text { often }\end{array}$ \\
\hline $\begin{array}{l}\text { Do you deliberately eat foods that are } \\
\text { slımming? }\end{array}$ & & never & seldom & sometımes & often & $\begin{array}{l}\text { very } \\
\text { often }\end{array}$ \\
\hline $\begin{array}{l}\text { When you have eaten too much, do } \\
\text { you eat less than usual the following } \\
\text { day? }\end{array}$ & $\begin{array}{l}\text { not } \\
\text { relevant }\end{array}$ & never & seldom & sometımes & often & $\begin{array}{l}\text { very } \\
\text { often }\end{array}$ \\
\hline $\begin{array}{l}\text { Do you deliberately eat less in order } \\
\text { not to become heavier? }\end{array}$ & & never & seldom & sometimes & often & $\begin{array}{l}\text { very } \\
\text { often }\end{array}$ \\
\hline $\begin{array}{l}\text { How often do you try not to eat } \\
\text { between meals because you are } \\
\text { watching your werght? }\end{array}$ & & never & seldom & sometimes & often & $\begin{array}{l}\text { very } \\
\text { often }\end{array}$ \\
\hline $\begin{array}{l}\text { How often in the evenings do you try } \\
\text { not to eat because you are watching } \\
\text { your weight? }\end{array}$ & & never & seldom & sometımes & often & $\begin{array}{l}\text { very } \\
\text { often }\end{array}$ \\
\hline $\begin{array}{l}\text { Do you take your weight into account } \\
\text { with what you eat? }\end{array}$ & & never & seldom & sometımes & often & $\begin{array}{l}\text { very } \\
\text { often }\end{array}$ \\
\hline
\end{tabular}




\section{APPENDIX C}

The disınhıbition scale from the Three Factor Eatıng Questıonnaire (TFEQ; Stunkard \& Messick, 1985).

1 When I smell a sizzling steak or see a juicy piece of meat, I find it very difficult to keep from eating, even if I have just finished a meal True False

2 I usually eat too much at social occasions, like parties and picnics True False

3 Sometımes things just taste so good that I keep on eatıng even when I am no longer hungry

True False

4. When I feel anxious I find myself eating True False

5. Since my weight goes up and down I have gone on reducing diets more than once True False

6 When I am with someone who is overeating I usually overeat too True False

7. Sometımes when I start eatıng, I just can't seem to stop True False

8. It is not difficult for me to leave something on my plate True False

9. When I feel blue I often overeat True False

10 My weight has hardly changed at all in the last ten years True False

11. When I feel lonely, I console myself by eating True False

12 Without even thinking about it, I take a long tıme to eat True False

13 While on a diet, if I eat a food that is not allowed I often then splurge and eat other high calorie foods True False

14 Do you eat sensibly in front of others and spurge alone?
1.
2
3
4
Never
Rarely
Often
Always

15 Do you go on eatıng binges though you are not hungry? 


$\begin{array}{lll}\text { Never } & \text { Rarely } & \text { Sometımes }\end{array}$

16 To what extent does this statement describe your eatıng behavior? -

"I start dietıng in the morning, but because of any number of things that happen during the day, by evening I have given up and eat what I want, promising myself to start dieting again tomorrow."

$\begin{array}{cccc}1 & 2 & 3 & 4 \\ \text { Not like me } & \text { Little like me } & \begin{array}{c}\text { Pretty good } \\ \text { description of me }\end{array} & \begin{array}{c}\text { Describes me } \\ \text { perfectly }\end{array}\end{array}$

NB For items 1-7, 9, 11, and 13 a score of 1 is given for a 'true' response and zero for a 'false' response.

For 1tems 8,10 , and 12 a score 1 is given for a 'false' response, and 1 for a 'true' response.

For items 14, 15, and 16 options 1 and 2 score zero points and options 3 and 4 score 1 point. 


\section{APPENDIX D}

A picture of the card that participants used to indicate their desired portion size of pizza An example of a portion size which a participant might select is indicated.

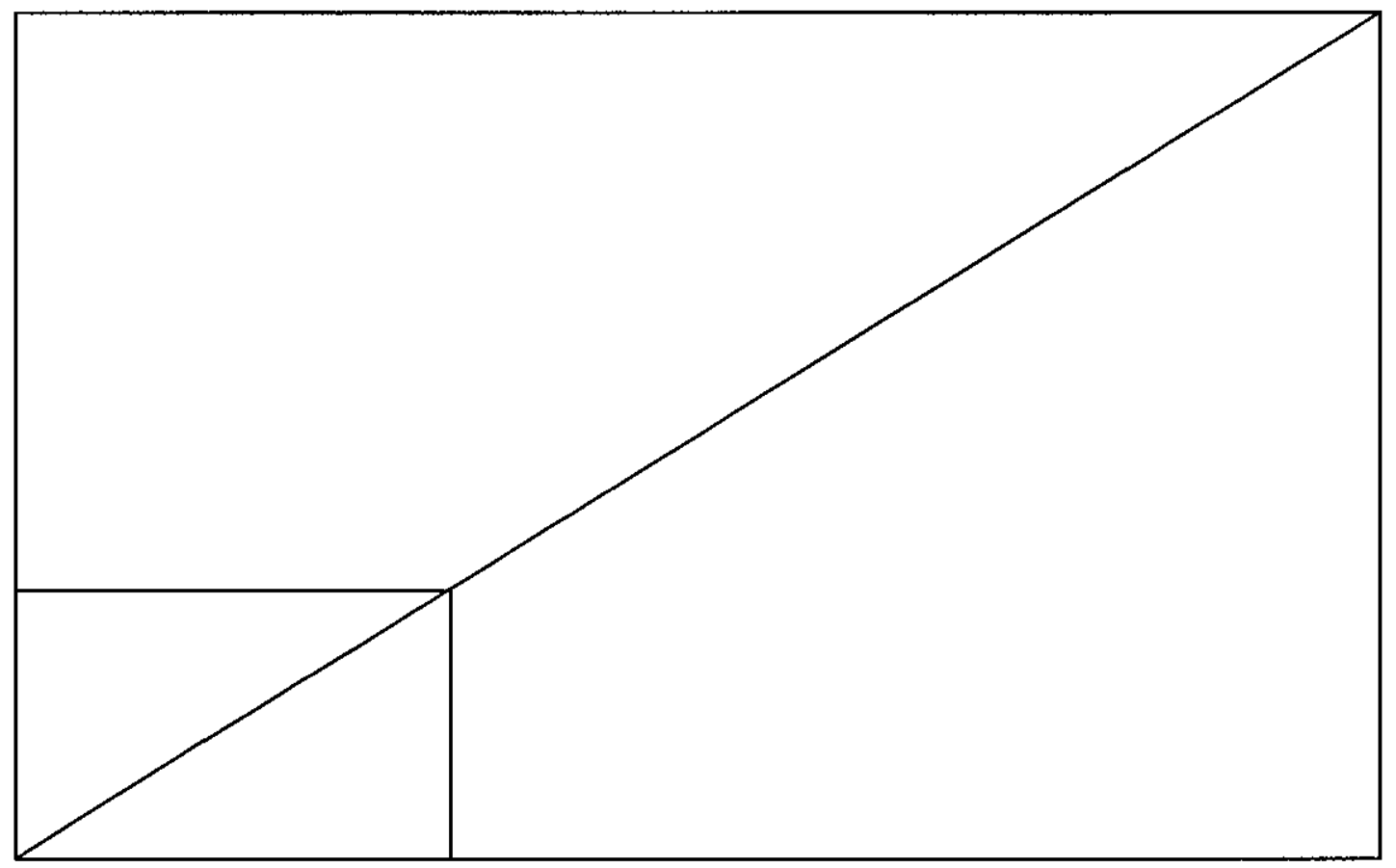




\section{APPENDIX E}

Pictures of the food models used in Experiments 4 to 6 .

Chips

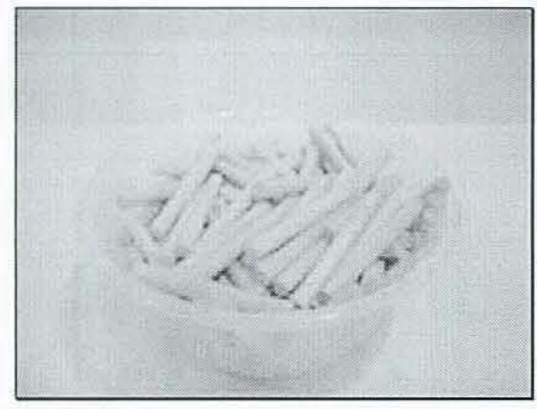

Peanuts

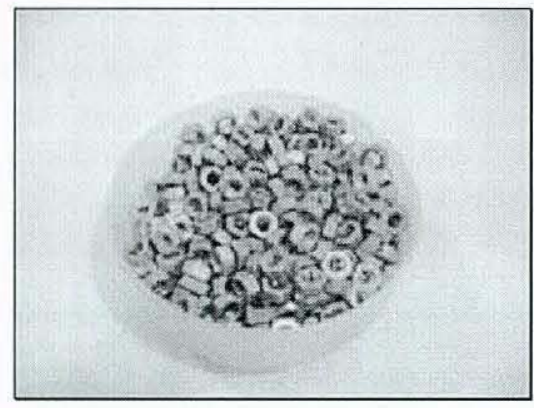

Pizza

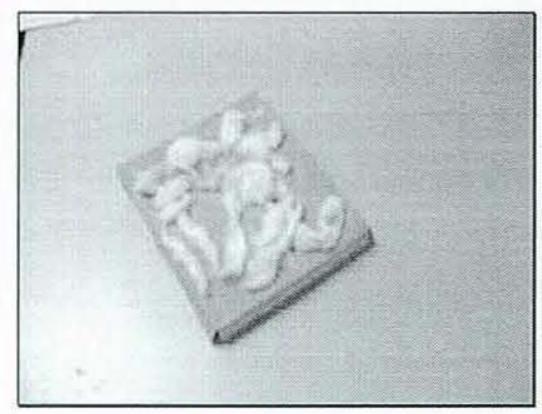

Chocolate cake

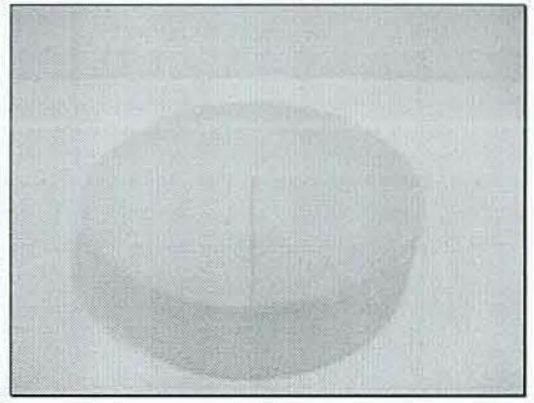

Garlic bread

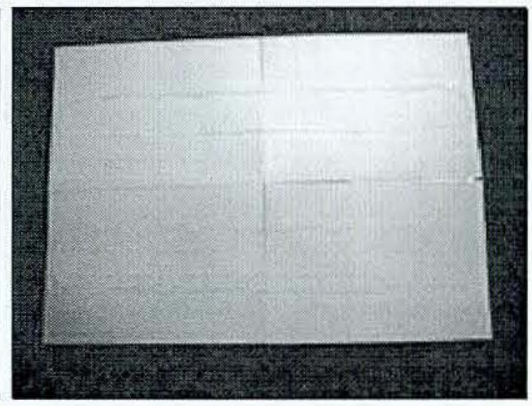

Chocolate

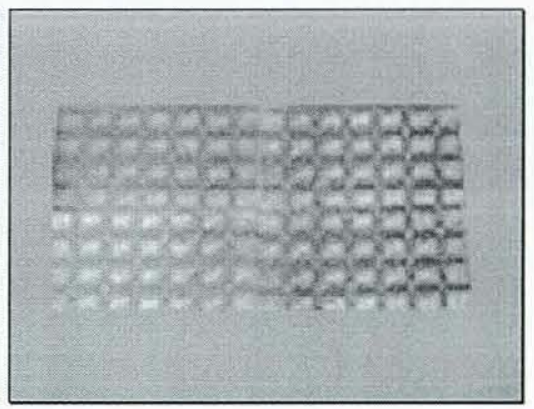




\section{APPENDIX F}

Health screenıng questionnaire

1 Age

2 He1ght

3 Werght

4 Do you smoke?

5 If so, how many cigarettes do you smoke a week?

6 Approximately, how many units of alcohol do you drink each week (a pint of average strength beer is 2 units, a $125 \mathrm{ml}$ of wine 1 s 1 unit, $25 \mathrm{ml}$ of spirits 1 s lunit)?

7 How often do you engage in physical activity each week and what type of activities do you engage in?

8 Are you currently takıng any medicatıon? 


\section{APPENDIX G}

The Sensitivity to Reward scale (SR) from the Sensitivity to Reward and Sensitivity to Punıshment Questionanıre (SRSPQ; Torrubia, et al , 2001)

1 Does the good prospect of obtaining money motivate you strongly to do some things? Y N

2 Are you frequently encouraged to act by the possibility of being valued in your work, in your studies, with new friends or with family? Y N

3 Do you often meet people that you find physically attractıve? $\mathbf{Y ~ N}$

4 Do you like to take some drugs because of the pleasure you get from them? Y N

5 Do you often do things to be praised? $\mathbf{Y} \mathbf{N}$

6 Do you like being the centre of attention at a party or a social meetıng? $\mathbf{Y} \mathbf{N}$

7 Do you spend a lot of your time on obtaining a good umage? $\mathbf{Y ~ N}$

8 Do you need people to show their affection for you all the time? $Y \mathbf{N}$

9. When you are in a group, do you try to make your opınıons the most intelligent or the funniest? $\mathbf{Y} \mathbf{N}$

10 Do you often take the opportunity to pick up people you find attractive? $\mathbf{Y ~ N}$

11 As a child did you do a lot of things to get peoples approval? Y N

12 Does the possibility of social advancement, move you to action, even if it involves not playing fair? $\mathbf{Y} \mathbf{N}$

13 Do you generally give preference to those actıvitıes that imply an immediate gain? Y $\mathbf{N}$

14 Do you often have trouble resisting the temptation of doing forbidden things? $\mathbf{Y ~ N}$

15. Do you like to compete and do everything you can to win? $\mathbf{Y} \mathbf{N}$

16 Is it easy for you to associate tastes and smells to pleasant events? Y N

17 Are there a large number of objects or sensations that remind you of pleasant events? $\mathbf{Y} \mathbf{N}$

18. When you start to play with a slot machine is it often difficult for you to stop?

Y N

19 Do you sometımes do things for quick gains? Y N

20 Does your attention easily stray from your work in the presence of an attractive stranger?

Y N

21 Are you interested in money to the point of being able to do risky jobs? Y N

22 Do you like to put competitıve ingredients in all your actıvities? $\mathrm{Y}$ N 
23 Would you like to be a socially powerful person? $\mathbf{Y} \mathbf{N}$

24 Do you like displayıng your physical abilities even though this may involve danger? $\mathbf{Y} \mathbf{N}$ 


\section{APPENDIX H}

The impulsıvity Questionnaire from Esyenck's Personality Questionnaire (EPQ, Eysenck \& Eysenck, 1975)

1 Do you often buy things on impulse?

$\begin{array}{lll} & \mathbf{Y} & \mathbf{N} \\ \mathbf{Y} & \mathbf{N} \\ \mathbf{Y} & \mathbf{N} \\ \mathbf{Y} & \mathbf{N} \\ \mathbf{Y} & \mathbf{N} \\ \mathbf{Y} & \mathbf{N} \\ \mathbf{Y} & \mathbf{N}\end{array}$

8 Do you often get involved in things you later wish you could get out of it $\mathbf{Y ~ N}$

9 Do you often get 'carned away' by new and exciting ideas, that you never think if possible snags? Y N

10 Do you need to use a lot of self-control to keep out of trouble? $\quad$ Y N

11 Would you agree that almost everything enjoyable is 1 llegal or immortal? $\mathbf{Y ~ N}$

12 Are you often surprised at peoples reactions to what you do or say? $\quad$ Y N

13 Do you think an evening out is more successful if it is unplanned or arranged at the last moment? $\mathbf{Y N}$

14 Do you usually work quickly, without bothering to check?

Y N

15 Do you often change your interests?

Y N

16 Before makıng your mind up, do you consıder all the advantages and disadvantages? Y N

17 Do you usually like to 'sleep on it' before makıng decisions? $\quad$ Y N

18 When people shout at you do you shout back? $\quad$ Y N

19 Do you usually make up your mind quickly? $\quad$ Y N

NB. All 1tems except 5, 16, and 17 score 1 point for a 'yes' response and zero for a 'no' response.

Items 5,16 , and 17 score 1 pint for a 'yes' and zero for a 'no.' 
